\title{
PRE-DORSET SETTLEMENTS AT THE \\ SEAHORSE GULLY SITE
}

\author{
A Thesis \\ Presented to
}

The Faculty of Graduate Studies and Research

The University of Manitoba

In Partial Fulfillment

of the Requirements for the Degree

Master of Arts

Department of Anthropology

by

David A. Meyer

November 1970

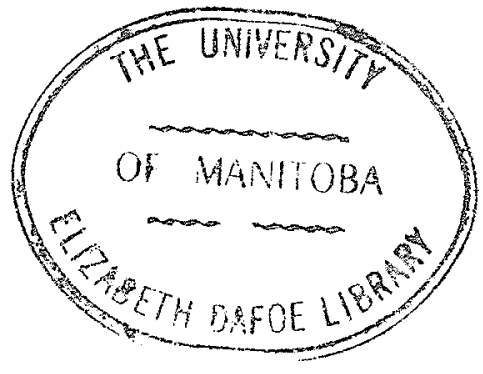




\section{ABSTRACT \\ Pre-Dorset Settlements at the \\ Seahorse Gully Site}

The Seahorse Gully site near the town of Churchi11, Manitoba, was discovered by Chipewyan Indians in 1966. During the summer of 1968 an archaeological crew directed by Dr. R.J. Nash of the Manitoba Museum of Man and Nature surveyed and excavated portions of the site. These investigations revealed extensive Pre-Dorset habitation on a mile long gravel ridge. This occupation occurred from a level ninety-five feet above the present sea level to the top of the 115 foot high ridge.

Twelve Pre-Dorset dwellings were excavated and/or recorded. Also recorded was a small activity area. Another twelve disturbed occupational areas were also noted. These disturbed houses, their artifacts, and other scattered surface finds are not discussed in detail here. The site is divided into three settlements, each characterized by distinctive house ruins and differing tool kits.

The Seahorse Gully Pre-Dorset culture is similar to that of Second Burton Rock (not considered here) and Twin Lakes, both of which were islands at the time of occupation. When inhabited, the Seahorse Gully site was also a small island, the outermost of an archipelago that stretched out from the coast.

Faunal remains inside and outside of the dwellings were common finds. The majority of the skeletal parts were of ringed seal. Other animals such as the bearded seal, the polar bear, and the wolf were represented by only a few bones. Bird bones were present in some houses and 
were all of migratory species including passerines, gul1s, and the black guillemot. Seal bones from one of the dwellings yielded a radiocarbon date of $2900_{-100}^{+}$years B.P.

The presence of watercraft is inferred from the marine location, the utilization of marine fauna, and the faunal indications of summer occupation of the island. A coastal economy based on the ringed seal was characterized by the use of the harpoon and a tool kit consisting primarily of burins. This Pre-Dorset culture is distinguished from all others by the presence of large tools; of gouges, picks, adzes, and scraper planes.

The Pre-Dorset hunters are believed to have lived much of the year in local groups of a few families. Larger seasonal gatherings of whole bands may be fossilized at such sites as Seahorse Gully. As yet, the season of population concentration is not clear, but may have lasted from late winter through the first half of summer. It is likely that fall and early winter were spent inland fishing and hunting caribou. The analysis and interpretation of the Pre-Dorset occupation of the Seahorse Gully site was approached with a conjunctive orientation based in settlement archaeology. This approach may be described as an attempt to recreate the settlement pattern of these Pre-Dorset Eskimos with a view to then constructing the community pattern and suggesting some simplistic features of the social organization.

Five Dorset habitations were also found on the Seahorse Gully site ridge. These were located a half a mile from the Pre-Dorset site, at an altitude of sixty to seventy feet above sea level. The Dorset finds are not considered in this thesis. 


\section{ACKNOWLEDGEMENTS}

My involvement in the subject matter of this thesis is directly attributable to Dr. W.J. Mayer-Oakes, head of the Department of Anthropology at the University of Manitoba. He recruited two incoming graduate students, myself included, to supply Dr. R. Nash with a needed field crew for the 1968 Churchil1 expedition. During the field season Dr. MayerOakes visited the crew in the field and suggested that I might well tackle the site, or some aspect of it, as a thesis topic. Dr. MayerOakes eventually became my thesis advisor and in this capacity and as professor of Archaeological Theory, molded my thoughts and approaches in the treatment of the Seahorse Gully material.

While Dr. Mayer-Oakes' influence and the influence of the archaeological theorists to whom he introduced me is an integral part of this thesis, the presence of Dr. Ronald J. Nash's work and ideas is perhaps equally evident. Not only did his detailed investigations into the Manitoba Pre-Dorset (including his monograph "The Arctic Small Tool Tradition in Manitoba") help determine the course of this thesis, but they laid a basis of research on which the present thesis could be solidly founded. Naturally, Dr. Nash's sense of problem in the field determined to a large extent the problems tackled in this thesis and it is a tribute to his feel for significant data that the problems could be handled and answered, successfully I hope. Of course, Dr. Nash's assistance did not end with the field work and the ensuing two years have seen many useful mini-seminars on the subject of the Seahorse Gully Site, Pre-Dorset culture, and Dorset culture across the north.

Thanks must also be extended to my fellow crew member, Ric 
Windmiller, whose dedicated and accurate field work has aided in the preparation of this thesis and whose presence as a fellow graduate student has been very helpful; first in discussions of the Seahorse Gully Site and secondly as one writing a thesis concerned with Dorset and PreDorset art and thus involved in a common interest area.

I am also obligated to many of my professors at the University of Manitoba and Saskatchewan for ideas incorporated into this thesis; to Mr. R.G. Williamson and Mr. T.C. Correll for insights into the culture of the modern Eskimos; to Dr. C.T. Shay and Mr. L. Pettipas for their treatment of palaeo-environment and the relationship of prehistoric man to his environment. My obligations extend to my fellow graduate students, especially my friend Ian Dyck with whom I have engaged in numerous long and thought provoking conversations on the nature of anthropological archaeology, of relationships between living peoples (especially those in band societies) and their archaeological remains.

In the Churchill area, we must extend thanks to Mr. and Mrs. I.H. Smith who were most helpful, both as repositories of artifacts collected at Seahorse Gully and also for their aid in last minute packing, etc., while in the town of Churchill. Mr. Ernie Senior, then editor of the "Taiga Times", must also be thanked for publicity (television and newspaper) and for frequent offers of assistance. We must acknowledge our debt to Mr. Larry Collins in the provision of his partially completed "hote1" near Ward Mountain for the crew's use for half the field season. In the field we were also indebted to one of our nearest neighbours, Mr. Joe Bighead, not only because he initially found the Seahorse Gully Site, but also because he good humouredly allowed us free access to what he must consider as his territory. He visited us several times 
and was visited in turn. His presence and his boat were a reassurance to the crew in case of any mechanical breakdown or other mishap.

In laboratory analysis and the preparation of this thesis, I must acknowledge the aid of Dr. W.E. Taylor and Dr. R. McGhee, both of the National Museum of Canada, with whom I corresponded concerning several aspects of the Seahorse Gully Pre-Dorset Site. I am also indebted to those who aided in the identification of faunal remains from the Seahorse Gully Site. These include Dr. G. Lammers of the Manitoba Museum of Man and Nature, Dr. P.W. Parmalee of the Illinois State Museum, and Dr. H. Savage of the Royal Ontario Museum. Dr. R. McGhee also aided, indirectly, in faunal identifications. He identified the faunal remains from the Dorset component at Seahorse Gully and his identifications of seal bones were used to compare and identify the Pre-Dorset faunal remains.

I must extend thanks to Jonathan Maas whose patience in his position as supervisor of the Laboratory of Anthropology and whose drawings of several Pre-Dorset artifacts greatly aided the preparation of this thesis. Last, I must indicate my great debt to Mr. Les Leonoff whose knowledge and ability in photography was invaluable in the production of the photographic plates for this thesis. 
ABSTRACT. . . . . . . . . . . . . . . . . . . . . . . . . . $i i$

ACKNOWLEDGEMENTS. . . . . . . . . . . . . . . . . . . . . . iv

LIST OF TABLES. . . . . . . . . . . . . . . . . . . . . . . . ix

LIST OF MAPS. . . . . . . . . . . . . . . . . . . . . . $\mathrm{x}$

LIST OF FIGURES . . . . . . . . . . . . . . . . . . . . . . . . . xi

INTRODUCTION. . . . . . . . . . . . . . . . . . . . . . . 1

CHAPTER

I THE CONTEMPORARY ENVIRONMENT. . . . . . . . . . . . . 10
Topography
Geology
Climate
Vegetation
Fauna

I I THE PALAEO ENVIRONMENT. . . . . . . . . . . . . . . .

Introduction

Isostasy and Uplift Rates

Palaeo-Topography

Palaeo-Climate

Summary

III FIELD WORK. . . . . . . . . . . . . . . . .

The Problem

The Site

The Excavations

IV BASIC DESCRIPTIVE CATEGORIES. . . . . . . . . . . . 60

Introduction

Dwelling Remains

Artifacts

Summary

V THE SOUTHERN SETTLEMENT . . . . . . . . . . . . .

Introduction

House 1

House 2

Activity Area 3

Summary of Settlement Evidence 
TABLE OF CONTENTS - Continued

Page

CHAPTER

VI THE CENTRAL SETTLEMENT. . . . . . . . . . . . . 132

Introduction

House 4

House 5

House 6

House 7

Summary of Settlement Evidence

VII THE NORTHERN SETTLEMENT . . . . . . . . . . . .

Introduction

House 8

House 9

House 10

House 11

House 12

House 13

Summary of Settlement Evidence

VIII SETTLEMENT AND SETTLEMENT PATTERNS. . . . . . . . . 250

Introduction

Settlement Archaeology

The Settlement and the Community

Circumpolar Settlements

The Exploitive Pattern

The Settlement Pattern

IX COMMUNITY AND COMMUNITY PATTERN . . . . . . . . 264

Introduction

The Community and its Patterning

The Pre-Dorset Communities and Community

Patterns

Summary

BIBLIOGRAPHY . . . . . . . . . . . . . . . . . . . 274 
LIST OF TABLES

Page

TABLE

1 Monthly and Annual Averages of Precipitation and
Daily Mean Temperatures at Churchill, Manitoba. . .

2 Varieties and Attributes of Dwelling Alignments. . . 62

3 Seahorse Gully Site Artifactual Material . . . . . 64

4 Burin Attributes . . . . . . . ..... 70

5 Attributes of Burins from House 2. . ....... 106

6 Characteristics of Burins from House 2. . . . . 107

7 Lithic Debris from House 2. . . . . . . . . 116

8 Tools from the Southern Settlement . . . . . . 129

9 Attributes of Burins from House 5. . . . . . . 143

10 Characteristics of Burins from House 5 . . . . . 144

11 Lithic Debris from House 5. . . . . . . . 158

12 Faunal Remains from House 5. . . . . . . . . . 160

13 Lithic Debris from House 7 South . . . . . . . . 181

14 Tools from the Central Settlement. . . . . . . 185

15 Attributes of Burins from House 8. . . . . . . . 190

16 Characteristics of Burins from House 8... . . . 191

17 Lithic Debris from House 10........... 218

18 Attributes of Burins from House 13........ 234

19 Characteristics of Burins from House 13. . . . . . 235

20 Lithic Debris from House 13. . . . . . . . . 243

21 Tools from the Northern Settlement . . . . . . . 248 
LIST OF MAPS

Page

MAP

1 Province of Manitoba. . . . . . . . . . . 2

2 Thyazzi, Twin Lakes, and Seahorse Gully Sites . . . . 4

3 The Seahorse Gully Area . . . . . . . . . . 11

4 The Tyrrell Sea . . . . . . . . . . . . . 17

5 Seahorse Gully Island .............. 40

6 The Pre-Dorset Coastline. . . . . . . . . . 43

7 The Seahorse Gully Site Area. . . . . . . . . . . 53

$8 \quad$ Seahorse Gully Site, Pre-Dorset Settlements . . . . . 59

9 Floor Plan of House 1............... 96

10 Floor Plan of House 2............. 103

11 Scattergram of Activity Area 3. . . . . . . . 123

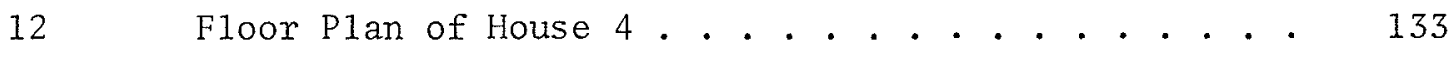

13 Floor Plan of House 5............... . 141

14 Floor Plan of House 6.............. . 168

15 Floor Plan of House 7............... 174

16 Floor Plan of House 8............... 188

17 Floor Plan of House 9................ . . 198

18 Floor Plan of House 10. . . . . . . . . . . 205

19 Floor Plan of House 11............... 223

20 Floor Plan of House 12. . . . . . . . . . . . . 227

21 Floor Plan of House 13............. 230 


\section{LIST OF FIGURES}

Page

FIGURE

1 Exponential Curve of Uplift in the Churchil1 Area Compared with the Present Uplift Rate (2.4 feet per century). . . . . . . . . . . . . . . 39

2. Tools from the Highest Portion of the Cobble Mantle. 56

3 Burin Terminology. . . . . . . . . . . . 68

4 Burins, End Blades and Harpoon Blades. . . . . . 72

5 Side Blades, Knives and Scrapers . . . . . . . 77

6 Scraper Terminology. . . . . . . . . . . . 79

7 Scrapers, Blades, Whetstone, and Gouge . . . . . . 81

8 Gouge and Picks. . . . . . . . . . . . 85

9 Scraper Planes and Adze Blades . . . . . . . . . 87

10 Ivory Toggle Heads . . . . . . . . . . . . 89

11 Soapstone Vesse1 . . . . . . . . . . . 90

12,a. The Southern Extremity of the Cobble Mantle. . . . 94

$12, \mathrm{~b} \quad$ House 1 before Excavation. . . . . . . . . . . 94

$13 \Rightarrow$ Tools from Houses 1 and 2. ........... 101

14 Tools from House 2. . . . . . . . . . . . . 110

15 Fragmentary Steatite Vesse1 from House 2 . . . . . 114

16 , Tools from Activity Area 3............ 124

17 Tools from Houses 4 and 5. . . . . . . . . . . 139

18 Tools from House 5 . . . . . . . . . . . 146

19 Tools from Houses 5, 6, and 7. . . . . . . . . 151

20 Tools from House 5. . . . . . . . . . . . . 154

21, a The Excavation of House 5. . . . . . . . . . 175 
FIGURE

21,b The Excavation of House 7 North. . . . . . . . 175

22 Tools from Houses 8 and 9. . . . . . . . . . . 196

23 Tools from House 10............... 209

24 Tools from House 10............... 214

25 Artifacts from Houses 10, 11, and 12....... 221

26,a The Excavation of House 10......... . . 232

26, b The Excavation of House 13........... 232

27 Artifacts from House 13............. 236

28 Tools from House 13. . . . . . . . . . . . . . 240 


\section{INTRODUCTION}

The presence, near Churchill (Map 1), of an archaeological site once occupied by Pre-Dorset Eskimos was unknown until the summer of 1967. In 1966, a high bedrock ridge along the northeastern coast of Button Bay (Map 2) was almost completely burned over. The fire which denuded this two mile long ridge burned for the whole of the summer of 1966, destroying the thick tundra layer of matted heaths and lichen. This laid bare the gravel and sand that once supported the vegetation.

Because of the fire, artifacts once encased in the organic layer were left exposed on the subsoil. These artifacts, left by the Pre-Dorset inhabitants of the site, littered the uppermost portion of the rock ridge. The local Chipewyans were quick to note the uncovered artifacts. The principal collector became Mr. Joe Bighead who lives near the Churchill River about a mile from the site. In the summer of 1967 he brought his finds to the attention of Mr. and Mrs. I.H. Smith of the town of Churchill. Mrs. Smith purchased those artifacts that Mr. Bighead found.

Mr. Bighead recognized as artifacts predominantly the large tools from the site, especially those of red pyroclastic material (a volcanic sediment). He collected between 70 and 100 tools, all of which are now in the possession of three bodies; the Eskimo Museum in Churchill, the Laboratory of Anthropology, University of Manitoba, and Mrs. I.H. Smith. Fortunately, Mr. Bighead did not recognize smaller artifacts such as burins and therefore, this portion of the site's artifacts remained undisturbed. The large numbers of large tools recovered suggests that the surfaces of some of the dwellings at the site may have been nearly littered with large tools. Numerous flakes of pyroclastic material in certain dwellings suggest that this is true. 


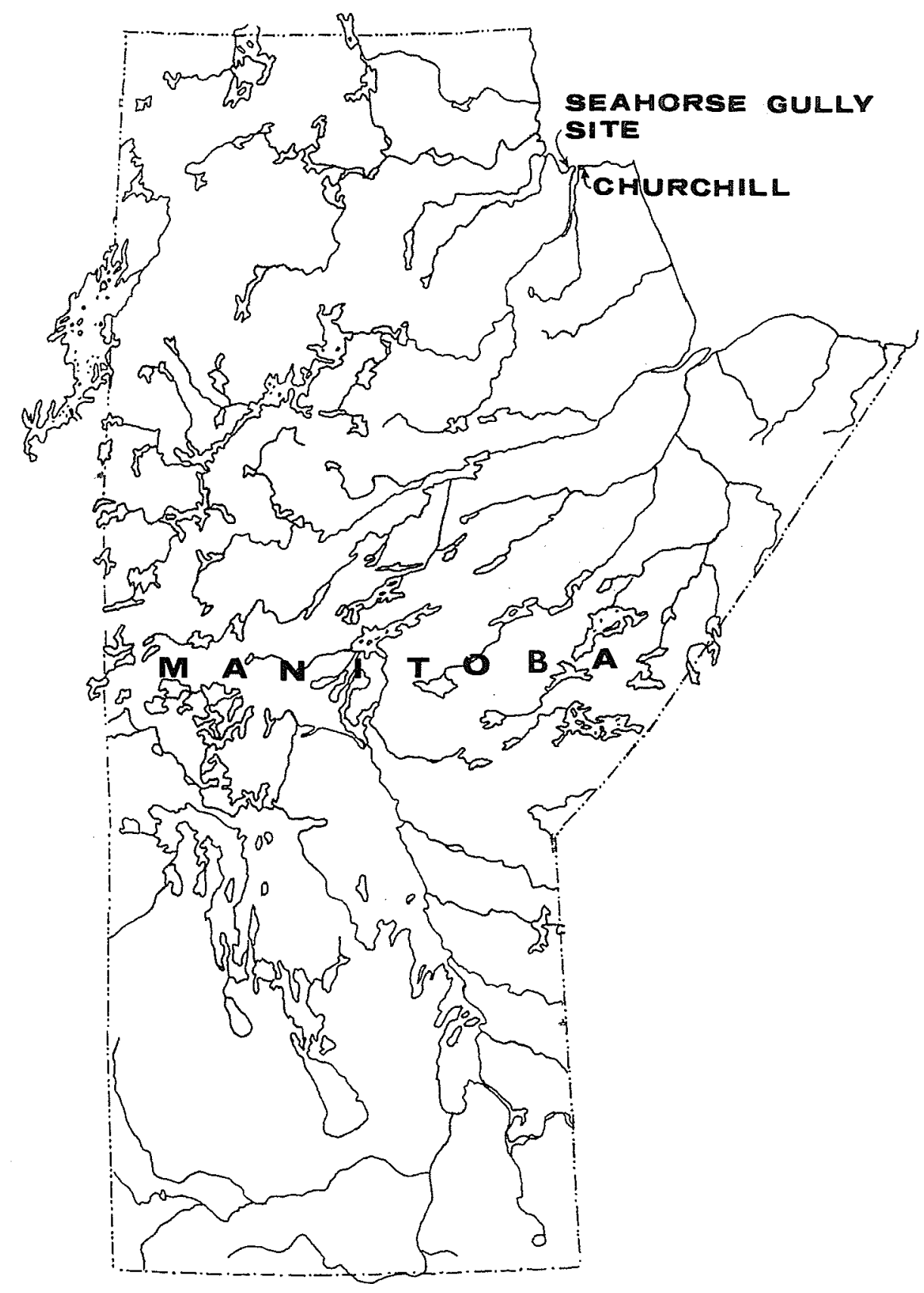

Map. 1. Province of Manitoba illustrating the locations of the town of Churchi11. and the Seahorse Gully site. 
Mrs. I.H. Smith brought the large tool finds to the attention of Ronald J. Nash who was then studying the Arctic Small Tool tradition in the Churchill area. The apparent discovery of large tools in an Arctic Sma11 Tool context was particularly intriguing since gouges, picks and adzes had been found in large numbers at no other Pre-Dorset site.

Near the end of August, 1967, Dr. Nash made a quick trip to Churchi11. His intention was to examine the Seahorse Gully site and to assess its possibilities as the site of future archaeological investigations. He visited Mrs. I.H. Smith in order to examine more of her artifacts and to ascertain who had been finding them. Dr. Nash decided to contact Mr. Bighead in order to locate the site. Mr. Bighead agreed to relocate the site and $\mathrm{Dr}$. Nash has written as follows about the visit which they made to the site, accompanied by Mrs. Smith:

A number of events conspired to give me only about one hour at the site itself. This was enough however, to walk out the immediate site, take some photos and find a couple of burins to confirm it as a Sma11 Tool site. (Nash 1967:16)

This short visit, one late summer afternoon, encouraged Dr. Nash to consider archaeological investigations at Seahorse Gully. During the fall and winter of 1967 plans were made for a return to the Churchill area in the summer of 1968. In the eventuality that Seahorse Gully would prove an unproductive site, plans were made for surveys of other areas near Churchi11. Dr. Nash (Preliminary Report: Archaeological Research in Northern Manitoba, 1968:1) has summarized the basic information about the 1968 Churchill expedition as follows:

Archaeological survey and excavations were undertaken in the Churchill area under the auspices of the Manitoba Museum of Man and Nature and the Department of Anthropology of the University of Manitoba. The field supervisor was Dr. Ronald J. Nash, Curator of Archaeology at the Manitoba Museum. Field assistants were David Meyer and Ric Windmiller, both graduate students in anthropology at the University of Manitoba. A grant 


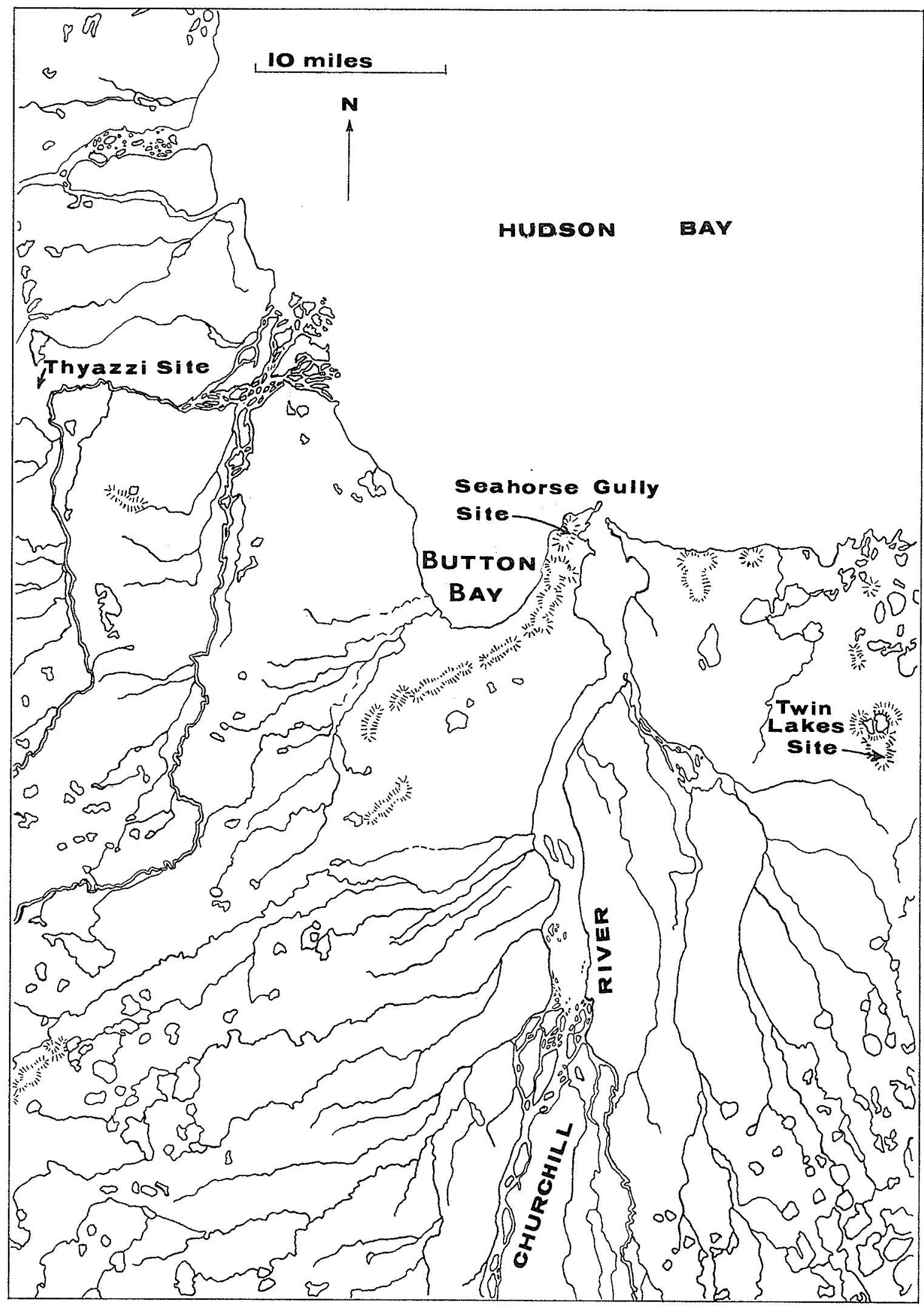

Map 2. Locations of the Thyazzi, Seahorse Gully, and Twin Lakes sites. 
of $\$ 3,000.00$ from the Northern Studies Committee of the University of Manitoba, made the expedition possible.

The three members of the party met for the first time on the twentieth of June, 1968 and a few days later began the lengthy train journey to the mouth of the Churchil1 River. Upon arrival, Mr. and Mrs. Smith were visited and some of their most recent artifact acquisitions from Seahorse Gully were examined. Strong northwesterly winds and floating ice held up travel on the Hudson's Bay, so it was decided to simply move across the Churchill River. A Cree boatman was engaged to aid in the ferrying of tools and supplies across the river. The breezy evening of June 26 the Crees, Jim Spence and his adult son, arrived with their large motor canoe. This boat and the smaller canoe that belonged to the expedition were loaded and everyone made a choppy crossing of the mile wide river mouth. A temporary camp was set up near a small cluster of buildings on Cockles Point at the base of a quartzite ridge known as Ward Mountain (Map 3).

For the first week, the site was approached by walking west across the muskeg and tundra to the site ridge. An ancient beach of the Hudson Bay was followed, resulting in a slightly longer but drier journey to the site. On July 7 th the weather was very warm and perfectly calm so it was decided to move around to the shore of Button Bay where the crew would be in closer walking distance to the site. The party's canoe was loaded and the journey out the mouth of the river, into the Hudson Bay, and down the east side of Button Bay was made. Here, at the mouth of Seahorse Gully, a camp of two tents was established and this remained the expedition's headquarters until August 14th when increasingly bad weather prompted the crew to return to the Cockles Point base. 
Upon close examination of the Seahorse Gully site and the initiation of excavations in July, the site was found to be rich in dwellings, artifacts and faunal remains. For this reason, although a larger survey was originally envisioned, excavation and survey were confined to the Seahorse Gully area and continued from June 27 th to September 4th. Although archaeological work was quite steady throughout this time (except during bad weather and trips to town) the whole site could not be intensively investigated and many dwellings were left unexcavated.

The survey and excavation at Seahorse Gully is the latest effort in fifteen years of research into the Arctic Small Tool Tradition in the Churchill area. This research was initiated by the incredible good fortune of J.L. Giddings who pinpointed an Arctic Small Tool site during his visit to Churchill in 1953. His publications concerning the relatively early Thyazzi site sparked interest in Pre-Dorset culture on the west coast of the Huds on Bay but further work was not done until 1960 when W.N. Irving examined the Twin Lakes site. In the fall of 1964, Dr. W.J. Mayer-Oakes continued investigations at Twin Lakes. The work of these three men was continued in 1965 when Ronald J. Nash, with the aid of P. Bleed, excavated at Twin Lakes and Thyazzi. Nash also examined the Seahorse Gully site briefly in 1967.

Archaeology at Churchill is not easy, although it is considerably easier than farther north in the Arctic. The influence of the perpetually cold Hudson Bay prevents summer temperatures from attaining the daytime highs normal for the latitude. The usual daytime high is from 50 to 55 degrees and is frequently lower. When these cool days are accompanied by brisk northwesterly winds, heavy clothing must be worn to work comfortably at excavations. During the summer of 1968, (which was particularly 
cool and rainy throughout western Canada) frequent showers were characteristic of the Churchill weather pattern. The crew members came to expect that several short showers were likely to pass over each afternoon. During the period of shower activity the archaeologists huddled beneath their rain gear in an attempt to remain dry. Luckily, the gravel and sand composing the soil of the site was not much affected by the showers and work could usually resume after the rain had ceased to fall or, in some cases, while it was still drizzling.

Through necessity some dwellings were excavated in the rain. House 10 (Chapter VII) was one of these. A relatively rich feature, its prolificacy was initially underestimated, and it had to be finished before the crew left the field. For this reason, although it drizzled much of the last day spent at the site, excavations of this dwelling were completed under such trying conditions.

A warm, calm day can be more of a work problem than a windy cold day since on still days clouds of mosquitoes and black flies rise to torment the excavator. However, the insect problem can be minimized by the use of insect repellants, the wearing of heavy clothing and head nets and by a compensatory psychological adjustment. Unfortunately, head nets reduce visibility and were found a hindrance in excavation where subtle features or minute artifacts were present and necessary to discern.

These problems may have resulted in some information loss that would not have occurred in the less severe environments of the south. However, the fact that the archaeologists did not have to battle true Arctic conditions may have resulted in more comprehensive control and recording than is possible under freezing or permafrost conditions. On the other hand, the lack of permafrost resulted in poor preservation of 
organic materials that are usually found in good condition in the Arctic. In general, bone, antler, and ivory at the Seahorse Gully site were in a disintegrating state. Only those pieces that had been overgrown by tundra vegetation and were sheltered from the sun and rain were well preserved.

The Seahorse Gully site proved to be one of the richest Pre-Dorset occupations yet found on the northwestern coast of the Hudson Bay. The intensity of occupation exceeded expectations and more than fulfilled Dr. Nash's hopes expressed in this prediction from his 1967 "Preliminary report of Archaeological Research in Northern Manitoba":

Extensive excavations at Seahorse Gully would prove most profitable. Here is the opportunity for a more complete conjunctive-type approach to a Pre-Dorset site, something which was impossible at Thyazzi because of its inaccessibility and at Twin Lakes because of a light occupation. (Nash 1967:18)

It is the intention of this writer to attempt a conjunctive approach to the interpretation of the Pre-Dorset occupations at Seahorse Gully. Detailed comparative and descriptive studies of Arctic Sma11 Too1 tradition artifacts have already been made by Dr. R.J. Nash (1969). Tools from Thyazzi, Twin Lakes and Seahorse Gully have been compared with each other and with Arctic Small Tool sites across the Arctic. For this reason, although the Seahorse Gully artifacts will be described, the major emphasis of this thesis is on the reconstruction of the Seahorse Gully occupation as a settlement of interacting social units and individuals involved in the daily problem of survival in a subarctic environment.

The conjunctive approach, according to Walter W. Taylor (1948:93-94),

...aims at drawing the completest possible picture of past human life in terms of its human and geographic environment. It is chiefly interested in the relation of item to item, trait to trait, complex to complex (to use Linton's concepts) within the culture-unit represented and only subsequently in the taxonomic relation of these phenomena to similar ones outside 
of it.

It is an integral part of this major aim to make every effort to interpret the concrete, empirical findings of archaeology in terms of culture itself, of cultural behaviour, and of the non-material results of cultural behaviour whereby the materialistic and "lifeless" data may be given life and depth. 
CHAPTER I

THE CONTEMPORARY ENVIRONMENT

TOPOGRAPHY

This description includes that area around the tidal lagoon at the mouth of the Churchill River. Also considered is the eastern shore of Button Bay as well as Seahorse Gully and First and Second Burton rocks (Map 3). That portion of the quartzite ridge east of the river, now occupied by the town of Churchill and the military establishment of Fort Churchill, is also considered.

The famous explorer-geologist, J.B. Tyrre11, investigated the mouth of the Churchil1 river during his expeditions of 1893 and 1894 . His concise description of this region is worthy of quotation not only because of its accuracy, but also because of its historic value:

The trading store and mission at Churchill are situated on the west side of the tidal lagoon at the mouth of the Churchill River; on an old sandy beach a few feet above high tide level. Back of this old beach, which is between 100 and 200 yards in width, steep bare, rounded hills rise to a heighth of 80 to 100 feet, forming part of the rocky ridge which extends along the west side of the river for several miles, out to the extreme end of Eskimo Point at the old fort, forming the bold promintory between the river and the east side of Button Bay. A similar rocky ridge also forms the east side of the mouth of the tidal lagoon, and thence extends eastwards for a number of miles along the shore of Hudson Bay towards Cape Churchil1. (Tyrrell 1898:90)

Tyrrell has correctly determined the height of Second Burton Rock above old Fort Churchill (Map 3), however, farther west the rock rises to over 125 feet. 01d Fort Churchill was established by the Huds on Bay Company after the French destruction of Fort Prince of Wales in 1783. All that remains at present are many hummocks and the cellars whose walls of dry-laid limestone slabs are still intact. Above the trading post is 


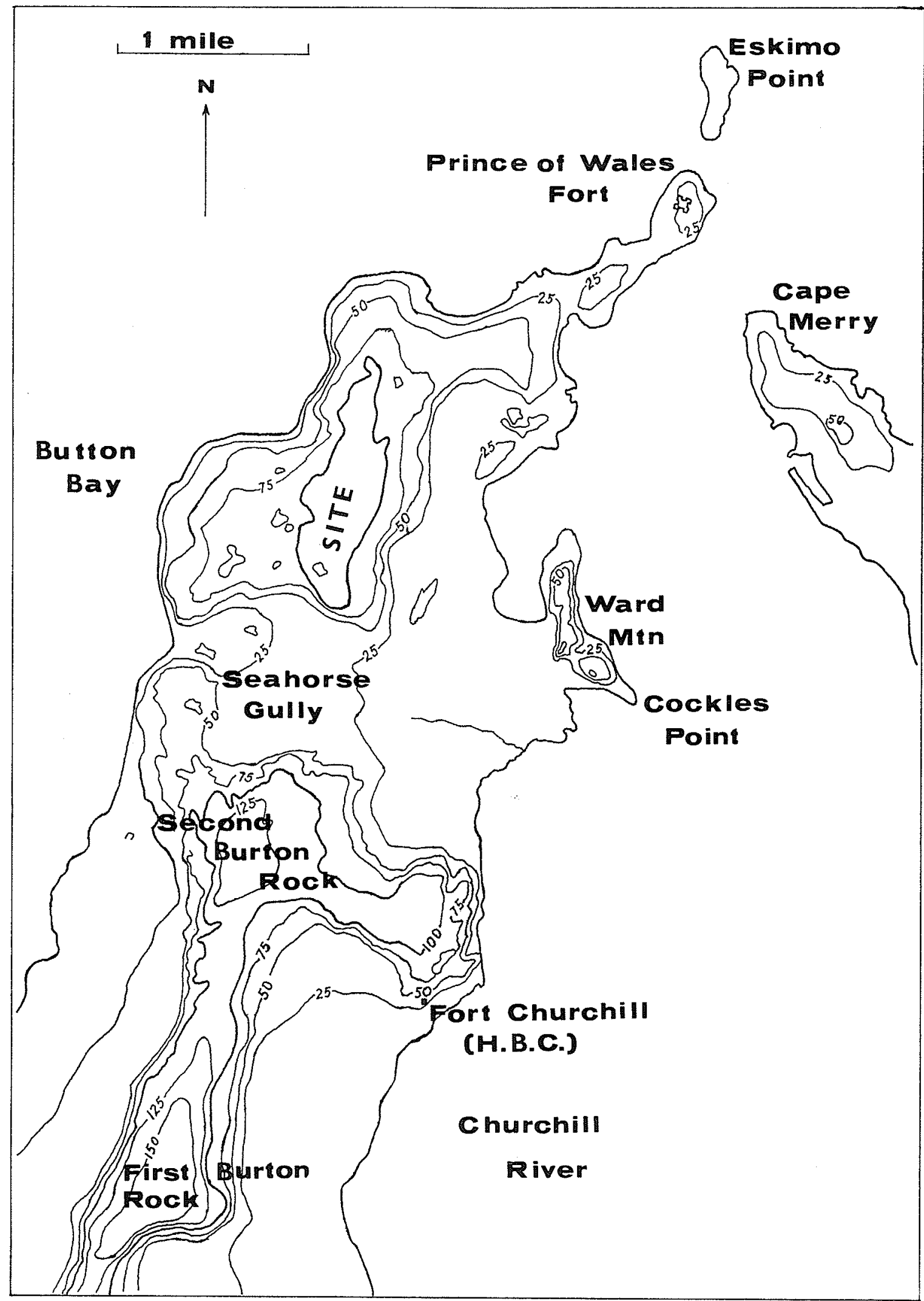

Map 3. The Seahorse Gully area. 
a small graveyard whose marble headstones indicate use by the European traders.

The quartzite ridge is widest on the east side of the river where it is occupied by the towns of Churchill and the military base. Here, as Tyrrel1 stated, the ridge follows the seashore and is oriented in an east-west direction. The ridge rises above 100 feet at Fort Churchill, high enough to have been occupied by peoples with a Pre-Dorset culture. Unfortunately, most of this area is now occupied by the military base and the airport. This quartzite ridge extends east from Cape Merry for approximately six miles.

On the west side of the river the ridges are higher and narrower and therefore appear more prominent. Here, the ridges trend in a northsouth direction. Directly across the tidal lagoon from the town of Churchill is a quartzite ridge called Ward Mountain. It is over seventy feet high and about three quarters of a mile long. At its northern end is Sloops Cove which was utilized by the Prince of Wales mariners of the eighteenth century.

To the west of Ward Mountain, along the northeastern coast of Button Bay is another large ridge the highest part of which extends one and a half miles north from Seahorse Gully. This portion is over 100 feet above the present sea level and is relatively narrow. The summit of this elongated ridge is capped by a long narrow beach-like mantle of grave1, cobbles and sand. This "cobble mantle" may have formed as an offshore bar when the ridge was submerged in Hudson Bay. With the gradua1 uplift of the land, wave reworking of the mantle took place. Sand was deposited in quantity only at the southern end of the mantle, in the lee 
of a small boulder field to the northwest. This quartzite ridge does not seem to have been named so it will simply be referred to as the "site ridge" since the Seahorse Gully site is located here.

To the south of the site ridge is Second Burton Rock. Also a north-south trending rock, it is higher and wider than the site ridge. Second Burton Rock extends along the eastern side of Button Bay and has been arbitrarily divided from another ridge to the south, First Burton Rock. That portion of Second Burton Rock forming the southern edge of Seahorse Gully is elongated east-west and extends from Button Bay to the Churchill River. All of this northern half of Second Burton Rock was surveyed on foot. Unlike the site ridge, this rock has not been burned and remains covered with a thick layer of tundra. Because of this blanket of heath and lichen the recognition of Pre-Dorset occupation is very difficult.

First Burton Rock extends to the south slightly around Button Bay. The north end of the rock reaches heights in excess of 150 feet and could be a significant area for the discovery of Pre-Dorset habitation older than that of the Seahorse Gully site. The slopes of this more southerly ridge are wooded as is much of the summit, making surface survey even more difficult. On all the ridges a few gravel patches remain bare of vegetation and are only encrusted with green and white lichens.

The lowland between the quartzite ridges consists of tidal flats whose major relief is formed by ancient strand lines of the Hudson Bay. A prominent shingle beach composed of limestone flags extends from the south end of Ward Mountain and trends north northwest towards the site ridge. The crew followed this fossil beach when walking between ward 
Mountain and the site ridge. Seahorse Gully proper is found between the southern end of the site ridge and the northwestern end of Second Burton Rock. The bottom of Seahorse Gully is flat and characterized by many ponds, scattered grey boulders and occasional spruce and tamarack. Among the ponds, rocks, and trees are areas of climax tundra, but some true muskeg may also be present here.

The north and south slopes of Seahorse Gully are steep and high. The north slope of Seahorse Gully is unusual with several vertical cliffs from twenty to thirty feet high. Fortunately, near Button Bay the site ridge can be ascended by a more gradual slope. Although the south slope of the gully is not so cliff-like, it does not have any very gradual slopes and therefore, the rough hillside must be scaled with some care. Accidents are likely to occur during and after showers when lichens form a greasy surface on the rocks. Fortunately, the crew members were surefooted and no sprains or broken bones were incurred. The tops of the ridges are flat and relatively easy to traverse. Usually old caribou paths or contemporary Chipewyan trails can be followed.

The lowland between Ward Mountain and Second Burton Rock is saturated and is simply an extension of Seahorse Gully. The physiography is essentially the same. Although very wet, tundra and occasional spruce grow in the higher areas. Many rivulets drain the ponds; dwarf willows and birch tend to line these waterways.

$\underline{\text { GEOLOGY }}$

The bedrock ridges of this area are composed of a grey rock that J.B. Tyrrell termed "Churchill arkrose sandstone". He described it as follows: 
The rock is a greenish-grey even-grained, falsebedded, felspathic arkrose sandstone, in places very massive, and in other places more thinly bedded, often cut by many irregular veins of dull white quartz, which contains a large quantity of magnetite. ... Its clastic character is everywhere apparent, and here and there, scattered very irregularly through the beds, it contains well rounded pebbles, some of which are as large as the fist, of white clastic quartzite similar to the Huronian quartzite of marble island. (Tyrre11 1898:90)

While the quartzite of these ridges is believed by Tyrrell to date to the Cambrian, more recent limestones are found on the beaches and apparently have been transported from some nearby source. According to Tyrre11 (1898:175) these date to the Silurian period. Williams (1947) finds that the dolomites and limestones found at the mouth of the Churchil1 are of Silurian and Ordovician age.

Williams also considers the Churchill quartzite to have formed during the Pre-Cambrian period from the erosion of quartzose rocks:

... cleanly washed and sorted quartz sand was laid down on a great flood plain at the mouth of one or more great rivers. Changing currents produced highly cross-bedded deposits, which with deep burial and time were compressed into massive sandstone. Small amounts of silt and clay gradually changed to sericite.

Compression deep within the earth's crust folded the sediments into a great syncline and huge granite batholiths melted and wedged their way upward, helping to metamorphose them into quartzite. (Williams 1947:42)

Following the formation of the sedimentary rocks of Ordovician age, other geological periods (except the Pleistocene) are not represented in the Churchill area. The great ice ages are evidenced by the glacial till that covers most of this area. The whole of the Hudson Bay was at the middle of the Wisconsin glaciation at its greatest extent (Lee 1960:1609). The Keewatin glacier, one of the three major glacial centres during the last glaciation, over rode the Churchill area. It and the previous 
glaciations deposited till, "consisting of silt, calcareous clay and pebbles, boulders, and rock flour" (Ritchie 1956:272). Because of the glaciation:

The bare quartzite hills have Roches Mountonees [ rounded] surfaces, but unlike the hills further north along the shore of Hudson Bay, they are planed and scored on every side, instead of being on one side smoothly rounded and on the opposite jagged and broken. (Tyrre11 1898:91-92)

Glacial ice, estimated to be up to 9,000 feet thick covered the Churchill area during the Pleistocene (Williams 1947:42). This great weight of ice produced an isostatic effect which depressed the Hudson Bay area hundreds of feet below sea level. The ice, which extended far to the south, reached its maximum extent and began to recede between twelve and thirteen thousand years ago. A few thousand years later, that portion of the ice sheet still remaining in the Hudson Bay disintegrated and salt water invaded the glacial depression.

The last land based remnant of the glacial ice had persisted as a north-south trending dam across northeastern Manitoba. Since it lay across the Nelson River valley it continued to pond Glacial Lake Agassiz on its west side and was simultaneously lapped by a greatly enlarged Hudson Bay (the Tyrrell Sea) on its eastern edge. As the ice melted, channels were cut through allowing Glacial Lake Agassiz to drain into the Bay. With the disappearance of the ice before 7,300 years ago (E1son 1967:94) the marine waters extended far inland (Map 4), forming the Tyrrell Sea (Lee 1960:1609). On the west side of the bay the highest marine beaches are found 400 to 600 feet above the present sea level while on the east side they are found up to 900 feet (Lee 1960:1609). Radiocarbon dates obtained from shells collected from these highest beaches indicate that the Tyrrell Sea 


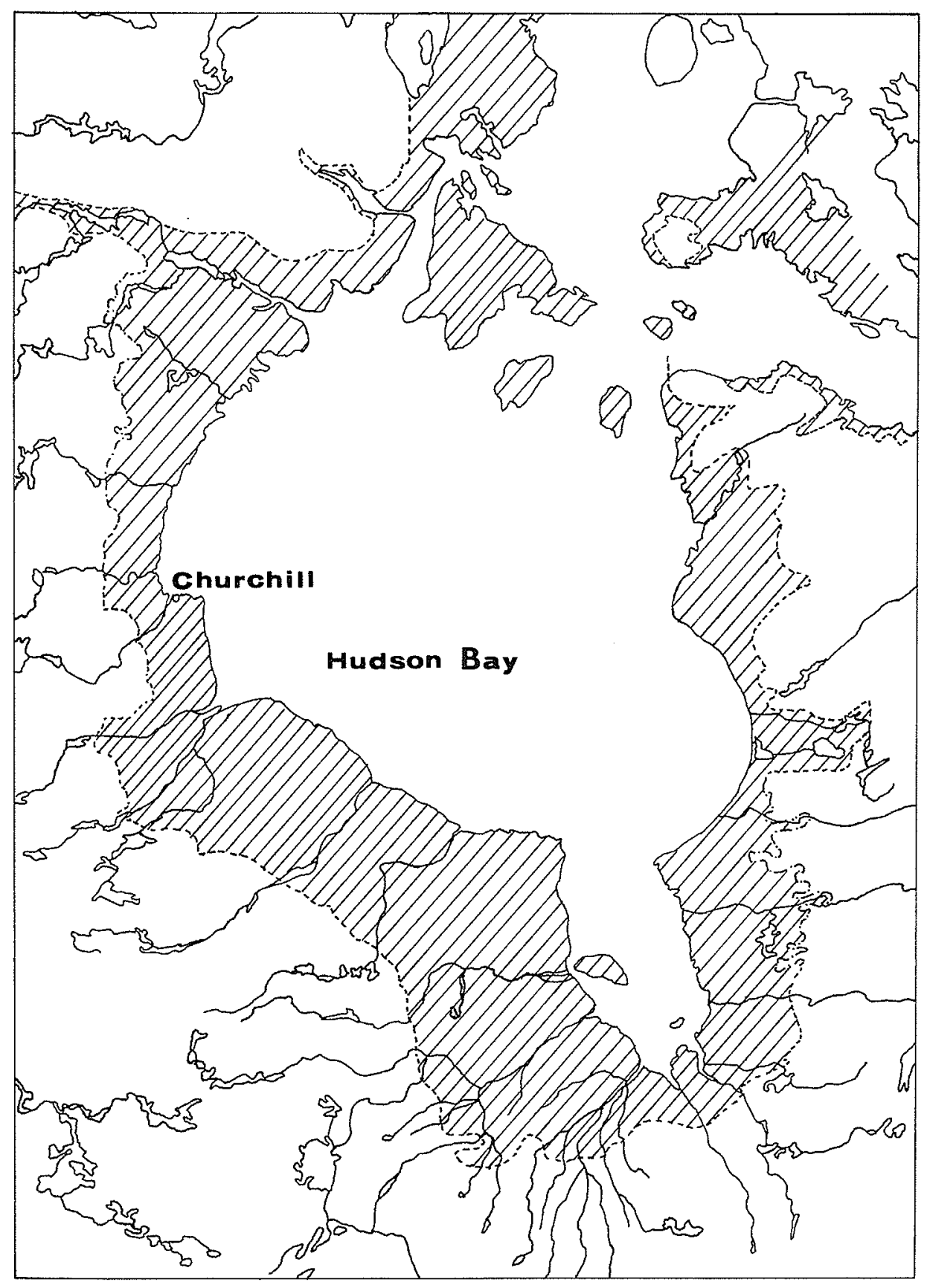

Map 4. Hatched area indicates the maximum extent of the Tyrre 11 Sea (After Lee 1968:515 and Pelletier et a1 1968:567). 
reached its maximum extent between seven and eight thousand years ago (Lee 1960:1609). Released from the ice, the land began to rise comparatively rapidly, resulting in a recession of the Tyrrell Sea. According to Lee:

The rate of emergence around Hudson Bay follows an exponential curve with an initial rapid uplift of the order of 20 feet per century and later a much decreased rate of the order of 1 to 3 feet per century. (Lee 1960:1610)

\section{CLIMATE}

The Churchill summer climate has been typified in the introductory remarks of this presentation. The weather in the summer is essentially marine, since it is profoundly influenced by the presence of the Hudson Bay. This huge body of cold water never warms appreciably and exerts a marked cooling effect on coastal temperatures. For this reason, the daily summer maximums at Churchill are lower than those inland to the west and are unusually cool for the latitude. On the other hand, the Churchil1 area rarely experiences nightly frosts as are likely to occur in the transitional forest. The prevailing westerlies keep this maritime climate from penetrating far inland, and, as Cheney and Beckel (1955:56) have noted:

Such a maritime climate makes its presence felt for a distance of five or more miles inland, beyond this distance quite different weather conditions may, and often do, occur.

Careful meteorological records have now been kept at Churchill for about forty years. The accompanying chart (Table I) indicates the monthly averages of daily mean temperatures taken from Scoggan (1957:8) and also the average monthly precipitation. The warmest months of July and August usually have several days during which the temperature climbs into 70 and 


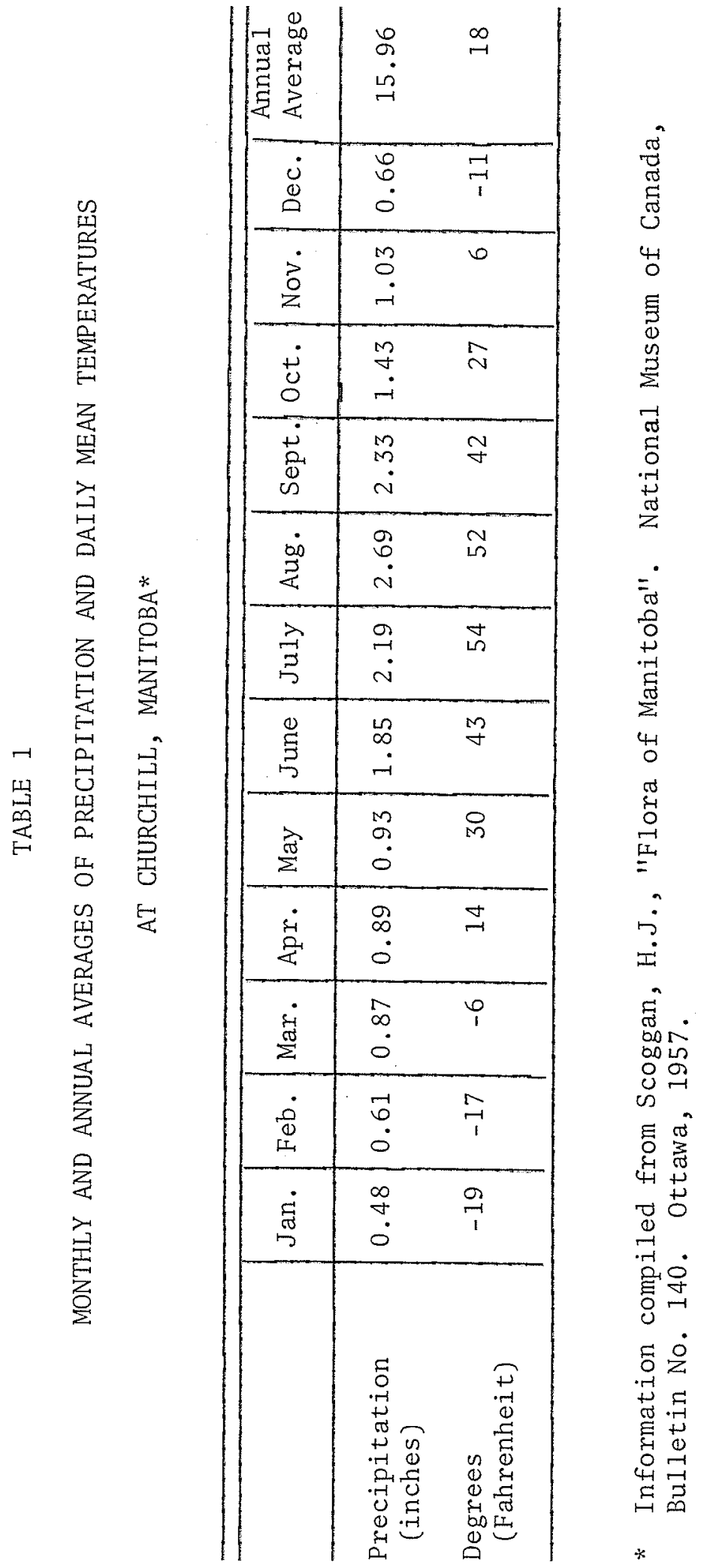


$80^{\circ} \mathrm{F}$ range, genera11y when hot air masses push through from the west and southwest. Not unusual is a cold rush of air from the north or from the waters of the Bay, in which case temperatures will reach highs of 40 to 50 degrees fahrenheit.

Churchill receives an average of 15.96 inches of precipitation a year. Most of this, 10.27 inches, falls during the warmest months as rain. This high summer rainfall has unfortunate implications for efficient archaeological endeavours in this region. The rest of the precipitation is received as snow, 5.69 inches on the average. Much of this falls in the late Autumn months.

The autumn, beginning about the second week of September is the stormiest period of the year. It is a short season and by late September, temperatures are often below freezing and the weather is wintry. According to H.A. Thompson $(1968: 269)$ :

From the time the first cold Arctic air masses advance over the Bay in September until its waters are ice covered in December, low pressure areas cross the region in almost regular succession, generally at three- or four-day intervals.

The stormy weather which results from these low pressure systems dumps large amounts of snow over the bay, so that October and November (December to a lesser extent) are the months of greatest snow fall. The Autumn is characterized by overcast skies 75-80 per cent of the time, by snowstorms with low clouds, and prevailing high northwesterly winds.

The two coldest months are January and February. Temperatures sometimes fall to $40^{\circ} \mathrm{F}$ or more below zero. The record low for January is -51 degrees fahrenheit (Scoggan 1959:14). If the Hudson Bay remained open all winter, this would dramatically affect the climate. It has only 
been in the last decade, since the establishment of a weather base at Coral Harbour on Southampton Island, that it has been ascertained that the Hudson Bay freezes over completely during the winter. At the floe edge, open leads up to five miles wide are found and in winter a great deal of vapour arises from these. This vapour obscures huge areas of the Bay and is one of the reasons that visual inspection from the air is difficult. Because of the prevailing northwesterly winds:

The shore lead or 'floe edge' is generally wider and more persistent on the west side of the Hudson Bay than on the east. (Cheney and Becke1 1955:232).

While the winter temperatures around the Hudson Bay do not drop to the extremes of the adjacent inland areas (especially to the west), the high winds of the region give it one of the highest wind chill values for the winter months in Canada (Thompson 1968:274). The prevailing wind is from the northwest, although west and south winds are also frequent.

By the middle or end of May the snow has melted away in the Churchill area and about the middle of June the river breaks up. By this time the ice of the Bay may be broken up, but it continues to float about until the first week or so of July. Depending on wind direction, pack ice may or may not be present in the Churchill area in early summer. The presence of permafrost must be noted, not only because of its influence on vegetation and habitation, but also because it can influence the course of archaeological endeavours. Although permafrost is general in the Churchill area, it was not encountered in the excavations of the summer of 1968. Garbage pits, dug near camp in the peat of the floor of Seahorse Gully, encountered permafrost at a depth of about a foot and a half. 
The $50^{\circ} \mathrm{F}$ isotherm is generally accepted as the limiting factor in tree growth. Churchi11, with two months well above the $50^{\circ}$ average should not, therefore, be on the treeline. In fact, the $50^{\circ}$ fahrenheit isotherm occurs about halfway between Churchill and Chesterfield Inlet. A more accurate indication of climatic conditions affecting tree growth is the Nordenskjold line (Scoggan 1959:15). In the computation of this line, the mean temperature of both the warmest and the coldest months are considered. This line does run through the Churchill area and must be considered the limiting factor in tree growth.

There has been considerable debate among scientists of several disciplines as to the climatic zone of the Churchill area. It seems clear that this argument arises because Churchill is on the border of two climatic zones, the low Arctic and the high subarctic. Scoggan $(1959: 20)$ would place Churchill in the subarctic zone because it is possible to grow vegetable gardens there. Thompson (1968:284) has summarized the Hudson Bay climate as follows:

... Hudson Bay has a typical Arctic climate closely dependent during all seasons on changes in the state of the surface water. Winters are cold and long with the ground snow covered from October to May or June. Although low temperatures are not as extreme as in many continental areas, the persistent winds combine with the cold to make this the coldest part of Canada on the basis of wind chill. Summers are short and cool with daily air temperatures only ten degrees higher than those of the cold waters of the bay.

VEGETATION

The relatively mild marine summers of the Churchill region, coupled with the convergence of the arctic and subarctic environmental zones, result in a great variety and abundance of plant life. According to Scoggan:

... the collections and published reports (1isted else- 
where) for the coastal district in the vicinity of Churchill

indicate a vascular flora of between 375 and 400 species.

In contrast, only 83 species of vascular plants have been found to the west in the transitional forest of the Baralzon-Nejanilini area (Scoggan $1957: 20)$.

For systematic presentation of this diverse collection of plants, the plant communities which inhabit certain distinctive geographical areas will be described separately. Becke1, Law, and Irvine (1954) have described nine major terrain types at the mouth of the Churchill River. However, for the purposes of this presentation, grosser divisions are satisfactory. Ritchie (1956) recognizes four "main features of topography" in the Churchill region; (1) the outcrop ridges, (2) the low plains, (3) the coastal sandy areas, and (4) the gravel ridges. Each of these "major physiograpic formations" supports a "discrete aggregation of plants" (Ritchie 1956:275). Ritchie's four divisions are similar to the five terrain types that are distinguished by Smith and Foster (1957). These are; (1) rock ridge, (2) low tundra, (3) beach, (4) open spruce-larch forest, and (5) sheltered woods. In the following discussion, the plants of each of Ritchie's four topographic features are considered as four separate distinctive groupings.

The quartzite ridge flora is of particular interest because the Seahorse Gully site is located on one of the ridges. Before the site ridge was burned it supported a thick organic mat similar to that still blanketing Second Burton Rock. Four or five inches thick, this tundra climax vegetation is mainly a mixture of lichens and heath. According to Smith and Foster (1957:100) the dominant 1ichens are Cladonia alpestris, C. rangiferina, Cetraria nivalis, and Alectoria ochroleuca. Growing with 
these are several heath species. These include two species of alpine bear berry, (Arctostaphylos alpina) and (A. rubra), the alpine azalea (Loiseleuria procumbens), two species of blue berries, (Vaccinium

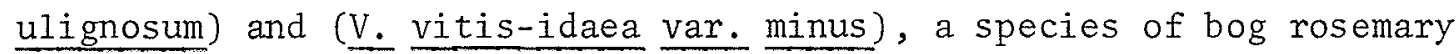
(Andromeda polifolia) and a species of 1 apland rosebay (Rhododendron 1apponicum). Also present are species of labradour tea (Ledum decumbens), (L. groenlandicum) and a species of crowberry (Empetrum nigrum) . On the most exposed seaward portions of the quartzite ridges, almost no trees are found. However, seven species of dwarf willows (Salix spp.) do occur on the tundra as does the dwarf birch (Betula glandulosa). Only a few struggling spruce trees are found in the crevasses and small ravines along the slopes of the seaward ridges.

In the more sheltered areas of the ridges several berry bearing plants are found. These include the blueberries mentioned above (unfortunately the writer thought them tasteless as compared with those of the southern boreal forest). Even more common than the blueberries are the lowbush cranberries (Vitis-Idaea puntata). In sheltered places the gooseberry (Grossularia oxyacanthoides) grows upright, but on the windswept uplands it branches along the ground. Two species of raspberry are found, one, the Arctic raspberry (Rubus arcticus) is a low shrub while the other, the baked-apple berry (Rubus chamaemorus) is a creeping plant. (Beckett 1954:104)

Also found on the ridges is a host of wild flowers. A different assortment of plants are present around the ponds. Here, four species of meadow grasses (Poa spp.) grow as well as the same number of sedge (Carex spp.) species. Several other grasses and sedges are found as well 
as the juniper (Juncus alpinus):

The open spruce-1arch forest is a terrain type that is found on both the rocky ridges and the low plains. On the rocky ridges, this forest consists of black spruce (Picea mariana) and larch (tamarack) (Larix laricina). This open forest is found on the southern portion of Second Burton Rock and on most of First Burton Rock. The trees grow on the slopes and to some extent on the summits. In one area, about an acre in size, on top of Second Burton Rock, a stunted grove of populars (Populus balsimifera) was noted. Only about knee-high, these poplars were the only ones noticed on the rock ridges. The poplar "forest" is sheltered on all sides by spruce trees.

The spruce and tamarack in these forests are always scattered with almost no underbrush. Between the well spaced trees the ground is covered with heath in which labrador tea (Ledum spp.) is most common. Also incorporated into this thick organic layer are mosses and lichens. The ubiquitous dwarf willows and birches are found here as well. The species found in the sheltered woods are the same as those of the open spruce stands. However, the trees of these areas are isolated from the main body, often growing in dense clumps in sheltered "ravines" along the seaward parts of the quartzite ridges.

On the better drained coastal portions of the low plain, open spruce-larch forest is also present. This forest is anomalous in the Churchill area as the spruce are predominantly white spruce (Picea glauca). Ritchie (1957) has demonstrated that this is a pioneer forest growing in the basic soils deposited by river silts. The fact that new soils are continuously being exposed at the Churchill mouth may be 
related to the likelihood that the land is still rising. As the sprucetamarack forest of the maritime treeline (Hustich 1954) becomes established, a layer of organic material and peat is formed. This eventually reaches a thickness great enough to insulate the subsoil and the permafrost level is therefore raised. This prevents adequate drainage and conditions advantageous to the growth of spaghnum moss result. A thick peat layer quickly accumulates and since it is acidic it is avoided by white spruce, but favoured by black spruce (Picea mariana). This, according to Ritchie, is the most plausible explanation at present for the existence of an open spruce-tamarack forest along the maritime treeline in the Churchill area.

The plants of the low wet tundra, which is full of ponds, are essentially the same as those found about the ponds on the rock ridges. Smith and Foster (1957:100) have provided this description of the low tundra:

These wet areas are often interspersed with dry hummocks of climax tundra similar to that of the rock ridge, with many shallow ponds, and by clumps of low willows and dwarf birch.

The dry upper portions of the third major topographic feature, the beaches, support thick clumps of grass (Smith and Foster 1957:100). With the grass (Elymus spp.) also grows a sandwort (Arenaria peploides), while a groundse1 (Senecio congestus) grows in wet places. On the stable beaches above the sandy upper beach many plants of the tundra and forest are found, establishing new communities. Horsetails (Equisetum spp.) are common as are grasses (Poa spp.) and sedges (Carex spp.). Six species of dwarf willow are found as well as the dwarf birch. Dryas (Dryas integrifolia) is a dominant species on the dry upper beaches. A distinctive set of plants is also present on the gravel ridges 
(Ritchie 1956:281). On the higher, well drained summits a "lichen-heath vegetation" is found while in areas saturated with water, sedges and grasses grow abundantly. The species found in these two plant areas have already been listed for geographically similar parts of the rock ridge and the low plain.

FAUNA

The fauna of the Churchill area includes a complex assemblage of bird and mammal species from three major environmental zones, the tundra, the transitional forest and the coastal marine. In general, each natural community contains a unique set of mammals, although there is some overlap between tundra and forest and tundra and marine. Of course, the waters of the Hudson Bay offer a radically different environment and its sea mammals were probably responsible for the movement of Pre-Dorset Eskimos into the Churchill area.

\section{MAMMALS OF THE TRANSITIONAL FOREST}

The plants of this community have been briefly outlined above. Since the northern transitional forest forms the largest nearby environmental zone, the animals of this area were probably most readily available to inland hunting parties of Pre-Dorset peoples. The moose (Alces americanus) is the largest of the forest species, although it is not very common. It is a solitary animal and does not herd as do the barren-ground caribou. The caribou (Rangifer tarandus groenlandicus) are found in the transitional forest mainly during the winter. They begin their migration from the forest as early as the middle of April. Most of the movement takes place during May, although stragglers may not complete the migration 
until the middle of June.

The grey wolf (Canis lupus occidentalis) is found in the forest as are the red, black, and cross foxes (Vulpes vulgaris). The wolverine (Gulo luscos) is found both in the forest and on the tundra. Black bears (Ursus americanus) are found throughout the forest area.

Beavers (Castor canadensis) and muskrats (Ondatra zibethicus albus) are found in the forest. Only a few muskrats follow the Churchill River to its mouth and these animals are relatively rare in the Churchill area. Another aquatic mamma1, the otter (Lutra canadensis) occurs in the forested areas. Martens (Mustela americana) are common in the transitional forest, but the only one of these species which is found at the coast is the weasel (Mustela erminea richardsoni). Small mammals of the taiga in the Churchill area include the red squirrel (Tamiasciurus hudsonicus) and several species of voles and mice. Most of these, including the squirrel have here reached the northern limit of their distribution. (Smith and Foster 1957:98)

MAMMALS OF THE TUNDRA

Four large animals were common on the tundra of the Churchill area at the time of initial European exploration. These were the barrenground caribou (Rangifer tarandus), the muskox (Ovibus moschatus), the tundra wolf (Canis tundrarum), and the polar bear (Thalarctos maritimus). At present only the caribou and polar bear are still numerous. The barren-ground caribou spends the summer on the tundra far to the north of Churchi11. Having arrived on the tundra in May or the middle of June at the latest, the animals begin to drift southwards at the end of the summer. This movement begins about early August and is quite leisurely 
as the animals do not reach the forest until September. According to Ke1sa11 (1968:109)

In October or early November, during or just after the rut, the migration becomes strongly directional and rapid, straight into the forest.

Those caribou along the west coast of the Hudson Bay migrate through the Churchill area in the spring and fall and many remain in the vicinity throughout the summer. (Shelford and Twomey 1941:54)

The polar bear is another animal which inhabits two of the natural communities. In the spring it appears to move north along the coastal tundra strip and is generally not seen at the mouth of the Churchill River in the summer. In the fall it moves south along the coast and awaits the formation of ice on the Hudson Bay. If the ice is slow in forming, the bears sometimes become concentrated in the Churchill area and are particularly numerous in the vicinity of Cape Churchill.

The muskox is no longer found in the Churchill area and probably was always rare. It was hunted by the European traders of the eighteenth century and the last record of muskoxen killed is from 1897 in the little barrens to the south of Churchill. (Preble 1902:43-44). The discovery of possible vertebral fragments of a muskoxen in the Dorset settlement at the Seahorse Gully site suggests the existence of muskoxen in this region prehistorically.

Also now absent from this area is the tundra wolf. In contrast to the grey wolf of the forest, this wolf is white. It preys on the caribou herds.

Four smaller mammals are common on the tundra. These are the Arctic fox (Alopex lagopus), the Arctic hare (Lepus arcticus), the 
collared lemming (Dicrostonyx torquatus), and the weasle (Mustella erminea) (Shelford and Twomey 1941:55). These species, together with the brown lemming (Lemmus sibiricus) reach the southern limits of their range at Churchi11. (Smith and Foster 1957:98)

MAMMALS OF THE MARINE COAST

The faunal analysis of the bones in the Pre-Dorset dwellings of the Seahorse Gully site indicate a major economic reliance on the sea mammals of the Hudson Bay. The animal hunted was the seal and the species most commonly taken was the little ringed seal (Pusa hispida). This seal is ubiquitous throughout Arctic Canada although it is not particularly abundant in the Churchill area. Several of these seals were spotted during the occasional boat journey's undertaken on calm days. Seals were sometimes seen in Button Bay along its rocky eastern shore. The commonest seal in the Arctic waters, the ringed seal is the most important animal in the Eskimo economy.

The ringed seal breeds wherever the ice is solid and stable throughout the winter and spring since the pups are born on the ice in early April (Mansfield 1967:21). If the ice breaks up too early, the pups will become separated from their mothers and die or mature slowly into dwarfed adults. According to Mansfield:

Good ice most often occurs along complex coastlines containing many bays with numerous islets scattered offshore. Along straight coasts, the ice is often unstable and there is usually only a narrow strip of fast ice. ... Seals from northern latitudes are considerably larger, probably through the same effect of more stable ice conditions in these areas. (1967:23)

The Churchill coast, with its straight or gently curved shore lacking small offshore islands, as well as its southerly position, does not 
have particularly stable ice. This is probably a major factor in the contemporary low seal population of this region. In the period of PreDorset occupation, around 3,000 years ago, the coast was more irregular than at present and several small islands, including the site ridge, lay offshore. The sea ice should have been more stable, and a higher seal population may have been present. Therefore, sealing could have been more productive in the past.

Adult ringed seals spend the winter beneath the sea ice near shore where they keep several breathing holes open. The usual Eskimo hunting pattern is to harpoon the seals in the breathing holes during the winter, to harpoon them at the floe edge in the spring and to harpoon them from kayaks during the summer. (Mansfield 1967:23)

The bearded seal (Erignathus barbatus) is a rare and solitary sea1. It does not remain beneath the winter ice, but prefers areas of open water. It is a very large seal, reaching an average adult weight of 750 pounds, in contrast to 150 pounds for the ringed seal. These seals are scattered throughout Arctic Canada and along the shores of the Hudson Bay. Eskimos prefer its thick hide for lines, kamik soles, kayak covers, etc.

The harp seal (Pagophilus groenlandicus) is migratory, spending the winter off Newfoundland and in the Gulf of St. Lawrence. Here they mate and give birth to their pups before setting off on their journey to the Arctic waters, in early May. This species is relatively unimportant as far as Churchill sealing is concerned since they rarely, if ever, reach the Churchill area.

The harbour seal (Phoca vitulina) is occasionally found in the 
Hudson Bay, and does occur in the Churchill area. These seals like fresh water, and according to Mansfield (1967:6):

... there is recent evidence of another group of freshwater seals inhabiting lakes on the Thlewiaza River draining into the Hudson Bay about 100 miles north of Churchill.

Adults attain weights of approximately 200 pounds. This seal does not winter under the sea ice, but seeks areas of open water.

Only a small number of walruses (Odobenus rosmarus) are found along the northwestern coast of the Hudson Bay. These are clustered immediately north of Chesterfield Inlet. Walruses spend the winter in leads of open water found in the pack ice (Mansfield 1967:28). They are relatively huge animals, the males weighing between 2,000 and 3,000 pounds at maturity.

One other sea mammal is common in the Churchill area. This is the migratory beluga whale (Delphinapterus leucas). It appears that most of these small whales spend the winter in the open water of Davis Strait. However, Doan and Douglas (1953:5) state that:

Further information indicates that Beluga may live throughout the winter along the western coast of Hudson Bay in the open strip of water off the shelf of solid shore ice, the floe edge.

Here, small numbers are sighted almost every winter, although visibility is limited because of the vapour that rises as fog from the open water.

With the spring migration of the beluga back into the bay, large numbers of the small whales ascend the Churchill mouth with every incoming tide. In July, a portion of one herd was counted and sixty anima1s were enumerated before the count was ended. Probably about 200 animals were present in this "herd", a number which has been commonly counted by biologists (Doan and Douglas 1953:4). Beluga whales are 
sma11, averaging about ten feet in length. Males up to fifteen feet long are occasionally taken. Those animals over twelve feet in length usually weigh more than 1,000 pounds.

BIRDS

The confluence of the northern edge of the transitional forest with the tundra zone, both of which are adjacent to the coastal marine environment, results in a remarkable concentration of bird species in the Churchill area. Only a few of these species remains in the Churchill region the year around. These include the willow ptarmigan (Lagopus lagopus) which is common on the tundra (one large brood shared the site ridge with the archaeological crew). The rock ptarmigan (Lagopus mutus) is found in this area mainly during the winter (Jehl and Smith 1970:35). A forest species, the spruce grouse (Canachites canadensis) is rare but could occur throughout the year.

Also resident for most of the year is the snowy ow 1 (Nyctea scandiaca). It nests on the tundra, feeding mainly on lemmings (Taverner and Sutton 1934:60-61). Other avian predators include the short-eared owl (Asio flammeus), the rough-legged hawk (Buteo lagopus), the marsh hawk (Circus cyaneus), the peregrine falcon (Falco peregrinus) and the pigeon hawk (Falco columbarius). All appear during the summer to feed upon lemmings, voles, and other small mammals and birds.

The vast majority of the 209 bird species reported from Churchill (Jeh1 and Smith 1970:21) are migratory, using the area for summer nesting. These include many species of song birds, shore birds, and waterfow 1 . The Canada goose (Branta canadensis) is quite common. During the summer of 1968 one pair nested in the low tundra between Second Burton 
Rock and Ward Mountain. The snow goose (Chen caerulescens) migrates through Churchill in the spring and fall. Ducks are not particularly common, perhaps because the clear ponds do not offer abundant food. Mallards (Anas platyrhynchos) are rare and probably seldom nest in this region. The black duck (Anas rubripes) is a common summer resident (Taverner and Sutton 1934:17). Pintails (Anas acuta) are also common in the Churchill area, nesting during the summer.

The most numerous waterfowl are the old squaw ducks (Clangula hyemalis) and the pintails. The red-breasted merganser (Mergus serrator) is also very common. Several other waterfowl species such as the American widgeon (Mareca americana), the teals (Anus carolinense), (Anas discors) and the shoveller (Spatula clypeata), are summer residents. The The red-throated loon (Gavia stellata) is a faixly common migrant and another loon, the Arctic loon (Gavia arctica) is common along the shores of the Hudson Bay and breeds on the lakes of this area (Taverner and Sutton 1934:11).

In this coastal environment, gulls are common. These include Bonaparte's gul1 (Larus philadelphia), the herring gul1 (Larus argentatus), the glaucous gull (Larus hyperboreus), etc. Several species of jaegers (Stercorarius spp.) occur, although the parasitic jaeger (Stercorarius parasiticus) is the most common.

Shore birds are very numerous, including plovers, snipes, and many species of sandpipers. Small song birds are even more common and include warblers, longspurs, larks, and sparrows.

\section{$\underline{\text { FISH }}$}

The most economically important fish of the Churchill area are 
those that spend much of their lives at sea but return to inland lakes and rivers to spawn. These include the Arctic char (Salvelinus alpinus), the brook char (S. fontinalis), the whitefish (Coregonus clupeaformis), and the shallow water cisco (Oregonis artidii). After the spring breakup, these fish move quickly out into the bay to feed for the summer. They move down the rivers into the Bay so quickly that they cannot be easily caught (Hunter 1968:363). Their numbers are more concentrated when they return to the rivers and lakes in the fall and they can be more easily caught at shallows or in fish traps. Almost no Atlantic salmon are present in the Hudson Bay so that this species does not ascent the rivers in great numbers as elsewhere. According to Hunter (1968:361), almost all of the marine fishes "are small, obscure bottom dwelling forms, occurring in low abundance and devoid of any apparent value in the economy of man." The waters of the Bay are frigid and together with the short summers, they do not provide a favourable environment to any fish except a few Arctic species. Even these are few in numbers and reproduce slowly. Only two species of marine fish, the Greenland cod (Gadus ogac) and the capelin (Ma1lotus villosus) are likely to be of any economic value to man.

Freshwater fish frequenting the rivers and streams of the Churchill region include those species that sometimes spend the summer at sea. Also of potential economic importance are graylings (Tymallus arcticus), northern pike (Esox lucius), suckers (Catostomus spp.), and trout-perch (Percopsis omiscomaycus). Others such as sturgeon (Acepenser fulvescens) and burbot (Lota lota) may also be of importance while several other species of smaller fish are not likely to figure significantly in any economy. 
CHAPTER II

THE PALAEO-ENVIRONMENT

INTRODUCTION

In the preceding chapter the contemporary environment has been described in some detail. It cannot, however, be assumed that the topography, climate, flora, and fauna were exactly the same 3,000 years ago during the period of Pre-Dorset Eskimo occupation of the Churchill region. Therefore, this chapter is presented with the intention of outlining, to the extent that information is available, the major characteristics of the ancient environment.

ISOSTASY AND UPLIFT RATES

Twenty thousand years ago the Churchill region was near the centre of the Wisconsin Laurentide ice-sheet. With the recession of this vast blanket of ice and the eventual opening of the Hudson Bay, the Tyrrel1 Sea flooded the land which had been depressed far below sea level by the weight of the glacier. In the Churchill area, the maximum extent of the Tyrrell Sea lies sixty or more miles inland. Here, the highest strand lines are found at elevations from 350 to 500 feet above the present sea leve1.

Released from the weight of the ice, the land began to rise. Initially the uplift was very rapid, in the order of twenty feet per century (Lee 1960:1609). Gradually the rate of uplift decreased as the land approached a more stable position, until at present, in the Churchill area, it is about 2.4 feet per century. This rate has been calculated by Barnett (1966) utilizing tide gauge data from the Churchill port as recorded on Lee's graph and although only nine radiocarbon dates are plotted 
against sea level, it appears that around 3000 years ago (the period of Pre-Dorset occupation) uplift was more rapid than at present. In fact, at that time, it seems to have been occurring at a rate of about four feet per century.

The 100 foot contour at the Seahorse Gully site (Map 5) encompasses all the Pre-Dorset archaeological remains (with the exception of a chisel found on a high knoll to the southwest - see Map 5). Most of the dwellings and activity areas are about 200 yards from this contour. One dwelling, House 10 (described in Chapter VII), is only about 100 yards from the 100 foot contour. A distance of 100 to 200 yards would provide a reasonable gap between the waters of the Bay and the dwellings of these Pre-Dorset Eskimos. It is postulated, therefore, that the present 100 foot contour approximates a water level important during the final period of Pre-Dorset occupation. It is likely that this was the high tide level. Contemporary tides in the Churchill region average about twelve feet in height. While the average height of the tides during the PreDorset period is not known, it may safely be assumed that it was in the range of twelve feet. If so, the mean sea level at the time of Pre-Dorset occupation would have been about ninety-five feet above the present sea leve1.

Care must be exercised in the determination of sea levels from dwelling locations. Taylor (1968:98-99) has discussed the fact that actual house locations may bear little relationship to sea levels since a combination of local conditions influences the actual sites occupied:

Beaching boats, snow conditions, shelter, drinking water, visibility for off-shore hunting, fishing and hunting opportunities and conditions in the immediate area and the availability of such building materials as gravel, stone, and turf are factors, along with proximity to water's edge, that influence a choice of camp location. 
Although their dwellings may be situated hundreds of yards from the sea shore, and many yards above sea level, it is evident that Eskimos, as hunters of sea mammals, prefer to be as close to the marine waters as possible. In most cases, the locations of Eskimo dwellings do provide at least a rough indication of the sea level at the time of occupation.

The graph presented in Figure 1 represents the exponential curve of uplift in the Churchill area during the past 3500 years. Unfortunately, only two of the points are securely tied to radio-carbon dates, although even they cannot be confidently assigned absolute altitudes. These two points are computed from; (1) the date of $130 \pm 95$ years B.C. (I-3973) for the Dorset settlement at Seahorse Gully (Map 5) with an altitude of sixty feet (Nash 1970:9) and, (2) the date of 945- 100 years B.C. (S-521) for the Pre-Dorset settlements which were inhabited when the waters of the Bay stood ninety-five feet above their present level.

The points for Thyazzi and Twin Lakes are not based on radiocarbon dates, but on dates obtained by typological comparisons with dated Pre-Dorset sites in the central Arctic. Unfortunately, a firm altitude cannot be given for Thyazzi, although Nash (1969:50-51) indicates that it is between 115 and 120 feet. Therefore, this graph must be viewed as tentative and experimental, useful in outlining hypotheses, but liable to correction with the collection of more data.

Utilizing an uplift rate of four feet per century, the thirtyfive foot difference in altitude between the Dorset and Pre-Dorset occupations corresponds to 875 years. This compares well with the 815 year span obtained by subtracting 130 years from 945 years.

\section{PALAEO-TOPOGRAPHY}

The contemporary topographical characteristics of the Churchill 


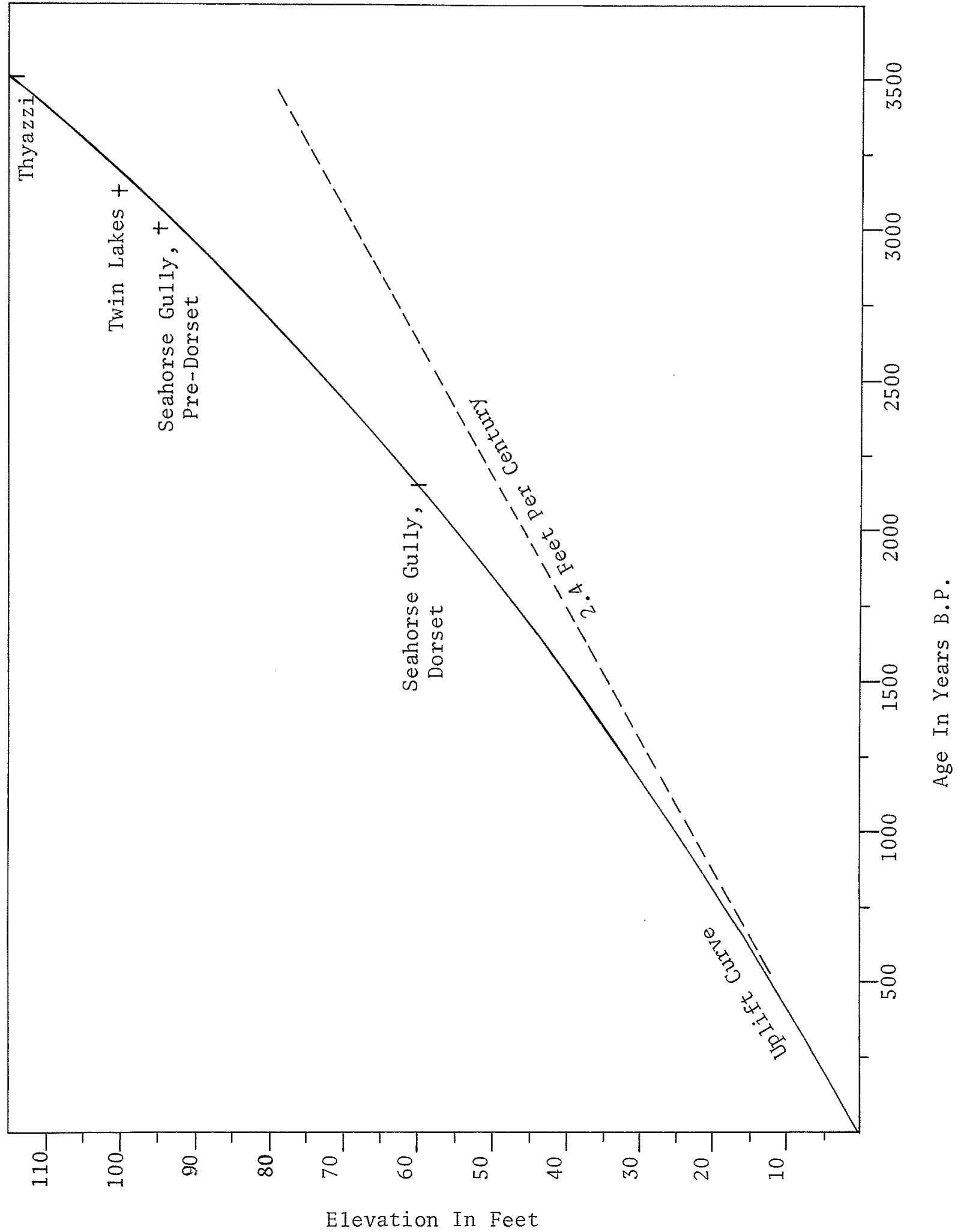

Fig. 1. Exponential uplift curve in the Churchill area compared with the present uplift rate (2.4 feet per century). 


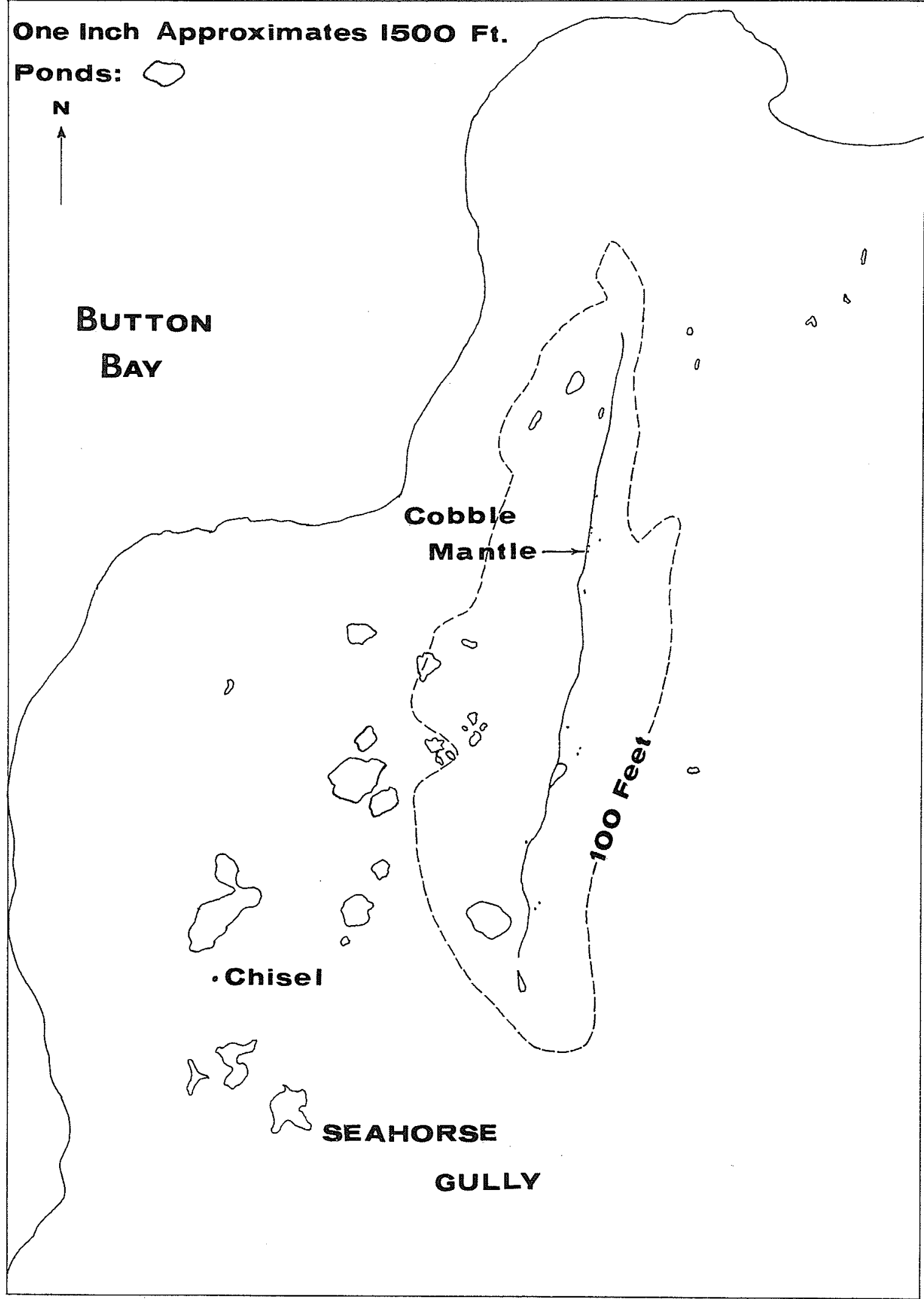

Map 5. 100 foot contour indicates the approximate shape and size of the island when occupied by Pre-Dorset Eskimos (i.e., high tide at a mean sea level of ninety-five feet). 
area are radically different from those familiar to the Pre-Dorset hunters. When occupied 3000 years ago, the site (at an altitude of ninety-five feet) was a narrow island over a mile long and more than a third of a mile wide (Map 5). Since the date of $945^{+} 100$ years B.P. relates to the most recent Pre-Dorset habitation of the site, earliex occupants would have lived on an even smaller and narrower island.

Dwellings could probably have been established on the island when the mean water level was 100 feet above the present level. This initial occupation may have occurred at a time when the island was still cut in two at high tide. Later, when the island rose to the ninety-five foot level, the central portion of the island became available. Here, a scattered, thin, archaeological settlement was present which, on the basis of house type and artifacts, is recognized as later than the settlements of the higher northern and southern portions of the site. (this settlement was radiocarbon dated).

At the time of final occupation, the island was low and windswept, probably more devoid of vegetation than it is now. Certainly no spruce were growing on the island, although a few dwarf willows may have been present. The fact that some of the artifacts were found lying on two inches of organic material indicates that a tundra layer was present on the island at the time of occupation. Portions of the island must have been exposed for several centuries before being occupied, providing time for tundra growth and the accumulation of an organic layer.

Three thousand years ago the coast in the Churchill area was clearly more jagged than at present. Several islands were present offshore, the site ridge being one of them. It was the outermost island of an archipelago stretching out into the bay from the mainland. This string 
of islands was formed by the tops of First and Second Burton rocks and other quartzite ridges to the south of them. To the east, the area now occupied by Fort Churchill was a small roundish island and Twin Lakes Island was present several miles to the southeast. Seahorse Gully, Second Burton Rock and Twin Lakes were frequented by the same or related bands of Pre-Dorset Eskimos, although it is not yet known if the Fort Churchill Island was. Ironically, this, the most accessible area, has not yet been archaeologically surveyed.

It is difficult to outline the shore line when the waters stood ninety-five feet above their present level as contour lines usually related only in a general way to ancient strand lines. Erosion during the last 3000 years may have substantially altered the contours of the land. However, Map 6 is presented as an approximation of the Churchill coast line during the Pre-Dorset period.

\section{PALAEO-CLIMATE}

Palaeo-climatological studies in the Churchill region are few. Joint investigations have been made by Bryson, Irving, and Larson (1965) in the Ennadai Lake area about 200 miles to the northwest of Churchill. Here, at the present tree line, they found that the forest had twice advanced far beyond its present limits. From 3500 to 1500 B.C. the trees extended about two degrees farther north than at present. Bryson, Irving, and Larson $(1965: 46)$ conclude that this period was characterized by a "relatively mild climate".

Similarly, Nichols (1967) in his study of Ennadai peats has recognized a warmer period lasting from 3700 B.C. to 1600 B.C. During this time the mouth of the Churchill River was almost certainly wooded although a strip of tundra may have been present along the coast as at 


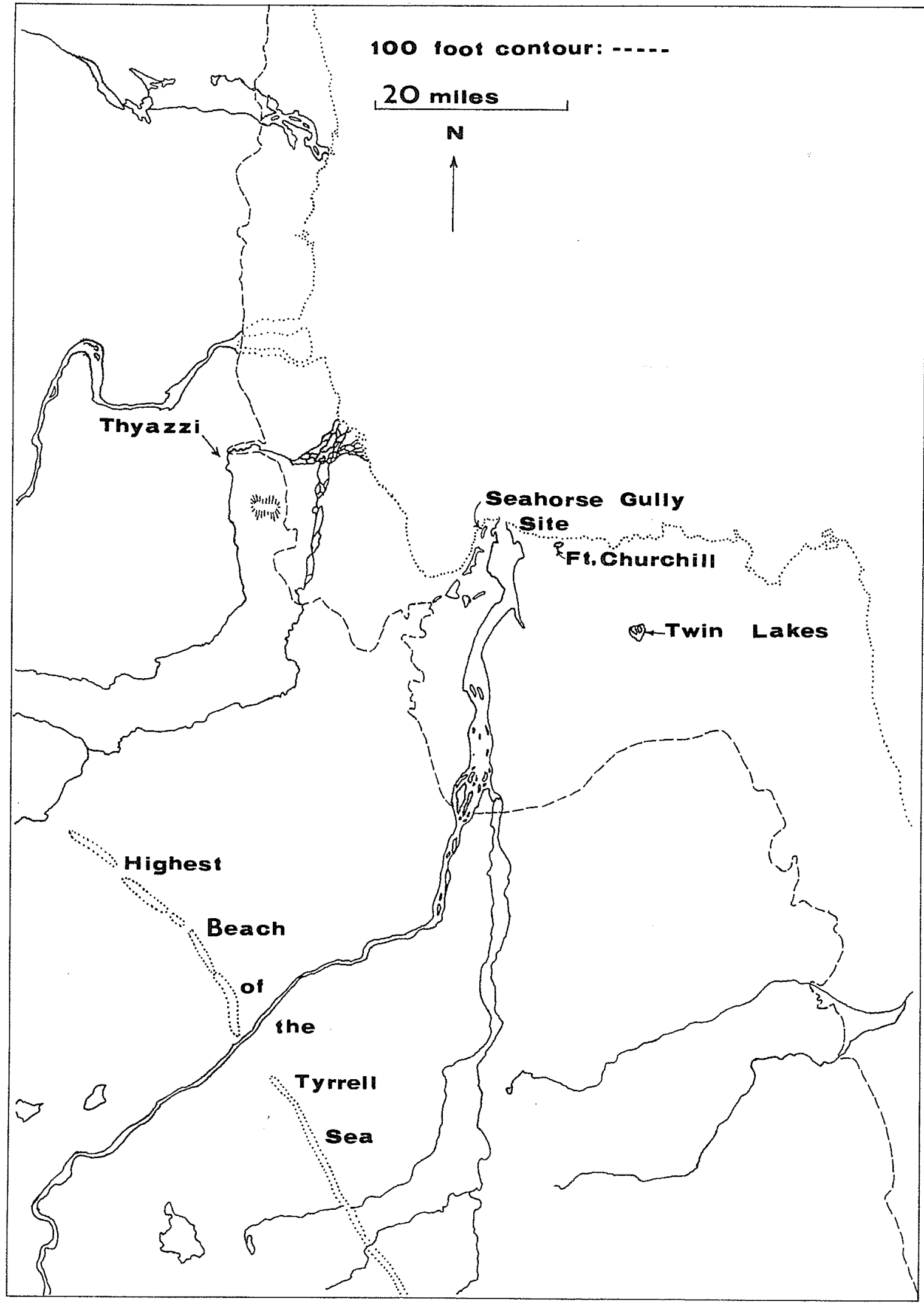

Map 6. Dashed line indicates the approximate outline of the Hudson Bay coast 3000 years ago (i.e., high tide at a mean sea level of ninety-five feet above present). 
present. Nichols also has presented evidence for much cooler climatic conditions following 1600 B.C. At this time the Arctic front remained farther south in the summer. This front determines the tree line:

From July through October the tree line coincides with the average position of the northern edge of the Arctic frontal zone; from November through February it marks the southern edge of this zone (Bryson, Irving, and Larson 1965: 46).

With the advent of colder weather, the northern edges of the forests failed to regenerate after forest fires of the period. As a result the tree line retreated southwestward, eventually reaching south of its present position (Bryson, Irving and Larson 1965:47). This cooler climate pushed the tundra zone farther south and extended the environment to which the arctic sea mammal hunters were adapted. The arrival, therefore of Pre-Dorset Eskimos in the Churchill region around 1500 B.C. is evidently linked to this climatic change. The author of the following statement is probably William Irving (Bryson, Irving and Larson 1965:48):

The first arrival of Arctic culture in the region (pre-Dorset stage of the Arctic small tool tradition) probably took place 3000 to 4000 years ago, with the onset of more severe climate and the retreat of the forest border.

Albert Dekin (1969) has shown that the period from about 1500 to 1100 B.C. was generally cool and wet throughout the eastern Arctic. In the eastemArctic this cooling trend was ended by 1100 B.C. and the period up to 650-700 B.C. was characterized by a warmer and more stable climate. It is likely that the west coast of the Hudson Bay was also warmer at this time and that the Pre-Dorset occupation at Seahorse Gully (945 B.C.) falls at the end of the cool period or perhaps in the transitional period between. 
In interpreting a pollen sequence from Ennadai Lake, Nichols (1967: Fig. 2) has shown that Sphagnum moss peaks occurred five times between 1670 B.C. and A.D. 1350. These peaks indicate periods of increased warmth and wetness. One of these occurs about 1190 B.C., the other about 500 B.C. The 1190 B.C. peak is near the date of $945^{+} 100$ years B.C. for the Seahorse Gully Pre-Dorset occupation, and it is possible that these early Eskimos were living during a period of warmer temperatures and increasing precipitation.

In western Greenland, Jorgen Meldgaard (1960b:66) found that the Sarqaq (Pre-Dorset) and subsequently the Pre-Dorset cultures:

... disappeared from Sermermiut before or at the beginning of a period of increased precipitation, which may mean that snow conditions became more difficult; probably neither of them were in possession of dog-pulled sleds.

This depopulated break between Sarqaq and Dorset occupation in west Greenland has been eloquently and convincingly questioned by Taylor (1968:9093) and it seems that climatic change may not have inhibited habitation to the degree suggested by Meldgaard.

The Pre-Dorset occupation at Seahorse Gully ends above the 100 foot contour. While not enough is yet known of Pre-Dorset and Dorset occupation of this region to safely state that this is true of the whole region, still, it can be suggested that a combination of climatic factors resulted in a temporary abandonment of this region by Pre-Dorset Eskimos. Meldgaard's last sentence in the above quote suggests that with increased snow, movement would become very difficult as these early Eskimos did not use the dog sled. Rather, it is likely that the high winds of the Arctic would simply pack the snow into larger drifts which would be no more difficult for people to move across than small drifts. More 
important might be the effect of the snow fall upon the relationship of Arctic fauna to its environment.

The importance of snow depth and density to caribou grazing and general behaviour has been clearly demonstrated by W.O. Pruitt (1959). He found that caribou did not remain in areas where the snow was over two feet deep, even though it might be the fluffy snow sheltered within the northern forest. Caribou will also avoid areas in which the snow, either through drifting or crystalization, has reached a density of 0.19 to 0.20 . The highly variable wintering ranges of the caribou are closely related to the vagaries of local weather and its effect on the composition of the snow cover.

Therefore, a combination of factors, including a warming of the climate and an increase in precipitation, may have greatly altered the environment of the Churchill region about 3000 years ago. In a peripherally arctic-subarctic area such as this, minor climatic changes can be expected to have drastic effects on the ecology of the local fauna. Warmer temperatures would result in less stable ice along the coast in the spring. This ice would break up relatively early, providing poor whelping areas for the ringed seal and frequent separations of mothers and pups. As a result, seal numbers would decrease, perhaps greatly. If winter precipitation was on the increase, caribou herds might avoid this region because of the greater difficulty in reaching the buried vegetation during this season.

The resource base of the economy of the local Pre-Dorset bands may, therefore, have been seriously depleted by a decrease in seal numbers and a movement of caribou herds to other wintering ranges. 
Such a depletion would take place gradually as the climate changed imperceptibly over the decades. However, a point would eventually be reached at which the Pre-Dorset Eskimos of the Churchill region would find survival very difficult. At this point, these early Eskimos must have retreated north along the western coast of the Hudson Bay to areas of more stable ice and better sealing.

SUMMARY

Three thousand years ago the shape of the Churchill coast was less smooth than at present, with more bedrock ridges extending into the Bay and more offshore islands. A narrow, southward extending strip of tundra was probably present along the coast. The forest, as now, must have extended almost to the mouth of the Churchill River. Projecting from the western side of the Churchill mouth, a string of quartzite ridges formed a miniature archipelago out into the Hudson Bay. The Seahorse Gully site ridge formed the outermost island of this group.

At the time of initial Pre-Dorset occupation of the Churchill region, the forest may have extended somewhat north of its contemporary extent, however, it eventually retreated south of its present limit. The concomitant extension of the tundra may have encouraged the PreDorset Eskimos of the Churchill area to hunt caxibou far inland. As the tundra expanded and the early Eskimos followed it, it is likely that the inland population (Indian) which was adapted to the subarctic forests, retreated with the forests. Therefore, at least two factors should have been operating to encourage Pre-Dorset peoples to move south along the coast; (1) the tundra was present and expanding, and (2) a human population, already present for about 2000 years (R. Nash, personal communica- 
tion), had retreated south.

About 3000 years ago there is evidence of a climatic warming trend accompanied by increased precipitation. This may have resulted in a decrease in marine fauna as we11 as a change in caribou ranges and movements. Such unfavourable conditions appear to have resulted in an end to Pre-Dorset occupation of the Churchill region, perhaps in a retreat of the population to the north. The Seahorse Gully site ridge seems to have remained uninhabited for 800 years until a few Dorset culture families lived on the island between 100 and 200 years B.C. (Nash 1970). 


\section{CHAPTER III}

FIELD WORK

THE PROBLEM

The initial archaeological investigations at the Seahorse Gully site were based about two problems; (1) a need to investigate the site in order to ascertain what was there, and (2) to salvage the Seahorse Gully Pre-Dorset artifacts. The site had to be studied quickly before information became permanently lost.

Dr. R.J. Nash did have a third problem in mind, however, and a direction in which to orient investigations if the archaeological remains permitted it. This is evidenced in his statement of 1967 , concerning the proposed Seahorse Gully study (Nash 1967:18):

Here is the opportunity for a more complete conjunctive type approach to a Pre-Dorset site, something which was impossible at Thyazzi because of its inaccessibility and at Twin Lakes because of its light occupation.

For this reason, when dwellings, some of which were rich in both artifacts and faunal remains, were found, work was concentrated on them. Another major problem to be solved was, "to determine whether the complex of large tools was the work of the Pre-Dorset Eskimo or a second and different group of people." (Nash 1968:ii). Happily, firm and extensive evidence relating to both of these problems was gathered during the 1968 field season.

Problem formulation is an initial and fundamental part of the process of doing archaeology. All archaeologists, regardless of their protestations of a blank, sponge-like approach, enter the field with biases and subconscious problem orientations. Such implicit or explicit orientations mold the process of information gathering in the 
field. Such directed field work, while incorporating obvious drawbacks, seemingly cannot be avoided. Therefore, rather than entering the field with a vague problem, the archaeologist should make the best of a "bad" situation and carefully formulate his problem and the concommitant manner in which the site is to be attacked. This does not imply that certain data must be ignored, it suggests rather that parts of a site will be excavated emphasizing the detailed recording of specified phenomena. Hopefully, other cultural phenomena will be recorded in a detailed enough way for use by other archaeologists. While a particular excavation may not result in the preservation of a totality of information relevant to all problems, that portion of the data gathered may prove to be adequate or, at least, very useful.

W.W. Taylor has shown that a site must be chosen for investigation by reference to its possibilities for answering specific questions:

But once the selection has been made and when the actual excavation has begun, there can be only one objective; to exploit fully and without abridgement the cultural and geographical record contained within the site attacked. (Taylor 1948:153)

Notwithstanding Taylor's statement, the excavation of a site typically results in detailed information on certain aspects only. For this reason it is very difficult or impossible to utilize these data in dealing with different problems. As the Seahorse Gully site was recorded with a problem orientation involving the settlement pattern (a concept closely related to cultural ecology and societal organization), data relating to these aspects (or which are believed to relate to these aspects) of the prehistoric culture have been gathered. Therefore, an attempt to reconstruct the Seahorse Gully Pre-Dorset occupation in terms of conjunctive archaeology, relying on cultural ecological 
data and the settlement pattern, is conceived as the best possible emphasis of this thesis. While more limited problems could be answered with the available data from Seahorse Gully, it is likely that more complex interpretive problems could not be adequately considered.

The Seahorse Gully archaeological occupation is reconstructed as three settlements each composed of interacting social units and individuals involved in the daily problems of survival in an Arctic environment. An attempt is made to delineate the annual economic cycle in an effort to approach cultural ecology. Here, K.C. Chang's (1962:28) statement is relevant:

The effect of cultural ecology (Steward 1955:30ff) upon social organization through the settlement pattern is a problem area that has received little of the concentration of attention that it deserves in current anthropological literature, yet it is of vital concern to archaeologists who attempt the reconstruction of prehistoric society.

Nowhere is cultural ecology of greater importance to social organization than in the Arctic and subarctic. It is, therefore, a basic premise of this thesis that the settlement pattern is a reflection of the social organization which in turn is profoundly influenced by ecological relationships of the inhabitants to their environment.

The work of the crew in the field was influenced by intensive perusals of K.C. Chang's "Rethinking Archaeology" in which settlement archaeology is outlined. While the settlement is not here considered as the basic archaeological unit (as Chang argues), it is evident that Chang's settlement approach can be profitably applied to the Seahorse Gully situation in which houses and activity areas are clustered into differentiable and patterned groups. 
DEFINITIONS USED

Chang's definitions are used for several major concepts such as the settlement (see Chapter VIII), the settlement pattern (Chapter VIII) and the community and community pattern (Chapter IX). Definitions from David Clark's recent tome (1968:406-407) are used for; (1) the artifact, "any object modified by a set of humanly imposed attributes", (2) the artifact attribute, "a logically irreducible character of two or more states, acting as an independent variable within a specific artefact system", (3) the artifact type, "an homogeneous population of artefacts which share a consistently recurrent range of attribute states within a given polythetic set", (4) the assemblage, "an associated set of contemporary artefact-types", and (5) the archaeological culture, "a polythetic set of specific and comprehensive artefact-types which consistently recur together in assemblages within a limited geographical area".

Stuart Struever (1968:287) has presented definitions of terms such as "tool kit" and "activity area". A tool kit corresponds to or reflects the activities which have been carried out in a specific area of a site. More than one tool kit may make up an activity area such as a cooking locality.

THE SITE

The Pre-Dorset occupation at Seahorse Gully covers a Iong narrow strip on and bordering the cobble mantle that tops the quartzite ridge. The cobble mantle (Map 7) is composed of gravel with some larger cobbles and rocks. The gravel appears to have been scooped by wave action out of the boulder fields that border the mantle and deposited in a heap along the highest part of the ridge. This deposit is about five feet thick and varies in width from twenty to more than thirty feet. 


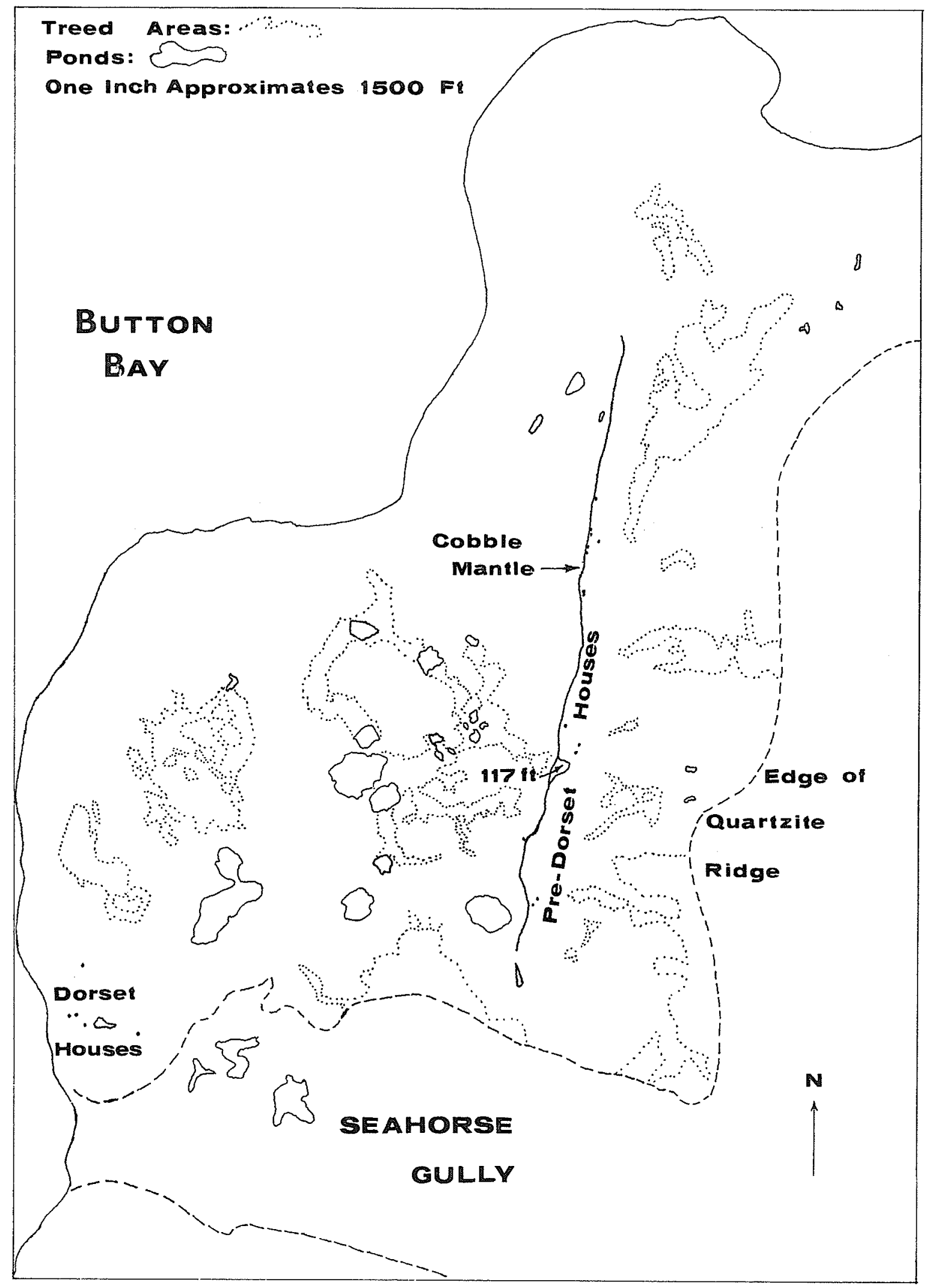

Map 7. The Seahorse Gully site area. 
The cobble mantle is elongated north-south and stretches for nearly a mile along the top of the ridge. Two sections, each a quarter-mile long, at the north and south ends are the highest parts of the ridge and the cobble mantle. These are also the areas with the greatest concentrations of Pre-Dorset habitation. The central half mile of the mantle is the lowest, approximately ten feet lower than the northern and southern ends. This central area has a thinner and more diffuse cobble mantle and was the location of a scattered Pre-Dorset occupation.

A layer of organic material several inches thick once blanketed the ridge. The accumulation of thousands of years of climax tundra growth, this thick mat has been largely burned off the ridge and appears to be regenerating very slowly. This fire exposed the evidence of ancient habitation, making survey relatively simple. It is certain that no areas of occupational concentration were missed by the field party.

The occurrence of Pre-Dorset artifacts in relationship to the cobble mantle is of particular interest. Perhaps half of the occupational debris is found on the cobble mantle, indicating that it was a favoured activity area and that many dwellings were placed there. The remainder of the Pre-Dorset occupation occurs to the east of the cobble mantle. Two factors are likely to have influenced this use of the lee side of the island; (1) the cobble mantle was high enough to provide some shelter from the prevailing wind, and (2) the water on the east side of the island was calmer and better suited for the beaching of watercraft. These two factors, in combination with others not known now, may have resulted in strong pressures on the Pre-Dorset occupants to live along the eastern side of the island. 
Only in one area does any occupational debris occur to the west of the cobble mantle. This is at the extreme southern end of the mantle, from 2500 to 2700 feet south of datum (Map 8), where a large patch of fine yellow sand has been deposited. Three factors may have resulted in this overflow of Pre-Dorset activity off the western edge of the mantle; (1) the soft dry sand was an attractive living area, (2) this was the most intensively occupied portion of the site and this concentration of humans might be expected to expand their activities into normally unused space, and (3) this was the nearest point to Second Burton Rock and it may have been a frequent boat landing and launching place.

The highest portion of the cobble mantle extends from 1100 feet south of datum to about 1200 feet south (Map 8). Here the mantle area is protected along its western side by a mass of quartzite boulders. These boulders project several feet above the mantle and have modified the manner in which the waves deposited the gravel and cobbles of this area. In the lee of these boulders the mantle is high and wide, bulging to the east (Map 8).

On this highest area $\left(115^{+}\right.$feet $)$two artifacts typical of a more ancient Arctic Small Tool culture were found. Both are small, fragile, and characterized by a delicate and minute flaking style not found among the other Pre-Dorset tools. One tool (Fig. 2,a) is a bipointed end blade of milky chert. The other is a narrow rectangular side blade of fine brown chert, and is now broken. As this portion of the island is the highest and was available for occupation first, it is likely that these tools were lost by very early inhabitants of the site. These tools are not considered to have formed a part of the tool kits of the Pre- 


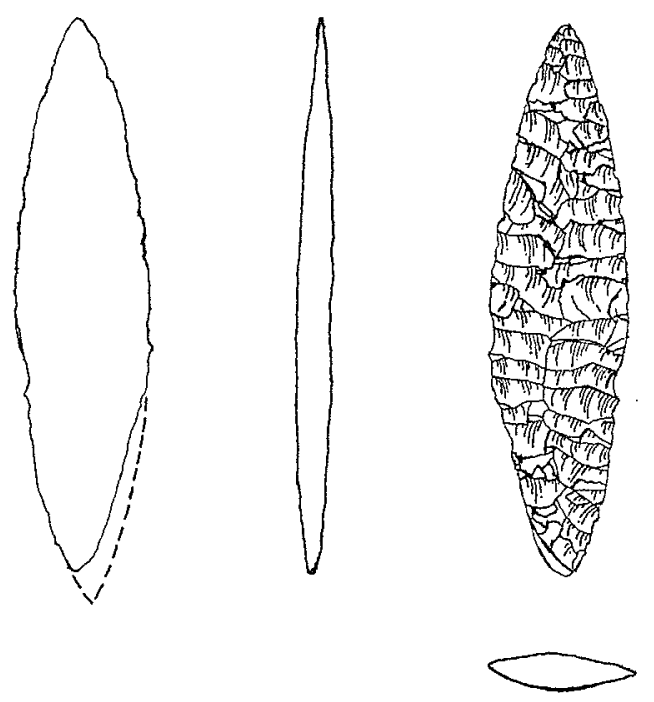

a
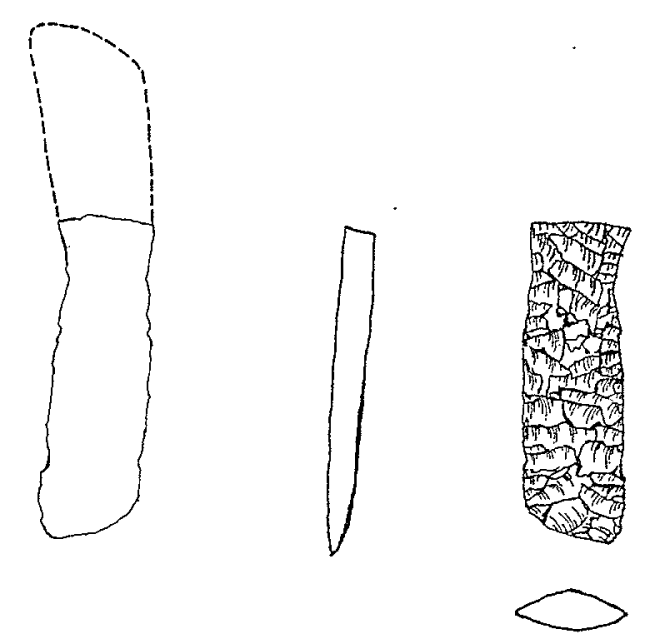

b

Fig. 2. Tools from the highest portion of the cobble mantle. a, end blade; b, side blade. Drawings are actual size. 
Dorset Eskimos who inhabited the southern settlement around 3000 years ago. They may be more closely related to an assemblage such as that of Thyazi, although no good analogues are present there.

The northern end of the cobble mantle also revealed a concentration of Pre-Dorset occupation. Here, no artifacts were found off the western edge of the mantle although several dwellings had been constructed along the mantle summit. Signs of habitation did extend off the eastern edge of the mantle and one house (10) was situated several yards to the east.

THE EXCAVATIONS

Ten houses were excavated at the Seahorse Gully site. All of these excavations were shallow and in most cases only added a few artifacts to larger surface collections. Although the southern end of the site was the most intensively inhabited, the richness and superimposition of occupation made this area difficult to interpret and record in the field. House outlines have either been disturbed by various Pre-Dorset occupants or by historic Eskimo, Indian, or European activities. Two of the dwelling ruins (Houses 1 and 2 - see Chapter V) were singled out for careful excavation and recording. These houses were excavated in two three inch levels, the position and depth of each tool being recorded as found. Usually a pit was dug in the bottom of the six inch excavation to ascertain that no earlier occupation lay beneath and that sterile gravel had been reached.

In the low central area of the site, five house outlines were discernable and all of those found were excavated (Chapter VI). In the field, each of these dwellings was drawn to scale, i.e. "planviewed", 
(as were all other houses) and the artifacts lying on the surface were recorded and then bagged. As was usual, the houses were excavated in two arbitrary three inch levels.

The high northern end of the cobble mantle also provided evidence of Pre-Dorset occupation. Here, six houses were recognized and a11 of these were planviewed. However, on1y four of these dwellings were excavated. As with all the other houses, excavations were confined to the insides of the habitations since in most cases surface collection around the houses seemed to provide an adequate sample of tools lost and a valid indication of the extent, amount and kinds of activities outside the dwellings. The locations of artifacts outside the dwellings was also recorded.

A transit was used to lay a base line down the centre of the site, as near to occupied areas as possible. The datum point was established near the centre of the cobble mantle (Map 8) and was tied in to the navigational beacon at an angle of $90^{\circ}$ directly to the west. From the datum, the base line was extended north for 1400 feet when it was turned $6^{\circ} 20$ ' to the north north east as the cobble mantle curved in that direction. Similarly, the line was established to the south of the datum and at 1200 south, a few yards south of the mantle's gravel bulge, it was turned $15^{\circ}$ to the south southwest in order that it would more nearly follow the cobble mantle. A1l dwellings and scattered artifacts collected from the surface were recorded in relationship to this line. 


$$
\text { 怠 }
$$

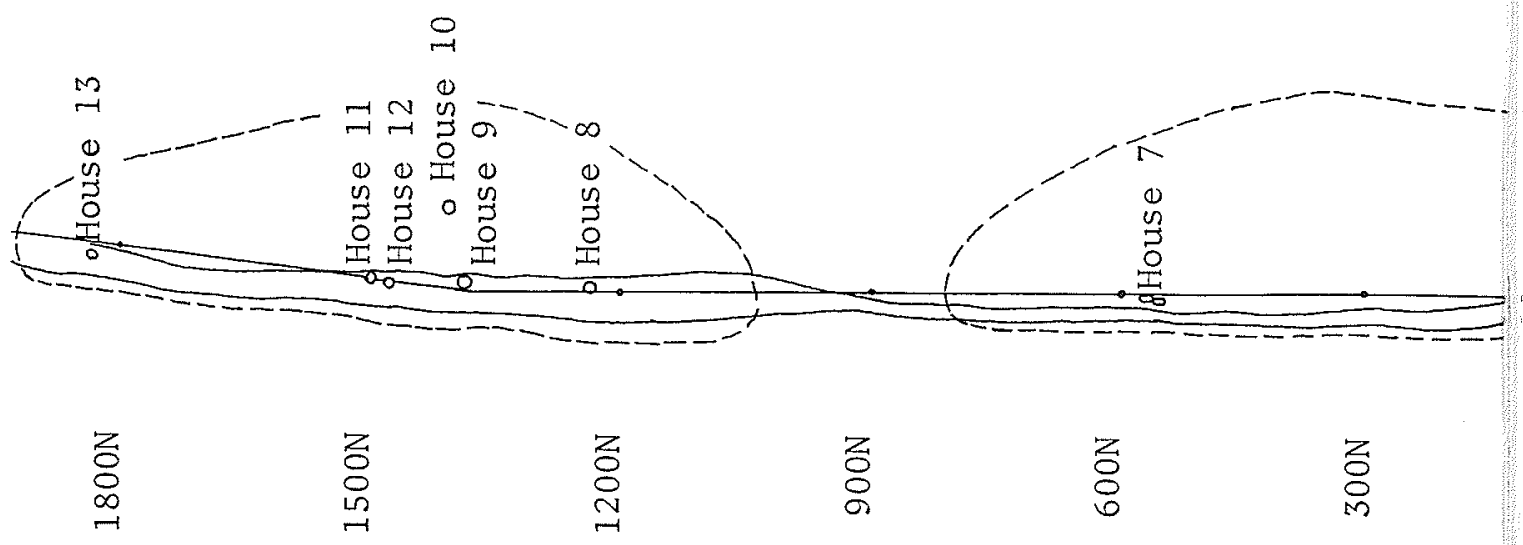




\section{BASIC DESCRIPTIVE CATEGORIES}

\section{INTRODUCTION}

In the preparation of the information presented in this chapter, all of the recorded dwelling remains and all of the artifacts, whether from excavations or surface collections, have been considered. In the text, each illustrated tool is referred to by its figure number and alphabetical letter. This procedure is continued in the succeeding chapters, although the figure number and letter of each artifact is used in another way as well. The floor plans of each of the dwellings have been presented near the beginning of each house description. The locations of the tools found in each dwelling are indicated by placing each artifact's figure number and letter in the appropriate place on the map. Those tools for which exact provenience data is not available are not marked on any map.

\section{DWELLING REMAINS}

In all, a minimum of twenty-four habitation remains were noted at the Seahorse Gully site. Of these, twelve possessed stone alignments or other features which could be drawn to scale and treated as architectural remains. Another, (Activity Area 3) had no structural remains but did have a number of tools, of which a scattergram was drawn. The stone alignments are similar to those found about the bases of recent Eskimo tents. These stones are used to hold down tents since woodfor stakes is often unavailable or the ground is rocky or frozen and stakes can not easily be used. In general, the shapes of abandoned tent rings used by ethnographically known Eskimos compare well with the 
original shapes of the bases of the tents. The round tent rings found at Seahorse Gully may have surrounded tents very like those used until recently by the Caribou Eskimos. These conical tents were round or eliptical at the base. They were composed of a frame of spruce poles supported on two poles over which was stretched a caribou hide cover (Birket-Smith 1929:35). Large stones were placed about the base of this hide cover in order to hold the tent down.

There are two basic Pre-Dorset dwelling forms at Seahorse Gully. One form is rectangular or square while the other is round or oval. In the Iglulik area Meldgaard has found that circular alignments are the oldest and most typical of the Pre-Dorset culture. With reference to the dwellings of the Jens Munk (Kapuivik) site near Iglulik, Meldgaard (1960b:74) writes:

Round, or oval, heavy stone rings with a central fireplace dotted the terrace-ridges from 51 metres to 23 metres revealing the Sarqaq habitations; rectangular depressions marked the houses of the Dorset culture from 22 metres to 8 metres, and the massive stone and sod buildings of the whalehunting Thule people appeared in a period contemporary with the final Dorset stage.

At Iglulik, rectangular dwellings are assigned by Meldgaard to the Dorset period. At Seahorse Gully, five dwellings are rectangular in shape. Interestingly, all but one of these dwellings were found in the low central portion of the site, and probably were occupied by the last Pre-Dorset inhabitants of the site. Such a style change is consistent with the now general hypothesis that the Pre-Dorset culture developed into the Dorset culture (Taylor 1968:89) (Maxwe11 1962:39-40). One other attribute indicates that the subrectangular dwellings are late and are becoming Dorset-like. This is the presence of a midpassage in two houses (Table 2). In the case of these two Pre-Dorset houses, the mid- 
VARIETIES AND ATTRIBUTES OF DWELLING ALIGNMENTS

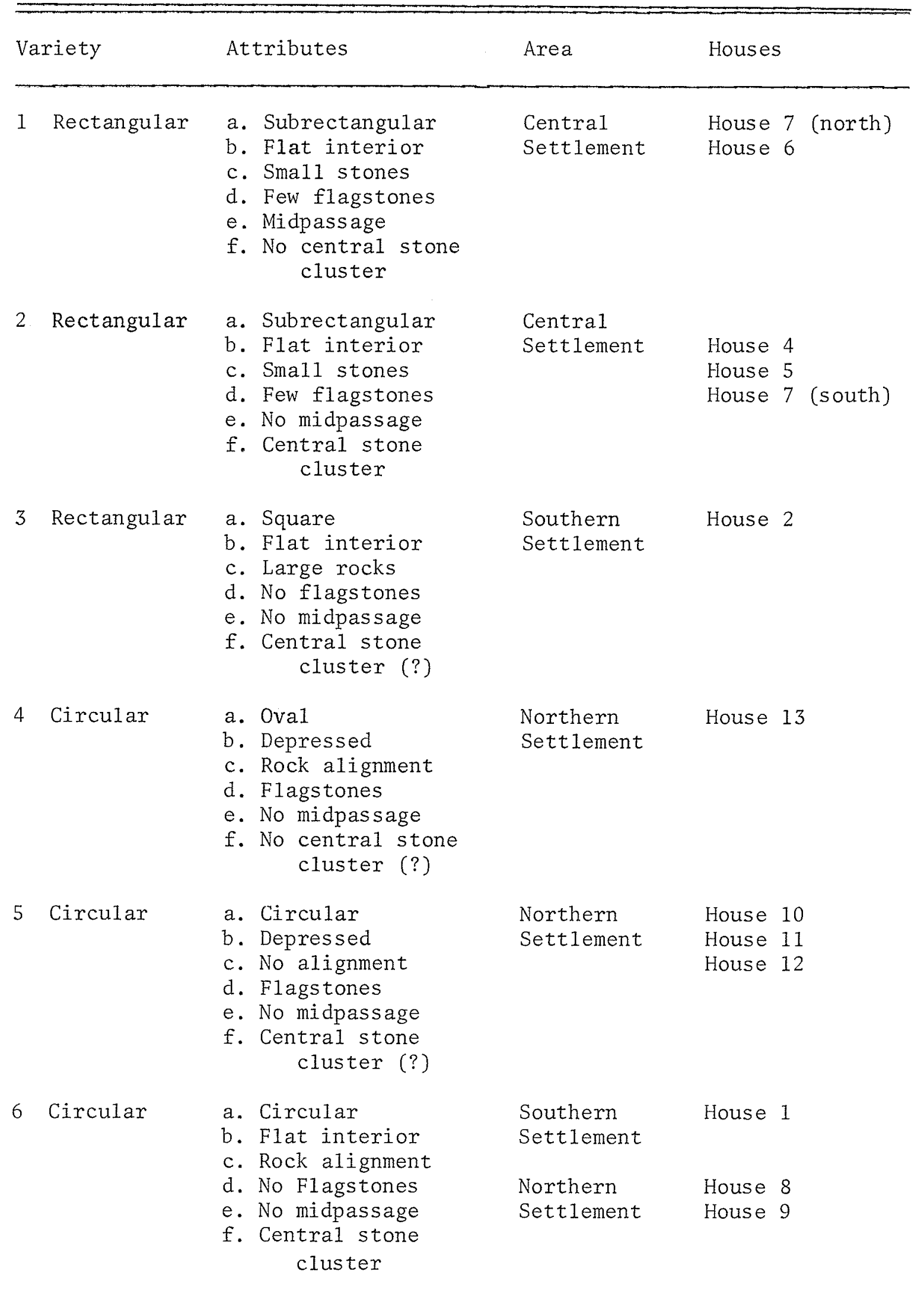


passages consist of two parallel rows of stones, about three feet apart (see the floor plan drawing of House 6).

Identifiable circular dwellings are most common at the northern end of the cobble mantle. However, these differ in several respects from those at Kapuivik. The Seahorse Gully rings are not heavy; they are composed of many sma11 stones and in one case (House 13) mostly of limestone flags. Unlike the Iglulik rings, central fireplaces can not often be confidently identified, although clusters of stones are usually found within the houses. The Seahorse Gully tent rings often have depressed interiors, a feature not mentioned by Meldgaard as characteristic of the Sarqaq dwellings.

On the basis of this limited evidence, three varieties of each of the major dwelling categories (rectangular and circular) have been recognized. These varieties and their attributes are listed in Table 2. It should be noted that two of these are based on only one dwelling each and that another variety is based on only two dwellings.

\section{ARTIFACTS}

Although only ten of the twenty-four identifiable houses at Seahorse Gully were excavated, those artifacts that were exposed on the surfaces of the various activity areas were collected and their approximate locations recorded. The tool categories and varieties listed in Table 3 are a result of the consideration of all the tools from the site. The tools illustrated in this chapter are not those found at excavated houses, but are all surface finds. It must be realized that almost all portions of the cobble mantle had been occupied by Pre-Dorset Eskimos and a rich sprinkling of artifacts was generally present. For the 
SEAHORSE GULLY SITE ARTIFACTUAL MATERIAL

(After Taylor 1968:24-25)

\begin{tabular}{|c|c|c|}
\hline & Category & Variety \\
\hline I. & Burins & $\begin{array}{l}\text { a. Left concavity (Fig. 4,a) } \\
\text { b. Right concavity (Fig. 13,g) } \\
\text { c. Double concavity (Fig. 13,j) } \\
\text { d. Burin-like Blade (Fig. 23,f) }\end{array}$ \\
\hline II. & Burin Spalls & $\begin{array}{l}\text { a. Unworked primary } \\
\text { b. Unworked secondary } \\
\text { c. Retouched primary } \\
\text { d. Retouched secondary }\end{array}$ \\
\hline III. & End Blades & $\begin{array}{l}\text { a. Bi-pointed (Fig. 4,c) } \\
\text { b. Lanceolate (Fig. 4,d) } \\
\text { c. Ova1 (Fig. 13,o) } \\
\text { d. Contracting stem (Fig. 4,e) } \\
\text { e. Single Shoulder (Fig. 16, c,d) } \\
\text { f. Side-notched (Fig. 4, f,g) }\end{array}$ \\
\hline IV. & Harpoon Blades & $\begin{array}{l}\text { a. Large triangular (Fig. } 4, \mathrm{~h}, \mathrm{i} \text { ) } \\
\text { b. Small Triangular (Fig. } 22, \mathrm{n} \text { ) }\end{array}$ \\
\hline V. & Side Blades & $\begin{array}{l}\text { a. Rectangular (Fig. } 5, \mathrm{a}) \\
\text { b. Concavo-convex (Fig. 13,p) } \\
\text { c. Semi-lunate (Fig. } 17, \mathrm{c})\end{array}$ \\
\hline VI. & Knives & $\begin{array}{l}\text { a. Wide, side-notched (Fig. } 5, \mathrm{~d} \text { ) } \\
\text { b. Narrow stemmed (Fig. } 5, \mathrm{~b}, \mathrm{c} \text { ) } \\
\text { c. Ovoid biface (Fig. } 5, \mathrm{e}, \mathrm{f})\end{array}$ \\
\hline VII. & Scrapers & $\begin{array}{l}\text { a. Convex (Fig. } 5, g, h \text { ) } \\
\text { b. Concave (Fig. } 5, i, j \text { ) } \\
\text { c. Narrow end scraper (Fig. 7,a) } \\
\text { d. Wide end scraper (Fig. } 7, b, c \text { ) } \\
\text { e. Side scraper (Fig. } 19, \mathrm{~m} \text { ) }\end{array}$ \\
\hline
\end{tabular}




\begin{tabular}{|c|c|c|}
\hline & Category & Variety \\
\hline VIII. & Blades, Microblades & $\begin{array}{l}\text { a. Raw (Fig. } 7, \text { d) } \\
\text { b. Retouched (Fig. 22,s) }\end{array}$ \\
\hline IX. & Flake Tools & $\begin{array}{l}\text { a. Perforator (Fig. 14,g) } \\
\text { b. Notched (Fig. } 22, q, r)\end{array}$ \\
\hline$x$. & Gouges & $\begin{array}{l}\text { a. Wide (Fig. 7,f) } \\
\text { b. Narrow (Fig. 8,a) }\end{array}$ \\
\hline$X I$. & Chisels (Picks) & $\begin{array}{l}\text { a. Wide (Fig. 8,b) } \\
\text { b. Narrow (Fig. 8,c) }\end{array}$ \\
\hline XII. & Scraper P1anes & $\begin{array}{l}\text { a. Retanguloid (Fig. 9,a) } \\
\text { b. Ovoid (Fig. 9,b) }\end{array}$ \\
\hline XIII. & Adze Blades & $\begin{array}{l}\text { a. Stemmed (Fig. 9, c) } \\
\text { b. Unstemmed (Fig. 9,d) }\end{array}$ \\
\hline XIV. & Worked Organic Tools & $\begin{array}{l}\text { a. Toggle head (Fig. 10,a-f) } \\
\text { b. Ringed and snapped bird bone } \\
\text { c. Chopped Antler (Fig. 20,f) } \\
\text { d. Ivory Fragment (Fig. 20,c) } \\
\text { e. Grooved bone (Fig. 20,f) }\end{array}$ \\
\hline$X V$. & Other Lithic Tools & $\begin{array}{l}\text { a. Steatite vessel (Fig. 11) } \\
\text { b. Whetstone (Fig. } 7, e) \\
\text { c. Grooved weight }\end{array}$ \\
\hline
\end{tabular}


purposes of this thesis (and brevity) only those artifacts found in excavated houses will be described in any detail (in Chapters V, VI and VII).

The categories of Table 3 are, in most cases, indicative of a group of artifacts similar on the basis of material or supposed use. The varieties listed within these categories are considered (except perhaps in the case of miscellaneous bone, antler, and ivory objects) as tool types. Following Clarke (1968:37), each artifact-type is believed to form a polythetic group:

... a group of entities such that each entity possesses a large number of the attributes of the group, each attribute is shared by large numbers of entities and no single attribute is both sufficient and necessary to the group membership.

In utilizing the polythetic artifact-type, the archaeologist can group into a type tools with a reasonably wide variation in attributes, as long as all of the tools share a large number of the attributes. The more obvious attributes of the tool varieties (types) from the Seahorse Gully Pre-Dorset are described in the following pages.

$\underline{\text { Sma11 Tools }}$

While the tools from the Pre-Dorset occupation can not all be neatly classified, two major classes are discernable. These two classes are, (1) small tools and (2) large tools. The small tools include the end and side blades, burins and scrapers, as well as the knives common to any settlement occupied by peoples with a culture within the Arctic Smal1 Tool Tradition. The large tools include the gouges, chisels (picks) and plane scrapers which seem to be unique to the Pre-Dorset of the Churchill area. 
Burins

Burins dominated among the small tools collected from the Seahorse Gully site. In all, 117 burins were recovered, although only sixty-two of these were associated with recorded dwellings. These burins are made on thin flakes, usually of fine-grained whitish cherts. The manufacturers of these burins employed a standardized pattern of orientation of the flake blanks out of which the burins were made. The various edges of each burin were always placed in the same positions with reference to the ventral and dorsal surfaces of the flake blanks used. Two other points of reference, (1) the proximal (striking platform) end of the flake blank and (2) the opposing distal end, were also important in the positioning of burin attributes. This pattern of orientation may be most readily grasped by consulting Figure 3 which presents outlines of two burins (Fig. 4,a,b) from the southern portion of the cobble mantle. In this thesis, a11 of the illustrated burins (with the exception of that shown in Figure $4, b)$ are oriented in the same manner. The ventral surface of each burin (which is the ventral surface of the original flake blank) is faced down, away from the observer, leaving the dorsal surface in view. The base is placed towards the bottom of the page while the distal platform points upwards to the top of the page.

In this position, the typical Seahorse Gully burin (Fig. 3,a) has a left lateral margin which is subconcave. The shape of the right margin varies from concave to convex, but in this case it is straight. The base, as shown, is usually convex but may also be straight or, rarely, slightly concave. At the distal end, the striking platform is straight or slightly convex with a burin facet meeting it at an oblique angle.

In the description of the manufacture of burins and scrapers, a 

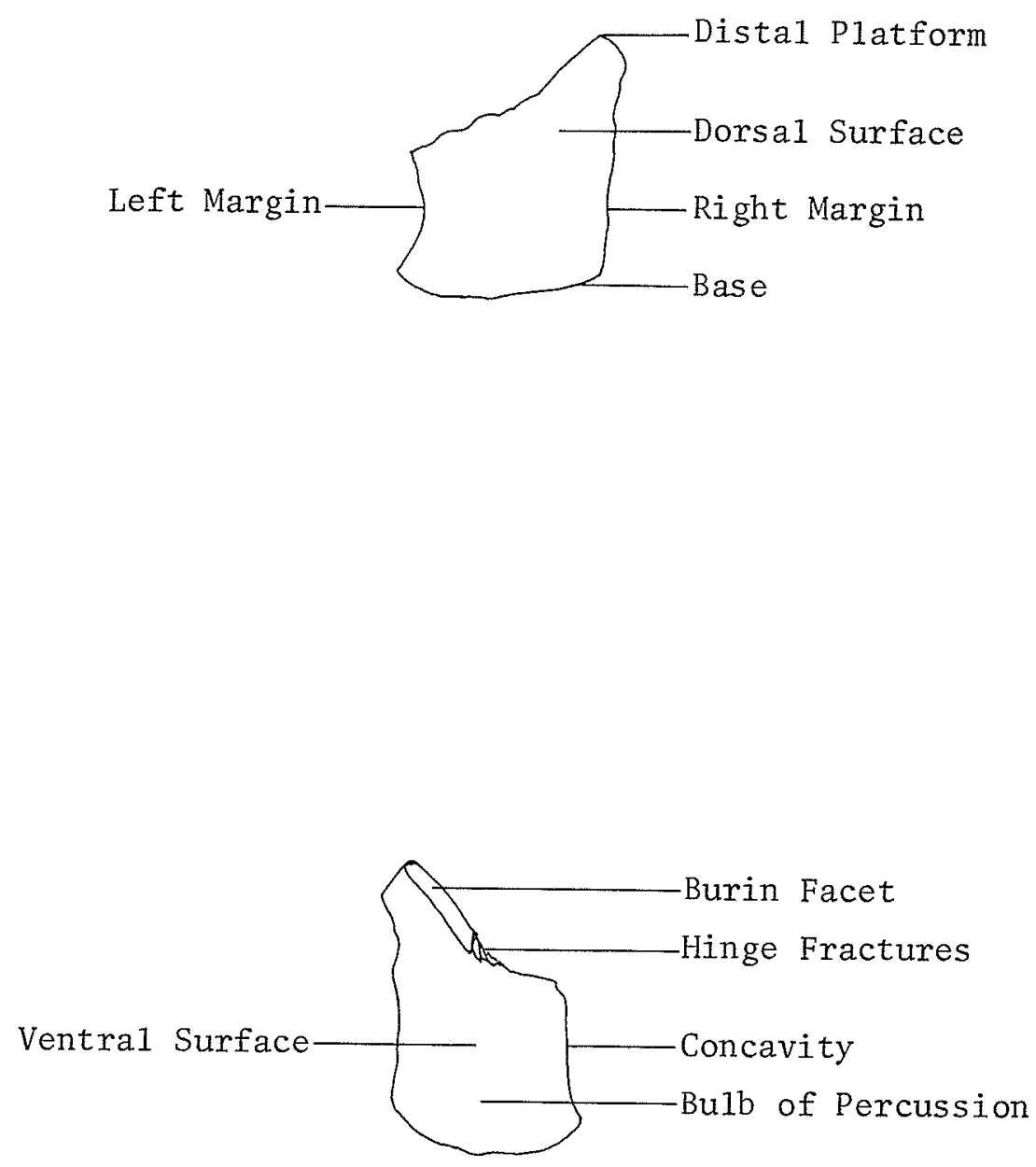

Fig. 3. Burin terminology. a, dorsal surface; b, ventral surface 
distinction is made between flaking to produce a steep bevel and flaking to thin a surface. These knapping techniques are termed bevelling and thinning respectively. The left concavity of a burin is typically bevel1ed on the dorsal surface and occasionally thinned on the ventral face. The right lateral margin is often treated the same way, but is frequently bifacially thinned (flaked). Most basal flaking appears to have been designed to remove some irregularity or unusual thickness. For example, since the bulb of percussion is always near the base on the ventral surface of the burin, thinning flakes are often removed from this. The distal platform of the typical burin has been prepared by dorsal bevelling or thinning with occasional ventral thinning as well.

Final preparation of the distal platform consisted of either grinding or of removing transverse spalls along the flaked distal margin. In some cases, the platform has been first ground and later spalled. The removal of burin spalls by striking the left edge of the distal platform resulted in the formation of both a burin facet surface (Fig. 3,b) and hinge fractures where the distal ends of the spalls snapped away from the burin. Counts of these hinge fractures indicate that, often, as many as ten spalls were struck off individual burins. The hinge fracture area was usually dorsally bevelled, probably to rejuvenate, by lengthening, the burin facet edge so that spalls could continue to be struck off.

A characteristic feature of these burins is the grinding present on the lateral margins. The left concavity was heavily ground while the lower half of the right margin was typically ground as well. The base was usually not ground. Very rarely, portions of the dorsal or ventral surfaces of these burins were ground or polished as we11. In 
BURIN ATTRIBUTES

Worked Edges

Attributes

A. Distal Platform

B. Base

C. Right Lateral Edge

D. Left Latera1 Edge

E. Burin Facet

F. Surface Grinding a. Ground

b. Dorsally Flaked

c. Ventrally Flaked

d. Transversly Spalled
a. Concave
b. Straight
c. Convex
d. Dorsally Flaked
e. Ventrally Flaked
a. Concave
b. Lateral Flare
c. Straight
d. Convex
e. Ground
f. Ventrally Flaked
g. Dorsally Bevelled
a. Concave
b. Notched
c. Straight
d. Convex
e. Ground
f. Ventrally Flaked
g. Dorsally Bevelled
a. Oblique
b. Vertica1
c. Acute
d. Dorsally Flaked
e. Ventrally Flaked
a. Ventral
b. Dorsal 
most cases this polish is very slight and can only be tentatively identified.

In the analysis of burin attributes, five flaked edges; (1) the distal platform, (2) the base, (3) the right lateral edge, (4) the left lateral edge, and (5) the burin facet, have been selected for careful consideration. Each is the location of several attributes which may be either present or absent (Table 4).

In the past, classification of burins in the Arctic Small Tools Tradition has often been according to systems formulated by M.C. Burkitt (1920) and G.V. Noone (1934). Lowther (1962:11) is undoubtedly correct when he states that the typologies of Burkitt and Noone:

... whilst no doubt adequate for European material, do not appear to be able satisfactorily to accommodate North American examples.

Although Taylor (1968) used Noone's classification system to describe the burins from the Arnapik site, he also has noted:

Noone's system is valuable for descriptive brevity and also for its apt terms. Nevertheless, as the body of data on arctic burins grows, the system will likely need to be abandoned as of minimal applicability inasmuch as many of the system's criteria of distinction seem to lack significance in Eskimo archaeology (Taylor 1968:34).

It is clear that the attributes of importance to, and controlled by the Pre-Dorset Eskimos are not those outlined by either Burkitt or Noone. For this reason, the European systems are not utilized in this thesis.

\section{Burin Spa11s}

Burin spalls were discovered in abundance in several dwellings. Usually, a slow but intensive, on the knees survey of a dwelling interior yielded many burin spalls. Primary spalls are typically triangular in cross-section and reveal the manner in which the upper left 
Fig. 4. Seahorse Gully site tools. $a-b$, burins; $c-g$, end blades; h-i, harpoon end blades.

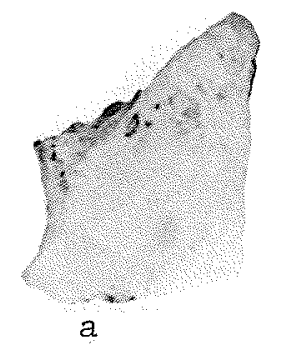

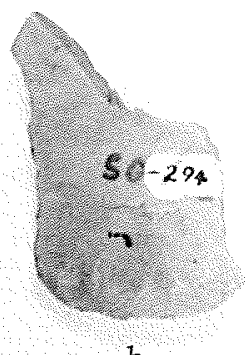

b

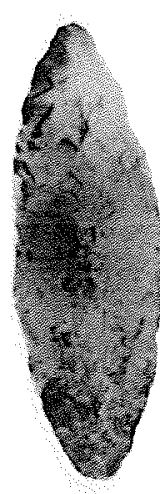

$\mathrm{C}$

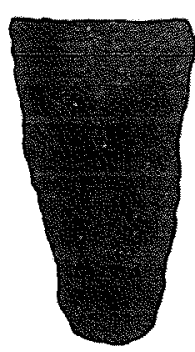

d

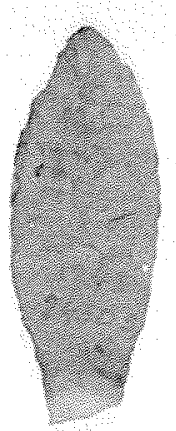

e

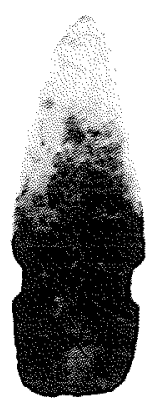

f.

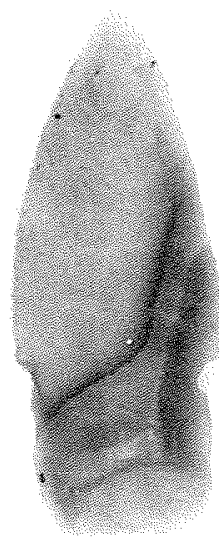

g

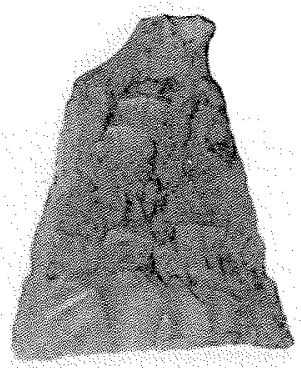

h

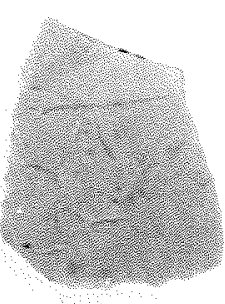

i

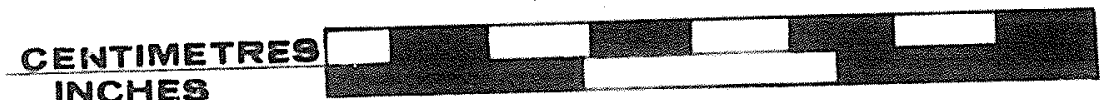


edge of the burin blank was prepared. Flaking of this edge was generally restricted to dorsal bevelling. The first, or primary burin spall removed, therefore, has three surfaces, (1) a lateral portion of the ventral surface of the blank, (2) the surface, containing a positive bulb of force, that matches the burin facet left on the burin, and (3) a portion of the flaked dorsal surface of the burin blank margin. The proximal end of the spall retains part of the ground striking platform. The distal end may terminate in a hinge fracture or may extend into the concavity worked into the lower left edge of the burin blank. In such a case, the distal end of the spall is sharply pointed with the remains of a part of the ground concavity on its dorsal surface.

Secondary spalls are generally quadrangular in cross-section or occasionally triangular. In either case, both the negative and positive scars of the spall facets are present, unlike the primary spall with only the positive scar present. The secondary spall normally retains one flaked surface because of the usual dorsal thinning of the burin facet. Both secondary and primary spalls were sometimes utilized as tools. Only the distal ends were used. These were shaped into a transverse edge either through use or deliberate flaking. The minute flake scars present on the discarded or lost spall tools are probably the result of use. Taylor $(1968: 38)$ presumes that, "... these spalls served, either hand-held or hafted, as miniature gravers or perforators."

End Blades

Six varieties of end blades were recognized at the Seahorse Gully site. All of the end blades are bifacially flaked (usually incompletely so) and are not ground on the lower lateral edges or the bases. One 
variety is bipointed (Fig. 4, c) and is evidently related to the older, more delicate end blade illustrated in Figure 2, a. Only one other bipointed end blade, a specimen (Fig. 16,e) from Activity Area 3, was found. A second end blade variety, the lanceolate, is represented by only two specimens, that illustrated in Figure 4,d (from the southern settlement) and another (Fig. 27,k) from House 13. Only one pointed oval end blade was discovered, in House 2 (Fig. 13,0). These end blades were common in the Pre-Dorset culture of the Iglulik area (Meldgaard $1962: 93)$

A single end blade with a contracting stem (Fig. 4,e) was found. It was collected from the surface of the southern end of the cobble mantle. Bifacially flaked of yellow-white chert, it is very similar to specimens illustrated by Taylor (1968:Fig. 16,c), from the Arnapik site.

A fifth end blade variety consists of stemmed points with a single shoulder only. Two specimens were found in Activity Area 3 (Fig. 16,c,d) and another in House 7 (Fig. 19,p). The sixth, and best represented end blade variety, is that composed of side-notched points. Two are illustrated in Figure 4,f,g, showing the range in size. Some, such as that in Figure 4,g, are marginally serrated.

Melgaard (1962:93) accepts the fact that these small end blades are arrow points and Taylor (1968:88) appears to agree with this position. The bow and arrow would have been useful in hunting land game including caribou, hares, foxes, wolves, and perhaps even polar bears. Birds may also have been hunted with the bow. The rarity of end blades at Seahorse Gully can be interpreted as reflecting the relative unimportance of the hunting of land mammals in this maritime situation. A truer indication 
of the range of attributes and varieties of these end blades could probably be gained from inland hunting sites.

\section{$\underline{\text { Harpoon Blades }}$}

Triangular harpoon blades were found in a few dwellings and two specimens (Fig. 4,h-i) were found on the surface of the southern extremity of the cobble mantle. Designed to be set in slots in the tips of toggle heads, these blades are triangular in shape with straight or slightly concave bases. They are not basally ground. The specimen shown in Figure $4, h$ is not unusual except that the tip has been modified by the addition of side notches. This end blade with dista1 side notches is so idiosyncratic that it cannot be considered as culturally significant. Evidently the result of an individual whim, it could prove significant if similar tools are found at other sites in the region. Interestingly, large harpoon blades apparently are not found in the Pre-Dorset excavations in the Iglulik area, but are characteristic of the Dorset (Meldgaard 1962:P1,5). Occasional large harpoon blades have been recovered from other Pre-Dorset sites in the Baker Lake, Pelly Bay, etc. regions and their absence, therefore, from the Iglulik area is puzzling.

Very small triangular end blades were found at the northern end of the site. These tiny triangles are usually straight based and bifacially flaked. Their presence in a technology oriented to the exploitation of marine resources and their similarity to the larger harpoon blades suggests that they were also made for insetting into toggle heads. None of these harpoon blades are basally ground. 
Side blades appear to have been of relatively little importance in the technology of the Pre-Dorset peoples of Seahorse Gully. Too few side blades were found for the establishment of reliable varieties, however, with assistance from the Twin Lakes collections, three main groups are discernable. One variety is composed of rectangular blades whose lateral edges are slightly convex. One specimen (Fig. 5,a) collected from the southern portion of the site is exactly the same as one found at Twin Lakes (Nash 1969:Fig. 22,6). Two other fragments of this side blade variety were recovered from the Seahorse Gully site.

A second variety of side blades is also rectangular in general shape but has one convex and one concave lateral edge. The best example is the specimen (Fig. 13,p) found near House 2. The third major variety of side blades consists of semi-lunate tools. However, only one example (Fig. 17,c), from House 4 is known. It is large, bifacially flaked, but broken in half, making the definite listing of attributes impossible.

\section{Knives}

Two varieties of asymmetrical knives were present at Seahorse Gully, as well as an oval bifacially flaked knife. The two kinds of asymmetrical knives are similar, differing mainly in width. They each have one short concave lateral edge and one longer convex lateral edge. One variety of asymmetrical knife is relatively narrow and delicate (thin). Some specimens (Fig. 5,b) are long and crescentric. They have no analogues in other Pre-Dorset sites, but may be related to the long narrow notched tools of the Dorset culture.

The second variety of asymmetrical knife is wider and thicker with more pronounced side notches. This offset knife is common in most 


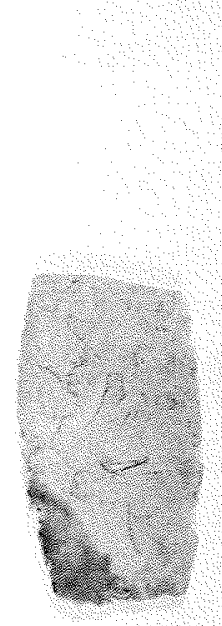

a

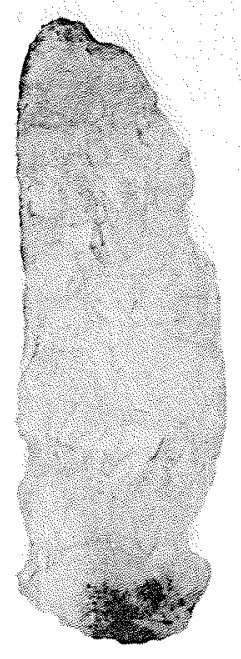

d

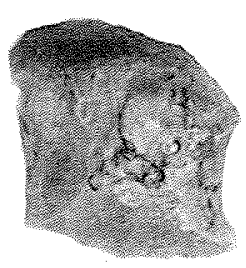

g

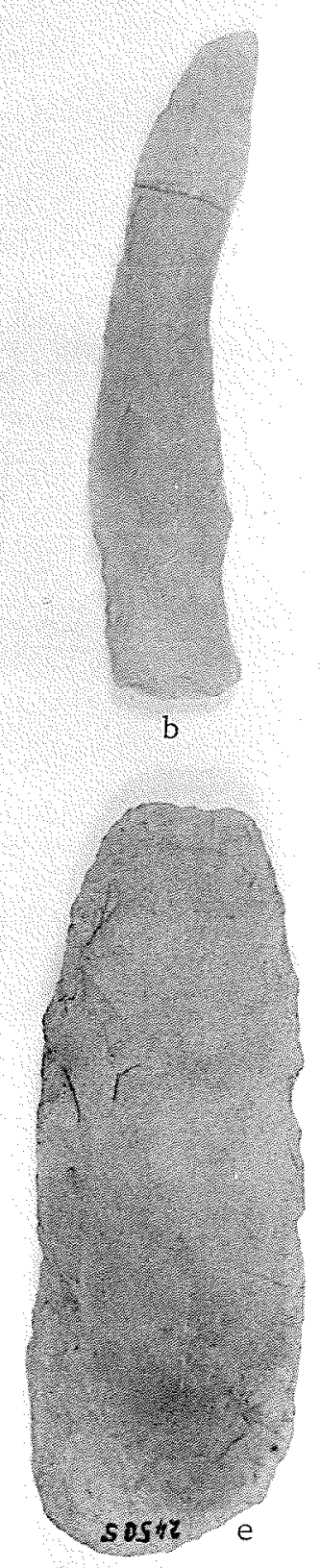

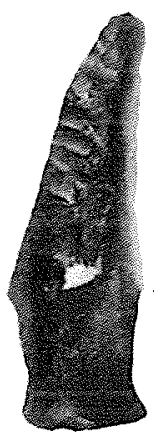

C

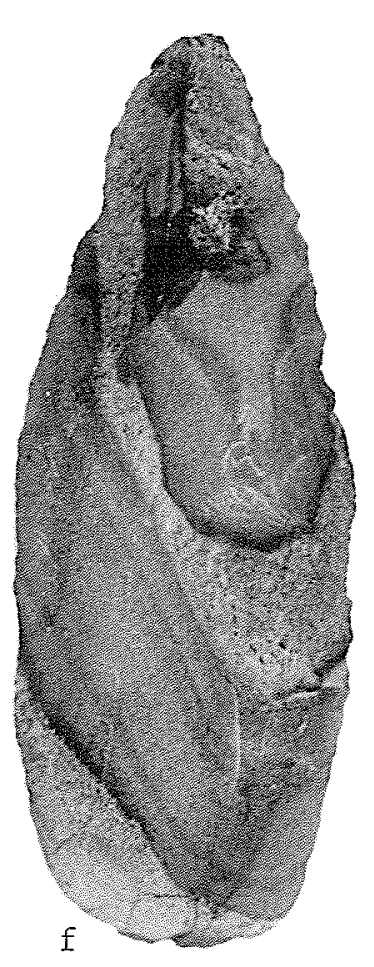

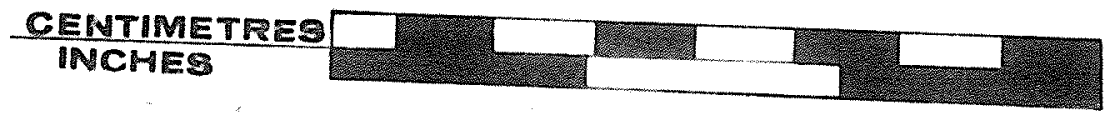

Fig. 5. Seahorse Gully site tools. a, side blade; b-d, hafted knives; e-f, ovoid knives; $g-h$, convex hafted scrapers; $i-j$, concave hafted scrapers. 
late Pre-Dorset sites and was present in the late Sarqaq occupation in the Iglulik area (Meldgaard 1962:94). It is also typical of the Dorset culture. Significantly, the specimen illustrated has double notches below the concave edge (Fig. 5,d). Double notching is a typical Dorset trait, where it is executed in slate and not chert (Meldgaard 1962:93).

A few oval knives, roughly bifacially flaked were also recovered. They are formed of large flakes of either fine white chert, or more commonly of large flakes of pyroclastic or cherty sediments that the large tools are made from (Fig. 5,e,f).

\section{Scrapers}

Several kinds of scrapers were found, but the main variety is the asymmetrical or transverse scraper. This variety is divisible into two (convex and concave) on the basis of the shape of the working edge (Fig. 5,g-j). However, the working edge is sometimes essentially straight. The bodies of these scrapers are essentially the same as those of the burins, however, the placement of attributes is reversed. When placed on their flat ventral surfaces (Fig. 6,a) the scrapers have a concavity on their lower right margins. The left margin is usually straight or flares distally, Both lateral margins are dorsally bevelled and heavily ground. The bases of these scrapers are usually convex and bifacially thinned, but are rarely ground. The oblique scraping edge slopes from the short edge up to the distal end of the longer left margin. The scraping edge, which is either concave or convex, is dorsally bevelled. These tools are usually made from cortex flakes and often retain a white core patina on their dorsal surfaces.

At least two varieties of side notched end scrapers were recover- 


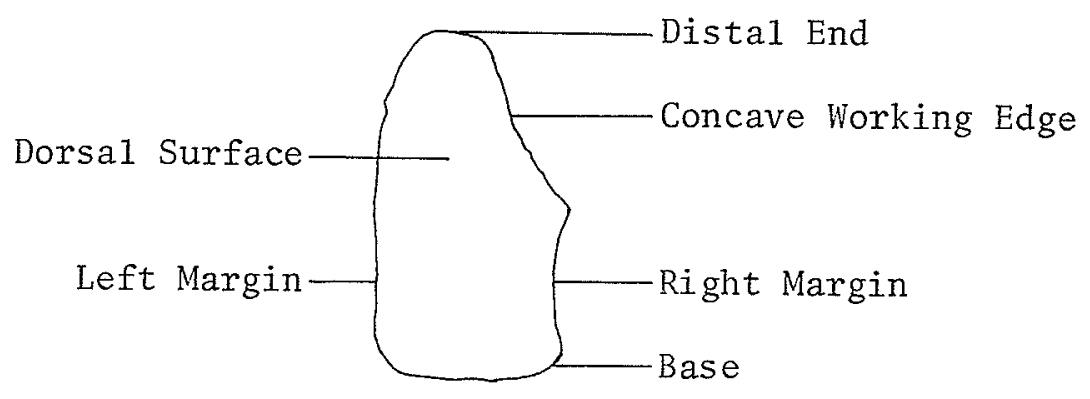

a

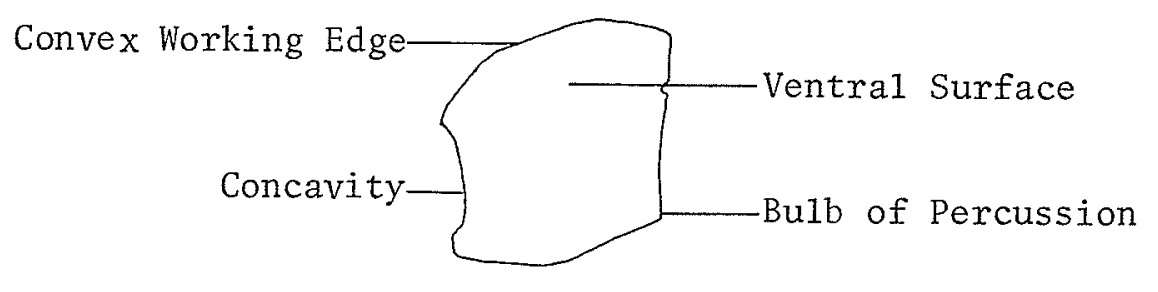

$\mathrm{b}$

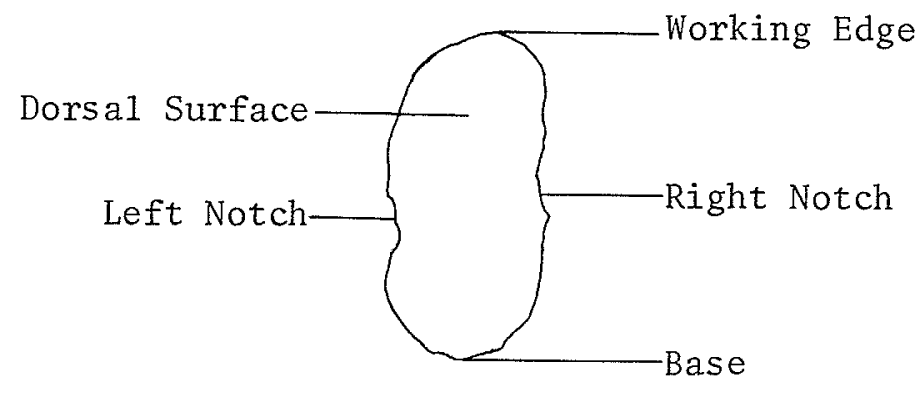

C

Fig. 6. Scraper terminology. a, dorsal surface of concave asymmetrical scraper; b, ventral surface of convex asymmetrical scraper; $c$, dorsal surface of end scraper. 
ed. One variety is small, thick, and oblong in outline (Fig. 7,a). It has shallow "notches" flaked about half way along each lateral side (Fig. 6,c). These depressions are carefully ground. The flaking of the working edge is a unifacial bevel on the dorsal surface. The proximal ends are often bifacially flaked, probably to better fit a handle. The second variety of notched scrapers differs mainly in its greater width (Fig. 7, b,c) and relative thinness. Only two specimens were collected, both from the region of the high central gravel bulb in the cobble mantle. The complete specimen is dorsally bevelled on all margins except for slight ventral thinning of the two lateral concavities. Both concavities are slightly ground. The broken specimen is dorsally bevelled on all margins, but much of the working edge is also ventrally thinned. The scraper has broken through the left lateral concavity which is dorsally bevelled and heavily ground.

Closely related to the oval flake knives are the side scrapers found in several of the dwellings. These are often long blade-like flakes of pyroclastic material which have been unifacially flaked along one edge (Fig. 19,m). These might be better classed as scraper knives as they often have one unifacially thinned margin and another which is bifacially dressed.

Unifacia1 B1ades and Microblades

These artifacts are notably rare at the Seahorse Gully Pre-Dorset settlements. Nash (1969) has illustrated several unifacial blades and microblades from the Seahorse Gully site, but noted that:

The irregular outline of the specimens indicates a poorlydeveloped microblade technology. Again, some of the more irregular specimens included here may have been simply byproducts of more general flaking processes. (Nash 1969:100) 
a
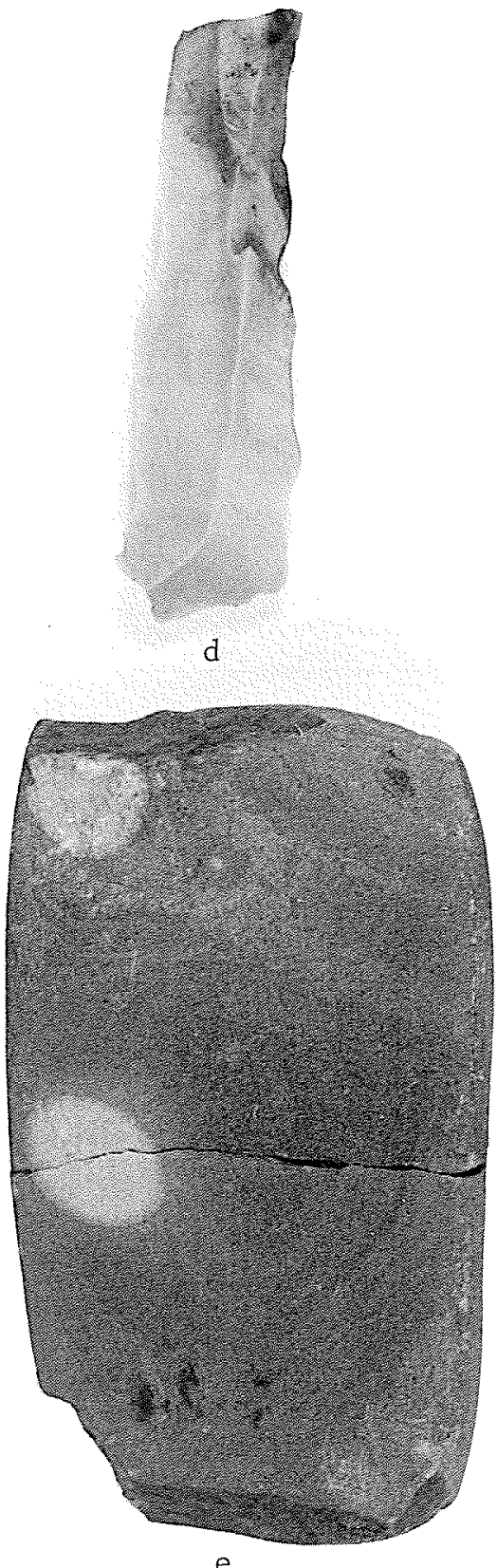
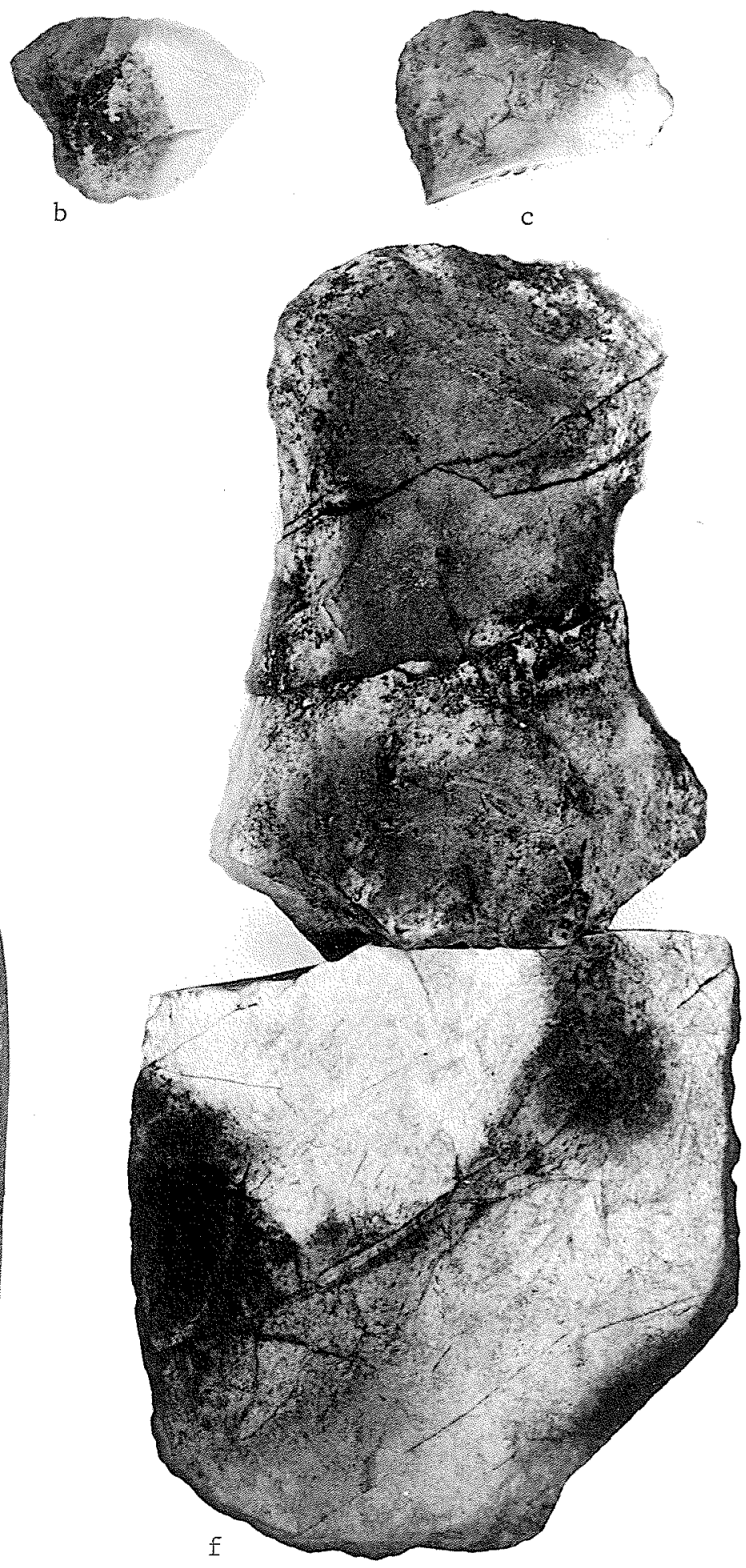

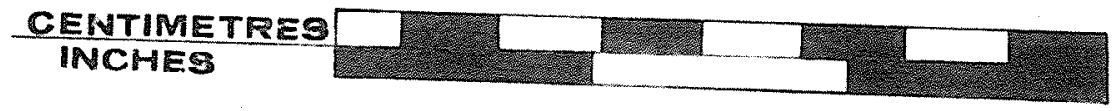

Fig. 7. Seahorse Gul1y site tools. a-c, side notched scrapers; $\mathrm{d}$, blade; e, whetstone; $f$, gouge. 
The latter statement must be stressed, for the 1968 field season yielded very few indisputable blades or microblades. In many cases, a few blade-like flakes were found, but since these were among thousands of other chert flakes, they are probably simply fortuitous. If it was not known that earlier Pre-Dorset and later Dorset cultures stressed blade production, this aspect of the Seahorse Gully Pre-Dorset might well go unmentioned or unrecognized. Perhaps the best example of a blade (Fig. 7,d) was found on the surface of the southern portion of the site near House 1.

\section{Flake Tools}

Although few in number, perforators were recovered from several dwellings (Fig. 14,g). They are typically formed on the edge of a chert flake. Two adjacent concavities are usually unifacially flaked on one margin of the flake, forming a pointed projection where they meet.

Flake tools with concave or notch-like unifaces worked on their margins form a minor portion of the Seahorse Gully lithic technology. They are generally not standardized, consisting of random chert flakes with unifacial retouch along a portion of the flake edge.

Large Tools

The large tools found at Seahorse Gully are perhaps the sites most unique contribution to our knowledge of Pre-Dorset cultures. As yet, similar large tools have not been found in Pre-Dorset sites outside the Churchill area although adzes occur in the Pre-Dorset of the Baker Lake area (Harp 1962:P1. 2, 28). It is clear however, that while a technology including adzes and gouges may have been possessed by a11 
Pre-Dorset peoples, the Seahorse Gully population emphasized these tools to the degree that they proliferated not only their number, but also their varieties and persumably their functions.

Nash (1969) recognized many different types, seventeen in al1 of these tools. However, for the purposes of this presentation, four main categories are recognized. These may be subdivided into varieties. The major categories are, (1) gouges, (2) chisels (picks), (3) scraper planes, and (4) adzes. Each of these can be subdivided into at least two varieties.

The large tools differ greatly from the small tools, not only in size, but in their grossness and rough percussion flaking. Another major difference is the material chosen;

...the majority are of a reddish pyroclastic volcanic ejecta which wears easily. According to the geological map of Manitoba, the nearest known source of this material is on the lower Seal River. (Nash 1969:103)

However, the 1968 investigations made it clear that there were many large pieces of pyroclastic material scattered among the cobbles and this stone could easily have been obtained from the mantle. All the large tools are of red, brown, or grey pyroclastic or of a variety of greenish, greybanded and black chert-like volcanic sediments. Although two asymmetrical knives and a few oval biface knives were made of these coarser materials, on the whole, fine white, brown, and grey cherts were chosen for the manufacture of small tools.

\section{Gouges}

The gouges are illustrated with their working (distal) edges oriented towards the bottom of the page. The opposite, proximal end of each gouge points toward the top of the page (see Fig. 7,f). All of the 
large tools, including the gouges, are illustrated with their flat (ventral) surfaces down. The dorsal, rounded surface is presented in the photographs.

This large tool category has been divided into two varieties. One gouge variety is relatively wide with notches (concavities) flaked on each proximal lateral margin (Fig. 7,f). This variety has a wide, squarecornered working edge which is slightly hollowed on its ventral surface. The second gouge variety is narrower with on $1 y$ shallow concavities on the upper lateral edges (Fig. 8,a). The working edge is rounded and hollowed on its ventral surface. Both varieties of gouges are ground and polished on one or both surfaces of their working edges. When in good condition, these tools have very sharp edges and would be effective tools, perhaps used in wood working.

\section{Chise1s}

The chisels are a relatively homogeneous group, although one small specimen (Fig. 8,c) was found which is so different that on the basis of this single artifact, a distinct variety is recognized. None of the chisels are notched or stemmed, evidence that they were not hafted, or were hafted quite differently from the gouges. Both lateral edges are slightly convex and taper sharply inwards to the narrow chise1 tip (the distal end). The ventral surface of this tip is flat and slants upwards to meet the rounded dorsal surface at a sharp angle. Both surfaces of the tip are ground and polished.

One chisel variety is relatively wide and long (Fig. 8,b). It is about the same size as the gouges and is either plano-convex or triangular in cross-section. The other variety is differentiated because of its 




a
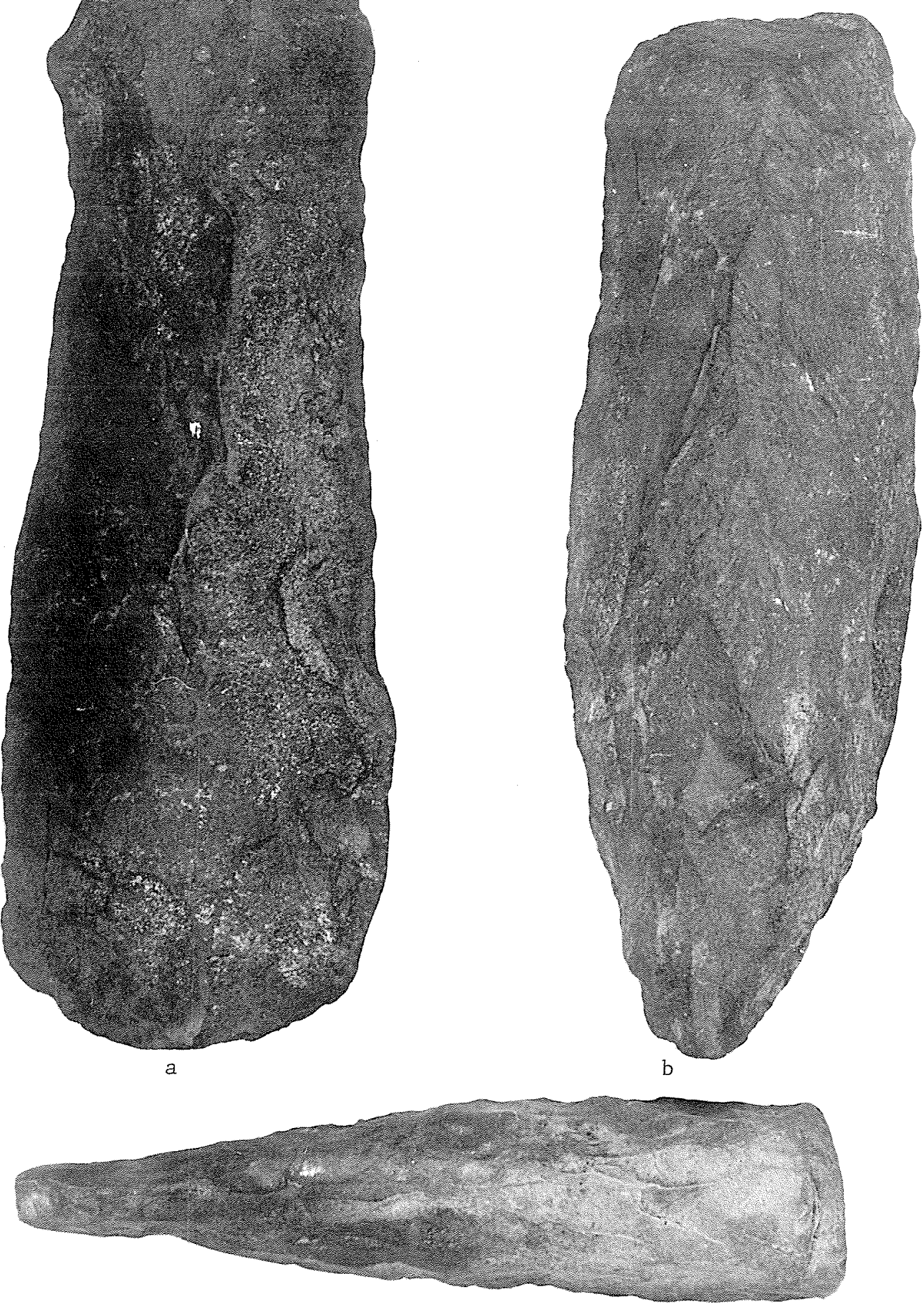

c

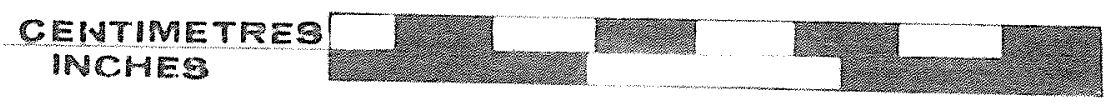

Fig. 8. Seahorse Gu11y site tools. a, narrow gouge; b, large chisel (pick); c, smal1 chisel. 
narrow, elongated form. It has a delicate polished working edge (Fig. 8, c).

\section{Scraper Planes}

This tool category can also be divided into two varieties. On the whole, the scraper planes are smaller than the gouges and picks and are less gross. One variety is almost oval in outline as both of its lateral edges are markedly convex (Fig. 9,b). These planes are completely flaked on the flat ventral surface as well as on the rounded dorsal side. The cross-section is plano-convex.

The other variety of scraper plane is usually larger. It differs in its rectangular outline created by lateral edges that are essentially straight (Fig. 9,a). This plane variety usually has a high keeled dorsal surface. Although the ventral surface may simply be the flat surface of the core, it is frequently flaked as we11. The ends of the scraper planes are rounded and cannot be differentiated into proximal and distal since they tend to be exactly the same.

\section{Adzes}

The Seahorse Gully adzes are roughly flaked, rectanguloid objects, characteristically bifacially thinned and biconvex (lenticular) in crosssection. They are smaller than the other categories of large tools and are more roughly made. Two varieties are discernable; one is stemmed (Fig. 9,c) and the other is unstemmed (Fig. 9,d). The stemmed adzes are thicker and tend to be plano-convex. They may simply be reworked gouges.

The adzes do not have ground working edges, although some do bear polished surfaces, apparently because they are reshaped gouges or 

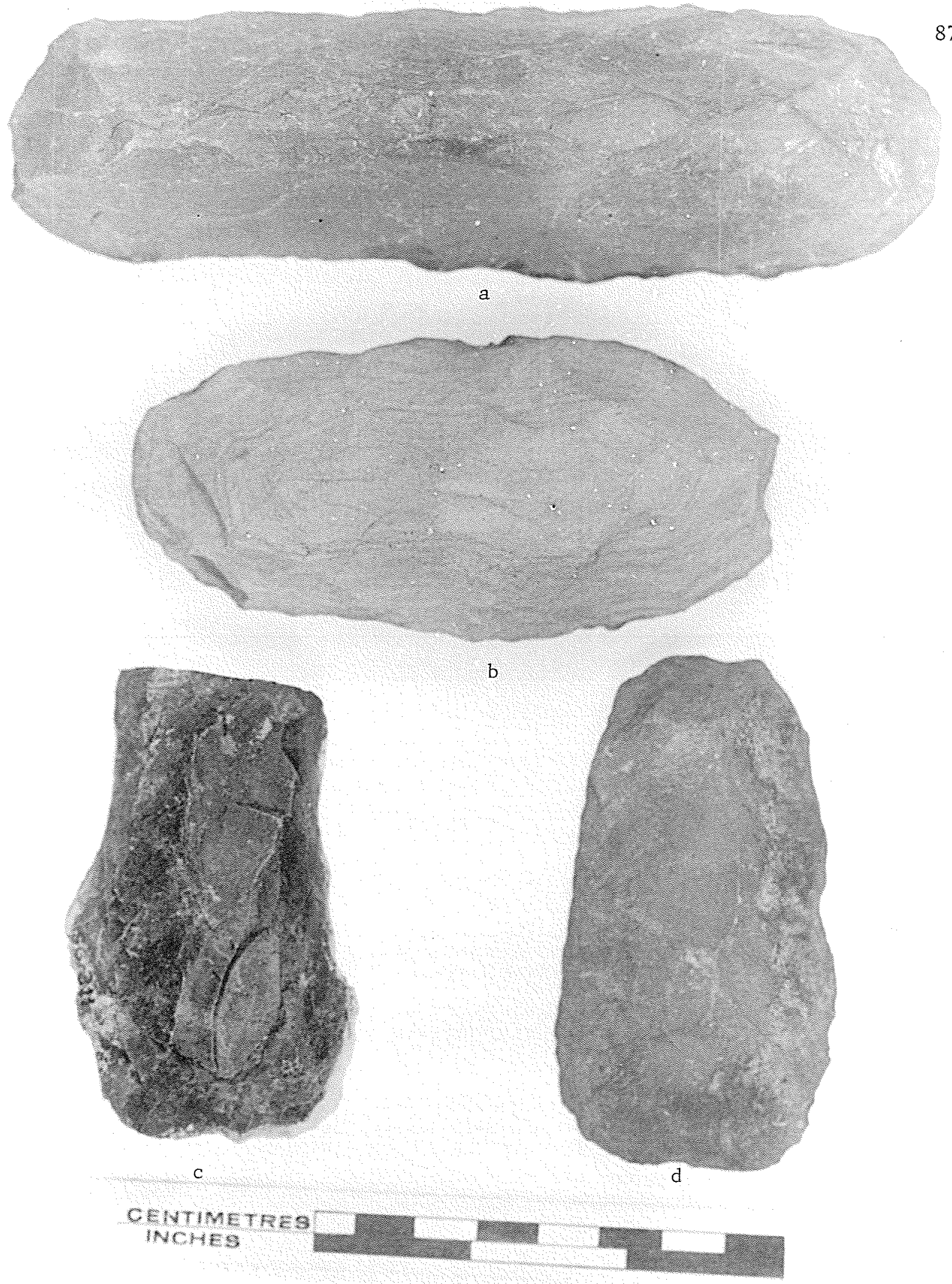

Fig. 9. Seahorse Gully site tools. a, large scraper plane; b, small scraper plane; c-d, adze blades. 
chisels. These were probably wood working tools, hafted in an L-shaped handle.

Other Tools

Tools of Organic Materials

Several ringed and snapped bird bones were recovered from the excavations of House 5. The use to which the bone tubes were put is not known. Also present was one length of bird bone with deep longitudinal grooves. Bone splinters removed from this bone could have been made into needles. Incising of these grooves was probably done with burins. Hacked and broken antler chunks were found in Houses 5 and 10.

Only two toggle heads were recovered from the site, both in association with House 5. Drawings of these toggles (Fig. 10,a-f) have been prepared in order to emphasize details not discernable in photographs. Both of these specimens are of ivory and are described in the section on House 5 .

Other Lithic Tools

A number of lithic artifacts found at the Seahorse Gully site can not be fitted into either the large or small tool classes. These include the steatite vessels (Fig. 11) and a grooved weight. The characteristics of one oval vessel discovered in House 2 are described in Chapter $V$, House 2. This description applies well to all of the vessels from the southern settlement, except that several have more rounded rim edges. Other steatite fragments, from House 13, are described in Chapter VII, as is the grooved weight from House 10 .

A single whetstone (Fig. 7,e) was discovered approximately 1160 feet south of a datum on the summit of the high bulge of the cobble man- 


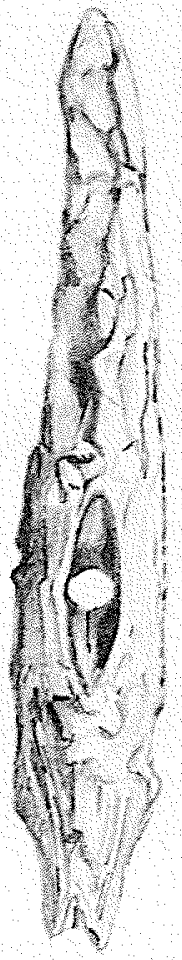

a

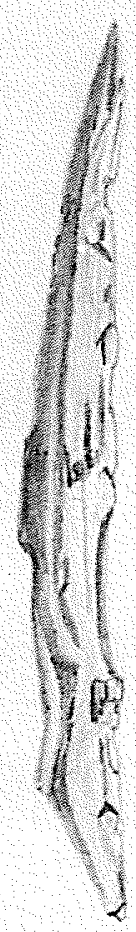

$\mathrm{b}$

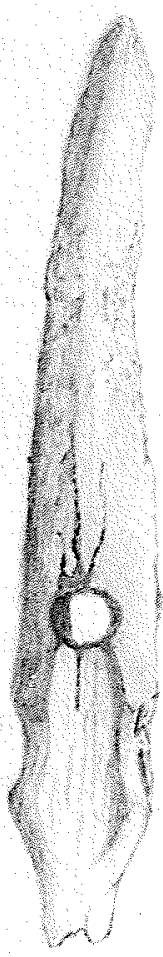

C

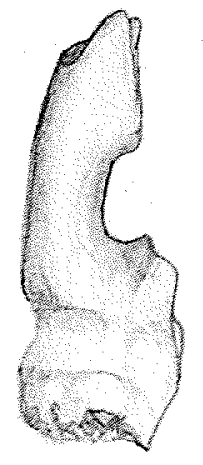

d

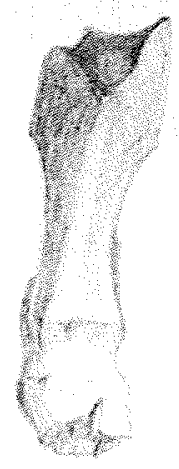

e

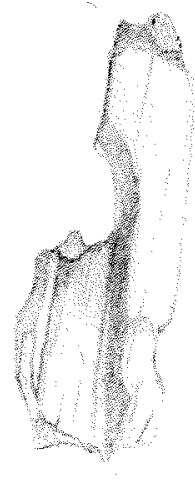

f

Fig. 10.Seahorse Gu1ly site tools. a-c, toggle head found west of House $5 ; \mathrm{d}-\mathrm{f}$, toggle head found east of House 5. Drawings prepared by Mr. Jonathan Maas, actual size. 
Fig. 11. Soapstone vessel from the southern portion of the Seahorse Gully site.

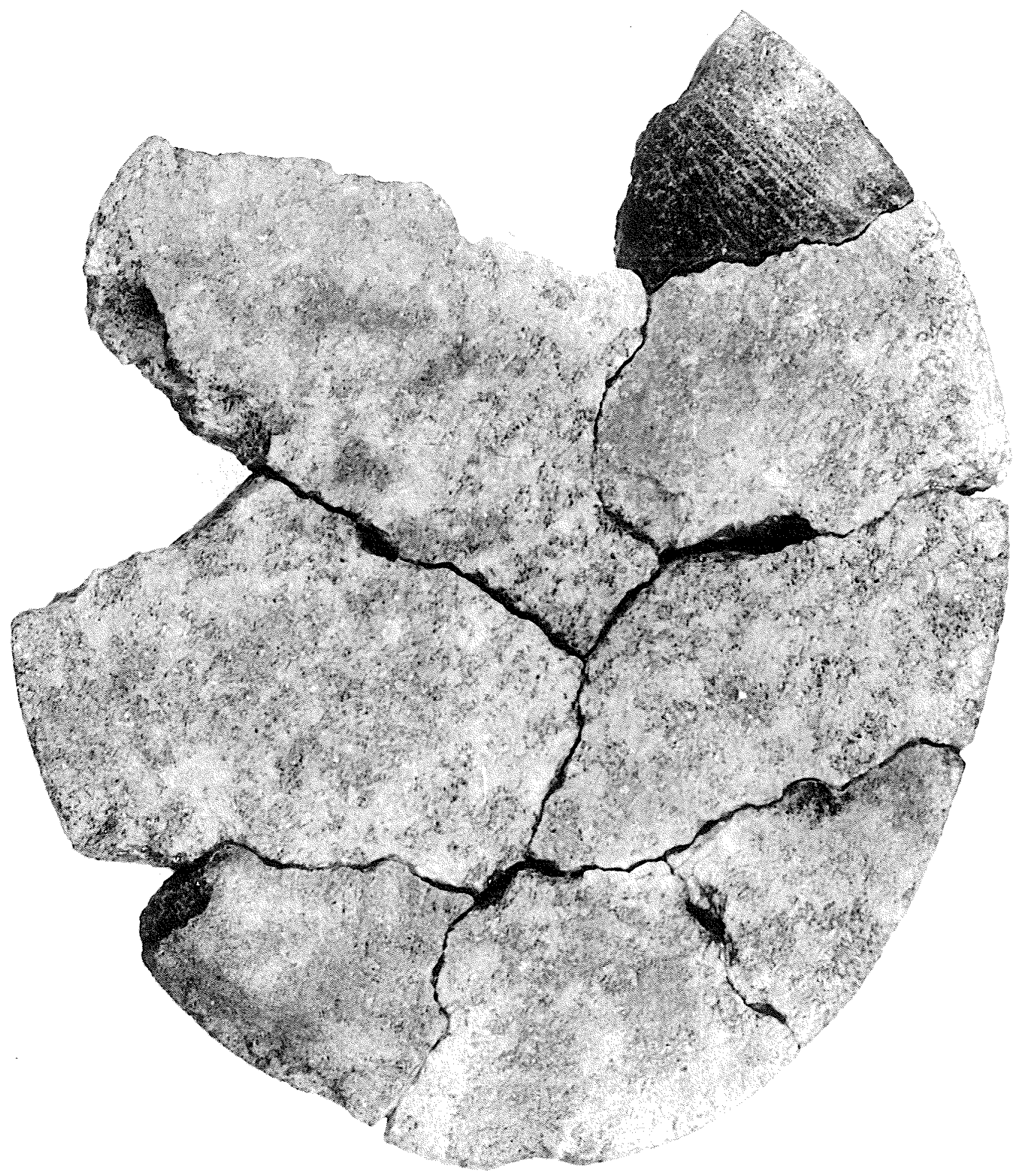

CENTIMETRES INCHES 
tle (see Map 8). It is composed of a reddish shaly material similar to that of certain large tools. The edges of this tool are flattened and are striated from being ground. The surface illustrated is highly polished and slightly depressed, while the opposite surface is rough and only partially smoothed by grinding.

SUMMARY

In the preceding sections of this chapter, fifteen categories of Pre-Dorset tools from the Seahorse Gully site have been presented. In general, these categories represent groupings of tools that were probably used for similar activities. Categories XIV and XV, however, are alI inclusive groups into which those tools that are neither large tools or small tools have been placed.

The varieties listed in the right column of Table 3 are considered as types, the individual specimens of which are characterized by a large number of shared attributes. The largest numbers of types occur among the end blades and the scrapers. These categories also include the greatest number of individual specimens (with the exception of the burins and burin spal1s). This proliferation of types and tools reflects the fact that hunting was the basis of the Pre-Dorset economy and that the preparation of skins (with scrapers) was also vitally important to survival.

Although relatively few burin types have been recognized, the importance of these tools is attested by the sixty-two specimens that were collected from the three settlements. Parallel striations such as would result from the use of burins are present in the line holes and 
shaft sockets of the two toggle heads recovered. Incised lines are also present on one fragment of bone (Fig. 20,f). It is likely, therefore, that burins were used in shaping ivory, bone and antler materials.

The Seahorse Gully tools are characteristic of a late Pre-Dorset culture. Nash (1968:88-89) has presented several lines of evidence which support this postulate; (1) the distal and lateral grinding of the burin margins (see Taylor 1962:90), (2) the presence of oval steatite lamps, and (3) the low frequency of microblades. With the present greater knowledge of the site, several other late traits can be listed; the presence (1) of the burin-like tool, (2) of rectangular dwellings with midpassages, (3) of large harpoon end blades (Meldgaard 1962:P1. 5), and (4) of asymmetrical notched knives (Meldgaard 1962:94).

While the above list is not exhaustive, confirmation of the late date of the Pre-Dorset occupation at Seahorse Gully is provided by the radiocarbon date of $945^{+} 100$ years B.C. Albert Dekin (1969:6) has presented the following information from M.S. Maxwe11's unpublished summary of his Lake Harbour research to 1963. According to Dekin, Maxwe11:

...has established the following divisions for the PreDorset -- Dorset continuum there (Maxwe11 n.d.):

$\begin{array}{lr}\text { Pre-Dorset } & 2200 \mathrm{BC} \text { to } 1300 \mathrm{BC} \\ \text { Intermediate } & 1300 \mathrm{BC} \text { to } 900 \mathrm{BC} \\ \text { Dorset } & 900 \mathrm{BC} \text { to } 480 \mathrm{AD}\end{array}$

The radiocarbon date of 945 B.C. for the Seahorse Gully site places it within Maxwell's intermediate division. On the basis of typological evidence and the radiocarbon date, therefore, the Pre-Dorset culture of Seahorse Gully is considered to be intermediate or transitional between earlier Pre-Dorset and later Dorset cultures. 
CHAPTER V

THE SOUTHERN SETTLEMENT

INTRODUCTION

The southern settlement stretches from approximately 1100 feet south of datum to about 3000 feet south, or as far as occupational debris extends. As mentioned in Chapter III, this portion of the site is high and dominated by the cobble mantle. The southern settlement was distinctive, partly because of the nature of its Pre-Dorset occupation. Many disturbed stone alignments (Fig. 12,a), apparently the remains of dwellings, were present. Most of these alignments were so amorphous and clearly disrupted that they were not planviewed or excavated. In general, the close massing of these dwelling units made confident separation of the artifacts belonging to each impossible. However, positions of surface artifacts were approximately recorded with reference to the base line.

The greater amount of occupation of this southern settlement is evidenced by a comparison of the tool totals of all three settlements. Only forty-eight of the tools found in the southern settlement were recovered from the recorded dwellings (Table 8). Another 137 tools were collected from the disturbed occupation areas of this settlement. Therefore, a total of 185 tools were removed from this area.

In contrast, only eleven tools were collected outside the recorded portions of the central settlement, and these, added to the ninetysix tools associated with recorded dwellings, make a total of on $1 y 107$ tools. Similarly, the northern settlement had ninety-two tools in 


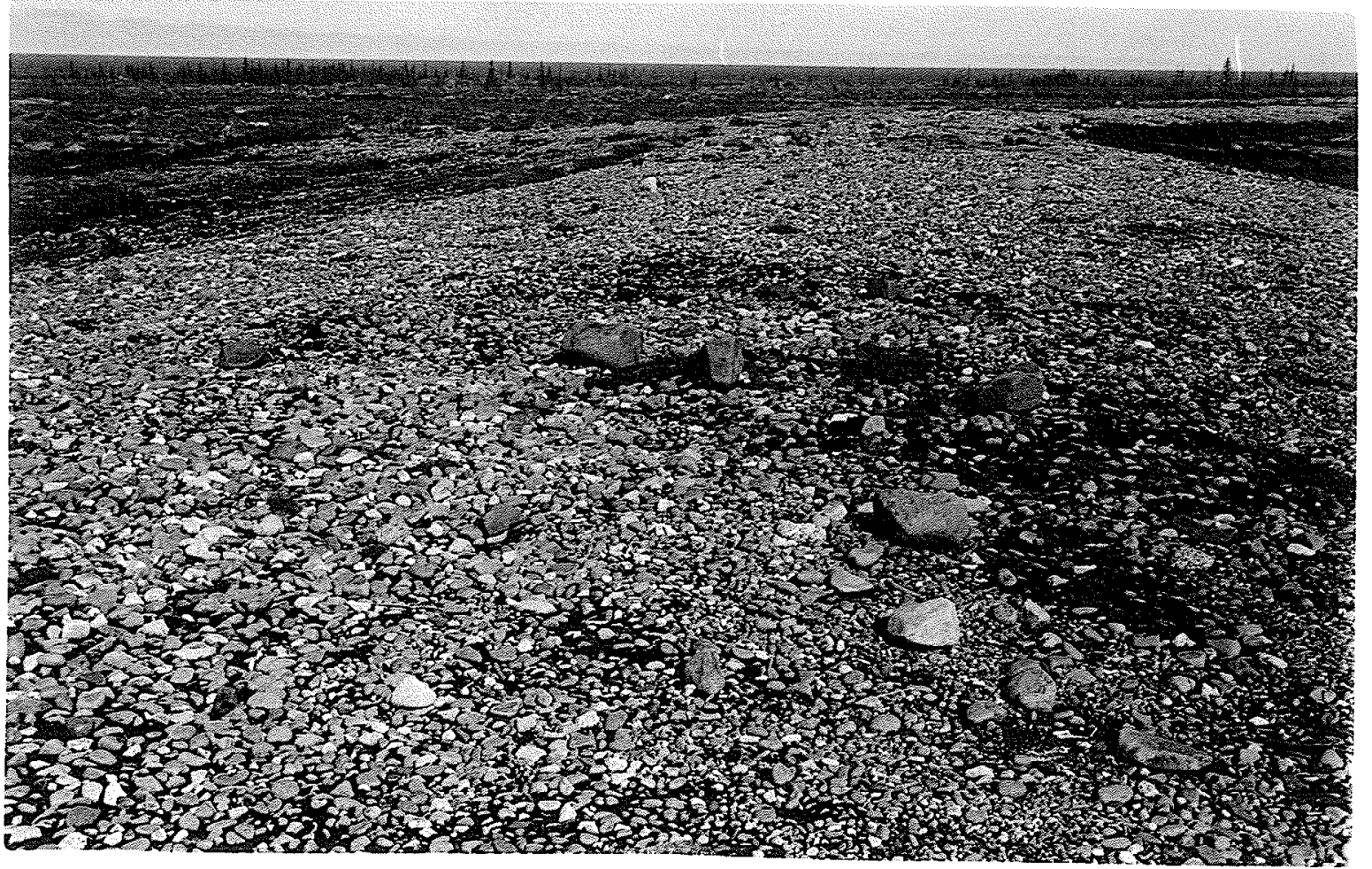

Fig. 12,a. The southern extremity of the cobble mantle, looking northwest. A disturbed stone alignment is present in the foreground.

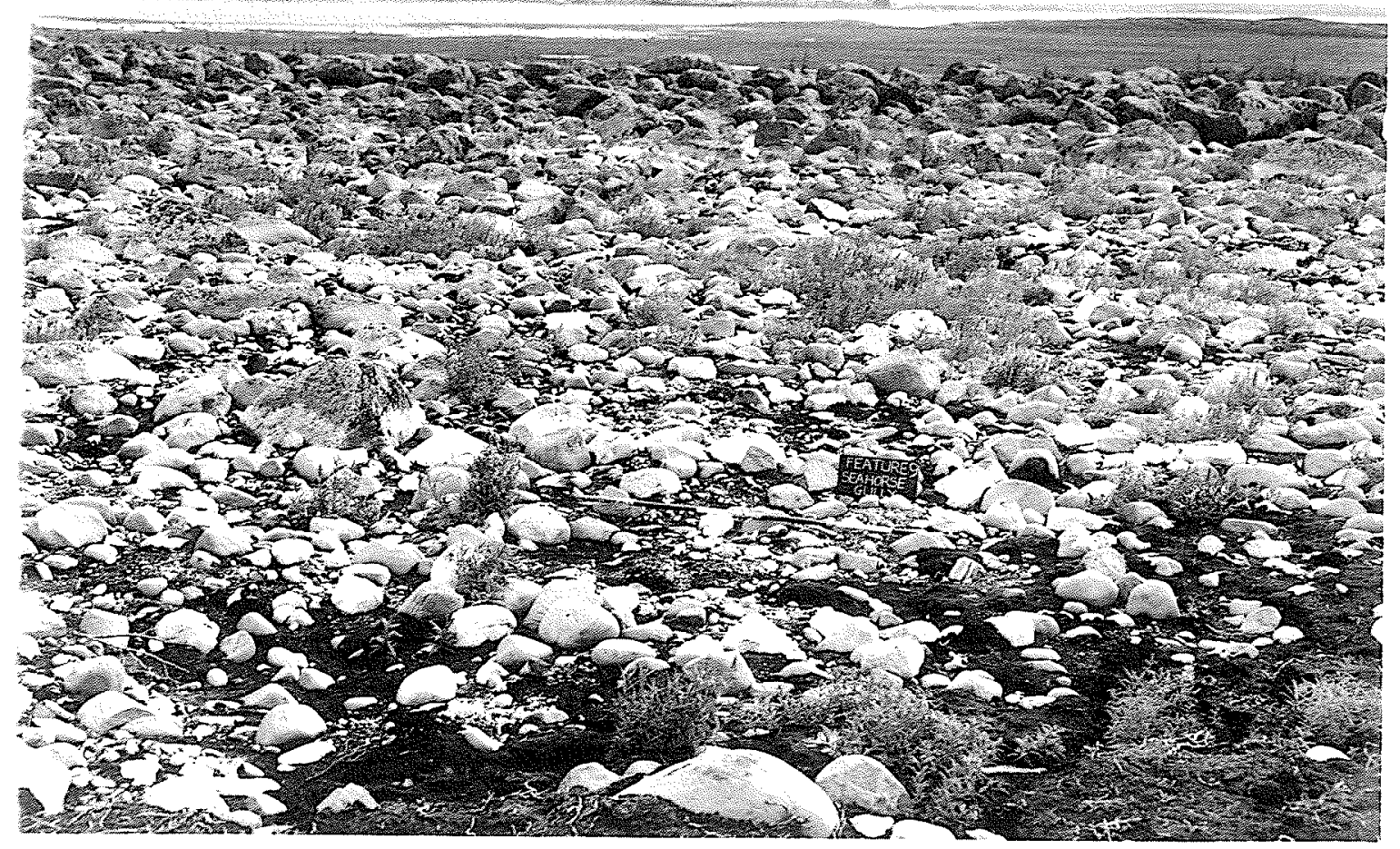

Fig. 12,b. House 1 before excavation. The grain elevators of the town of Churchill are visible to the east, across the mouth of the Churchill River. 
recorded dwellings, and eight tools which were not directly associated with any recognizable dwellings. From this it is clear that the southern settlement, with a minimum of 186 tools recovered, had almost twice as many tools as either of the other settlements.

HOUSE 1

House 1 was located 123 feet and 6 inches northeast of a point on the base line 2400 feet south of datum. The angle between the base line and a line to the southeastern corner of the house was $51^{\circ} 50^{\prime}$. House 1 was situated a few yards southwest of the stone alignment which marks the site of House 2. Both houses were in the stone strewn area between the cobble mantle on the west and a boulder field to the east (Fig. 12,b). Both also have many stones scattered inside and outside their alignments so that the actual shapes of the original dwellings cannot now be easily determined.

\section{DWELLING REMAINS}

An alignment of stones, formed by a ring of relatively large rocks, composed the dwelling remains that identified this house (Map 9). These stones are smaller than those of House 2, but are larger than those of other houses such as 5 or 7. If a circular interpretation is accepted for the House 1 alignment (Fig. 12,b), a tent ring about eight feet in diameter is present. In the centre of the tent ring, a cluster of eight small rocks that may have formed a hearth or lamp rest was found.

\section{ARTIFACTS}

Only a few artifacts were found inside this dwelling. These included two burins, an end blade tip, and a knife base. In addition, 


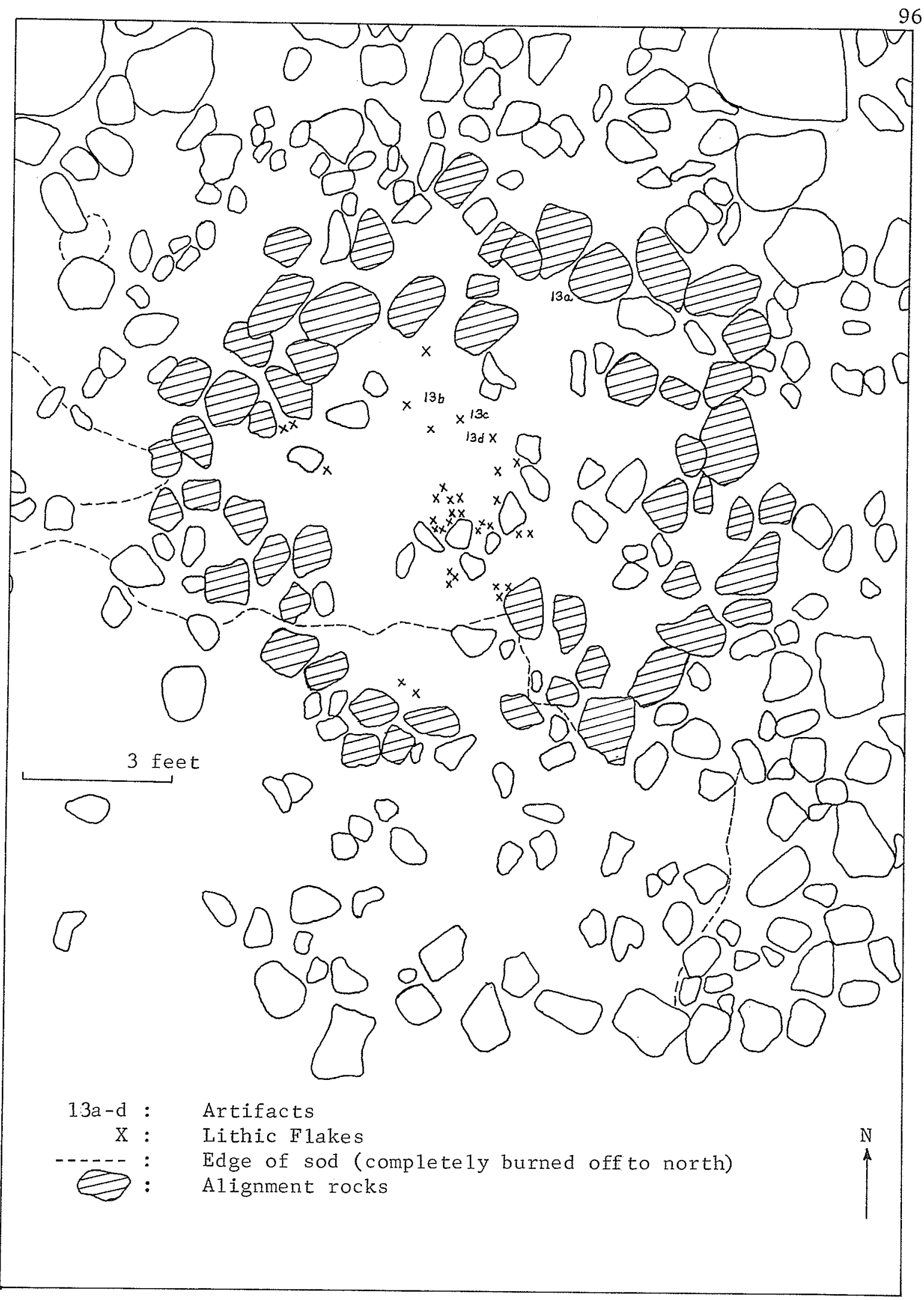

Map 9. Floor plan of House 1. 
many lithic flakes were collected.

Smal1 Tools

\section{Burins}

One burin (Fig. 13,a) was found on the surface near the northern wall of the dwelling. As is usual, the lower left edge is concave, and dorsally bevelled only. The right margin is bifacially thinned. Not characteristic of the Seahorse Gully burins is the lack of grinding on either lateral edge of this burin. The bulb of percussion at the base has been thinned by the removal of a few flakes and the distal striking platform has been prepared by grinding. At least four spalls have been struck from this platform. Dimensions (length, width, and thickness) are 24,14 , and $4.5 \mathrm{~mm}$.

Another burin (Fig. 13,b) was recovered from the excavation of level 1, at a depth of one and a half inches below the surface. It was also found on the western side of the dwelling. The blank was a thin cortex flake of dark grey chert on which a dorsal patina was present. The left margin is concave and dorsally bevelled while the right edge is only slightly concave and both dorsally bevelled and ventrally thinned. Both lateral margins are ground. The convex base is completely unworked, while the distal platform has been prepared by the removal of transverse spalls. Three spalls have been removed. Dimensions are 23, 12.5, and $3 \mathrm{~mm}$.

Burin Spal1s

These tools were not found in House 1. 
An end blade fragment (Fig. 13,c) was found on the surface a few inches west of the centre of the house (Map 9). This tip has been knapped from fine grey chert. The bifacial pressure flaking is delicate and carefully controlled. A minute serration, now largely obliterated, is present along the margins. There is an average of about six serrations in $5 \mathrm{~mm}$. of length. The thickness of this specimen is $3 \mathrm{~mm}$.

\section{Harpoon Blades}

Harpoon Blades were not recovered from House 1 .

\section{$\underline{\text { Side Blades }}$}

These tools were absent from House 1.

\section{Knives}

A quartzite knife base (Fig. 13,d) was discovered on the surface within the stone alignment of House 1 (Map 9). The use of quartzite material is very unusual at Seahorse Gully. This specimen was found adjacent to the end blade tip. It is carefully bifacially flaked and appears to have been reworked after a previous break. The side notches are ground, as is the base. The width of the base is $24 \mathrm{~mm}$. and the thickness is $6 \mathrm{~mm}$.

\section{Scrapers}

This tool category was not represented in House 1.

Blades and Microblades

These tools were not present in House 1 .

\section{Flake Tools}

A grey chert flake from the surface inside House 1 has been 
thick to be of a sea mammal. Probably a large herbivore such as a caribou is represented.

\section{SUMMARY}

House 1 was a circular dwelling, as evidenced by the stone alignment of rounded grey quartzite stones. This small tent ring contained a few delicately flaked stone tools. The distribution of the tools suggests that activities involving burins took place in the northern portion of the tent. Flakes tend to cluster about the presumed hearth stones, with a few random finds to the south. The eastern part of the interior is free of artifacts and non-technological activities (such as sleeping or eating) may have taken place here. Tools believed associated with both male (end blade, burins) and female (knife) activities were present. It is probable that a nuclear family inhabited the dwelling.

The lack of seal bones, the possible presence of herbivore remains, the absence of harpoon blades, and the presence of an end blade, are all factors that suggest non-maritime hunting. The end blade is an arrow or dart point suited for hunting land animals rather than sea mammals. The quartzite knife base also hints of an inland orientation. Chert is less available inland and, as is demonstrated in the Baker Lake area (Harp 1962:72), quartzites are used instead. This evidence suggests that the occupants of this dwelling may have recently arrived at the coast after an inland hunting journey.

Of interest is the fact that several traits link House 1 with House 8 at the northern end of the site. Both are circular and do not have depressed interiors. Both have a quartzite tool and both have end blades with serrated edges. The major difference is that House 8 was 


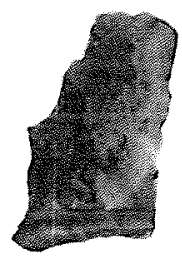

$a$

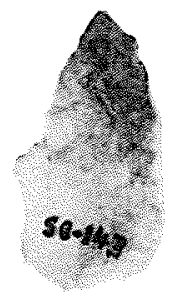

e

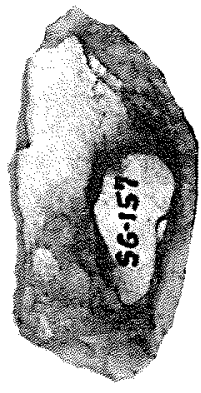

i

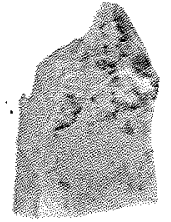

$m$

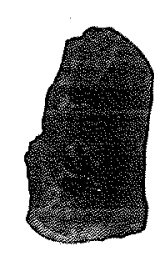

b

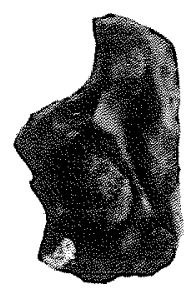

f

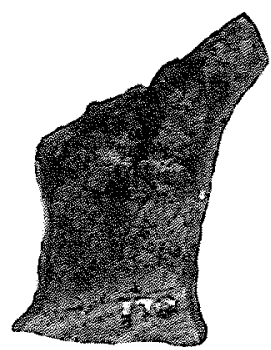

j

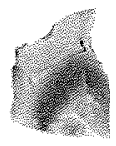

$\mathrm{n}$

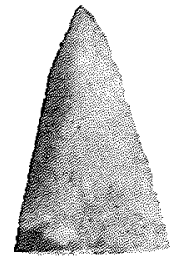

C

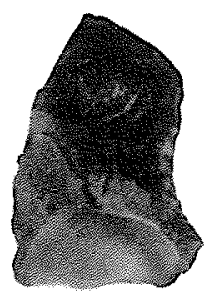

$\mathrm{g}$

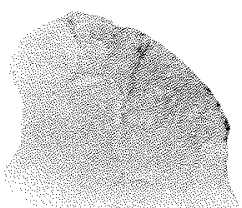

d

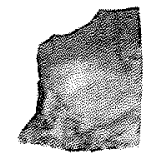

$\mathrm{h}$

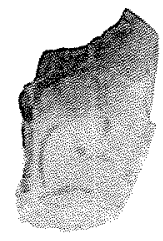

$k$

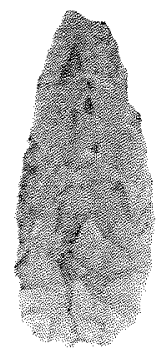

o

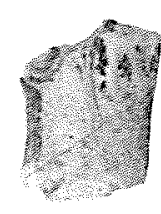

1

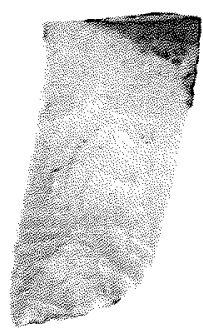

$\mathrm{p}$

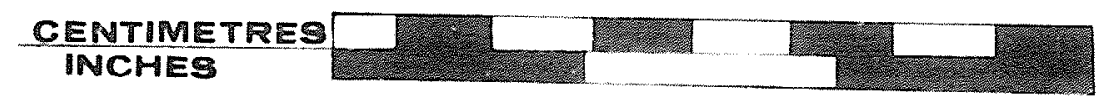

Fig. 13. Seahorse Gully site tools. House 1: a-b, burins; $c$, end blade tip; d, knife base. House 2: e-n, burins; o, ovoid end blade; $\mathrm{p}$, side blade fragment. 
occupied by hunters with a clear maritime economic orientation.

HOUSE 2

House 2 was discovered near the southern end of the cobble mantle. Its southwestern corner was located 185 feet and 3 inches northeast of the 2400 foot south stake on the base line. The angle between the base line and the line to the southwest corner of the house was $32^{\circ} 20^{\prime}$.

\section{DWELLING REMAINS}

The feature which characterized this dwelling was an alignment of massive rocks (Map 10). This dwelling outline was distinguishable, not because the rocks composing it were isolated from other similar sized rocks, but because the rocks were raised and sitting on the surface. The stones of this alignment are larger than those of any other Pre-Dorset dwelling at Seahorse Gully. They may average more than fifty pounds each. The house outline is square and unlike other dwellings the corners are not rounded. Many stones were scattered throughout the interior and may be the remains of a mid-passage. A central cluster of six or seven stones evidently formed a support for a steatite vesse1, the fragments of this were scattered around and beneath the stones. This dwelling was almost square, about ten feet by eleven feet.

At the time of occupation, the stone strewn surface was probably covered with several inches of organic material derived from the tundra mat. This may have presented a smooth surface attractive to occupation. Presently, this thick layer of sod has been burned away, revealing the sterile subsoil and a mass of Pre-Dorset cultural debris.

\section{ARTIFACTS}

This dwelling was one of the richer houses excavated during the 
summer of 1968. It lies in the densely occupied southern end of the site where occupational debris is virtually continuous. For this reason, it is possible that some of the surface artifacts believed to be associated with House 2 were dropped by earlier or later inhabitants of the area. This problem cannot be eliminated and all surface artifacts must be viewed with suspicion. Since the effective activity area around isolated houses such as 5 , is from ten to twenty-five feet wide, artifacts around House 2 to a distance of fifteen or twenty feet are considered as important in the interpretation of associated activities. Understandably, this procedure is risky in this densely occupied area, however, as this house is on the edge of the multi-occupation region, relative isolation and therefore, less mixing, is likely.

Sma11 Tools

Burins

As is usual for Pre-Dorset dwellings, the burin category contained the most specimens. Five burins were found on the surface inside or near House 2. One burin (Fig. 13,e) lay on the gravel subsoil on the inside edge of the south wall (Map 10). It is unusual because its surfaces are reversed. To orient it the same as other burins, the dorsal surface must be placed downwards. In this position, it is "normal" with a concavity on the left margin, a convex base, and a straight right margin.

An unusually thick burin (Fig. 13,g) was discovered on the surface about ten feet northwest of House 2. The dorsal surface of the base has been removed by a frost spall, but it appears that the base was convex and bifacially flaked. 
Five burins were recovered from the excavation of House 2. One (Fig. 13,j) has a pronounced lateral flare of the right distal edge. It is also unusual because both lateral margins are concave, giving it a stemmed appearance. A concentration of three burins (Fig. 13,1-n) was discovered in the centre of the house. One of these (Fig. 13,n) is unusual because it has had six spalls removed from its left margin and five from its right. A dubious burin fragment, possibly the distal half, was also found with this cluster of three burins.

Several of these burins (Fig. $13, f, h, j, k, 1$ ) have hinge fracture areas that are completely dorsally bevelled. This bevelling has removed all evidence of the burin spalls which were struck off and in most cases only the hinge fractures that have resulted from the last one or two spalls removed are present. The number of hinge fractures visible on each burin is presented in Table 6, under "Spalls Removed".

These ten burins form one of the most varied groups recovered from any of the dwellings. Each burin is quite different, incorporating the usual attributes in unusual combinations or proportions. Whether these differing burins were used for a variety of jobs, were made by several different individuals, or simply represent the random production of one individual is not certain.

\section{Burin Spal1s}

Six burin spalls were found in the central area of the interior surface of the dwelling. The five striking platforms still intact have been prepared by grinding. Two of the three primary spalls are fragmentary; one lacks the platform. The other primary spall has been 


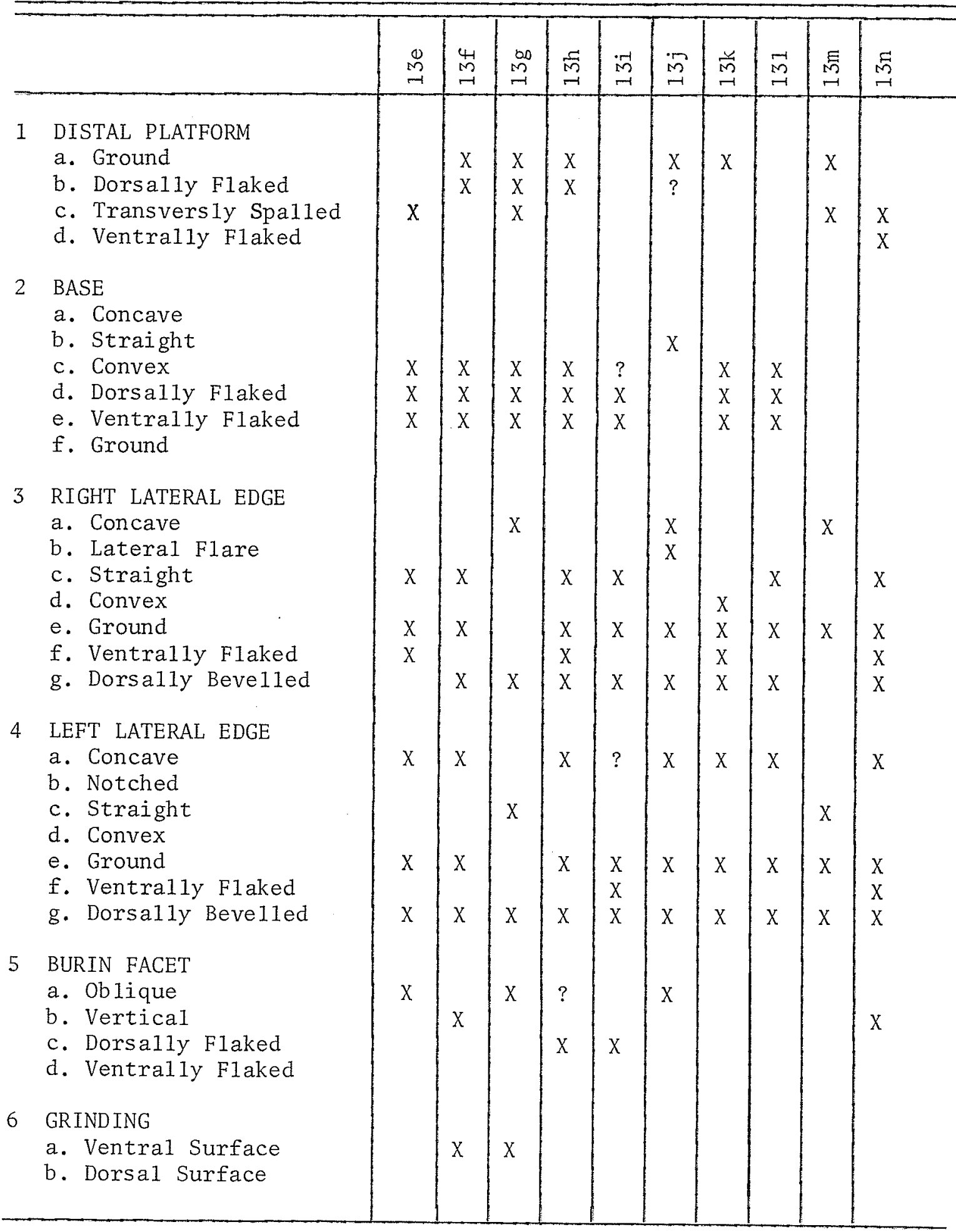




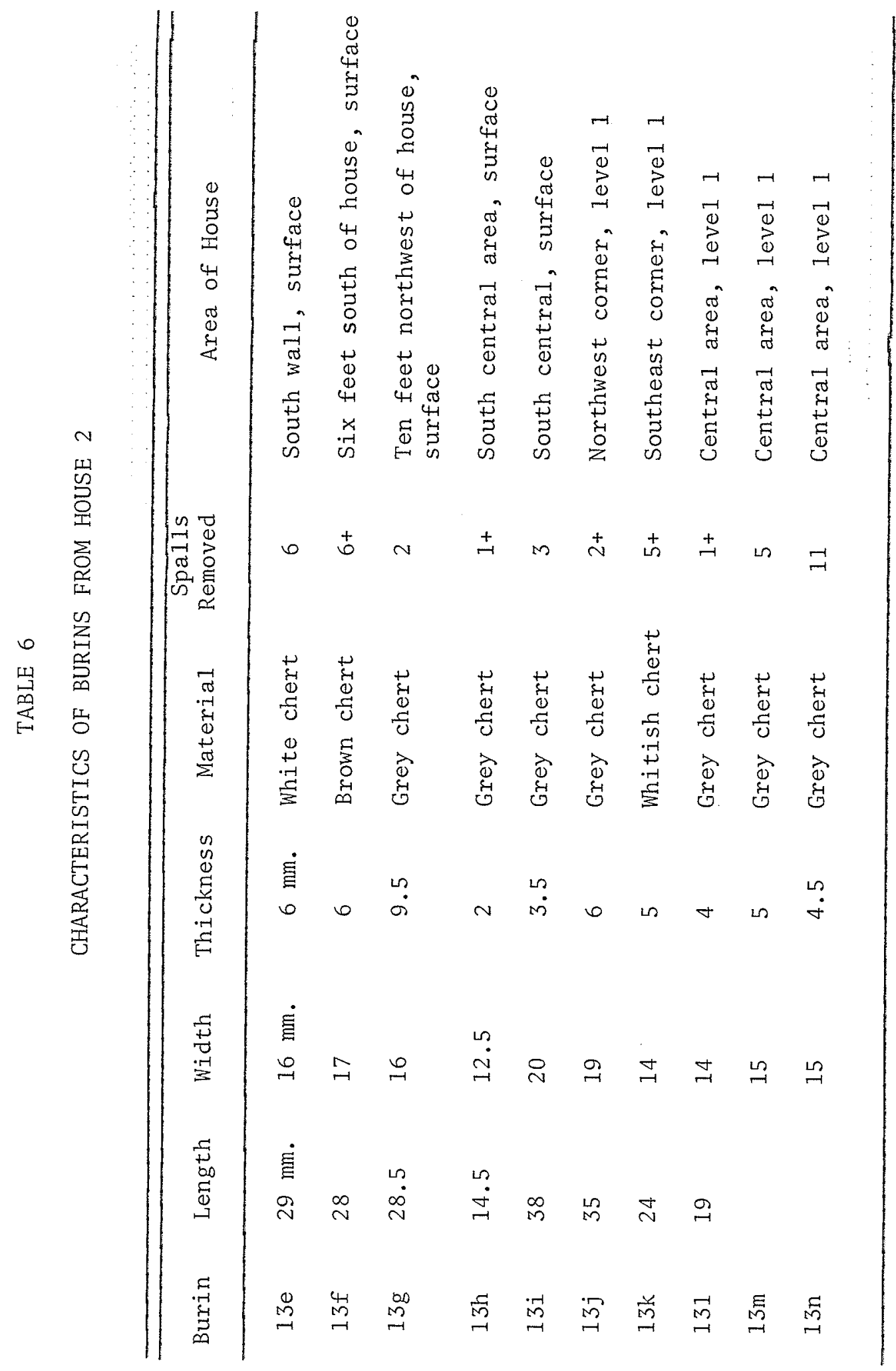


utilized, forming a dorsally flaked oblique edge on the distal end of the spall. The same has been done with two of the secondary spalls.

Three more burin spalls were recovered from the surface of the eastern half of the house. All are secondary spalls in a fragmentary state. Striking platforms are absent or indeterminate as to preparation. An unusual variety of material is present; one is of white quartzite, another of grey pyroclastic and a third of orange chert. The latter has been worked into a spall tool with a dorsaluniface.

Another three spalls came from the excavation of level 1 in the southeastern corner. These are larger and are of fine grey chert. A11 have ground platforms and the one primary spall has been unifacially flaked, forming a typical oblique spall tool.

\section{End Blades}

One end blade (Fig. 13,0) was excavated from level 1 of the northwestern corner of the house. Of grey-brown chert, it is bifacially flaked and is lanceolate in outline. The base is convex and neither it nor the lower lateral margins are ground. Dimensions are 24, 14, and $5 \mathrm{~mm}$.

\section{Harpoon Blades}

This tool category was not represented in House 2.

$\underline{\text { Side }}$ Blades

One concavo-convex side blade (Fig. 13,p) was collected from the surface nine feet northwest of the stone alignment. It is broken in half, but appears to have been symmetrical. One edge is slightly con- 
vex while the other is concave. The short edge of the rectangle is not at right angles, but forms an acute angle with the concave margin. A11 edges have been carefully bifacially thinned. The material of this delicate artifact is a glassy grey-brown chert. It is $16 \mathrm{~mm}$. wide and $3 \mathrm{~mm}$. thick.

\section{$\underline{\text { Knives }}$}

No asymmetrical knives were found within the dwelling, but two were found outside. One was located over thirty feet to the southeast and although it may have been lost by inhabitants of this dwelling, it is too far away to be confidently associated. The other knife (Fig. 14, c) was found ten feet west of the northwestern corner of the dwelling and is considered to be associated.

This knife (Fig. 14,c) is unusual as it is larger than any others found at the site and is made of banded grey-white pyroclastic, a material rarely used for anything other than large tools. The narrow base (17 mm. wide) is convex, bifacially flaked and unground. The lower lateral edges are notched and lightly ground. The body of the knife is asymmetrical; one edge is essentially straight and the other irregularly convex. Most of the edges are bifacially flaked. Dimensions are 64, 28, and $7.5 \mathrm{~mm}$.

Two ovoid knives, each quite different from the other, were discovered. One (Fig. 14,a), made from a large flake of grey pyroclastic material, was found near the middle of the south wall during the excavation of level 1. It has been roughly flaked, bifacially on one edge and dorsally on the other. The dorsal surface has been extensively ground, 


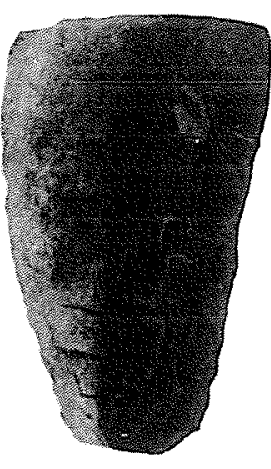

a
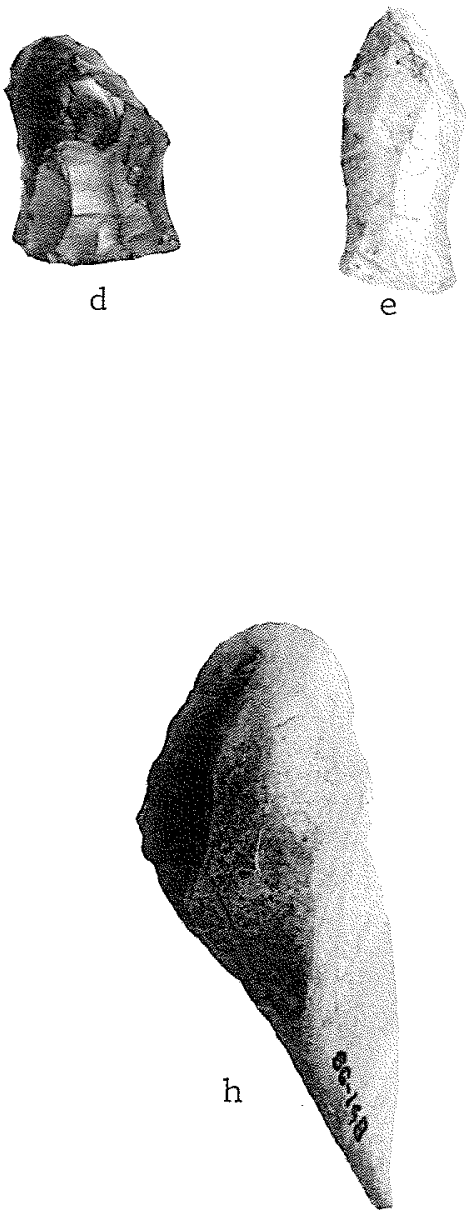
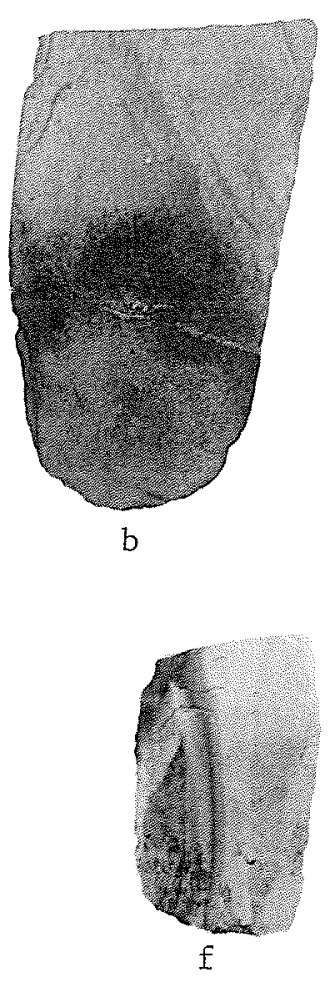
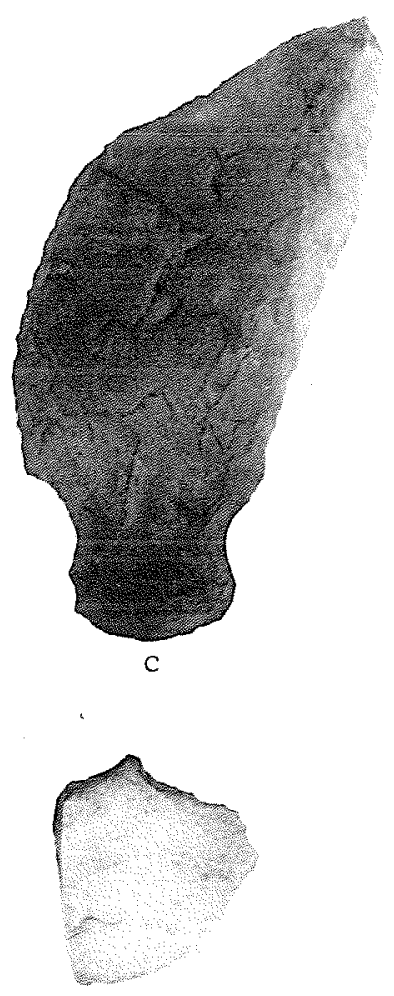

g

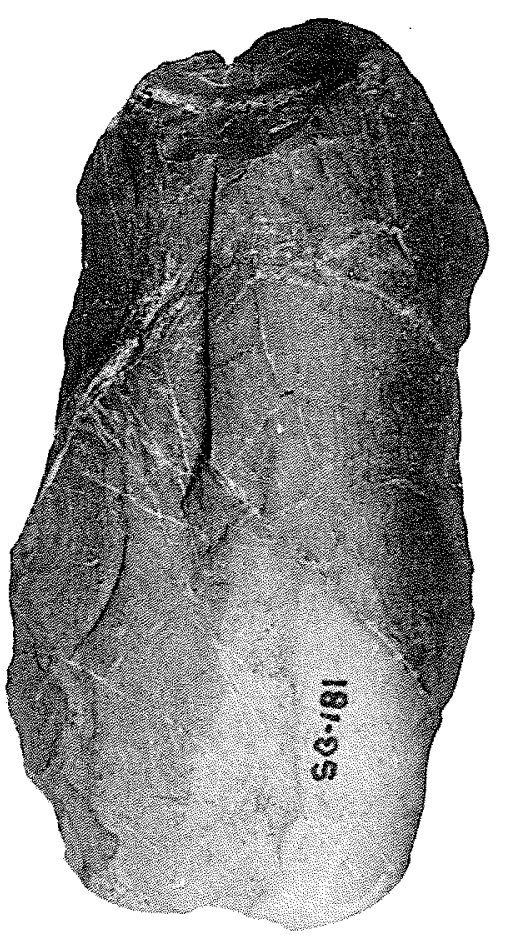

i

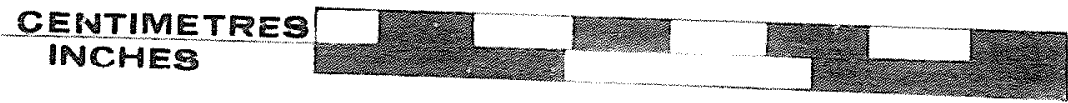

Fig. 14. Tools from the Seahorse Gully site. House 2: a-b, ovoid knives;

$c$, notched knife; d-e, hafted scrapers; $f$, blade fragment;

$g$, perforator; h, pick tip; i, gouge. 
the ventral surface only lightly. The edges have been dulled, probably through use. This specimen is $28 \mathrm{~mm}$. wide and $7 \mathrm{~mm}$. thick.

The second ovoid tool (Fig. 14,b) is of slate. It has been roughly bifacially flaked on all edges and both surfaces have been extensively ground. This ground slate specimen was discovered on the surface ten feet to the northeast of the dwelling. One end has been broken off, so the length cannot be measured, however, the width is $29 \mathrm{~mm}$. and the thickness $5 \mathrm{~mm}$.

\section{Scrapers}

One asymmetrical scraper (Fig. 14,d) was recovered from the excavations of leve1 1 in the northwest corner of the house. It is made on a curved flake of brown chert. The base is dorsally thinned while all the other edges are dorsally bevelled. The short right edge is concave, as is the longer left margin. Both lateral margins are heavily ground. Dimensions are 24, 14, and $5 \mathrm{~mm}$.

Another offset scraper (Fig. 14,e) was discovered in leve1 1 excavations inside the middle of the south wall. This scraper is elongated and completely dorsally bevelled, except for the convex base which is dorsally thinned and ventrally bevelled. The right margin is concave and unground, while the left is less concave and ground almost to the tip. The base is unground. Made of grey-white chert, the dimensions of the scraper are 29,13 , and $7 \mathrm{~mm}$.

\section{Unifacial Blades and Microblades}

A broken blade of fine greyish chert was found in level 1 excavations of the east central area of the house (Map 10, 14f). It is dorsally 
flaked along the right margin (as oriented in Fig. 14,f). Dimensions are 31,19 , and $5 \mathrm{~mm}$.

\section{Flake Tools}

A white chert flake was found on the eastern half of the dwelling surface. It was identified as a perforator since it has a sharp projection on one edge (Fig. 14,g). The projecting tip has been produced by the dorsal flaking of two adjacent concavities. The flake margin opposite the tip is ventrally bevelled and dorsally thinned. Dimensions are $24,20.5$, and $4 \mathrm{~mm}$.

\section{Large Too1s}

\section{Gouges}

One fragmentary and two complete large tools were associated with House 2. One of these (Fig. 14,i) was found in the excavation of level 1. It is a small battered specimen made of a grey banded sedimentary material. A reworked gouge, the distal lateral edges are slightly inset and ground. Grinding extends to the dorsal and ventral surfaces of the distal working edge as we11. This edge is convex, ventrally hollowed, battered, and dulled. Plano-convex in cross-section, the dimensions of this tool are $80.5,47$, and $20 \mathrm{~mm}$.

\section{Chise1s}

The distal end of a chisel was found in the centre of the house, associated with fragments of steatite. This fragment is composed of a grey banded cherty material. A working edge, it consists of a narrow convex tip, ventrally hollowed and dorsally ground and polished. Plano- 
convex in cross-section, this working tip is very sharp and suitable for wood working (Fig. 14,h).

A third large tool was located ten and one half feet southeast of the dwelling. Of grey pyroclastic, this is a battered pick or chisel. The dulled working tip retains some dorsal grinding, indicating that it was once sharp like "14h". Plano-convex in cross-section, the lateral edges of this chisel have been slightly stemmed and heavily ground for hafting. Dimensions are 107.5, 44.5, and $26 \mathrm{~mm}$.

Other Tools

Worked Organic

Tools of organic materials were not recovered from House 2.

Worked Inorganic

Twenty-nine fragments of grey steatite were discovered on the surface, just north of the centre of the dwelling. These fragments lay among and beneath a jumble of about six stones that may have served as a hearth or lamp platform. Eight rim fragments are present, three of the largest of which can be fitted together. To these, another seven body fragments can be added and in this way a large area has been assembled. The steatite fragments are the parts of an oval, platter-like vessel (Fig. 15). It has been carefully ground and smoothly finished and tapers from a thickness of $7 \mathrm{~mm}$. in the centre to $5 \mathrm{~mm}$. at a distance of $1 \mathrm{~cm}$. from the margin of the rim. The rim margin is almost sharp, it is not rounded. This vessel has a thin encrustation of charred material both inside and out. 


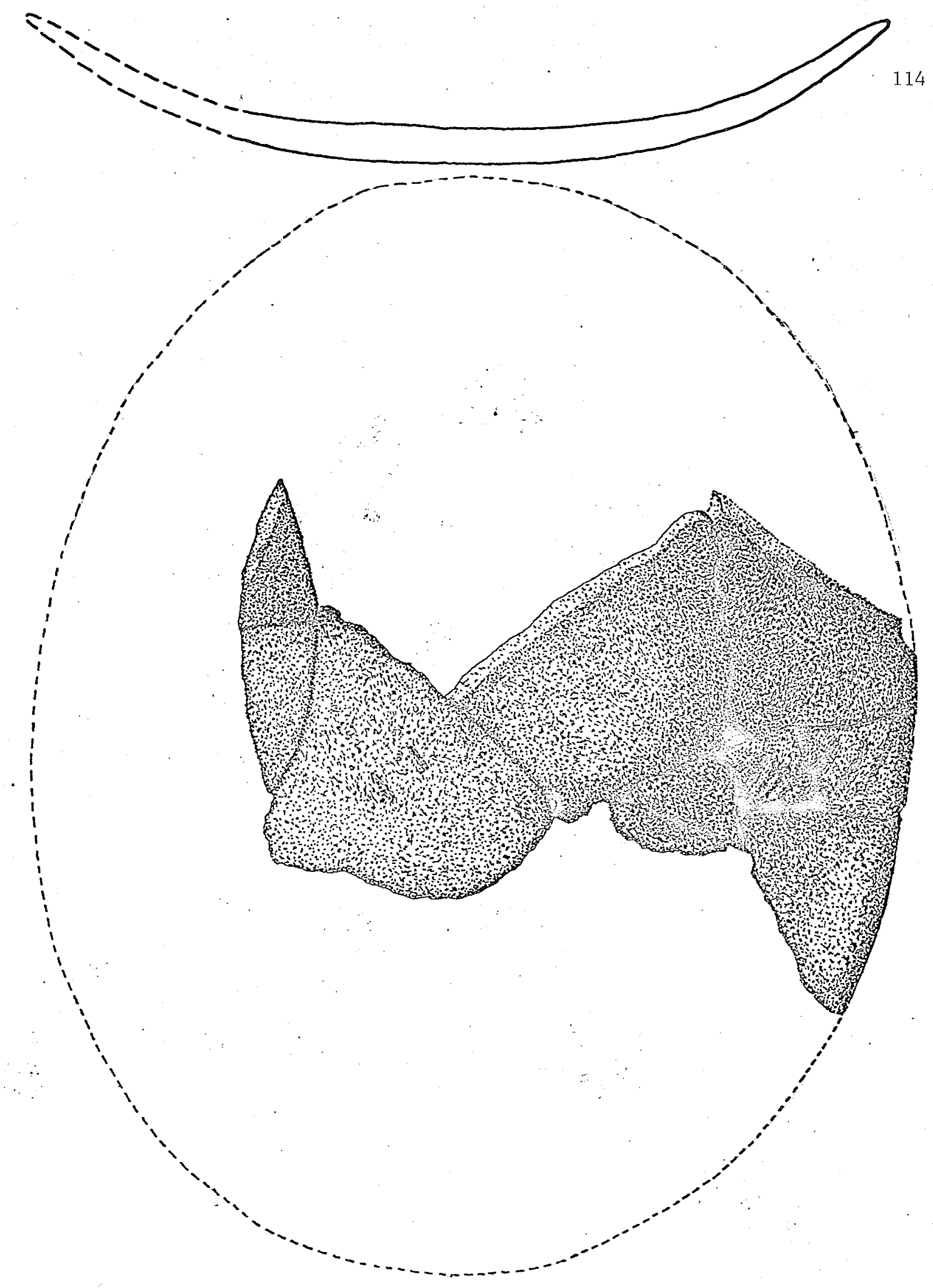

Fig. 15. Fragmentary steatite vessel from House 2. The drawing is actual size and was prepared by Mr. Jonathan Maas. 
House 2 contained more massed flakes than any other Pre-Dorset dwelling at the Seahorse Gully site. The greatest concentration was of chert flakes in the west central half of the house. The surface flakes and those from level 1 of the west central area were not separated as they were clearly one unit. A variety of cherts are represented, almost all of fine quality, the colours varying from white to brown to grey. Four-hundred and fifty-three of the larger chert flakes were counted, but an estimated 400 medium sized flakes and several hundred smaller flakes were not counted. Over a thousand chert flakes are massed in this small industrial area. Most of the flakes are short and wide and there is an absence of microblades. There seem to be no deliberately produced blades, although out of the hundreds of flakes a few with microblade characteristics can be culled.

In the northwestern corner of the house few flakes were found on the surface, however, the excavation of level 1 revealed an extension of the chert debris which characterizes the centre of the western half of the dwelling. Three-hundred and sixty-five small chert flakes as well as twenty-one larger flakes from chert cores were collected. Another fifty-five chert flakes were found in the southwestern corner. Many of the flakes are from the cortex of chert nodules.

Debris from the flaking of large tools also occurred in the western half of the dwelling, but in much lower frequencies (see Table 7). In other parts of the dwelling interior, large tool flakes outnumbered the chert flakes.

In the centre of the house a cluster of large tool flakes was found around the hearth mixed with the steatite fragments. A pick frag- 
LITHIC DEBRIS FROM HOUSE 2

\begin{tabular}{|c|c|c|c|c|}
\hline & Area & Material & Total & $\begin{array}{l}\text { Ground } \\
\text { Platform }\end{array}$ \\
\hline 1 & $\begin{array}{l}\text { Surface outside } \\
\text { north wall }\end{array}$ & $\begin{array}{l}\text { Whitish chert } \\
\text { Red pyroclastic }\end{array}$ & $\begin{array}{l}2 \\
2\end{array}$ & - \\
\hline 2 & $\begin{array}{l}\text { Surface outside } \\
\text { east wall }\end{array}$ & $\begin{array}{l}\text { Slate blocks (?) } \\
\text { Red pyroclastic }\end{array}$ & $\begin{array}{l}2 \\
2\end{array}$ & - \\
\hline 3 & $\begin{array}{l}\text { Surface outside } \\
\text { south wall }\end{array}$ & $\begin{array}{l}\text { Red pyroclastic } \\
\text { Shaly sedimentary } \\
\text { White chert flakes } \\
\text { White chert nodules }\end{array}$ & $\begin{array}{r}21 \\
12 \\
8 \\
17\end{array}$ & $\begin{array}{l}1 \\
2 \\
- \\
-\end{array}$ \\
\hline 4 & $\begin{array}{l}\text { Surface inside } \\
\text { east half of } \\
\text { interior }\end{array}$ & $\begin{array}{l}\text { Whitish chert } \\
\text { Green pyroclastic } \\
\text { Grey pyroclastic } \\
\text { Red pyroclastic } \\
\text { Grey shaly } \\
\text { sedimentary }\end{array}$ & $\begin{array}{r}19 \\
14 \\
10 \\
1 \\
23\end{array}$ & $\begin{array}{l}- \\
6 \\
4 \\
1 \\
3\end{array}$ \\
\hline 5 & $\begin{array}{l}\text { Surface and leve1 } \\
\text { one, interior } \\
\text { west wall }\end{array}$ & $\begin{array}{l}\text { Whitish chert } \\
\text { Red pyroclastic } \\
\text { Green pyroclastic } \\
\text { Grey banded cherty } \\
\text { sedimentary }\end{array}$ & $\begin{array}{r}1,123 \\
29 \\
6 \\
6\end{array}$ & $\begin{array}{l}- \\
2 \\
1 \\
2\end{array}$ \\
\hline 6 & $\begin{array}{l}\text { Level one, random } \\
\text { flakes inside } \\
\text { house }\end{array}$ & $\begin{array}{l}\text { Whitish chert } \\
\text { Grey-green pyro- } \\
\text { clastic } \\
\text { Grey banded cherty } \\
\text { sedimentary } \\
\text { Red pyroclastic }\end{array}$ & $\begin{array}{r}24 \\
14 \\
15 \\
3\end{array}$ & $\begin{array}{l}- \\
4 \\
1 \\
-\end{array}$ \\
\hline 7 & $\begin{array}{l}\text { Level one, north- } \\
\text { west corner }\end{array}$ & $\begin{array}{l}\text { Smal1 chert flakes } \\
\text { Larger chert flakes } \\
\text { Green pyroclastic } \\
\text { Banded grey cherty } \\
\text { sedimentary }\end{array}$ & $\begin{array}{r}365 \\
21 \\
31 \\
\\
2\end{array}$ & $\begin{array}{l}- \\
- \\
3 \\
-\end{array}$ \\
\hline 8 & $\begin{array}{l}\text { Level one, south- } \\
\text { west corner }\end{array}$ & $\begin{array}{l}\text { Whitish chert } \\
\text { Red pyroclastic } \\
\text { Greenish shaly } \\
\text { sedimentary }\end{array}$ & $\begin{array}{r}55 \\
4 \\
3\end{array}$ & $\begin{array}{l}- \\
3 \\
-\end{array}$ \\
\hline
\end{tabular}


TABLE 7 - Continued

\begin{tabular}{lllc}
\hline Area & Material & Total & $\begin{array}{c}\text { Ground } \\
\text { Platform }\end{array}$ \\
\hline $\begin{array}{l}\text { Leve1 one, south- } \\
\text { east corner }\end{array}$ & $\begin{array}{l}\text { Whitish chert } \\
\text { Grey-green pyro- } \\
\text { clastic } \\
\text { Red pyroclastic } \\
\text { Banded grey cherty } \\
\text { sedimentary }\end{array}$ & 1 & - \\
\hline $\begin{array}{l}\text { Level one, centre } \\
\text { of the house }\end{array}$ & $\begin{array}{l}\text { Whitish chert } \\
\text { Red pyroclastic } \\
\text { Grey-green pyro- } \\
\text { clastic } \\
\text { Green cherty } \\
\text { sedimentary } \\
\text { Grey shaly sedi- } \\
\text { Level two, inside }\end{array}$ & 1 & 1 \\
Black rhyolite \\
house
\end{tabular}


ment (Fig. 14,h) was found with these. Flakes were scattered around the house for a distance of several feet. Most were concentrated to the south of the dwelling. Here, Twenty-one red pyroclastic flakes were found, one of which is the blunted working edge of a chise1. Both surfaces are ground and polished. Also discovered were twelve grey shaly flakes, two with ground platforms. Chert was represented by eight flakes and seventeen nodules.

In Table 7 all the lithic flakes from different areas of the dwelling have been enumerated and those with ground striking platforms have also been noted. Only the large tool lithic flakes were found to have ground platforms. This phenomena may be explained as follows. The large tools are composed of relatively soft materials which are easily dulled and battered through use and, because of this, frequently were resharpened. This involved reflaking and grinding not only the working edges but also the lateral margins. Those flakes removed during the initial reshaping process, therefore, were struck from dulled or ground edges. For this reason, many of the flakes struck off in the reworking of large tools have ground platforms which are actually a portion of the margin of the tool.

Since each kind of large tool lithic material is recognizably different, it is possible to identify the various materials and from this to extrapolate the minimum number of large tools worked or reworked in a dwelling. If a concentration of large tools flakes of the same material is found, none of which have ground platforms, it can be assumed that a "new" large tool was knapped.

House 2 contained eight kinds of large tool materials. These 
are; (1) red, (2) grey, (3) green, and (4) grey-green pyroclastics, as well as, (5) grey, and (6) green shaly materials and (7) green and (8) grey banded cherty sediments. Since the three large tools associated with House 2 are of either grey banded cherty sediments or grey pyroclastic, it is evident that at least six other tools of other kinds of lithic materials were present in this dwelling.

FAUNAL REMAINS

Several bones were recovered during the excavation of level 1 of House 2. Near the centre of the dwelling a fragmentary right seal pelvis and an even more fragmentary left seal pelvis were found. From the southeastern corner a seal sacrum, broken in two, and five phalanges were excavated, as we11 as eight other bone fragments. From the excavations of the northwestern corner of the feature came two phalanges that are consistent with an animal of seal size.

\section{SUMMARY}

Several attributes of House 2 are not characteristic of the other Pre-Dorset house ruins at Seahorse Gully. Unique to this dwelling are the large rocks used in its construction and the sharp corners of the stone alignment. The heavy wall boulders are of grey quartzite and it is clear that care was taken to construct a substantial house. Probably intended for a lengthy occupation, this dwelling may have been lived in during the winter. The super-structure is believed to have been of poles covered with skins. The situation of this dwelling, a few yards to the west and in the lee of the cobble mantle suggests that the location was chosen in order to gain some shelter from the northwesterly winds. 
Ten burins were found in and around the house, reflecting the characteristic Pre-Dorset emphasis on burin manufacture and use. These burins generally conform to, or include those attributes believed typical of the Seahorse Gully Pre-Dorset. However, they are highly variable and less standardized than burins from other dwellings. The single asymmetrical knife is unusual, not only because it is made of a grey cherty material usually reserved for large tools, but because it is wider and more irregular in shape than any other offset knife. The occupants of this dwelling also produced the only piece of ground slate found at the site.

Also unusual was the mass of chert flakes in the western half of the house. This flake concentration related House 2 strongly with the southern settlement because the occupants of this portion of the site were the only ones who knapped fine-grained white cherts in massive quantities. In other settlements, flakes of pyroclastic and cherty sedimentary materials tend to predominate. Another factor indicating the close relationship of House 2 to the rest of the southern settlement is the presence of steatite vessel fragments. This broken steatite vesse 1 is similar in all of its attributes to six others, parts of which were found in many portions of the southern settlement.

On the basis of materials used, it seems that at least eight large tools were knapped in the house. All of this appears to have involved the reshaping and resharpening of large tools. These large tool flakes, in the absence of most of the large tools (probably removed by collectors), provide some indication of the minimum number of large tools which these social units carried with them at any one time. This number 
is surprisingly high.

It is probable that several small grey stones found clustered in the central area of the dwelling remains were used as a "hearth" and supported the steatite vessel which was shattered around them. The importance of this hearth area as a focus of activities is indicated by the presence of a cluster of three burins, a concentration of large tool flakes, an unfinished chisel tip of the same material, and several seal bones.

Although no artifacts directly connected with sea mammal hunting were recovered, the discovery of several seal bones indicates that a marine economy was probably the basis of life. The absence of harpoon blades is puzzling, but may simply be due to chance.

The season of occupation of this dwelling is not clear, or at least can not be stated with any decisiveness because of the paucity of faunal remains. However, the numerous artifacts suggest a lengthy period of habitation and the absence of summer species, especially of bird bones, indicates the possibility of a winter occupation.

$\underline{\text { ACTIVITY }}$ AREA 3

\section{DWELLING REMAINS}

No feature such as a stone alignment that once outlined a tent or a hearth or even a depression was present to mark this activity area as ever having been the site of a dwelling. However, eleven pieces of flaked chert representing eight tools were recorded and collected from this relatively isolated spot. No excavations were carried out in this area. 
A11 of the artifacts recovered from this activity area were on the surface and several were within a few inches of one another (Map 11). Initially it was believed that these artifacts represented the debris of an activity area where end blades were manufactured. While this may be so, as evidenced by the three end blades discovered, the other five tools are characteristic of the artifacts usually found within a dwelling. Therefore, it is likely that this artifact concentration indicates the location of a Pre-Dorset dwelling. Why the dwelling is not marked by a stone alignment or a depressed floor is not clear. Apparently some PreDorset shelters were of such a nature that they did not leave recognizable traces of their construction.

Sma11 Too1s

Burins

Two burins were discovered in the activity area. One (Fig. 16,a) is a completely utilized specimen. It has almost no burin facet surface left. The left edge is slightly concave while the right is straighter (the corner is missing). Both lateral margins are dorsally bevelled and ground. The left, concave, margin has also been ventrally thinned. The base has not been flaked or ground. At least seven spalls have been removed from the distal striking platform which has been prepared by grinding. Made on a cortex flake of pink and grey chert, this specimen retains a thick cortical patina on its dorsal surface. Dimensions are 25, 19, and $6 \mathrm{~mm}$.

The second burin (Fig. 16,b) is smaller and more carefully flaked. The left margin is concave and dorsally bevelled. The right edge is 


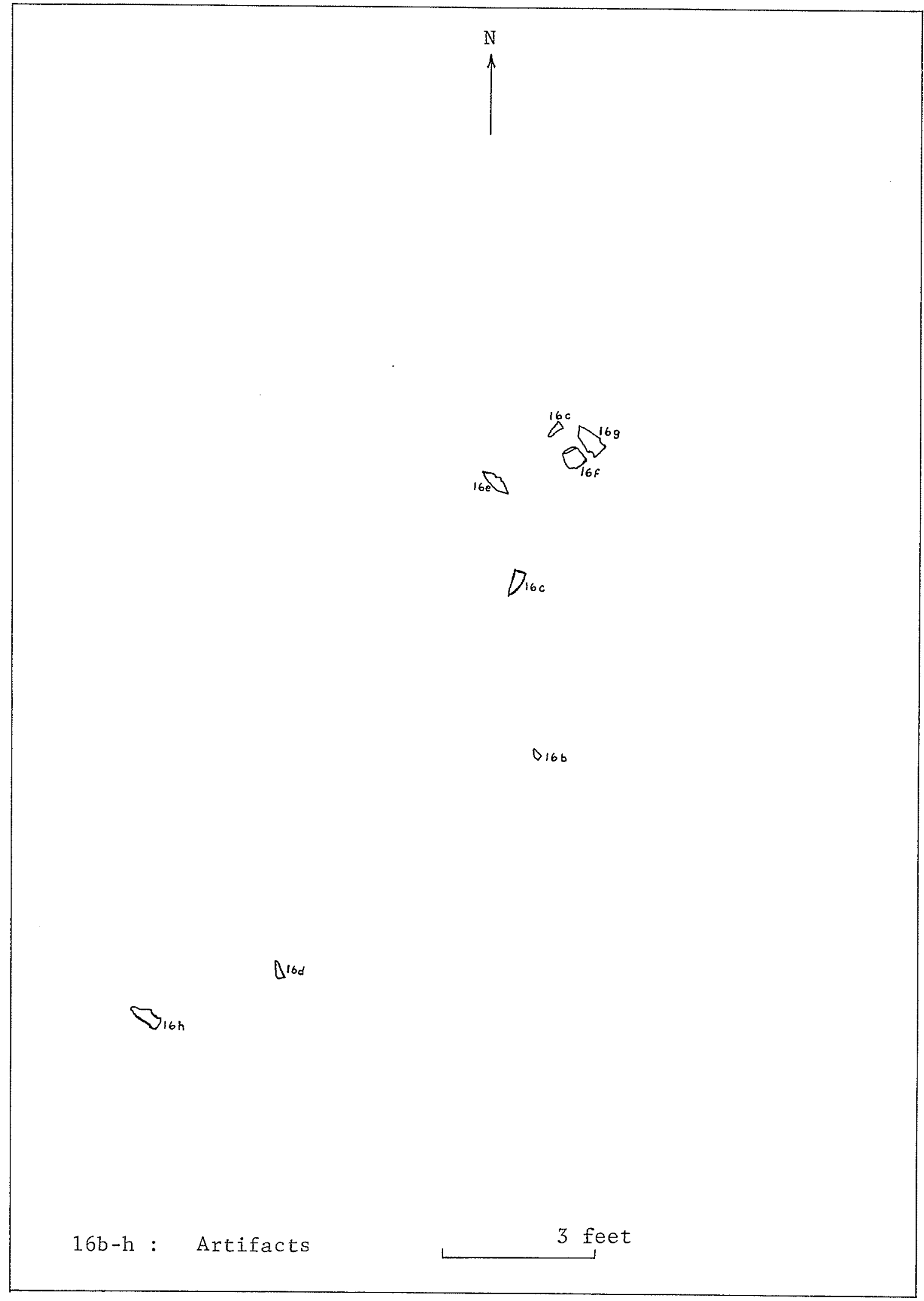

Map 11. Scattergram of tools in Activity Area 3. 


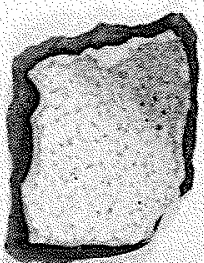

a.

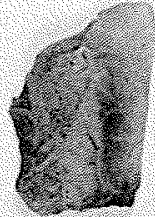

b
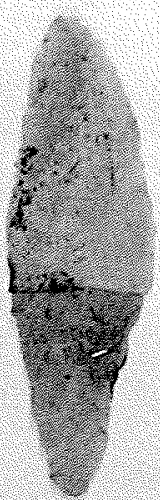

c

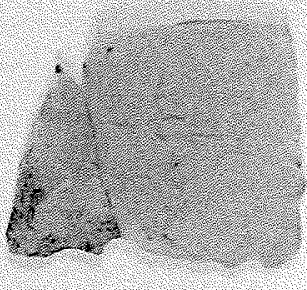

f

e

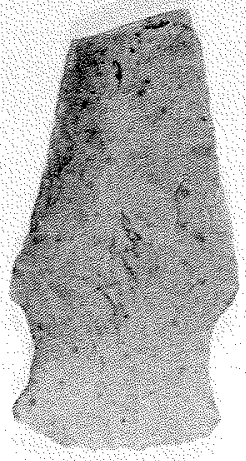

g

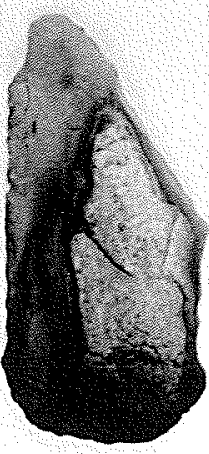

$\mathrm{h}$

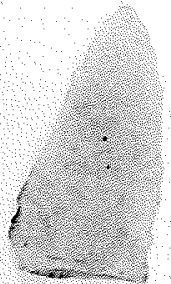

d 
straight, dorsally bevelled and ventrally thinned. Both lateral margins have been ground. The base is straight and bifacially flaked, but has not been ground. As with burin "16, a" the burin facet or hinge fracture edge has been dorsally flaked. However, at least seven spalls were removed. The distal platform is battered but appears to be ground. The material is a mottled pink, grey and white chert. Dimensions are 21,14 and $5 \mathrm{~mm}$.

\section{Burin Spa11s}

One secondary burin spall was recovered from the surface. The preparation of the striking platform of the burin from which it was struck is no longer determinable. Made of grey chert, this spall is 19 $\mathrm{mm}$. long and $5 \mathrm{~mm}$. wide.

\section{End Blades}

Three end blades were discovered. Two have single shoulders and are stemmed. One of these (Fig. 16, C) was found in two parts. It is made on a thin flake of pink and white chert. The ventral surface is only marginally retouched while the opposite surface is more completely flaked. Dimensions of this delicate artifact are 48, 15, and $3 \mathrm{~mm}$. Another end blade (Fig. 16,d) is the proximal end of a stemmed point exactly like " $c$ ". It has broken just below the single shoulder. This point has also been made on a thin flake of fine white chert with only marginal retouch. It is $14.5 \mathrm{~mm}$. wide, and $2.5 \mathrm{~mm}$. thick.

The third specimen (Fig. 16,e) is an unfinished end blade, also found in two pieces. It was clearly intended to be bipointed. Made on a thin flake of grey chert, one surface has been completely thinned, 
while the other still retains a portion of the ventral surface of the blank. Dimensions are 50, 20 and $3.5 \mathrm{~mm}$.

\section{Haxpoon Blades}

This fragmentary harpoon blade (Fig. 16,f) has been shattered but two pieces were found that could be fitted together. The blade appears to have broken during the process of manufacture, as flaking was continued after one corner had broken off. Now in a battered condition, it was bifacially flaked from fine white chert. The base is subconcave and 30 $\mathrm{mm}$. wide. The thickness is $4 \mathrm{~mm}$.

\section{Side Blades}

This tool category was not represented in Activity Area 3.

\section{Knives}

The single knife (Fig. 16,g) recovered is of light grey chert, which has been bifacially flaked. One edge of the cutting margin is slightly concave and bevelled to one surface. The other edge is straighter and has been bifacially thinned. The concave edge is dulled and crushed, perhaps because of use. Two other edges, the concavities of the "side notches", are also dulled and ground. The base is bifacially flaked, convex, unground, and $21 \mathrm{~mm}$. wide. The width of this specimen is $23 \mathrm{~mm}$, the thickness $5 \mathrm{~mm}$, and the original length was approximately $50 \mathrm{~mm}$.

Scrapers

This scraper (Fig. 16,h) is a good example of the asymmetrical concave scrapers from the Seahorse Gully Pre-Dorset. The left margin 
is straight, the right concave. Both lateral margins are dorsally bevel1ed and ground. The bifacially thinned convex base has not been ground. The oblique scraping edge is slightly concave and has been dorsally bevelled. This edge trends from the upper left to the lower right. The flake blank was a curved cortex chip, of fine grey-white chert.

Blades and Microblades

Tools in this category were not recovered.

F1ake Tools

This tool category was not represented in Activity Area 3.

Large Tools

Large tools were not found in this area.

Other Tools

This category was not represented.

\section{DEBITAGE}

Only a few flakes were recovered from the surface, evidence that extensive tool manufacture did not occur in this activity area. Two pink-white chert flakes were found with one red pyroclastic flake. The pyroclastic flake has a ground platform, indicating it was struck from a ground edge, probably a large tool in the process of reshaping. One flake of grey pyroclastic was also present. A mass of red pyroclastic flakes was discovered twenty-one feet west of the activity area. Whether or not they are to be associated with Activity Area 3 is unknown. 
FAUNAL REMAINS

The absence of faunal remains from the barren gravel surface of this activity area may simply be due to the lack of preservation of such organic materials.

SUMMARY

The absence of dwelling remains, of substantial debitage, of large tools, and of faunal remains, serves to differentiate this activity area from the dwellings at Seahorse Gully. No other occupied area of the site exhibits this combination of missing characteristics. For this reason, this inhabited area is termed an "activity area" and not a dwel1ing.

The abnormally large number (three) of end blades as compared with the total number of tools (nine) is also unusual. Probably, the manufacture of end blades was an important activity in this area. In contrast, the other six tools represent categories normally found in any dwelling and this suggests that similar activities occurred in both kinds of occupied areas. It is possible, therefore, that Activity Area 3 was an unusual kind of dwelling with some usual and some unusual activities taking place within it.

The activities of females are indicated by the offset knife and scraper, while the harpoon blade suggests the hunting of sea mammals. The presence of end blades, especially unfinished ones, may indicate preparations for a move elsewhere, perhaps inland. It is unlikely that the end blades were important in the coastal sealing economy. 
TOOLS FROM THE SOUTHERN SETTLEMENT

\begin{tabular}{|c|c|c|c|c|c|}
\hline & Categories & House 1 & House 2 & $\begin{array}{c}\text { Activity } \\
\text { Area } 3\end{array}$ & Totals \\
\hline 1 & Burins & 2 & 10 & 2 & 14 \\
\hline 2 & Burin Spalls & & 12 & 1 & 13 \\
\hline 3 & End Blades & 1 & 1 & 3 & 5 \\
\hline 4 & Harpoon Blades & & 1 & & 1 \\
\hline 5 & Side Blades & & 1 & & 1 \\
\hline 6 & Knives & 1 & 3 & 1 & 5 \\
\hline 7 & Scrapers & & 2 & 1 & 3 \\
\hline 8 & $\begin{array}{l}\text { Unifacial blades } \\
\text { and microblades }\end{array}$ & & 1 & & 1 \\
\hline 9 & Flake Tools & & 1 & & 1 \\
\hline 10 & Gouges & & 1 & & 1 \\
\hline 11 & Chisels & & 2 & & 2 \\
\hline 12 & Scraper Planes & & & & \\
\hline 13 & Adzes & & & & \\
\hline 14 & Worked Organic & & & & \\
\hline 15 & Other Lithic & & 1 & & 1 \\
\hline & Totals & 4 & 35 & 9 & 48 \\
\hline
\end{tabular}


The southern settlement occupies the most southerly portion of the Seahorse Gully Pre-Dorset site. According to an old map (Taverner and Sutton 1934:Plate XIV) this area of the cobble mantle rises to a height of 117 feet above sea level (Map 7). Because of its height, this part of the site was clear of water first and must have been the earliest portion of the island available for occupation. Perhaps because of its longer use, this settlement was the most intensively inhabited and is therefore the most difficult to evaluate and interpret. Evidence of PreDorset habitation is found all along the cobble mantle and for a few dozen yards to the east of the mantle (Map 8).

In this settlement only the stone alignments of Houses 1 and 2 could be recorded with any confidence. Scattered rocks marked the locations of several other habitations on the summit of the cobble mantle, however, only surface collections were made among these. Artifacts collected include; forty-three burins, eighteen burin spalls, seventeen end blades, two harpoon blades, three side blades, thirteen knives, eleven scrapers, two microblades, one flake tool, six gouges, two chisels, two scraper planes, four adze blades, seven large tool fragments, a whetstone, and at least six soapstone vessels, resulting in a total of 137.

Activity Area 3 differed as much from Houses 1 and 2 as they differed from one another. This activity area contained very light coloured cherts, in contrast to the cherts of Houses 1 and 2 , which are darker greys and browns. In fact, the artifacts of Activity Area 3 coincide in lithic materials and general style with those of House 5. Similarly, the inhabitant's of House 1 seem to have been culturally akin 
to the occupants of the northern settlement. Probably, neither House I nor Activity Area 3 are part of the same settlement as House 2. If this is so, on $1 y$ House 2 is left as representative of the archaeological culture of the southern settlement.

House 2 was the only recorded Pre-Dorset dwelling at Seahorse Gully to have a large portion of a steatite vessel inside it. The attributes of this vessel (Fig. 15) are similar to those of the other six vessels from this settlement. House 2 was also unique because of the presence of masses of white chert debitage within it. This chert detritus is matched by several other areas of massive chert knapping in this settlement. These two factors suggest an identity of the culture of the occupants of House 2 with that of the rest of the inhabitants of this southern area. The use of oval soapstone vessels, in square dwellings like House 2, with much chipping of fine cherts may, therefore, characterize the whole of the southern settlement. 
CHAPTER VI

THE CENTRAL SETTLEMENT

INTRODUCTION

The central settlement stretches from about 1000 feet south of datum to 800 feet north of it. In this area, the cobble mantle is relatively low and inconspicuous. It is flanked by extensive boulder fields along most of its eastern edge. Three of the houses were situated in the southern portion of the settlement while House 7 was located far to the north.

Relatively few artifacts were scattered on the surface in such a way that they could not be associated with any dwelling. These random finds included a burin, a possible end blade, a flake knife, an offset scraper, three blades, and four whole or fragmentary large tools. When it is noted that the artifact yield of Houses 4, 6, and 7 was very 1 ow, it is clear that the occupation of this central area was relatively light. This sparse habitation, in itself, aids in the separation of this settlement from the other two at the Seahorse Gully Pre-Dorset site.

Five rectangular dwellings were discovered in the central area and each of these was at least partially excavated. The characteristics of these house ruins and their artifacts are the subject of the following sections of this chapter.

HOUSE 4

House 4 is located on a flat stretch of gravel among several large quartzite boulders. Its setting is similar to that of House 5 which is 


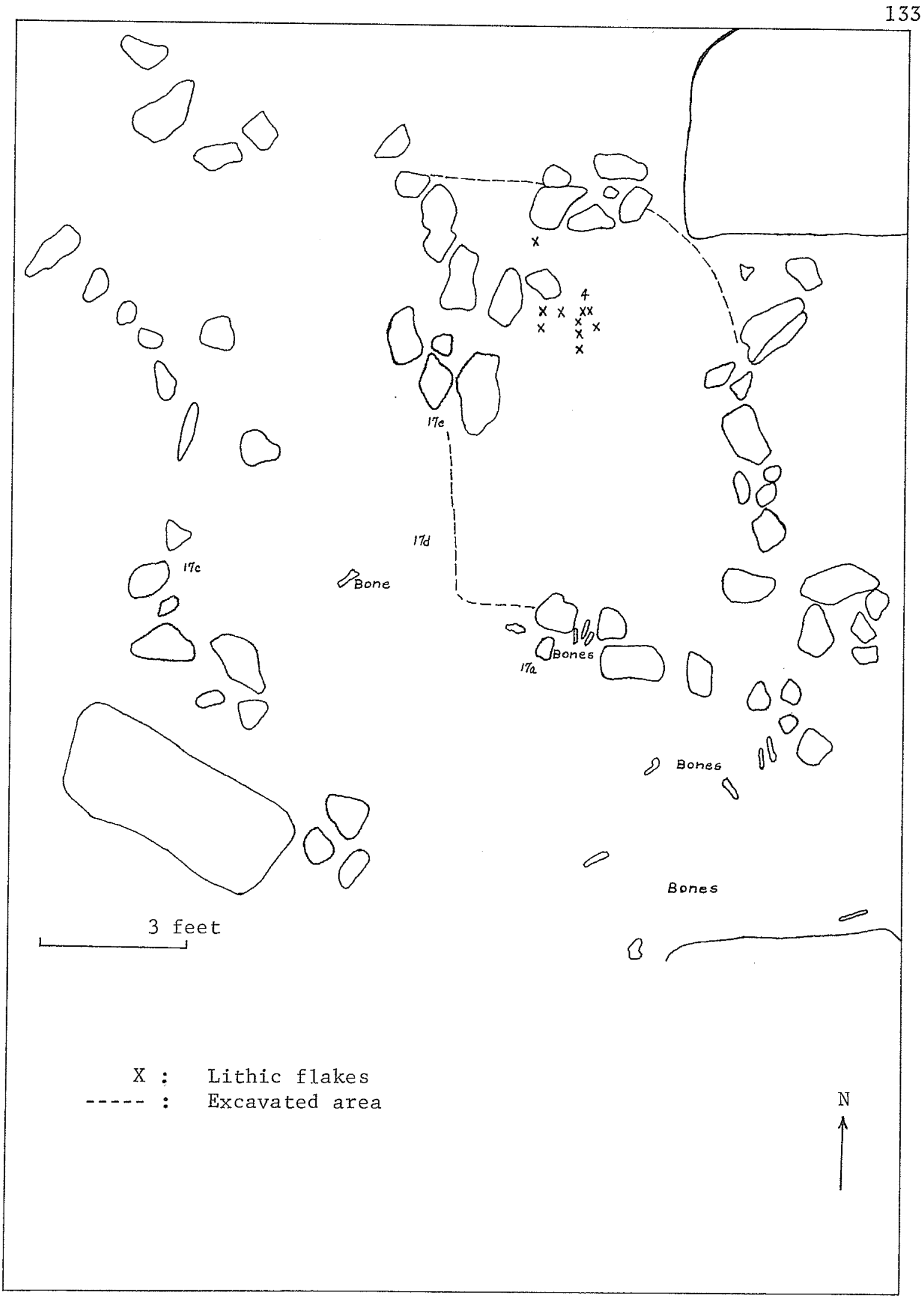

Map 12. Floor plan of House 4. 
ninety-two feet, five inches to the north northwest. Although the bare gravel patches within the boulder field to the east of the mantle were favoured Pre-Dorset dwelling places, several were examined that had not been used. The fact that all available living areas were not inhabited suggests that a relatively small population used this area.

\section{DWELLING REMAINS}

The location of House 4 was indicated by a disturbed alignment of stones that may have surrounded a small subrectangular dwelling (Map 12). Mainly grey quartzite cobbles, these stones are variable in size but are relatively sma11, like those of House 5. This dwelling alignment is approximately eight feet wide and ten feet long.

\section{ARTIFACTS}

Only five tools were recovered from House 4. All of these are small tools and all were found lying on the gravel surface of the dwe11ing floor. Each was recorded on the floor plan which was drawn of the stone alignment. Excavation was expected to produce a larger artifact sample, but it actually yielded only a few flakes and bones.

\section{Sma11 Tools}

\section{Burins}

A burin of grey chert (Fig. 17,a) was found on the surface near the outer edge of what is believed to be the south wall of the dwelling. The upper right corner of this burin is broken off, removing much of the striking platform (which is ground). The short left margin is dorsally bevelled, concave, and ground. Also dorsally bevelled, the right margin 
is only slightly concave and ground. The base is convex, bifacially flaked and unground. At the opposite end, seven hinge fractures are present and the burin facet is dorsally flaked.

Burin Spa11s

A large burin spall (Fig. 17,b) was also discovered on the interior surface of the house. Of grey chert, it is longer (24 mm.) and wider ( $5 \mathrm{~mm}$.) than most Seahorse Gully spalls. A secondary spall, it is too long to have come from the above burin. Another spall is represented by a distal tip only. This spall has been utilized as a tool and the oblique working edge is dorsally flaked.

\section{End Blades}

End blades were not found in this house.

Harpoon Blades

These tools were absent from House 4.

Side Blades

A broken side blade (Fig. 17,c), of large proportions, was found on the surface of the southwestern portion of the dwelling. This specimen is bifacially flaked on all edges. Although larger and coarser, it is similar to a side blade which Nash (1969:Fig. 13,5) has illustrated from Thyazzi. No comparable tools were discovered at the Twin Lakes site.

\section{Knives}

Another surface find, a stemmed knife (Fig. 17,d), is of especial 
interest as this knife variety appears to be unique to the Churchill PreDorset culture. One surface of this tool is completely flaked while the ventral face is only marginally retouched. The knife blade is asymmetrical, with one edge slightly concave and the other convex. Both the stem and the subconcave base are marginally ground. Made from fine, pinkwhite chert, this tool's dimensions are 50,13 , and $5 \mathrm{~mm}$.

\section{Scrapers}

A puzzling fragmentary tool (Fig. 17,e) which was found on the surface near the middle of the house, may be a scraper base. However, it has unusually long parallel sides, except for a lateral flare of the lower right margin. Both lateral margins are dorsally bevelled and ground. Grinding extends from the lower lateral edges on to the convex base for a short distance ( $2 \mathrm{~mm}$.$) . This base is dorsally thinned and also has two$ flakes removed from the ventral bulb of percussion. The material is a whitish chert.

\section{Unifacial Blades and Microblades}

This tool category was not represented at House 4.

\section{F1ake Tools}

No flake tools were recovered from House 4.

Large Too1s

No large tools were recovered from this dwelling. If present, they may have been removed by collectors.

\section{DEBITAGE}

Eight small flakes of red pyroclastic were found in the northeast- 
ern area of the dwelling (Map 12,4). Two of these have been struck from the ground edges of a large tool. Associated with these were several small flakes of grey-green cherty sedimentary material. In all, twentyfive of these grey-green flakes were discovered scattered over the surface of the dwelling. None have ground striking platforms. Three minute flakes of white chert and two of red pyroclastic were also collected.

A large tool of grey pyroclastic had been reworked near a boulder a few feet southeast of House 4. Four flakes were collected, one of which has been struck from a ground edge. Here also, a number of disintegrating bones were found.

Two pieces of slate were found outside the dwelling. They do not appear to have been worked, but their close proximity to the house suggests that they may have been collected by the inhabitants for use in tool manufacture. Three flakes of grey-green cherty material were located in the excavation of level 1 , but no tools were found.

\section{FAUNAL REMAINS}

Several bones were scattered about the dwelling and outside of it. Most were from the southern half of the dwelling, particularly the southeastern area. A number of bones have been identified, including the distal fragment of a left seal humerus, the proximal fragment of a left seal ilna, along with the distal end of a left seal ulna. Two phalanges, a vertebral fragment, four skull fragments, eight rib fragments, and twelve other bone pieces remain unidentified. All are consistent with a seal size animal.

While the above listed faunal remains are believed to be those of 
the ringed seal, one of the most interesting finds from House 4 was the sacrum of a bearded sea1. This was found on the surface immediately south of the dwelling. Like the rest of the bones it is badly disintegrated and charred from the recent tundra fire. According to Dr. Howard Savage (personal communication, 1970):

In size, the sacrum was intermediate between the sacra of a large Harp Seal and a Walrus, as would be expected of the Bearded Seal (Erignathus barbatus). Unfortunately, the sacrum of this seal is not included in our reference material here, and hence only a probable identification of Bearded Seal can be made.

\section{SUMMARY}

A diffuse stone alignment outlined the subrectangular base of House 4. This dwelling was situated on a flat gravel patch in a field of huge boulders. Its interior was flat and had never been dug out. Only five tools; (1) a stemmed knife, (2) a side blade, (3) a burin, (4) a scraper, and (5) a spall tool were recovered from the house. These few tools plus a relative paucity of lithic flakes suggest a brief occupation, probably by a small social unit. Three of the tools, the knife, the scraper, and the side blade are unusual. While tools in each of these categories are found throughout the site, similar varieties of only the knife have been found. However, though the varieties are unusual, attributes of each are shared with tools from other houses. Shape, setting, faunal remains and proximity all relate this dwelling to House 5. On the other hand, the tool kits differ greatly, as only the burin and possibly the hafted knife are shared. As at House 5, the staple food was the seal and scattered bones generally do not extend north of the stone alignment, suggesting that the entrance was to the south or to the east. 
Fig. 17. Seahorse Gully site tools. House 4: a, burin; b, burin spall; $c$, side blade fragment; d, hafted knife; e, scraper base (?). House 5: f-o, burins.

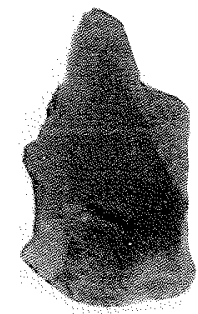

a

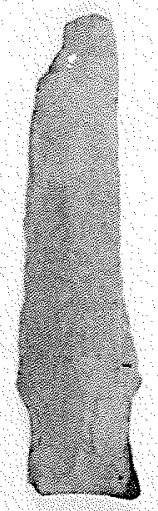

d

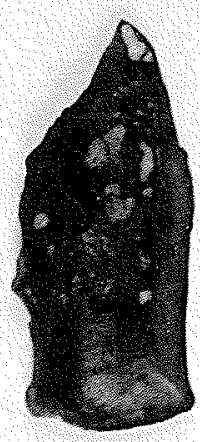

h

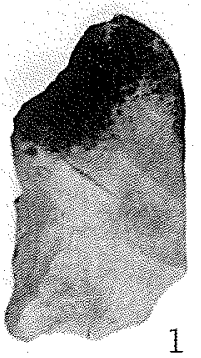

\section{(1)}

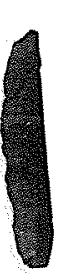

b

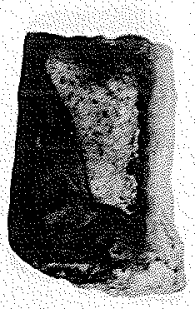

$\mathrm{e}$

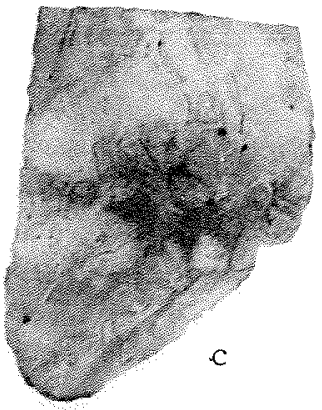

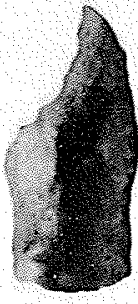

i

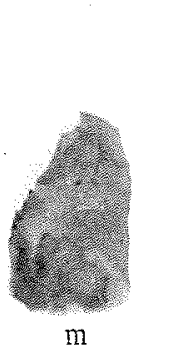

$\mathrm{m}$

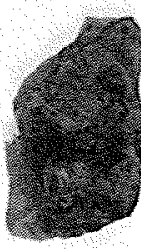

j

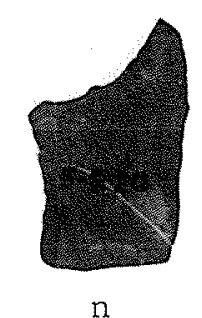

n

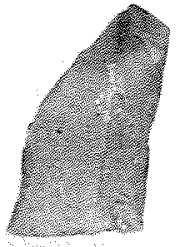

g

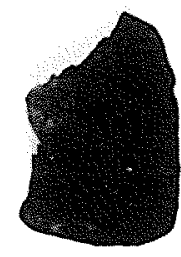

k
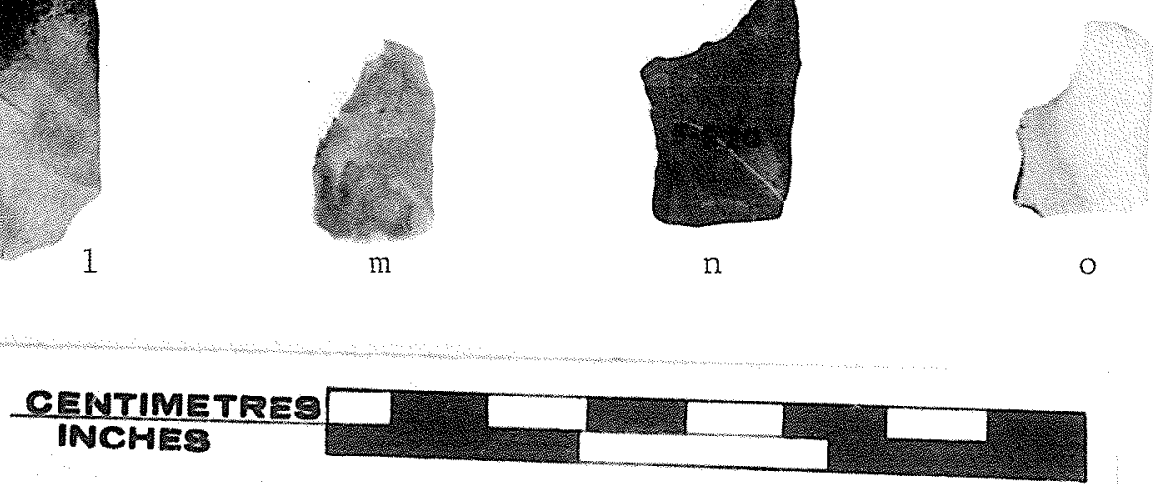
House 5 is situated on a flat patch of gravel surrounded by grey quartzite boulders. This location is approximately 270 feet east of the cobble mantle in the central area of the site. This house is relatively isolated, with only one other dwelling, House 4 , in the immediate vicinity. The interior of the house is flat. As the quartzite ridge was encountered, in the form of a flat table of worn grey rock, a few inches beneath the surface it is clear that the floor could never have been dug out.

\section{DWELLING REMAINS}

House 5 is characterized by an alignment of stones, from ten to twenty pounds in weight, arranged into a subrectangular outline (Map 13). Since the soil composing the dwelling floor was gravel and sand with a few larger cobbles, it was a relatively simple matter to identify those stones pertaining to the stone alignment. These stones were brought to the dwelling from the surrounding area and probably held down the edges of a skin tent, subrectangular at the base. This tent was approximately fourteen feet long and ten feet wide (inside dimensions). Five rocks that held down the southeastern corner have been displaced outwards and now lie adjacent to large bedrock boulders a few feet away. It is likely that three stones placed in the centre of the house either bounded a fire or supported a stone lamp.

\section{ARTIFACTS}

The organic layer that blanketed the soil at the time of PreDorset occupation and which once enveloped many of the artifacts has been burned away at House 5 . While small patches of sod remain around the dwelling, the interior was burned down to the gravel subsoil surface. 


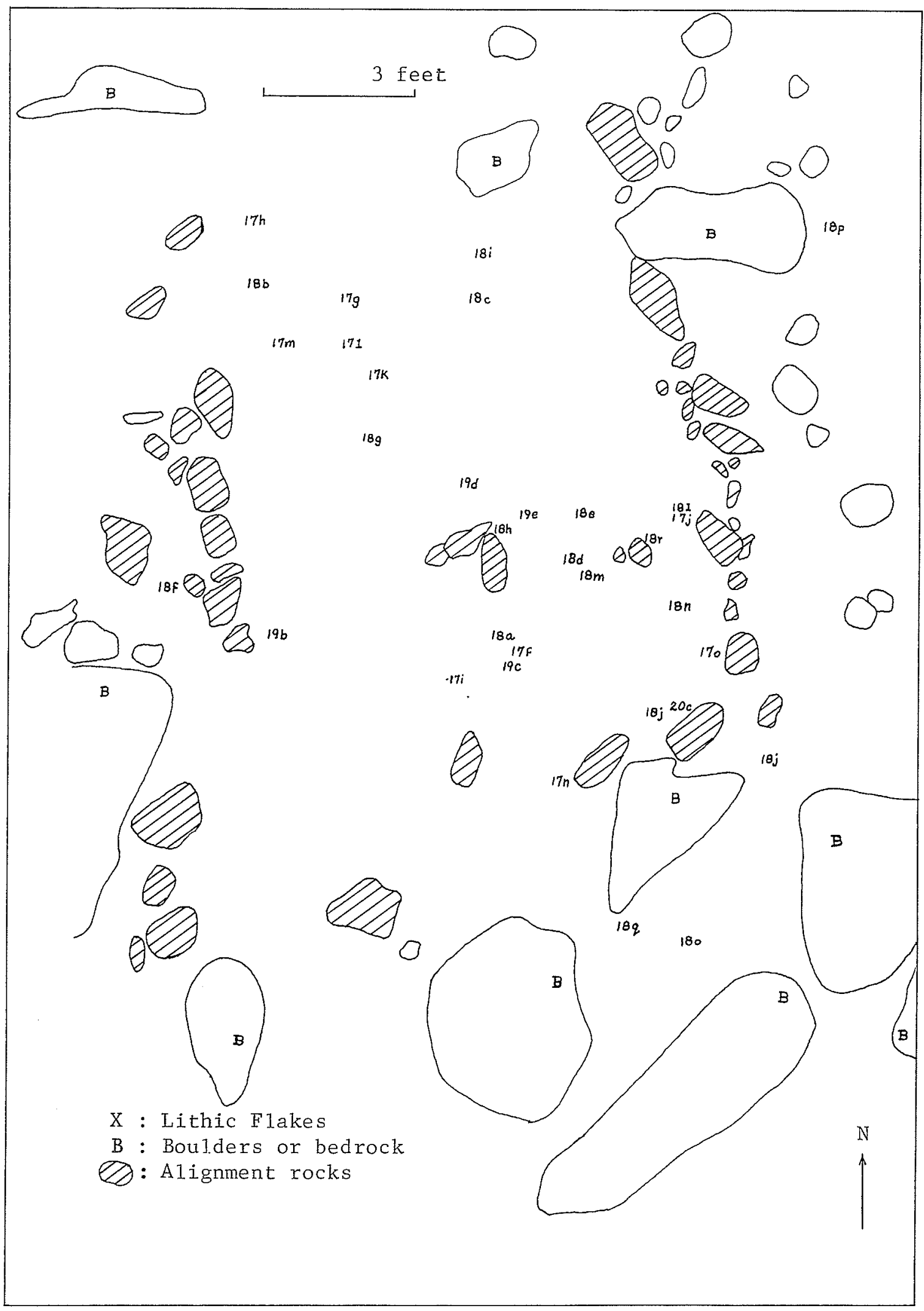

Map 13. Floor plan of House 5. 
The many artifacts discovered on this bare surface marked the house as potentially very productive. However, the surface finds composed the bulk of the artifacts and excavation was not particularly fruitful.

\section{Burins}

Eighteen burins were recovered from House 5, more than from any other dwelling. As with the other tools, the locations of these have been marked on Map 13, using the numerals and letters from Figures 17 and 18 to symbolize each burin. These same symbols are used in Tables 9 and 10 where the attributes, including dimension, 1ithic composition, and numbers of spall removals (hinge fractures) have been listed.

Two of the burins (Fig. 17,f,g) are unusual in the possession of a slight lateral flare to the distal right edge. It is likely that these burins were specialized tools that were used in incising activities. The rest of the burins incorporate the basic combination of burin attributes; (1) a concave lower left margin which is dorsally bevelled, often ventrally thinned, and almost always ground, (2) a convex base which is usually bifacially flaked and unground, (3) a right lateral margin which is characteristically straight, ventrally thinned, dorsally bevelled, and ground, (4) a distal striking platform which is prepared by the removal of a spall or by grinding, and (5) a burin facet that is oblique and almost always dorsally thinned.

Three other unusual burins were also found. One (Fig. 18,d) is perhaps the smallest burin from the whole site. A second (Fig. 18,c) is abnormally narrow in proportion to its length and a third specimen (Fig. $18, f)$ appears to be a burin blank. The former burin is carefully dorsally 
ATTRIBUTES OF BURINS FROM HOUSE 5

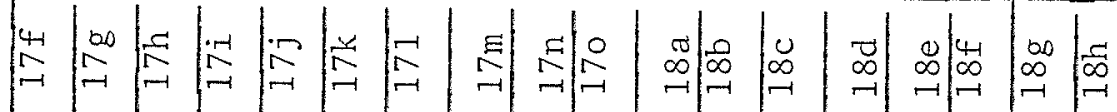

1 DISTAL PLATFORM

a. Ground

b. Dorsally Flaked

c. Transvers $1 y$ Spalled

d. Ventrally Flaked

2 BASE

a. Concave

b. Straight

c. Convex

d. Dorsally Flaked

e. Ventrally Flaked

f. Ground

3 RIGHT LATERAL EDGE

a. Concave

b. Lateral Flare

c. Straight

d. Convex

e. Ground

\begin{tabular}{l|l|l|l|l|l|l|l|l|l|l|l|l|l|l|l|l|l|l} 
f. Ventrally Flaked & $x$ & $x$ & $x$ & & $x$ & $x$ & $x$ & $x$ & & $x$ & $x$ & & $x$ & & $x$ & $x$ & & $x$ \\
$g$. Dorsally Bevelled & $x$ & $x$ & $x$ & $x$ & $x$ & $x$ & $x$ & $x$ & $x$ & $x$ & $x$ & $x$ & $x$ & $x$ & $x$ & & $x$ & $x$
\end{tabular}

$\mathrm{X}=\mathrm{X}: \mathrm{x}$

\begin{tabular}{l|l|l|l|l|l|l|l|l|l}
$x$ & $x$ & $x$ & $x$ & $x$ & $x$ & $x$
\end{tabular}

$\mathrm{X} \quad \mathrm{X}$

$\mathrm{x} / \mathrm{x}$

$\mathrm{X}$

$x \int_{x}{ }^{x} d x$

4 LEFT LATERAL EDGE

a, Concave

b. Notched

c. Straight

d. Convex

e. Ground

f. Ventrally Flaked

g. Dorsally Bevelled

\begin{tabular}{l|l|l|l|l|l|l|l}
$X$ & $?$ & $X$ & $X$ \\
$X$ & $x$ & &
\end{tabular}

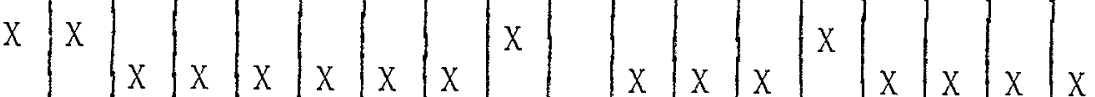
$x$

5 BURIN FACET

a. Oblique

b. Vertical

c. Acute

d. Dorsally Flaked

e. Ventrally Flaked

6 GRINDING

a. Ventral

b. Dorsa1 


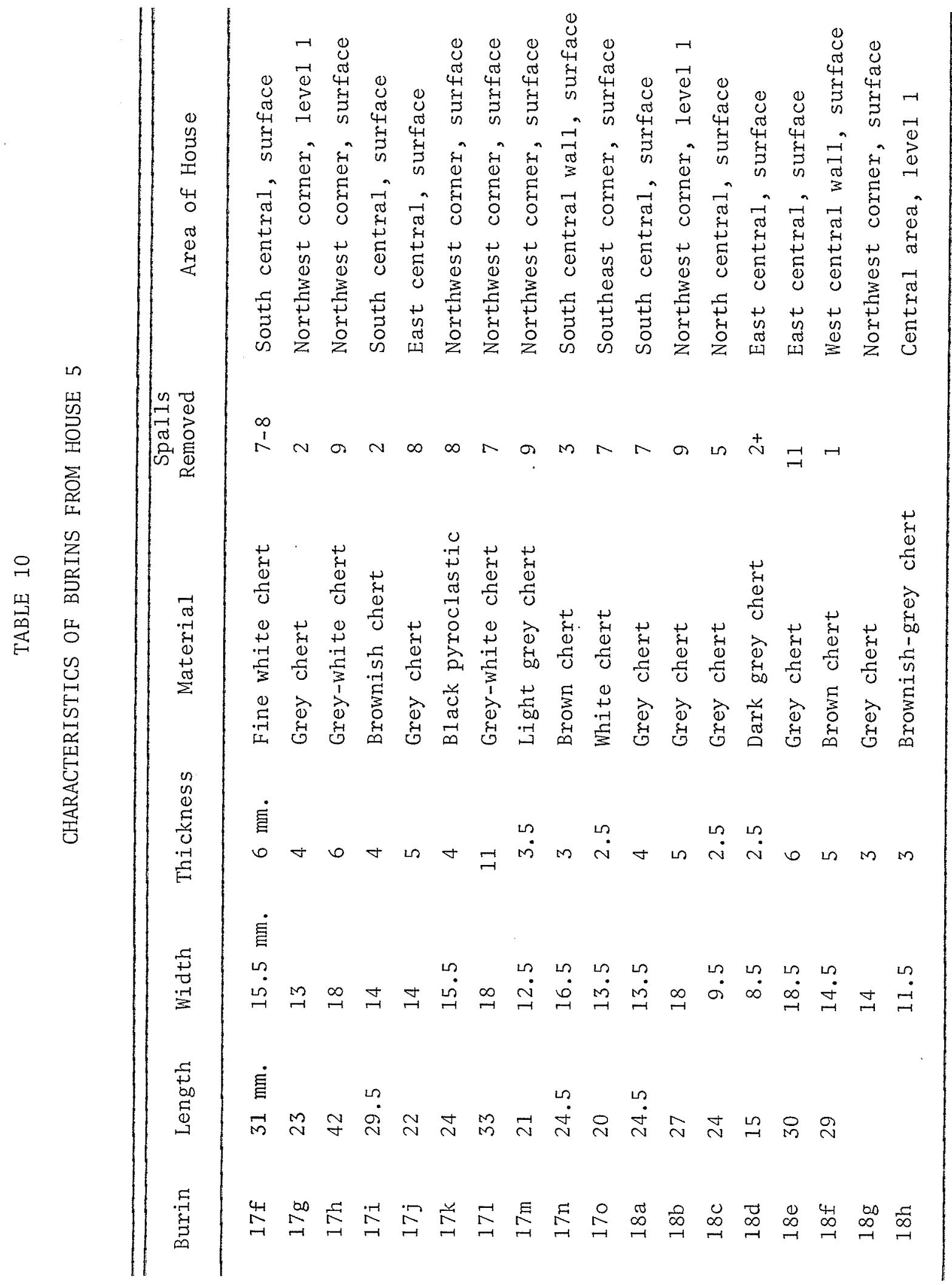


bevelled on its distal platform but has not been ground. One short spal1 has been struck off. Two burin bases were discovered (Fig. 18,g,h) as we11. One of these (Fig. 18,h) is unusually narrow. On the whole, however, these eighteen burins form the most standardized large sample from any of the houses.

Burin Spa11s

Burin spalls were common inside House 5, reflecting the numerous burins used by the occupants. Many spalls, fifteen in a11, were clustered on the surface of the northwestern corner of the dwelling. Ten of these are secondary spalls, three of which seem to have been used as spall tools. Only two of the primary spalls are distally utilized.

Several burin spalls were scattered to the north, south, and east of the "hearth". To the north, five wide spalls were discovered. Four of these are secondary spalls, two of which are tools. The single primary spall is broken. Three feet east of the hearth, another four spalls were found. Both of the secondary spalls are spall tools, as is one of the primary spalls. Four spalls were recovered two feet south of the hearth. One primary and one secondary spall have been used as tools. Both of the primary spalls retain a portion of the burin concavity on their distal edges. One other spall was associated with the hearth. It is broken but one edge has been unifacially utilized. In total, fourteen burin spalls were recovered from the east central portion of House 5 .

In the excavation of level 1, a large number of random flakes were collected as we11 as eleven burin spalls. The exact location of 


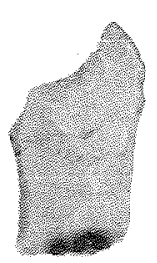

a

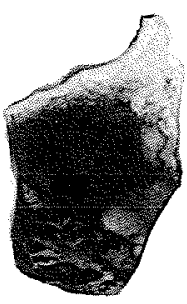

e

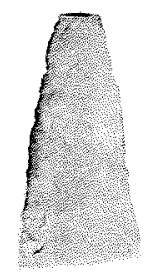

i
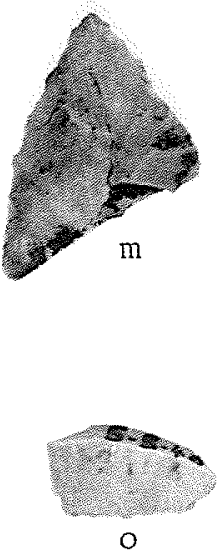

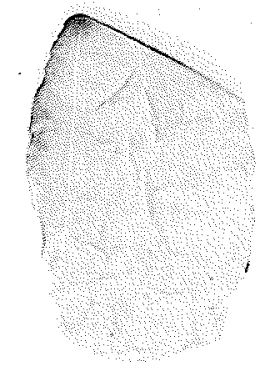

n.

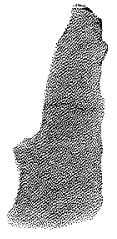

c

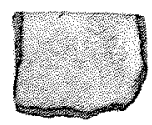

g
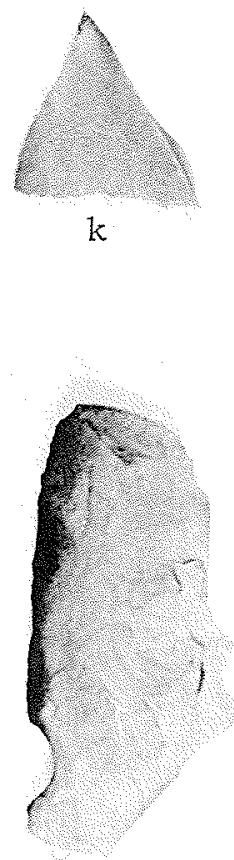

$\mathrm{p}$

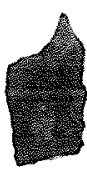

$\mathrm{d}$

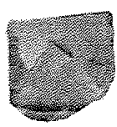

$\mathrm{h}$
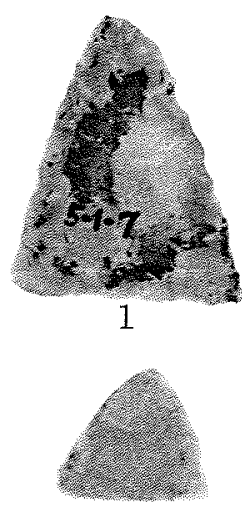

q

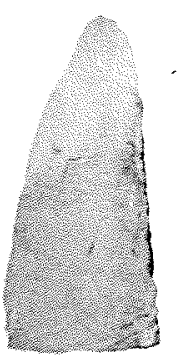

$r$

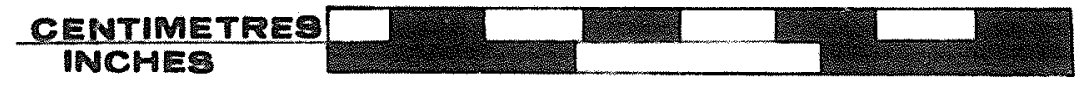

Fig. 18. Seahorse Gully site tools. House 5: a-h, burins; $i$, end blade tip; $j-m$, harpoon blades; $o-n$, side blades; $p-r$, knives. 
some of these spalls was not recorded. Nine of these are secondary spalls and two are primary. Five of the secondary spalls and both of the primary spalls have been utilized as spall tools.

The burin spalls are made from the same lithic materials as the burins and are clearly derived from them. It is no accident that the burin spalls are found in the same area of the dwelling as the burins. Burin spall tools are numerous. The straight or slanting unifacial working edges of these spalls may, however, be the result of use rather than intentional flaking.

\section{End Blades}

House 5 provides overwhelming evidence of a maritime economic orientation. However, the presence of at least one broken end blade suggests that some land hunting was carried on or that these hunting weapons were being stored. This end blade fragment (Fig. 18,i) is very similar in shape and flaking style to that of narrow, side-notched Dorset points such as were found in the Dorset settlement at Seahorse Gully. The material is a grey-brown chert which is bifacially flaked. This piece was found in the centre of the north side of the dwelling.

\section{Harpoon Blades}

Triangular end blades designed for inset into antler or ivory toggle heads were relatively common finds in House 5. Two whole and two fragmentary specimens were recovered. The finest example (Fig. 18,j) was found in two pieces. The tip was located a few inches outside the southeastern corner of the house, while the basal half was found a few inches inside the comer. The two pieces were about two and one half 
feet apart. The mended point is $23 \mathrm{~mm}$. wide across the base, $34 \mathrm{~mm}$. 1 ong from the tip to the centre of the basal concavity, and $2.5 \mathrm{~mm}$. thick. One surface of this delicate specimen has been completely flaked while the other is marginally retouched only. The material is a glassy grey chert. The basal corner of another triangular harpoon blade (Fig. 18, $\mathrm{k}$ ) is very similar to "18j". The material is a pink chert, regularly pressure flaked on both surfaces. Like "18j", the base is concave and unground. The thickness is $3 \mathrm{~mm}$. This fragment was discovered four feet south and five feet west of the southwestern corner of the house and is not shown on Map 13.

The other two triangular end blades are very similar to one another but are different from the two described above. One (Fig. 18,1) is complete and was found on the eastern side of the dwelling, associated with a concentration of seal bones. It was found two inches below the surface. This point of grey chert has a straight base, and is worked completely over one surface. Flake scars are wider and more irregular than those of the blades shown in Fig. 18,j,k. The opposite surface retains the white cortex patination and has only one edge retouched. Length is $29.5 \mathrm{~mm}$., width $24 \mathrm{~mm}$, and thickness $3 \mathrm{~mm}$. Another specimen (Fig. 18, m) is the tip of a harpoon blade of the same material as "181". It was also found in the concentration of seal bones, but nearer the central hearth. Like "181", it retains a white cortex over much of one surface while the other has been completely flaked. The thickness is $4 \mathrm{~mm}$.

The similarity of materials, style, workmanship and the spatial proximity of these two specimens strongly suggests that they were made by the same individual. The more delicate concave based harpoon blades 
were evidently made by someone else whose locus of activities was in the southern portion of the dwelling.

\section{$\underline{\text { Side Blades }}$}

The certain identification of side blades among the artifacts recovered from House 5 is difficult. However, two specimens are probably side blades. One of these (Fig. 18,n) was found three feet south of the southeast corner of the dwelling. It is irregularly flaked on a slightly twisted flake of white chert. One surface is completely knapped, while the other has been mainly edge retouched. Although one end is snapped off, the original shape was likely rectanguloid. The shape is similar to that of a side blade from Twin Lakes (Nash 1969:Fig. 22,6). The width is $24 \mathrm{~mm}$. and the thickness is $4 \mathrm{~mm}$.

Another possible side blade fragment (Fig. 18,c) was found inside Feature 5 near the centre of the east side. It appears to be the end of rectangular side blade like the above mentioned Twin Lakes specimen or that illustrated in this thesis (Fig. 5,a). Made of grey chert, it is bifacially flaked and unground. The width is $18 \mathrm{~mm}$, the thickness 3.5 $\mathrm{mm}$.

\section{$\underline{\text { Knives }}$}

Knives were rare in this dwelling, but fragments of three were found. One notched $\mathrm{knife}$ (Fig. 18,p) was discovered outside the stone alignment, behind a boulder to the northeast. Made from yellowish chert, it has been bifacially flaked. Because of its fragmentary condition, it is not possible to ascertain if it is asymmetrical or not. The single remaining side notch and that portion of the base still extant are margin- 
aliy ground. The base was originally convex. The greatest width at present is $23 \mathrm{~mm}$. and the thickness is $6 \mathrm{~mm}$.

This knife (Fig. 18,p) is similar to other knives previously collected from Seahorse Gully and illustrated by Nash (1969:101). Nash has noted that similar knives have been recovered by Meldgaard from the late Pre-Dorset of the Iglulik region (Meldgaard 1962:94).

The tip of an asymmetrical artifact (Fig. 18,q) probably a wide sidenotched knife, was found inside the house. of glassy grey chert, the edges are bifacially flaked and slightly convex. One edge is heavily ground while the other is sharp and jagged. The thickness is $3.5 \mathrm{~mm}$.

Another knife fragment (Fig. 18,r) was found inside the dwelling. It is the distal half of a narrow asymmetrical knife, probably of the stemmed variety (Fig. 5,b). The convex edge is dulled or ground while the other (slightly concave ?) is sharp. Of whitish chert, this specimen is bifacially flaked, $16 \mathrm{~mm}$. wide and $4.5 \mathrm{~mm}$. thick.

A fourth artifact, (Fig. 19,a) is difficult to identify but may be part of a large bifacially flaked knife. It is equally possible that it is a fragment of a large end blade. Both surfaces are completely knapped using a technique that has removed long wide flakes. The greatest width is $55 \mathrm{~mm}$, while the thickness is $5.5 . \mathrm{mm}$. Made of whitish chert, this specimen was found nine feet south and nine feet east of the southeastern corner of the dwelling.

\section{$\underline{\text { Scrapers }}$}

These tools formed a significant portion of the artifacts from House 5. One asymmetrical scraper (Fig. 19,b) was found in the southwestern quadrant of the dwelling. The lower portion of the right lateral 


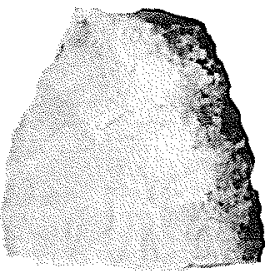

a

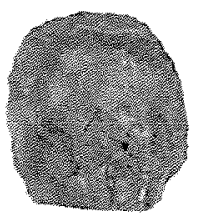

e

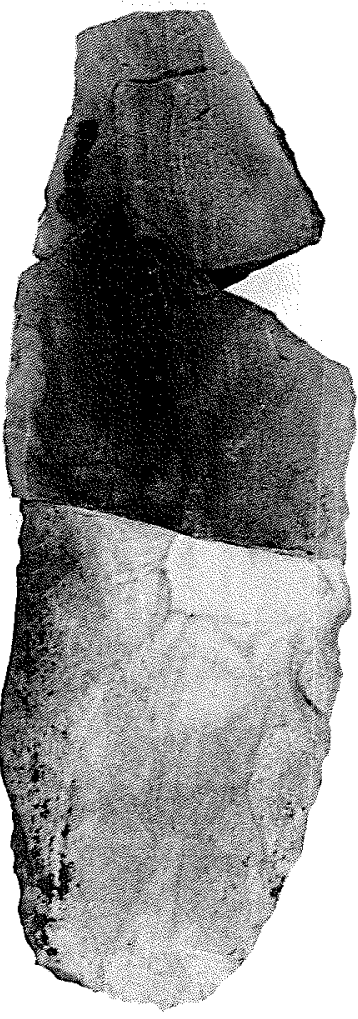

h
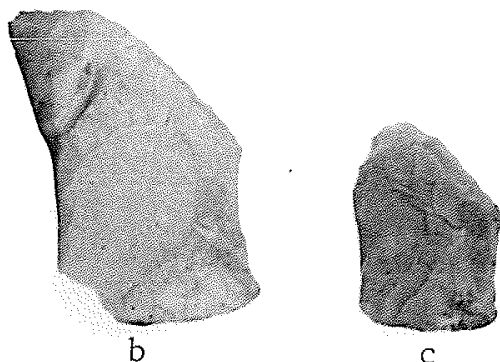

C

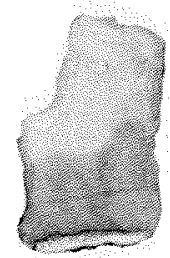

f

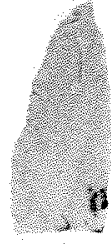

j

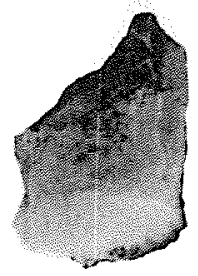

12

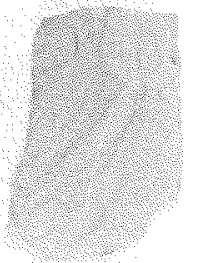

g

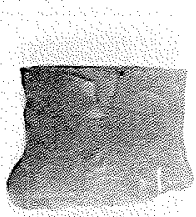

k

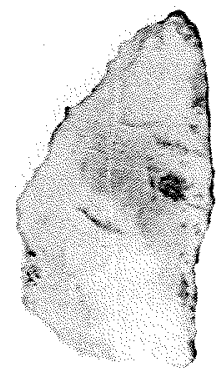

0
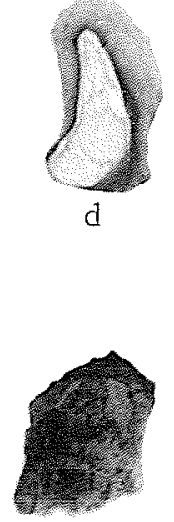

i

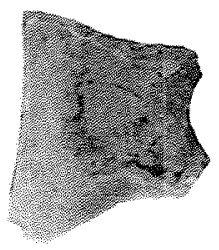

1

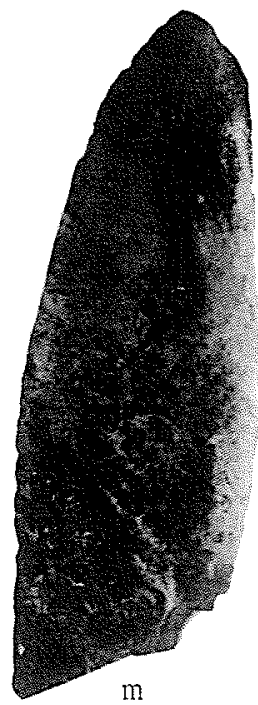

\section{CENTIMETRES} INCHES

Fig. 19. Seahorse Gu11y site tools. House 5: a, knife fragment (?); b-e, scrapers. House 6: f, burin; g, side blade fragment; $h$, side scraper. House $7: \mathrm{j}-\mathrm{p}$. 
edge is concave and ground. Like the right edge, the left margin is dorsally bevelled, but the lower (proximal) half is ventrally thinned and ground as well. The distal end of the left margin flares laterally. The oblique scraping edge is dorsally bevelled. It is slightly convex and has been crushed and dulled through usage. The material is a whitish chert. Dimensions are $34.5,20$, and $7 \mathrm{~mm}$.

An asymmetrical scraper (Fig. 19,c) of brownish chert was found near the centre of the dwelling, one and a half feet south of the hearth. It differs from the scraper described above in that it is much smaller and the convex base is both dorsally flaked and ventrally bevelled. The right margin is subconcave and the left slightly concave. The oblique scraping edge is straight and the distal tip is rounded. Both lateral edges and a few mm. of adjacent base have been ground. Dimensions are $22,15.5$, and $4.5 \mathrm{~mm}$.

A very small offset scraper (Fig. 19,d) was found two inches below the surface, about a foot north of the hearth. Both lateral edges are concave, dorsally bevelled and ground. The convex base is ventrally thinned and ground. The oblique scraping edge is convex and has been dorsally flaked. The most unusual attribute of this scraper is that two burin spalls have been removed from the distal tip of the left margin. These are very small, short spalls. Their material is a greyish chert and the dimensions are 21,11 , and $45 \mathrm{~mm}$.

A broken endscraper (Fig. 19,e) was located at a depth of one and a half inches below the surface in the mass of seal bones to the east of the hearth. It is flaked from a curved flake of grey chert. A11 edges are dorsally flaked or bevelled and only the distal end is ventrally 
flaked, to form a sharp cutting edge. The proximal end of this scraper has been borken off through the side notches which were once present. That portion of the notches left is heavily ground.

\section{Unifacia1 Blades and Microblades}

No certain blades or microblades were recovered from this dwel1ing. One possible blade was found on the sod a foot to the east of the hearth. Of a banded grey chert-like material, its margins show use wear (crushing). Dimensions are 60, 16, and $7 \mathrm{~mm}$.

\section{Flake Tools}

Two tools made on flakes of fine-grained white chert were found. One, which may be the midsection of a blade, is dorsally flaked along one edge. The width is $14 \mathrm{~mm}$, and the length $15 \mathrm{~mm}$. The other tool is made on a large flake, $42 \mathrm{~mm}$. 1ong, $32 \mathrm{~mm}$. wide, and $5.5 \mathrm{~mm}$. thick. It is dorsally flaked along one edge, and at one point a notch $3 \mathrm{~mm}$. deep is present.

Large Tools

Large tools were not found in or near House 5.

Other Tools

\section{Worked Organic}

Two objects of worked ivory were associated with House 5 . Both are fragmentary harpoon toggle heads. One (Fig. 20,b) is represented by that portion along one side of the line hole and part of the open shaft socket. The shallow foreshaft socket is longitudinally striated and 
Fig. 20. Seahorse Gul1y site tools. House 5: a-b, ivory toggle harpoon heads; c, ivory splinter; d, seal femur; e, antler fragment; $f$, incised bone.
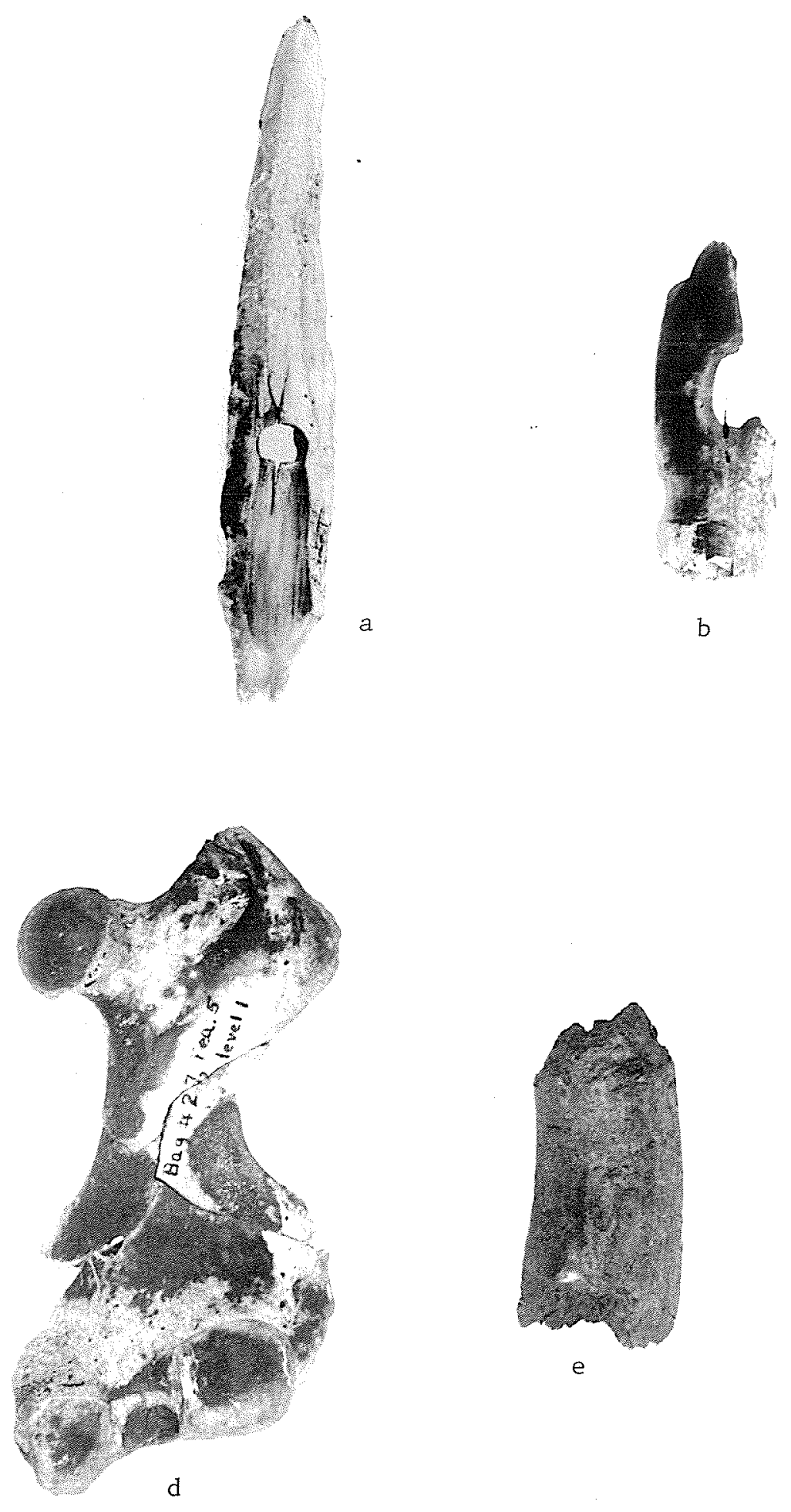

b

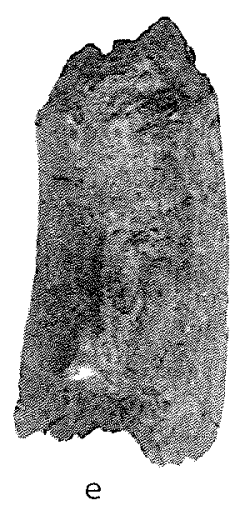

c

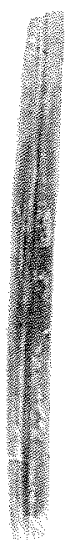

f

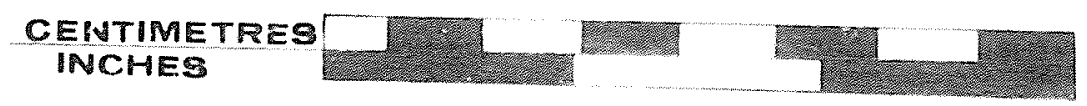


evidently has been gouged out with burins. It is $7.5 \mathrm{~mm}$. wide. The harpoon head is ringed about half way down the shaft socket. This ring (lashing groove) is wide $(7 \mathrm{~mm}$.$) and shallow (1.5 \mathrm{~mm}$. deep). The line hole is oriented at right angles to the shaft socket, which it is immediately above. The line hole is scraped smooth on the inside and no trace of gouging is evident. It is $8.5 \mathrm{~mm}$. long. The greatest thickness of this fragment is $12.5 \mathrm{~mm}$. As the single lateral edge still intact is almost sharp, this means that the original cross-section was biconvex or diamond shaped. The proximal spur of this fragment has been exposed to weathering and has disintegrated. This toggle head (Fig. 20,b) was found on the surface, 17 feet east of the east wall of the house, in an area of scattered seal bones.

Another badly weathered toggle head (Fig. 17,a) was discovered 16 feet west of the northwestern corner of the dwelling. It was lying on a two and one half inch thick clump of tundra sod. The surface that faced upwards was almost completely disintegrated, except for the deeply gouged line hole and the gouged bifurcation of the proximal spur (both of which are in good condition). The line hole is longitudinally gouged from this dorsal surface (weathered face), to a depth of $6 \mathrm{~mm}$. and a length (on the dorsal surface) of $20 \mathrm{~mm}$. The longitudinal striations inside the line hole suggest that it has been gouged by burins.

The ventral surface of the harpoon head is well preserved. A sharp keel runs up the centre of the blade and the original cross-section must have been diamond shaped. The line hole opening on this side is oval, being $7 \mathrm{~mm}$. across and $5 \mathrm{~mm}$. wide. The open shaft socket is shallow and longitudinally striated. It is $24 \mathrm{~mm}$. 1ong, $3.5 \mathrm{~mm}$. deep, with a 
maximum width of $10 \mathrm{~mm}$. A grooved ring encircles the point about half way down the shaft socket. The groove is $8 \mathrm{~mm}$. wide and $1 \mathrm{~mm}$. deep. A proximal spur flares outwards from the shaft socket. It is $16 \mathrm{~mm}$. 1ong and has a small bifurcation, now largely disintegrated at the end. The length of this point distally above the line hole is $55 \mathrm{~mm}$., the length below is $33 \mathrm{~mm}$. The total length is $93 \mathrm{~mm}$.

The preserved surfaces of both harpoon heads are highly polished and carefully shaped. Both indicate great attention to details and a concern for tools that were both functionally efficient and aesthetically pleasing.

Four other pieces of humanly modified organic materials were recovered. One (Fig. 20,c) is a sliver of dark brown ivory, gouged out of a larger piece of ivory. It was found on the surface in the southeastern corner of the dwelling, next to the base of a harpoon blade (Fig. 18,j). A few longitudinal striations are visible although the piece appears to have been polished. Dimensions are 40, 6 , and $2.5 \mathrm{~mm}$.

The other three pieces were found in the cluster of faunal remains to the east of the hearth, during the excavation of level 1 . One is simply a portion of antler (Fig. 20,e) which has been broken at one end and ringed (chopped) and snapped at the other. This chunk of antler is $45 \mathrm{~mm}$. long and $21 \mathrm{~mm}$. wide. Another fragment, a hollow bird bone, has been ringed and snapped at both ends. It is $23 \mathrm{~mm}$. 1ong and $9 \mathrm{~mm}$. in diameter.

A very interesting piece of bone (Fig. 20,f) has been longitudinally grooved along the outer surface. Portions of four parallel grooves are present, averaging two $\mathrm{mm}$. apart. The bone appears to be from a 
small mammal or bird and has been split in half through two of the grooves. The incising of these parallel grooves may have been the first step of a procedure for the removal of splinters of bone for manufacture into needles. This bone is $55 \mathrm{~mm}$. long and $4.5 \mathrm{~mm}$. in diameter. A1l of the bones are a dark brown colour.

\section{DEBITAGE}

Flakes were plentiful inside the dwelling and outside, particularly to the south. Twelve feet south of the house a concentration of 62 grey banded cherty sedimentary flakes was recorded and collected. These flakes are relatively large and are believed to be the debris from the working of a large tool. Another 62 grey banded flakes were scattered in this southern area, suggesting that the manufacturermoved a few feet during his work or that the flakes flew widely. Many of these flakes have ground striking platforms, suggesting that a large tool was reworked.

Inside the stone alignment, a more varied assortment of lithic materials is represented (see Table 11), although the grey banded cherty flakes are very numerous here also. Only white chert retouch flakes are more numerous. Grey and green large tool flakes tended to be concentrated in the hearth area.

The debitage from House 5 has been separated on the basis of differing lithic materials (Table 11). The numbers of flakes of each kind of material in each area have been counted and those flakes with ground striking platforms noted. Four colours of pyroclastic material were found; (1) red, (2) brown, (3) green, and (4) red-black. Two kinds of cherty sediments, green and grey, were present as we11 as two flakes of green quartzite-like material. 
LITHIC DEBRIS FROM HOUSE 5

\begin{tabular}{|c|c|c|c|c|}
\hline & Area & Material & Total & $\begin{array}{l}\text { Ground } \\
\text { Platform }\end{array}$ \\
\hline 1 & $\begin{array}{l}\text { Surface inside } \\
\text { house }\end{array}$ & $\begin{array}{l}\text { Whitish chert, small } \\
\text { Whitish chert, large } \\
\text { Whitish chert, cores } \\
\text { White quartzite piece } \\
\text { Red pyroclastic } \\
\text { Brown pyroclastic } \\
\text { Banded grey cherty } \\
\text { sedimentary } \\
\text { Green cherty sedimentary } \\
\text { Green quartzite-like } \\
\text { Green pyroclastic }\end{array}$ & $\begin{array}{r}83 \\
1 \\
3 \\
1 \\
10 \\
4 \\
\\
56 \\
34 \\
2 \\
4\end{array}$ & $\begin{array}{r}- \\
- \\
- \\
- \\
4 \\
3 \\
18 \\
4 \\
- \\
2\end{array}$ \\
\hline 2 & $\begin{array}{l}\text { Level one excavated } \\
\text { flakes }\end{array}$ & $\begin{array}{l}\text { Whitish chert flakes } \\
\text { Large whitish chert } \\
\text { Red pyroclastic } \\
\text { Brown pyroclastic } \\
\text { Grey banded cherty } \\
\text { sedimentary } \\
\text { White quartzite }\end{array}$ & $\begin{array}{r}112 \\
8 \\
11 \\
2 \\
70 \\
1\end{array}$ & $\begin{array}{l}- \\
- \\
\overline{1} \\
7 \\
-\end{array}$ \\
\hline 3 & $\begin{array}{l}\text { Surface outside } \\
\text { to southwest }\end{array}$ & $\begin{array}{l}\text { Grey banded cherty } \\
\text { sedimentary }\end{array}$ & 31 & 3 \\
\hline 4 & $\begin{array}{l}\text { Surface outside to } \\
\text { south (Map 13) }\end{array}$ & $\begin{array}{l}\text { Grey banded cherty } \\
\text { sedimentary } \\
\text { Brown pyroclastic }\end{array}$ & $\begin{array}{r}62 \\
7\end{array}$ & $\begin{array}{r}14 \\
2\end{array}$ \\
\hline 5 & $\begin{array}{l}\text { Surface outside } \\
\text { to southeast }\end{array}$ & $\begin{array}{l}\text { Grey banded cherty } \\
\text { sedimentary } \\
\text { Red pyroclastic } \\
\text { Quartzite pebble }\end{array}$ & $\begin{array}{r}31 \\
1 \\
1\end{array}$ & $\begin{array}{r}12 \\
- \\
-\end{array}$ \\
\hline 6 & $\begin{array}{l}\text { Surface outside } \\
\text { to northwest }\end{array}$ & $\begin{array}{l}\text { Frost shattered chert } \\
\text { nodules } \\
\text { Whitish chert flakes }\end{array}$ & $\begin{array}{l}2 \\
6\end{array}$ & - \\
\hline 7 & $\begin{array}{l}\text { Surface outside } \\
\text { to northeast }\end{array}$ & $\begin{array}{l}\text { Red-black pyroclastic } \\
\text { Red pyroclastic }\end{array}$ & $\begin{array}{l}4 \\
1\end{array}$ & $\begin{array}{l}1 \\
-\end{array}$ \\
\hline 8 & $\begin{array}{l}\text { Scattered flakes } \\
\text { random1y collected } \\
\text { from the surface }\end{array}$ & $\begin{array}{l}\text { Large whitish chert } \\
\text { Red-black pyroclastic } \\
\text { Red pyroclastic }\end{array}$ & $\begin{array}{r}2 \\
9 \\
8 \\
567\end{array}$ & $\begin{array}{l}- \\
4 \\
2\end{array}$ \\
\hline
\end{tabular}


A11 of these are large tool materials and all, with the exception of the green quartzite flakes, include some flakes with ground platforms. These platforms provide evidence that many of these flakes are the products of the reshaping of large tools. On the basis of lithic materials, therefore, it is clear that at least six large tools were once present and reknapped in House 5.

The majority of the identifiable faunal remains are of seal, providing evidence that these animals formed the food staple. These bones all appear to be of the little ringed seal (Pusa hispida), testifying to its frequent occurence during this period. The only other mammal represented is the bear, probably the polar bear (Thalarctos maritimus). The bones of bears are so rare that it is likely that these animals were not killed nearby, or at least their larger bones were not brought back to camp.

A single piece of antler (Fig. 20,e) provides the only evidence for caribou hunting. Of course, an antler can be picked up anywhere on the tundra and need not indicate the successful slaughter of an animal. In addition, many bird bones were found. Most of these cannot be identified, but the gull (Larus sp.) and the black guillemot (Cepphus grylle) have been identified (P.W. Parmalee, Illinois State Museum, personal communication 1970).

There is a striking difference in the frequency of occurrence of certain long bones in different areas of this dwelling. Eleven out of fourteen femurs were found within the dwelling, while eight out of nine radii were found outside of the house to the east. If sampling error can be discounted, it appears that front limbs were removed from the seals as 
160

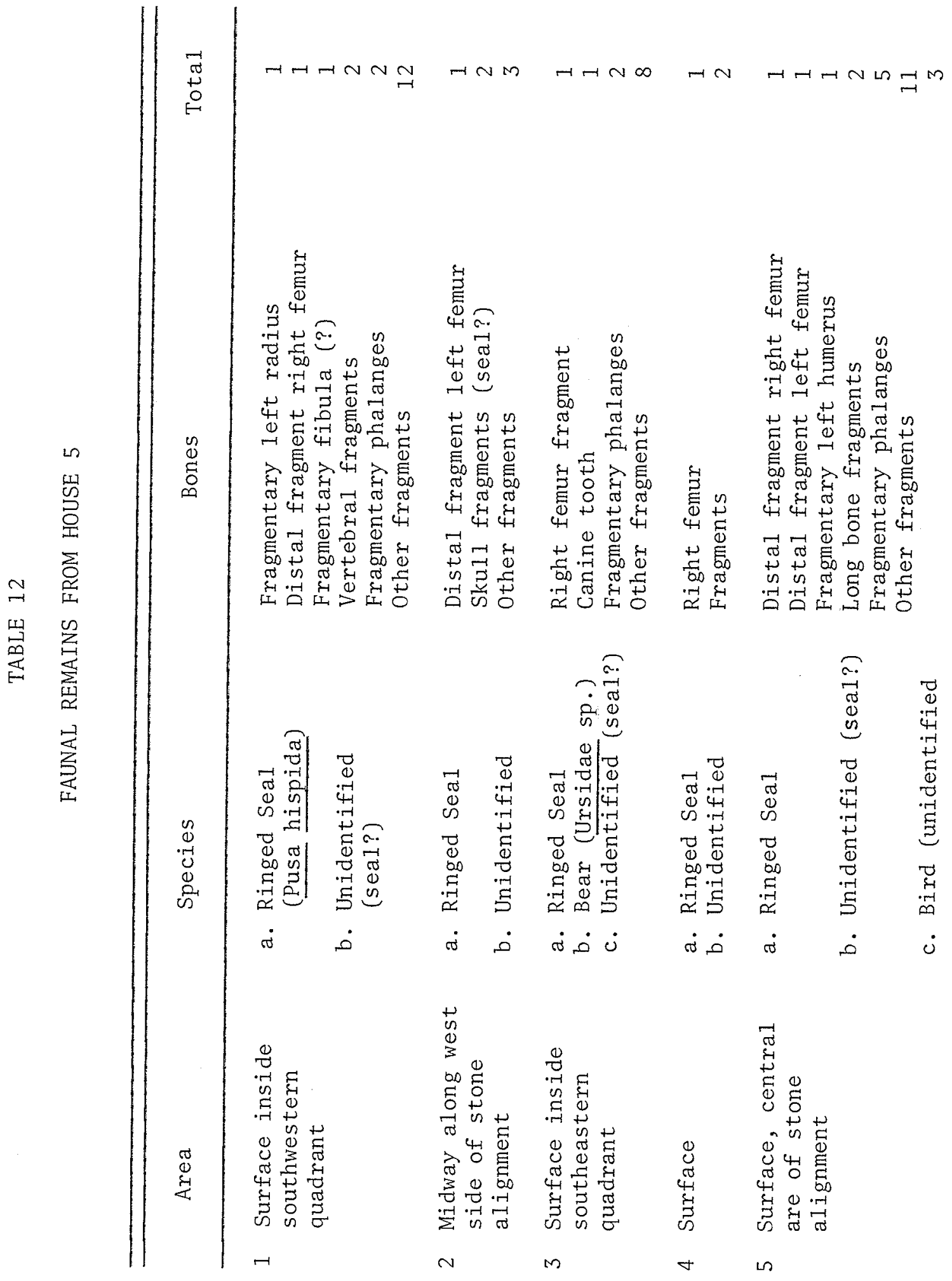


161

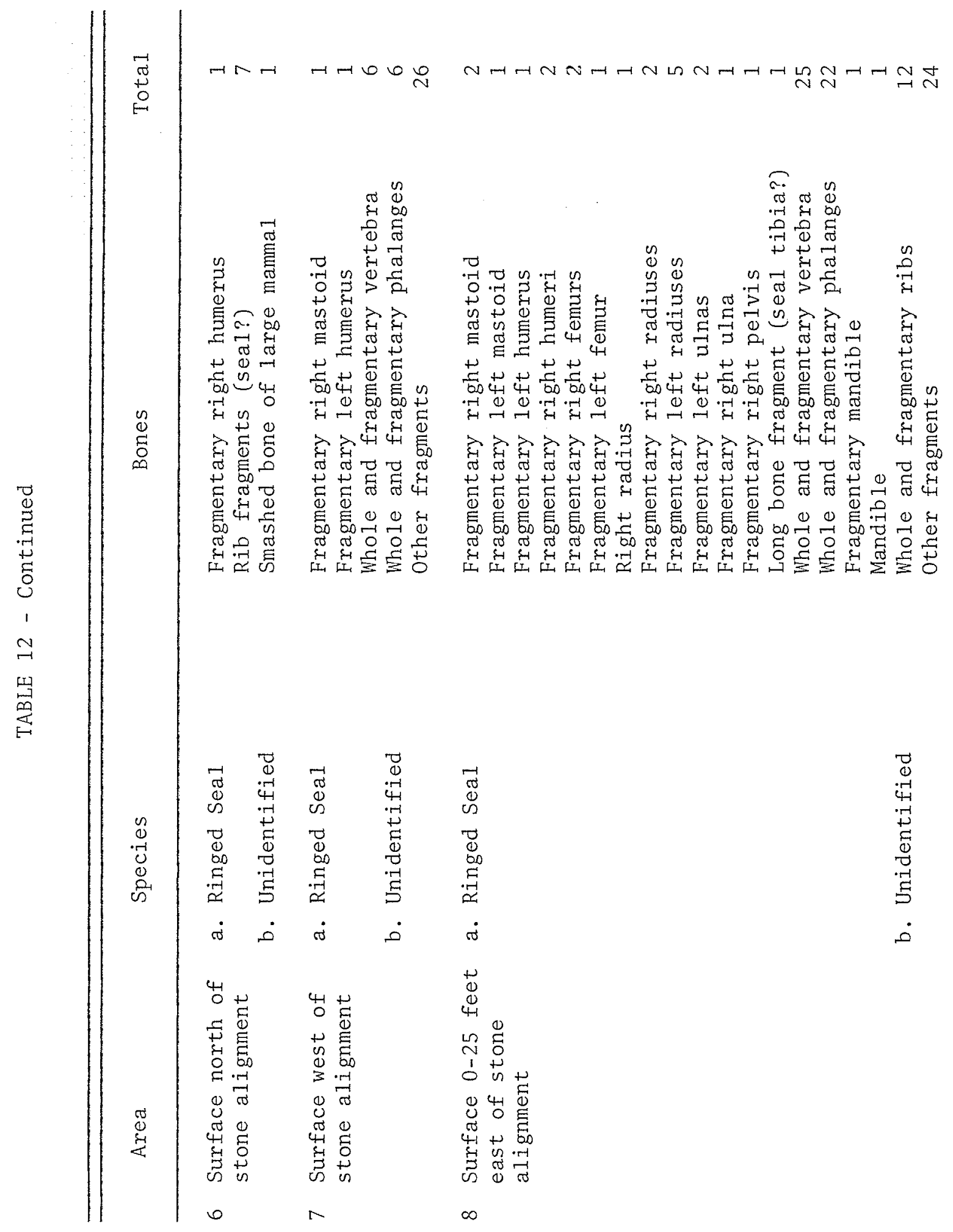




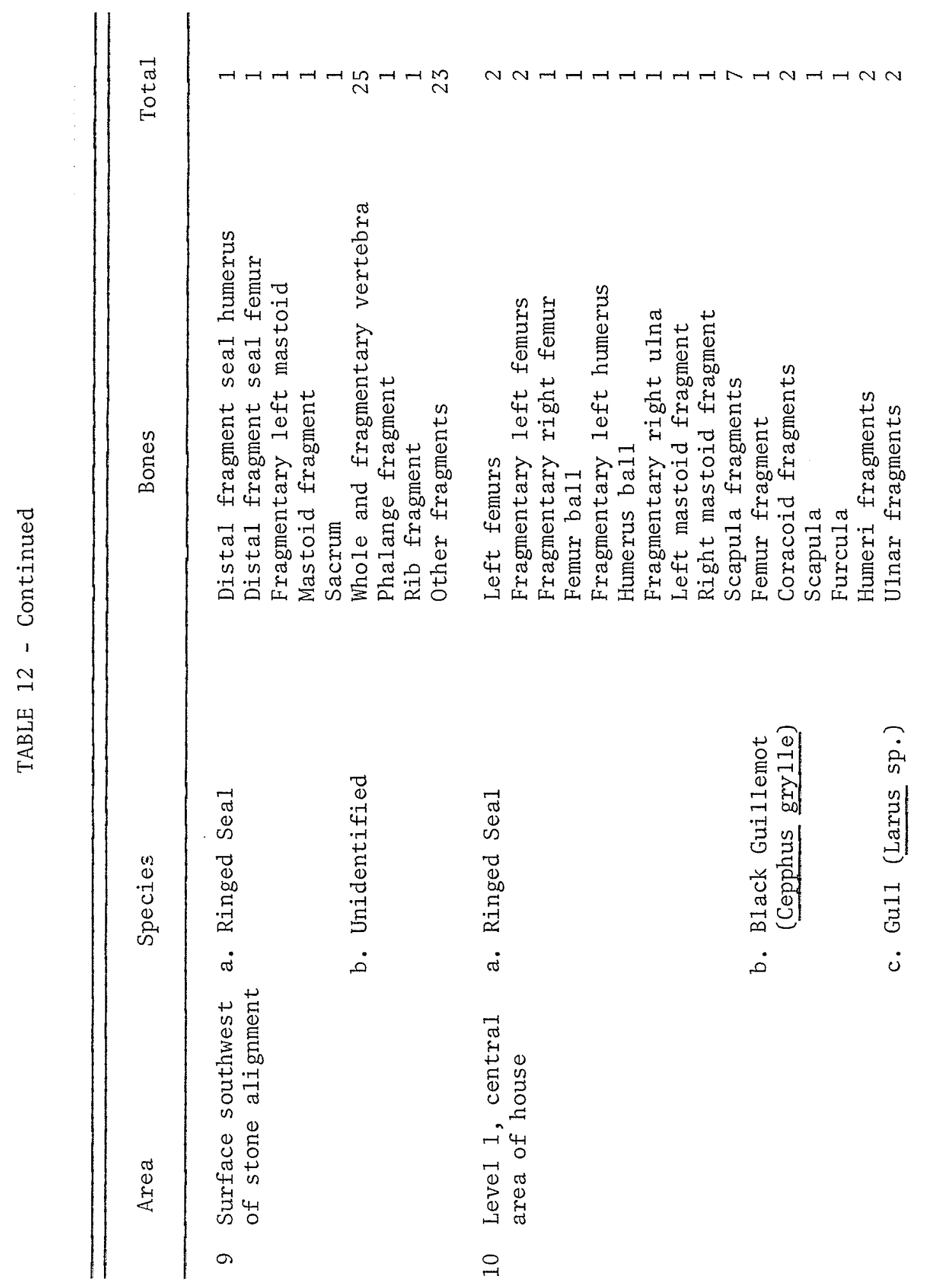




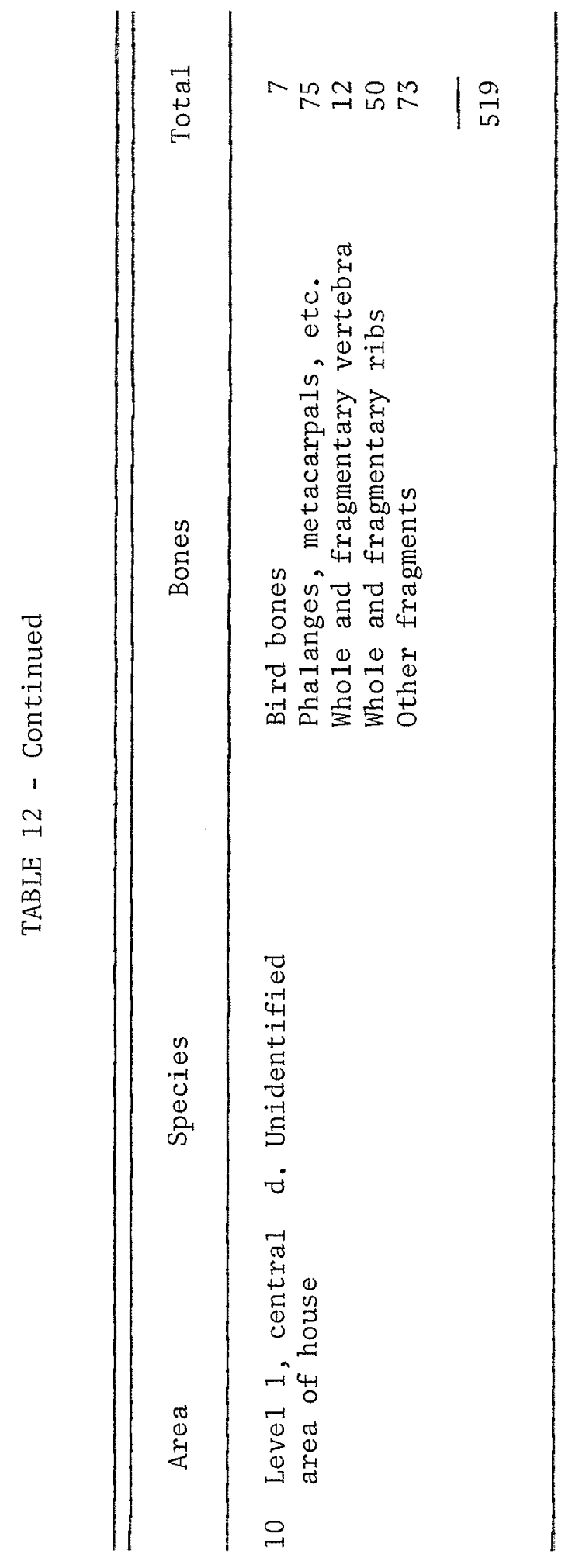


they 1 ay on the small gravel patch east of the habitation. As this is the seaward side, it is likely that watercraft were drawn up here and the products of the hunt laid out for butchering. Humerus and skull fragments were about equally distributed inside and out of the house.

The distribution of faunal remains around the dwelling indicates that relatively few activities took place to the north and west of the habitation. This distribution is echoed by the occurrence of lithic debris mainly to the south and southeast.

The large numbers of femurs, fourteen in all, found in association are useful for the estimation of numbers of individual seals present. Seven left femurs are present, indicating that at least this number of seals were killed by the hunters of the dwelling. This number is consistent with the relatively long span of occupation indicated by the many mislaid and discarded tools.

\section{SUMMARY}

The dwelling remains of House 5 consisted of an irregular alignment of stones, probably once placed around a tent which was subrectangular at the base. These grey quartzite stones were relatively small and were absent from the north wall of the alignment. It is probable that guy lines were attached to the top of the tent and tied to the surrounding boulders as the aligned rocks would not hold a tent down in a strong wind.

This dwelling, although small, was one of the richest in terms of artifact yield. In addition, no other house had as many bones preserved, nor as many seals (seven) represented by the faunal remains. The emphasis 
on sealing is clear, reflected not only by the bones of many ringed seals, but also in the presence of four harpoon blades and two ivory toggle heads.

A "hearth" has been tentatively identified in the centre of the dwelling. Composed of three stones, it seems to have been the focus of cooking and eating activities, as evidenced by a mass of bones between it and the eastern wall of the alignment. However, the presence of several pieces of worked organic materials as well as seven burins, three scrapers, a side blade, and two harpoon blades, is evidence that other activities took place here also.

House 5 yielded the most (eighteen) burins of any single dwelling and only end blades were not well represented in the artifacts recovered. The large number of burins testifies to the importance of the manufacture of tools of organic materials, most of which seem to have disintegrated. The discovery of several worked pieces of ivory, antler, and bone in the hearth area provides evidence of the extensive use of organic materials for tools. The offset scrapers and knives testify to the importance of hide working and butchering of animals. The absence of needles in these Pre-Dorset dwellings is puzzling, particularly since they are common finds in other Pre-Dorset sites. In the Iglulik area, Meldgaard found that needles were very common in both the Pre-Dorset and Dorset habitations. This may, of course, be related to the good preservation of organic materials in that region.

This dwelling is the only one at Seahorse Gully that produced Pre-Dorset ivory toggle heads. Two were found, one to the west and the other to the east of the house. Both are characteristically Pre-Dorset 
and are similar to those illustrated by Meldgaard from the Jens Munk (Kapuivik) site (1962:P1. 3; 1960b:P1. 1), and by Taylor (1967:Fig. 11). The absence of large tools from this house is surprising, but is likely a result of their collection by the Chipewyans. The presence of flakes of seven different kinds of large tool lithic material indicates that at least this number of tools were present within House 5 .

The distribution of artifacts within the dwelling appears to be patterned. Two concentrations are evident, one in the southeastern quadrant and the other in the northwestern quadrant of the house (Map 13). In both concentrations, burins and burin spalls are prominent. These two areas may be the major manufacturing places within the dwelling and attest to the stability of human occupation of space within the dwelling. It is possible that the northeastern and southwestern quadrants which are relatively free of artifacts may have been sleeping and sitting areas. It is difficult to estimate the number of persons who lived in this dwelling, but the presence of two different males may be indicated by the two different styles of harpoon blades. It is possible, therefore, that two families were present, and the division of the house into two "sleeping" and two manufacturing areas seems to support this contention. Because of the isolation of this dwelling from all others it is possible to outline the area around it in which butchering, skinning, manufacturing, and perhaps social activities were concentrated. This area of concentration of human activities extends to a distance of twenty-five to thirty feet to the east of the house, and from ten to fifteen feet out from the other three sides. It is characterized by the pressence on the surface of faunal remains, occasional tools and many 
1ithic f1akes.

The presence of many tiny bones of migratory birds very strongly suggests that this house was occupied during the summer months. If so, the use of watercraft would be a necessity, both for leaving the island and for seal hunting. The evidence for extensive outdoor activities also argues for the presence of relatively warm temperatures.

The large faunal sample from House 5 invited radiocarbon dating. A sample of ringed seal ribs, phalanges, metacarpals, etc., were selected from the leve1 1 excavations between the hearth and the eastern side of the dwelling. These bones were submitted to the Department of Chemistry and Chemical Engineering at the University of Saskatchewan for radiometric measurements. The date obtained was $2900 \pm 100$ years B.P. or about 945 years B.C. (S-521, A. Rutherford, personal communication).

HOUSE 6

House 6 is situated near the centre of the site a few yards east of the cobble mantle. In this area the mantle is only a low gravel ridge with a flat surface. This central portion of the cobble mantle is the lowest and was the least occupied during the Pre-Dorset period, for the fewest dwellings and artifacts were found here. This low area may have been available for occupation for the shortest period and thus can be expected to contain only the more recent Pre-Dorset remains.

House 6 is located in a boulder field to the east of the cobble mantle. This field is composed of smaller and more scattered rocks than others on the site ridge. Flat gravel areas large enough to contain dwellings are frequent. 


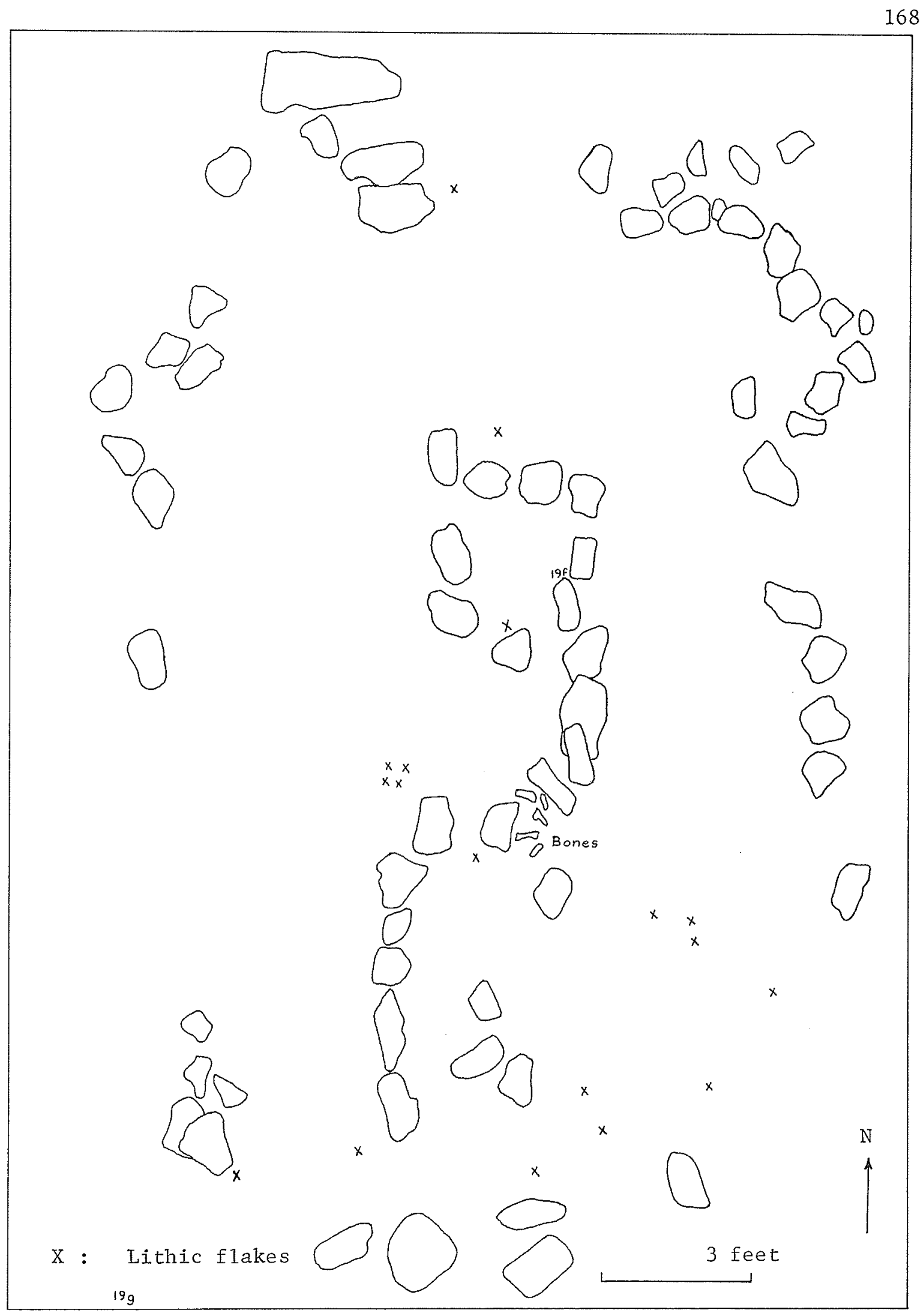

Map 14. Floor plan of House 6 . 
The stone alignment of House 6 remains difficult to interpret confidently. Initially it was thought to represent the remains of two small tent rings connected by a passage way. Some of the larger stones were believed too large to have been used in the dwelling construction. However, with the discovery of other stone alignments with even larger stones and at least one house (7) with a definite midpassage, an alternate interpretation of this feature is more feasible. The stone alignment evidently encircled the base of a large rectangular skin tent, approximately twenty feet long and twelve feet wide. Inside the tent were two rows of longitudinal stones which formed a midpassage in which a possible hearth, consisting of nine stones arranged in a circle, was located.

\section{ARTIFACTS}

Only three tools were associated with the dwelling. One (Fig. 19, f) is a burin, found at a depth of one ince in the hearth. Also found was a fragmentary chert side blade from the surface three feet southwest of the southwestern corner of the stone alignment. A large scraper was discovered four feet to the south of the southwestern comer of the alignment.

Sma11 Tools

Burins

The single burin (Fig. 19,f) is stylistically similar to other burins found at the site. All of the margins are dorsally bevelled and no ventral thinning is present. Both lateral margins are slightly con- 
cave and heavily ground. The base is straight and is unflaked and unground. The distal platform has been prepared through the removal of a transverse spall and seven hinge fractures are present. The burin facet is dorsally thinned. Of whitish chert, the dimensions of this burin are 24, 15, and $4 \mathrm{~mm}$.

\section{Burin Spal1s}

This tool category was not represented at House 6.

End Blades

No end blades were recovered.

Harpoon B1ades

This tool category was not represented.

\section{$\underline{\text { Side }}$ Blades}

A fragmentary side blade (Fig. 19,g) appears to have lain exposed on the gravel surface with the result that the chert is completely patinated to a creamy white colour. This artifact composes about half of a rectangular side blade. It has been manufactured on a thin chert flake by bifacial edge retouch. The dorsal and ventral surfaces of the flake blank are unmodified. This artifact is $17.5 \mathrm{~mm}$. wide and $3.5 \mathrm{~mm}$. thick.

\section{Knives}

Knives were not found in House 6.

\section{Scrapers}

A single scraper (Fig. 19,h) was found in three pieces. It is similar to other scraper knives from the site which have been made from 
large flakes of the material more commonly used for large tools. Perhaps, therefore, these large side scrapers should be classed as large tools. The striking platform of this large flake of grey-green pyroclastic is ground and crushed, indicating either deliberate preparation or its removal from another large tool. The convex edge is roughly dorsally flaked while some bifacial flaking is present on the concave edge. Dimensions are 104,36 , and $12 \mathrm{~mm}$.

Flake Tools

This category of tools was not represented.

Blades and Microblades

These tools were not recovered from House 6 .

Large Tools

The large tool categories were not represented among the House 6 specimens .

Other Tools

Unusual lithic tools or tools of organic materials were not recovered from this house.

\section{DEBITAGE}

Portions of at least two large tools were knapped in and around this dwelling. Twelve flakes of brown pyroclastic were recovered. Four of the larger flakes have ground and dulled striking platforms. These platforms were evidently once part of the edges of a battered large tool which was resharpened in this house. 
Another large tool is represented by four flakes of dark grey cherty sedimentary material. All four flakes have ground platforms, probably derived from the dulled edges of a large tool. One flake of banded light grey sedimentary material was found on the interior surface. This third kind of lithic material suggests the knapping of another large tool in House 6.

Also found on the surface were five small core-like stones. They are all of white and grey chert and are patinated on portions of their surfaces. They are very irregular in shape, and the largest is only 47 mm. long.

\section{FAUNAL REMAINS}

Six badly disintegrated bones were discovered on the surface of this feature, imbedded in an unburned patch of sod. One of these is the proximal end of a left seal scapula. The other five bones, including two phalanges and three bone fragments are unidentifiable.

SUMMARY

The large size of this dwelling suggests that a number of people occupied it, however, the paucity of artifacts indicates only a short stay. One burin, a side blade, and a side scraper were lost and at least two large tools were reworked. At least one seal was captured and consumed by the occupants of the dwelling.

The manufacture of tools and implements took place inside the house, as evidenced by the clustering of flakes there. However, the discovery of the side blade and the side scraper to the immediate southwest of the dwelling indicates that this was an important activity area, 
perhaps for seal butchering.

House 6 was constructed and inhabited by persons of Pre-Dorset Eskimo culture. The culture is closely related to that of other PreDorset occupants of Seahorse Gully. The maritime orientation of the occupants of House 6 is not directly reflected in their tools, but is indicated by the presence of seal bones. The period of habitation was too short to provide the archaeologist with more numerous mislaid and broken tools.

HOUSE 7

House 7 is treated as two separate entities since it appears that two adjacent dwelling alignments are present. This contention is strengthened by the occurrence of flakes and tools in each dwelling outline.

HOUSE 7 NORTH

DWELLING REMAINS

The northern dwelling has the clearest stone alignment of the two houses. This alignment (Map 15) outlines the base of a subrectangular structure. The alignment consists of medium sized (twenty - thirty pound) stones arranged to form an enclosure about fifteen feet long and twelve feet wide. Of particular significance is a double line of stones that form a longitudinal midpassage (Fig. 21,b).

\section{ARTIFACTS}

Al1 of the artifacts from this house were associated with the midpassage. A concentration of lithic flakes was present in the centre of the house, within the midpassage (Map 15). A burin and a knife base were 


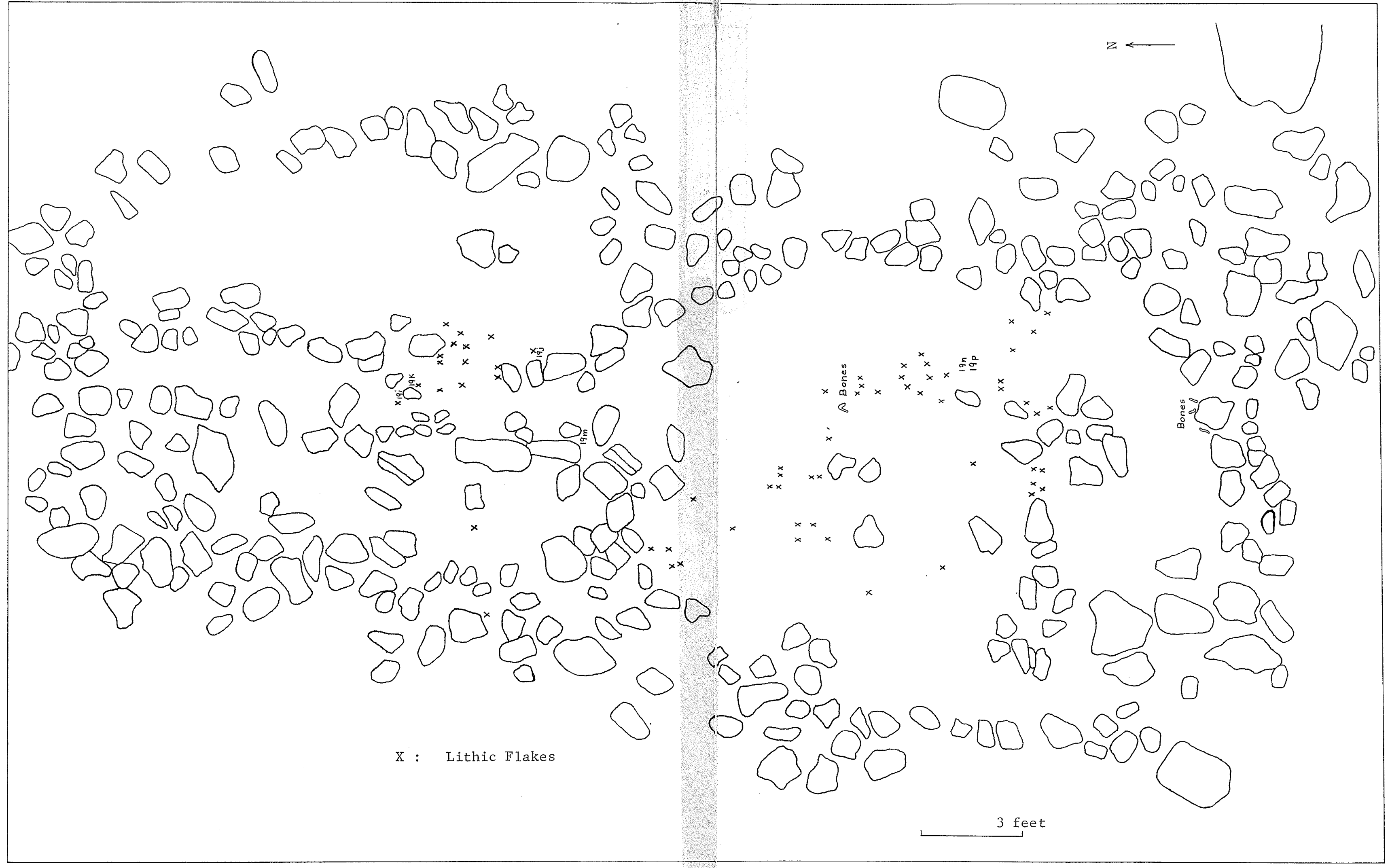




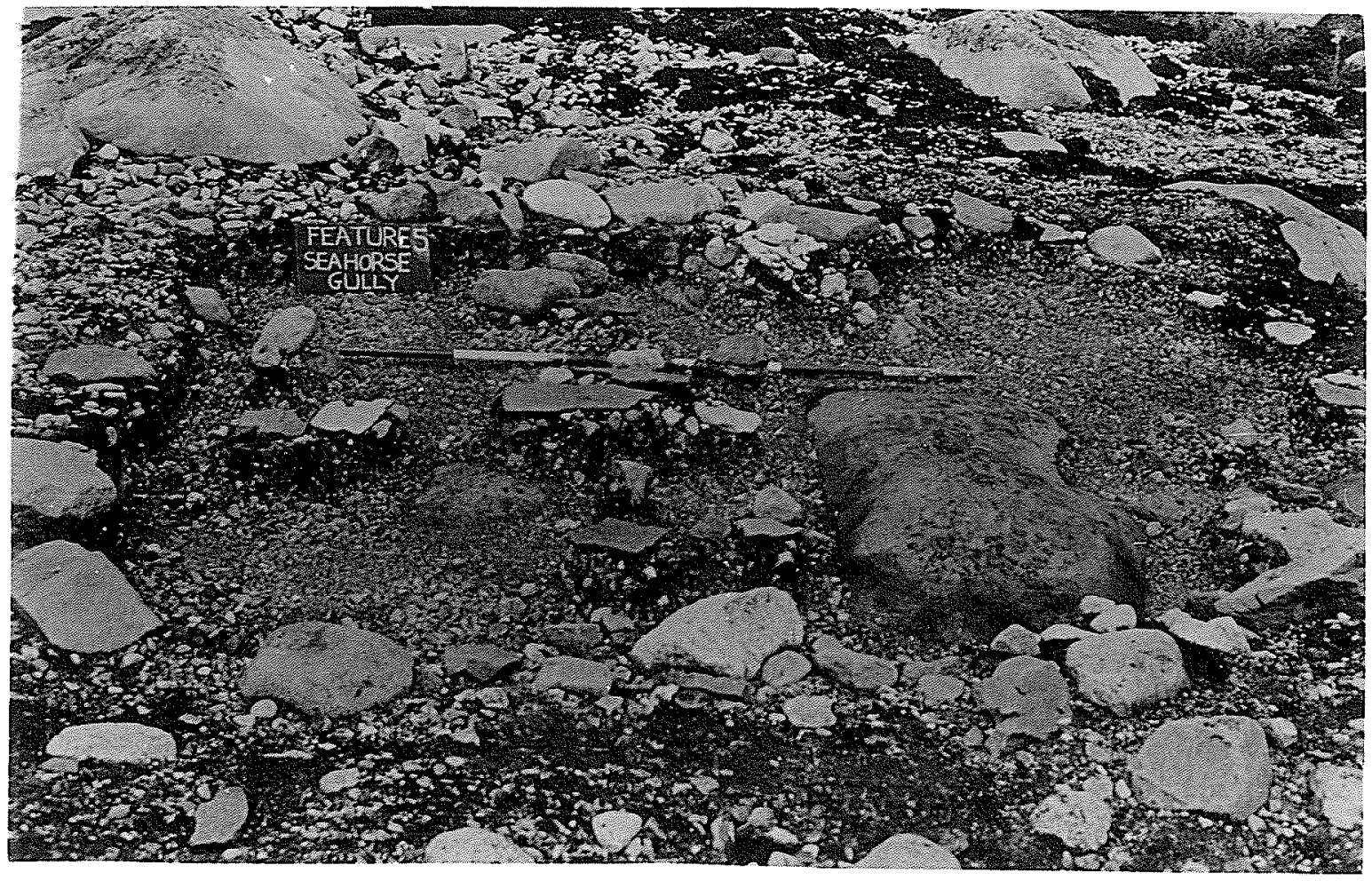

Fig. 21,a. The excavation of House 5, looking west.

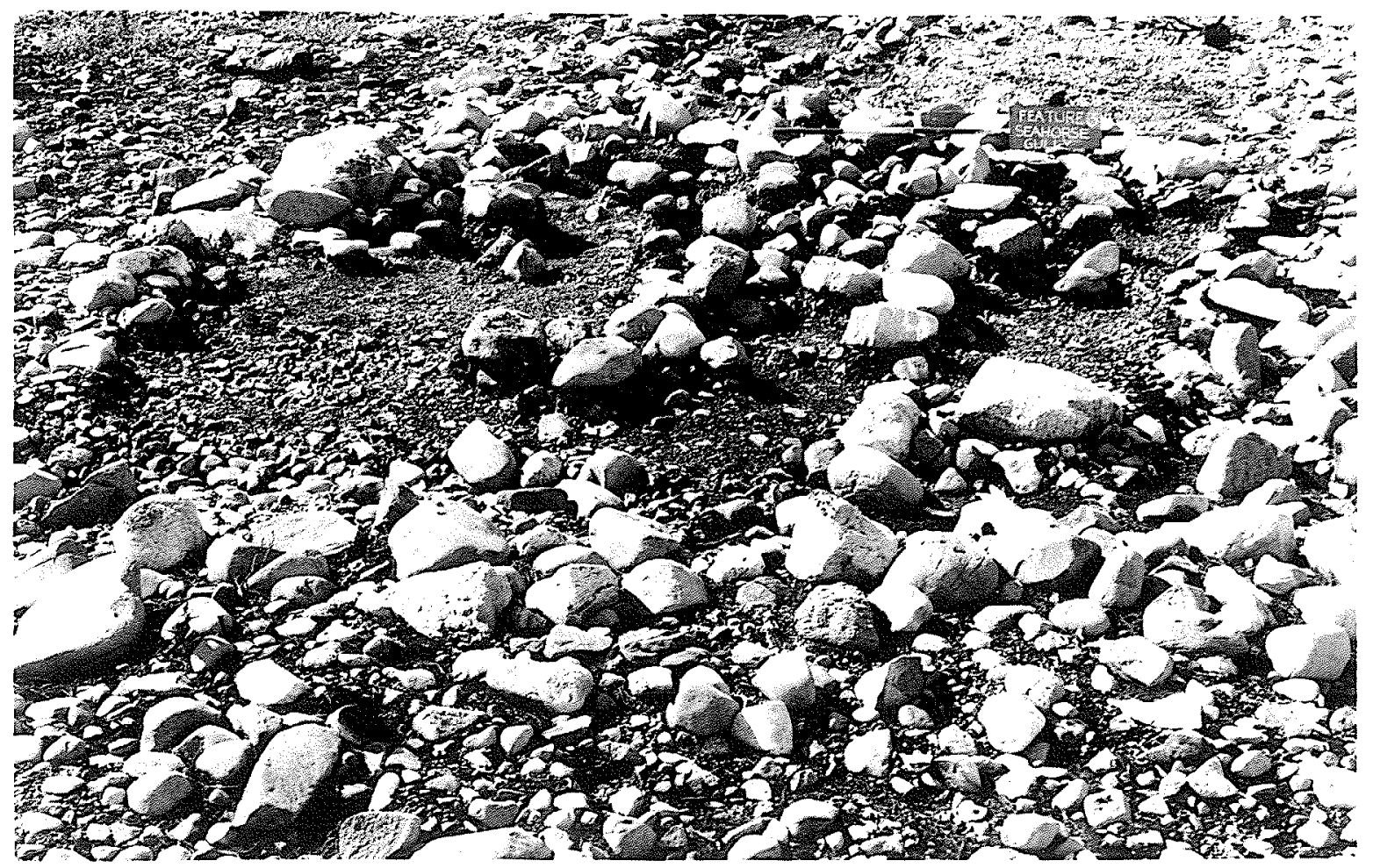

Fig. 21,b. The excavation of House 7 north, looking south 
also found in this area.

$\underline{\text { Sma11 Tools }}$

A single burin (Fig. 19,i) lay on the surface in the centre of the midpassage. Both the right and the left edges are dorsally bevelled and slightly concave. The right concavity is mainly a result of the lateral flare of the upper margin. The right edge is completely ventrally thinned and both margins are ground. The convex base is unground and partially bifacially flaked. Although the burin facet end has been completely reworked by dorsally flaking to form a pointed graver, one hinge fracture is still present, demonstrating that burin spalls were once removed from this burin. Made of whitish chert, the dimensions of this specimen are 17,12 and $3.5 \mathrm{~mm}$.

Burin Spa11s These tools were not recovered from House 7 north.

\section{End B1ades}

The distal portion of an end blade (Fig. 19,j) was found on the surface of the southern part of this dwelling. It is bifacially flaked on a thin blank of grey-white chert. The irregularity of outline, the irregular flake scars, and the incomplete flaking of one face, provide evidence that this tool was never completed. The width of this specimen is $10.5 \mathrm{~mm}$. and the thickness is $2.5 \mathrm{~mm}$.

\section{Harpoon Blades}

This tool category was not represented in this house. 
Side blades were not found in House 7 north.

\section{$\underline{\text { Knives }}$}

A tool fragment of greyish chert (Fig. 19,k) was found at a depth of three inches in the central area of the midpassage. It has two slightly concave lateral edges which are bifacially flaked and heavily ground. Its base is also bifacially flaked, but is convex and unground. This fragment is identified as the lower (proximal) portion of a knife of the narrow, stemmed variety. The basal width is $19.5 \mathrm{~mm}$. and the thickness is $2.5 \mathrm{~mm}$.

\section{Scrapers}

From leve1 1 excavations within the midpassage at the southern end of the house came a large side scraper (Fig. 19,m). It is made on a large twisted flake of greenish pyroclastic. The left margin (as illustrated) is dorsally bevelled while a portion of the right margin is ventrally thinned. Dimensions are 73,25 , and $7 \mathrm{~mm}$.

\section{Unifacial Blades and Microblades}

These tools were not recovered from House 7 , north.

\section{Flake Tools}

A flake of grey-brown chert with a unifacial concavity along one edge was found in the excavation of level 1 . This slight concavity is dorsally bevelled, and has been broken through the middle. Presently, this flake is $24.5 \mathrm{~mm}$. wide and $5.5 \mathrm{~mm}$. thick (Fig. 19,1).

Large Tools

No large tools were found in this dwelling. 
No other tools were found in this dwelling.

\section{DEBITAGE}

On the surface inside this dwelling numerous flakes were present. Three of these are large wide flakes of grey-white chert and six are smaller chert flakes. Also collected was a large flake of banded grey and another of green, cherty large tool material. The former has been struck from the ground or dulled edge of a large tool. Four small flakes of white chert were recovered from level 1 excavations.

\section{FAUNAL REMAINS}

The only faunal evidence was a fragmentary right seal femur that was discovered in level 1 excavations within the midpassage, in the centre of the dwelling.

\section{SUMMARY}

See House 7 south summary.

HOUSE 7 SOUTH

\section{DWELLING REMAINS}

This southern portion consists of an indefinite stone alignment which may have once surrounded a subrectangular dwelling. The stones are medium sized and the alignment is most diffuse along its western edge. A number of stones within the southern half of the feature may have formed a hearth or some other now destroyed alignment. This dwelling was about sixteen feet long and thirteen feet wide. 
Sma11 Tools

Only three small tools, a burin, an end blade, and a flake tool were recovered from this house.

\section{Burins}

One burin (Fig. 19,n) was found near the east central wall of the alignment. The convex base is unworked and unground. The short left margin is dorsally bevelled, concave and ground. The right edge is straighter, dorsally bevelled, ventrally thinned and ground. The burin facet and hinge fracture area is dorsally bevelled, removing the spall scars. The right corner of the distal platform has also been dorsally bevelled, resulting in a graver-like tip to the burin.

\section{Burin Spalls}

Burin spalls were not found in this dwelling.

End Blades

One end blade fragment (Fig. 19,p) was discovered on the surface of the southern portion of the dwelling. It appears to be the stem portion of a single shouldered projectile point. A complete specimen of this end blade variety was found in Activity Area 3 (Fig. 16,c). This fragmentary specimen is irregularly bifacially flaked and neither the lateral margins nor the convex base are ground. The width across the shoulders is $13 \mathrm{~mm}$. and the thickness is $5 \mathrm{~mm}$.

Harpoon Blades

These tools were absent from House 7 south. 
$\underline{\text { Side }}$ Blades

These tools were absent from this house.

\section{Knives}

This tool category was not represented.

$\underline{\text { Scrapers }}$

Scrapers were not found in this house.

Blades and Microblades

These tools were not present in this house.

Flake Tools

From a flake concentration on the surface of the east central part of the house, a flake tool (Fig. 19,0) was recovered. Of finegrained pink-white chert, the general shape is that of a large burin, but the lower edges are not carefully prepared or ground and burin spalls have not been removed. The whole of the thin left margin has an abrupt dorsal retouch. Dimensions are 37,20 and $3.5 \mathrm{~mm}$.

Large Tools

Large tools were not present in House 7 south.

Other Tools

No other tools were recovered.

DEBITAGE

Six different kinds of large tool material were present in this house (Table 13). These include, (1) red pyroclastic, (2) brown pyroclastic, (3) grey pyroclastic, (4) grey banded cherty sedimentary, (5) dark green cherty sedimentary, and (6) light green cherty sedimentary 
LITHIC DEBRIS FROM HOUSE 7 SOUTH

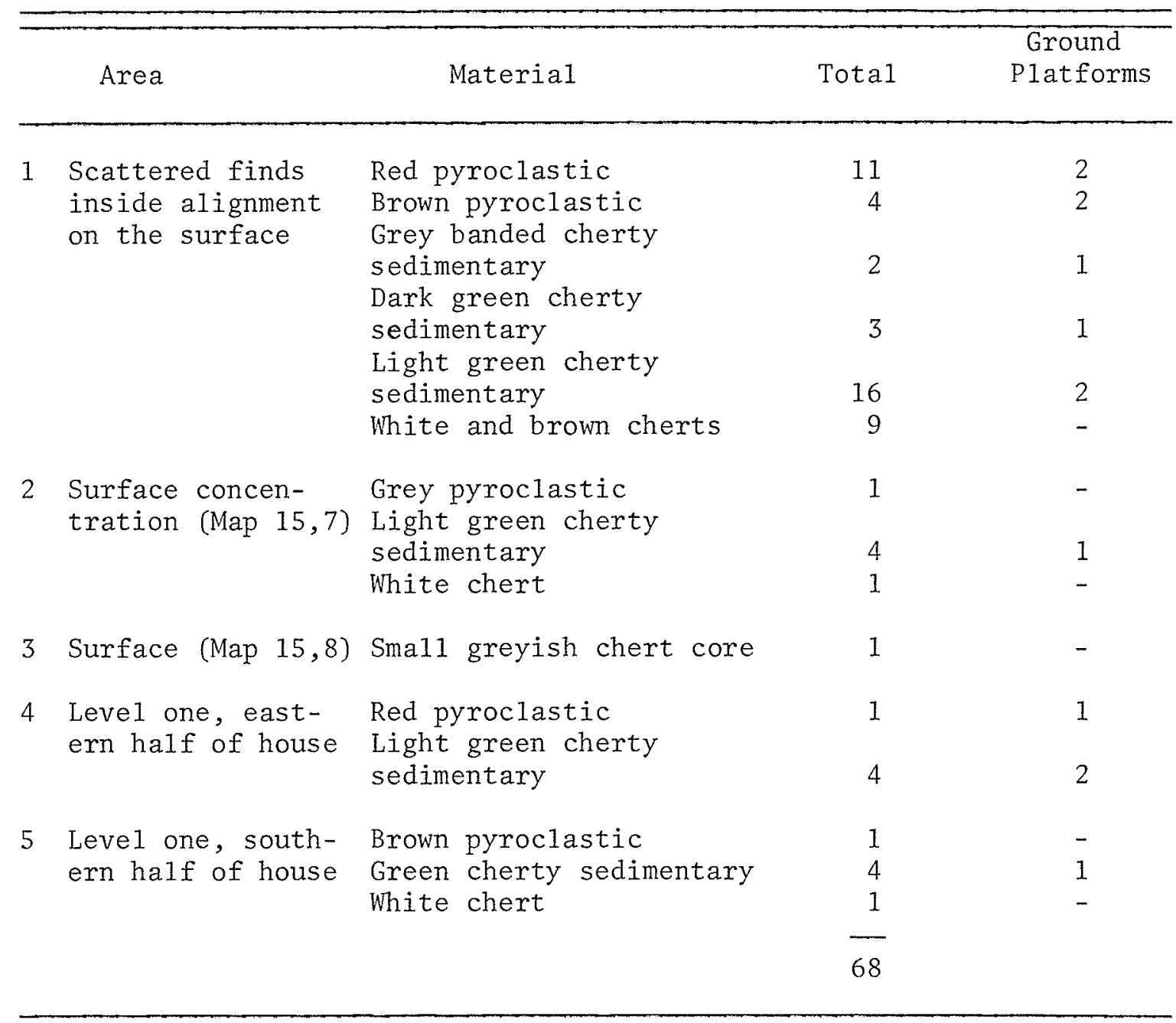


materials. Each kind of large tool material represents the detritus from the knapping of at least one large tool (or of more than one tool made of the same material). Since each group of flakes (composed of the same material) contains within it a few flakes that have been struck from the ground and battered edges of large tools, it appears that knapping activities were concentrated on the resharpening of dulled large tools, rather than on the manufacture of completely new tools.

Only fourteen flakes of fine-grained whitish cherts were recovered from this dwelling. This indicates that small tool manufacture was negligible. A few chert nodules, one of which is a small core, were also found.

FAUNAL REMAINS

Bones were concentrated in two places within the southern half of House 7 south. Near the centre of the dwelling were found three phalange fragments, three rib fragments and a possible seal fibula (fragmentary). One fragmentary seal pelvis was also found. With these were five pieces of bone that could not be identified as to species or anatomical name.

At the south end of the house, bones were excavated from around and beneath a limestone slab. This concentration consisted of a right seal ulna, a right seal tibia, a right seal radius, twelve rib fragments, two phalange fragments and six other unidentified fragments.

\section{SUMMARY OF HOUSE 7 NORTH AND SOUTH}

Two separate but adjacent dwellings are represented by the stone alignments of this portion of the site. Both are subrectangular, and one has a midpassage. Although the northern feature is the more clearly 
defined, the southern outline contained the most flakes and bones. The burins found in each dwelling are similar, even to finishing details of the working edges. They are unusual in that they have been worked into gravers with pointed tips, after all possible burin spalls were struck off. This, and the abutment of one house against the other, provide some evidence of the contemporaneous occupation of both houses. Although they may both have been occupied at the same time, the general paucity of artifacts and faunal remains indicates a short stay.

The lack of sea mammal hunting tools may be explained by the brevity of the occupation. This may also explain the absence of tools that might have been used by females. The faunal remains indicate that at least one seal was killed and it appears that most of it was utilized in the southern dwelling.

These houses were not the locus of extensive industrial activities and the only stone knapping that occurred appears to have been the resharpening of six large tools and a limited amount of chert flaking of fine-grained white cherts.

SUMMARY OF SETTLEMENT EVIDENCE

The occupation of the central area was sparse. Habitation is believed to have occurred during the final period of Pre-Dorset use of the island. There are several reasons for this assertion; (1) this lower portion of the site could only have been occupied when the land had risen to a point about ninety-five feet above the present sea level, (2) the dwellings are subrectangular, and (3) midpassages are present. The subrectangular outline and the midpassage are more characteristic of Dorset 
than of Pre-Dorset. Unlike Dorset dwellings, however, these do not incorporate floors and walls of stone slabs and are not semisubterranean as are those in the Iglulik area.

The tools associated with the dwellings of the central settlement are enumerated in Table 14. Artifacts from this central area are not distinctively different from those of other settlements. However, except for House 5 , the artifact yield was so low that comparisons are difficult to make. The low numbers of burins in Houses 4,6 , and 7 are unusual although House 1 had only two burins and Houses 11 and 12 had none at all. The complete absence of definite unifacial blades and microblades is a characteristic feature of this settlement. Although no large tools were found, their presence is evidenced by many flakes of pyroclastic and cherty sedimentary materials found in the dwellings.

Narrow stemmed knives were found in Houses 4,7 north, and 5 . Although two narrow knives were found in the area of the southern settlement, it is likely that this knife variety is characteristic of the central settlement. Steatite vessel fragments were absent from the central settlement, effectively separating it from the southern settlement. The presence of subrectangular dwellings clearly separates the central settlement from the northern.

Except for the five dwelling remains, the central area was relatively barren of surface artifacts. Some occupation had occurred on the cobble mantle, although the artifacts found there may have resulted from the activities of the dwelling inhabitants. Houses 4, 6, and 7 were almost bare of artifacts as well. Too few artifacts were found in these houses for any valid comparisons to be made to those of House 5. 
TOOLS FROM THE CENTRAL SETTLEMENT

\begin{tabular}{|c|c|c|c|c|c|c|c|}
\hline \multicolumn{2}{|c|}{ Categories } & \multirow{2}{*}{ House 4} & \multirow{2}{*}{ House 5} & \multirow{2}{*}{ House 6} & \multirow{2}{*}{$\begin{array}{c}\begin{array}{c}\text { House } \\
\text { North }\end{array} \\
1\end{array}$} & \multirow{2}{*}{$\begin{array}{c}\begin{array}{c}\text { House } \\
\text { South }\end{array} \\
1\end{array}$} & \multirow{2}{*}{$\frac{\text { Totals }}{22}$} \\
\hline 1 & Burins & & & & & & \\
\hline 2 & Burin Spalls & 2 & 40 & & & & 42 \\
\hline 3 & End Blades & & 1 & & 1 & 1 & 3 \\
\hline 4 & Harpoon Blades & & 4 & & & & 4 \\
\hline 5 & Side Blades & 1 & 2 & 1 & & & 4 \\
\hline 6 & Knives & 1 & 4 & & 1 & & 6 \\
\hline 7 & Scrapers & 1 & 4 & 1 & 1 & & 7 \\
\hline 8 & B1ades & & & & 1 & 1 & 2 \\
\hline 9 & Flake Tools & & & & & & \\
\hline 10 & Gouges & & & & & & \\
\hline 11 & Chise1s & & & & & & \\
\hline 12 & Scraper Planes & & & & & & \\
\hline 13 & Adzes & & & & & & \\
\hline 14 & Organic Tools & & 6 & & & & 6 \\
\hline 15 & Other Tools & & & & & & \\
\hline & Totals & 6 & 79 & 3 & 5 & 3 & 96 \\
\hline
\end{tabular}


It is significant that a11 occupation took place to the east of the cobble mantle. This phenomena argues strongly for the existence of prevailing westerly or northwesterly winds during the period of PreDorset occupation. The stormiest seas would have been along the west side of the island, while the east side should have been more sheltered, especially for the beaching of watercraft.

The sparseness of the central occupation suggests its brevity. It seems that this area was occupied soon after it emerged from the waters, but in a short time, the Pre-Dorset hunters abandoned the site or left the area, as their dwellings are not found at lower altitudes. The presence of Dorset-like attributes in the dwellings suggests the diffusion of ideas from the north. Probably, the selection of diffused traits by these peripheral Pre-Dorset hunters was random, a chance affair, giving the culture its distinctive features. While housing styles seem to have been changing, the tool kit appears relatively unaltered.

The central settlement is long, extending from approximately 1000 feet south of datum to 800 feet north of it. It is also the widest, as Houses 4 and 5 are farther from the cobble mantle than any other dwellings. The lack of pressure on living space is evidenced by the fact that several inviting flat gravel patches in the boulder field adjoining Houses 4 and 5 were never utilized. Much more intensive use of space occurred in the northern and southern settlements. 
CHAPTER VII

THE NORTHERN SETTLEMENT

INTRODUCTION

The northern settlement was more densely inhabited than the central area, but less so than the southern settlement. For this reason, it, as a pleasant medium is more easily dealt with. The northern settlement as delineated extends from 1000 feet to approximately 1900 feet north of datum. This settlement covered the smallest area but contained the most undisturbed and excavatable houses. The occupation in this area was restricted to the cobble mantle and a narrow area to the east of it. No occupational debris was found to the east of House 10. Of the many habitation areas evident at this end of the site, six dwelling remains were recorded and four of these were excavated.

HOUSE 8

House 8 was discovered on the summit of the cobble mantle, which is high and prominent in this area of the site ridge. This dwelling was located 1250 feet north of datum, on the eastern edge of the mantle. The actual stone alignment began about three feet west of the base line. Excavation of House 8 was carried out in two arbitrary three inch levels. The excavation was unusually productive and most of the tools found were discovered in the excavations, rather than on the fire-bared surface as was the situation with several other houses.

\section{DWELLING REMAINS}

The remains of House 8 consisted of an indefinite circular align- 


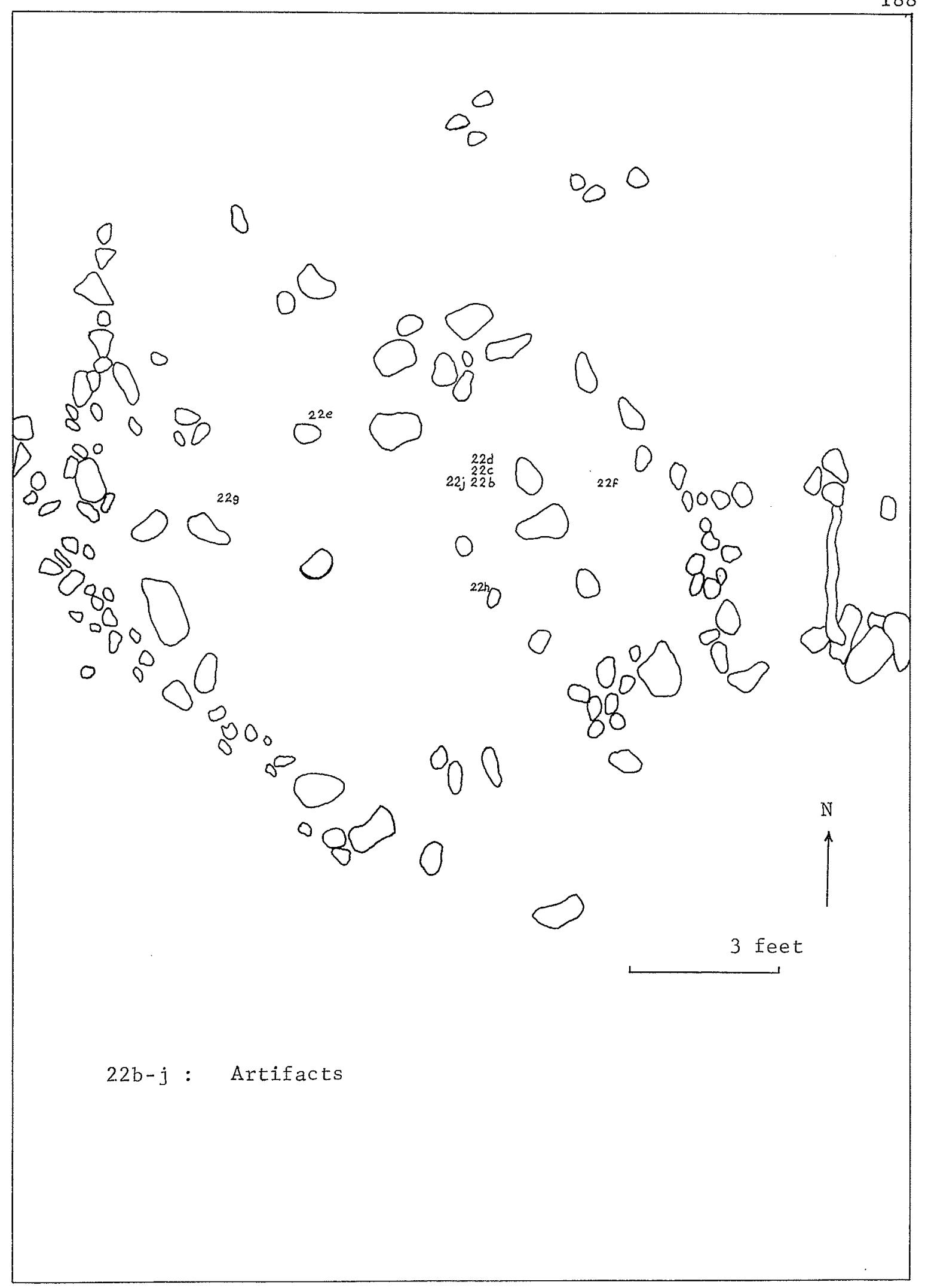

Map 16. Floor plan of House 8 
ment of rocks. These rocks were small, only a few pounds in weight, but very numerous. They were probably used to hold down the base of a circular or oval tent, about thirteen feet long and ten feet wide. When discovered, many of the stones were scattered and several were strewn inside the dwelling area. All of the rocks were on the surface and none were imbedded in the gravel of the mantle surface. No central depression was present in the interior of the alignment. An upright slab of limestone, two feet high and three feet wide had been set up on the eastern edge of the feature. Its function is unknown.

\section{ARTIFACTS}

$\underline{\text { Sma11 Tools }}$

\section{Burins}

Five whole and fragmentary burins were recovered from House 8 (Table 15). All are of unusually fine-grained chert materials, and they conform very closely to the characteristic attributes of the Seahorse Gu11y burin type as described in Chaper IV. These burins differ only in their size, which is smaller than normal. Three of these burins (Fig. 22,b,c,d,) were found in level 1 in a concentration in the central area of the dwelling interior (Map 16).

\section{Burin Spa11s}

Three burin spalls were discovered within this dwelling. Two were found in level 1 of the western half of the house. One of these is large, $22.5 \mathrm{~mm}$. long, $6 \mathrm{~mm}$. wide, and $2 \mathrm{~mm}$. thick. It is a secondary spall of greyish chert, struck from a platform prepared by grinding. The 
TABLE 15

ATTRIBUTES OF BURINS FROM HOUSE 8

1 DISTAL PLATFORM

a. Ground

b. Dorsally Flaked

c. Transversely Spalled

d. Ventrally Flaked

2 BASE

a. Concave

b. Straight

c. Convex

d. Dorsally Flaked

e. Ventrally Flaked

f. Ground

3 RIGHT LATERAL EDGE

a. Concave

b. Lateral Flare

c. Straight

d. Convex

e. Ground

f. Ventrally Flaked

g. Dorsally Bevelled

4 LEFT LATERAL EDGE

a. Concave

b. Notched

c. Straight

d. Convex

e. Ground

f. Ventrally Flaked

g. Dorsally Bevelled

5 BURIN FACET
a. Ob1ique
b. Vertical
c. Acute
d. Dorsally Flaked
e. Ventrally Flaked

6 GRINDING

a. Ventral Face

b. Dorsal Face

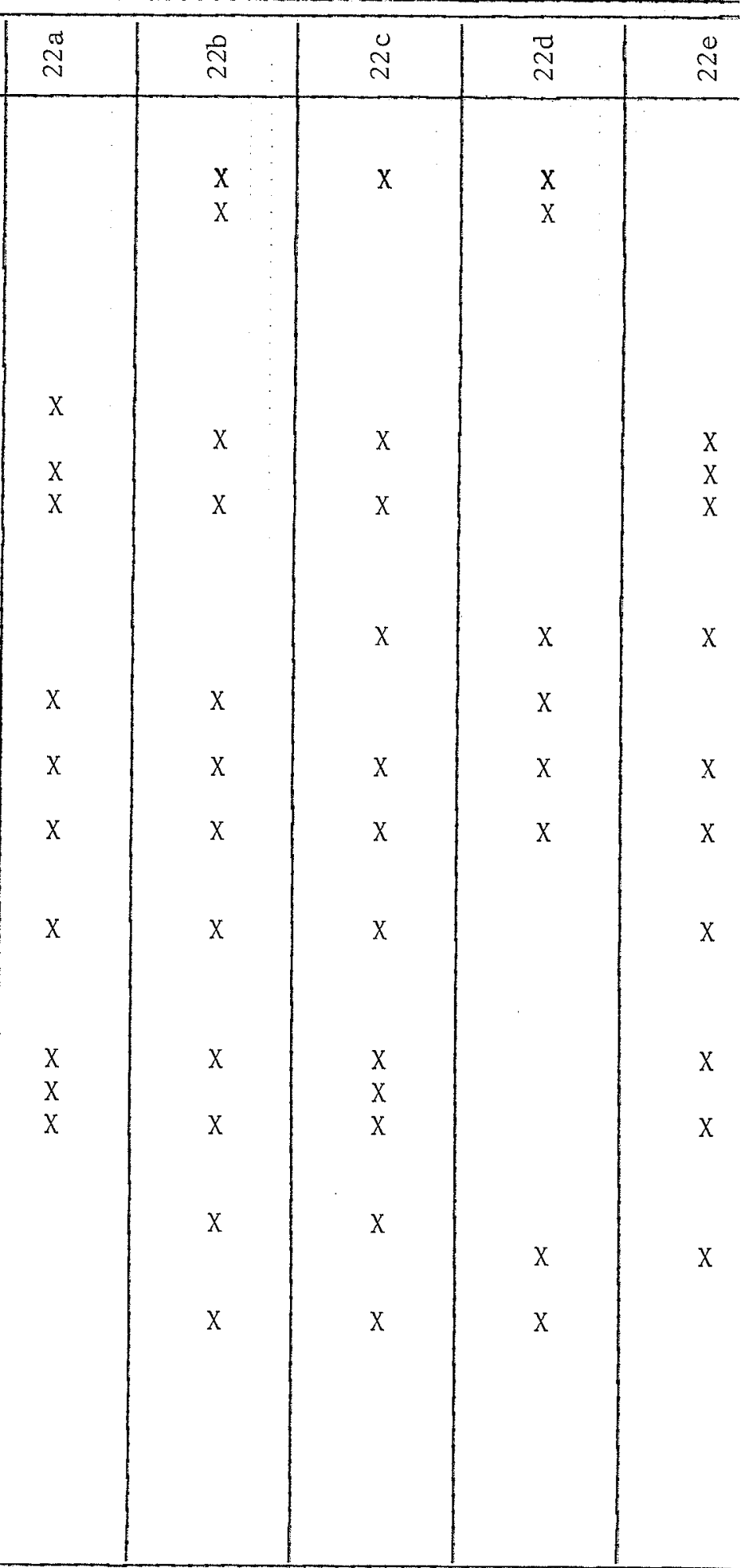




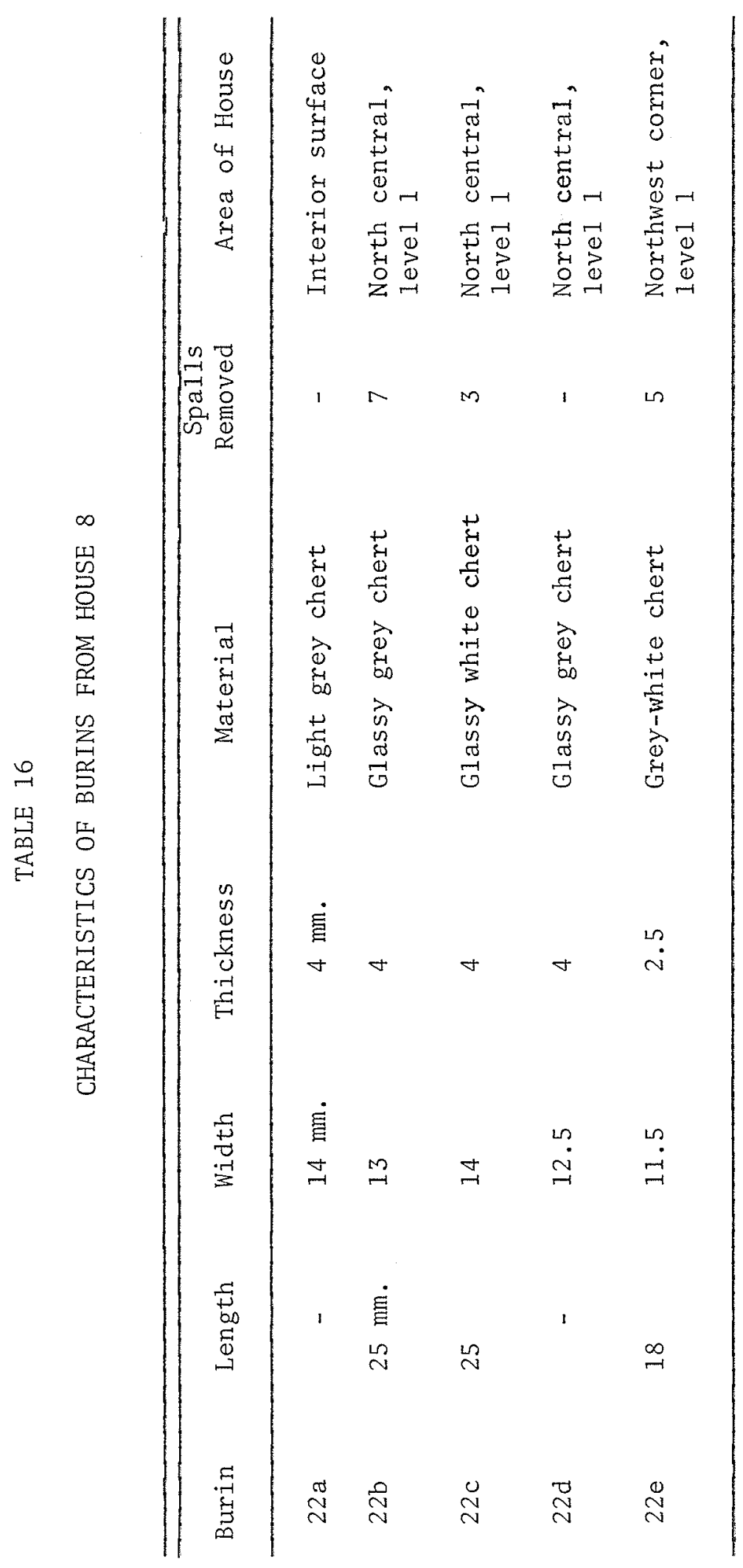


other spall is smaller and composed of whitish chert. A secondary spall, also struck from a ground platform, its dimensions are 16, 4, and $1 \mathrm{~mm}$. The third spall was recovered from leve1 2 of the eastern half of the house. It is long (20 mm.), narrow (2 mm.), and on $1 \mathrm{y} 1.5 \mathrm{~mm}$. thick. A secondary spall of greyish chert, it has been struck from a ground platform. The lithic materials composing these spalls do not match those of any of the burins found in this dwelling.

\section{End Blades}

End blades were not found in House 8.

\section{Harpoon B1ades}

A triangular end blade (Fig. 22,f) was discovered at a depth of two inches near the eastern edge of the dwelling. It is made on a thin quartzite flake, one surface of which is completely flaked while the other is only marginally retouched. The edges are serrated, an attribute that occurs on no other harpoon blade from the site. Although much damaged, there seem to be an average of 7.5 serrations per centimeter. The base is slightly concave and unground. The tip is snapped off, so that the present length is $29 \mathrm{~mm}$. The width is $20 \mathrm{~mm}$. and the thickness $3.5 \mathrm{~mm}$.

A proximal corner of another triangular end blade (Fig. 22,g) was found at a depth of two inches near the western wall of the house. It is of whitish chert, bifacially flaked, and was once concave based. The thickness is $4.5 \mathrm{~mm}$.

\section{Side Blades}

A rectangular side blade fragment (Fig. $22, \mathrm{~h}$ ) was excavated at a depth of two inches in the south central area of the dwelling. It has 
been knapped from grey-green pyroclastic. Both lateral edges are bifacially flaked, one more regularly than the other. This more regular edge is straight and ground, and the surfaces adjacent to it have been polished, evidently to facilitate insetting. The opposite margin is more evenly bifacially flaked and although dulled, seems to have been the cutting edge. The width of this specimen is $12 \mathrm{~mm}$. and the thickness is $4 \mathrm{~mm}$.

\section{Knives}

Knives were not recovered from this dwelling.

\section{Scrapers}

One asymmetrical scraper (Fig. 22,i) was discovered on the surface of the dwelling interior. It is slightly stemmed, the right edge being more concave than the left. Both lateral edges are dorsally beve11ed and unground, although dulled and crushed. The oblique scraping edge is convex in outline and dorsally bevelled. The distal tip of the scraper is rounded. Dimensions are 30,15 , and $5.5 \mathrm{~mm}$.

\section{Unifacial B1ades and Microblades}

These tools were not present in House 8 .

\section{Flake Tools}

No flake tools were found in this house.

Large Too1s

Gouges, scraper planes and adze blades were not recovered from this dwelling. 
One large tool fragment (Fig. $22, j$ ) of brown pyroclastic was found. It is the distal end of a chisel, a sort of pointed gouge-like tool. The cutting edge has once been dorsally and ventrally polished, but is now battered through usage. The ventral (flat) surface of the tip slants upward to meet the dorsal surface at a sharp angle. This specimen was discovered imbedded in the sod and stones of the surface, near the centre of the feature. Plano-convex in cross-section, this fragment is $45 \mathrm{~mm}$. wide and $21 \mathrm{~mm}$. thick.

Other Tools

No other tools were recovered from House 8

\section{DEBITAGE}

Only a few flakes were found on the surface of the feature. These included three small nodules of chert, as well as one flake of brown pyroclastic. The crushed and ground striking platform and the polished dorsal surface of this flake indicates that a much used large tool was reworked in this dwelling. This flake is of the same material as a large tool (Fig. 22,j) found on the surface of the house. The flake is probably a product of the reworking of this tool.

Only five flakes were recovered from level 1. Three of these are of fine grey-white chert while the other two are of greenish cherty sedimentary material. Flakes were equally sparse in leve1 2. From the western half of this level came one flake of whitish chert and another of greenish cherty material. Four tiny flakes of grey-black cherty sedimentary material and one of white chert were recovered in the level 2 excavations of the eastern side of the house. Considering that tools were 
relatively numerous in this dwelling, the lack of chipping debris is unusua1. The presence of green and grey-black cherty materials indicate that at least two more large tools were present in this dwelling.

\section{FAUNAL REMAINS}

No identifiable bones were recovered from this House 8 , although three bird bones were found on the surface. One distal half of a rib was found in the eastern half of the dwelling in the level 2 excavations. This rib fragment is consistent with an animal the size of a seal. It is relatively well preserved.

\section{SUMMARY}

The stone alignment of House 8 was composed of many sma11 rocks which were arranged in a rough circle. These rocks probably held down the base of a skin tent. There is a remarkable homogeneity in the attributes of the five burins found. In fact, these seem to comprise a recognizably distinct grouping within the Seahorse Gully occupations. The harpoon blades and the offset scraper are characteristic of the Seahorse GullyPre-Dorset as is the large tool fragment. Only two unusual features are present; one is the use of white quartzite in the manufacture of a tool (harpoon blade) and the other is the presence of a rectangular side blade which is polished on the surface.

The two triangular harpoon blades and the suspected seal rib indicate that sealing was carried out by the hunters of the dwelling. The paucity of faunal remains is puzzling, but may reflect poor hunting rather than poor preservation, as the single rib recovered is in good condition. The few tools, the lack of non-lithic finds, and the relative 


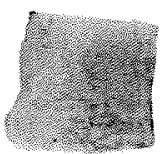

a

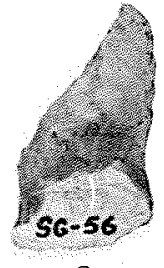

C

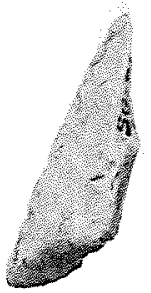

$g$

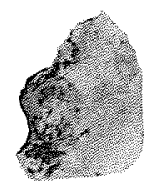

$k$

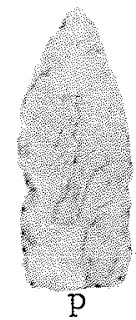

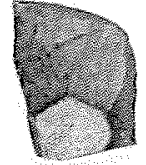

d

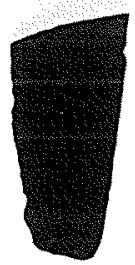

h
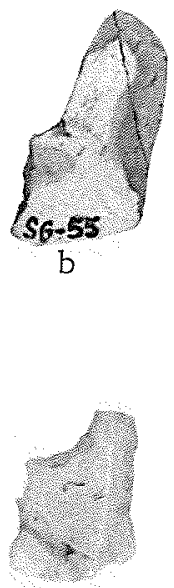

e
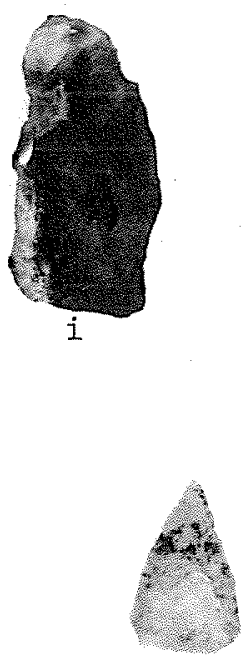

$\mathrm{n}$

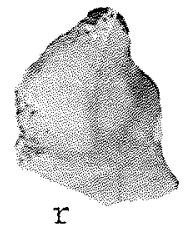

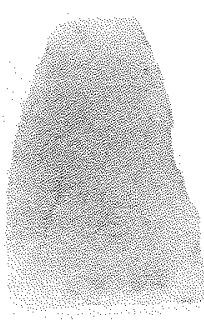

f
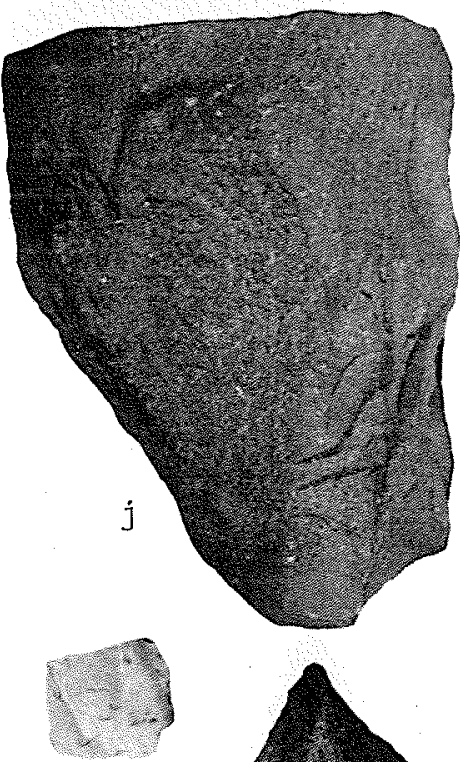

$\mathrm{O}$

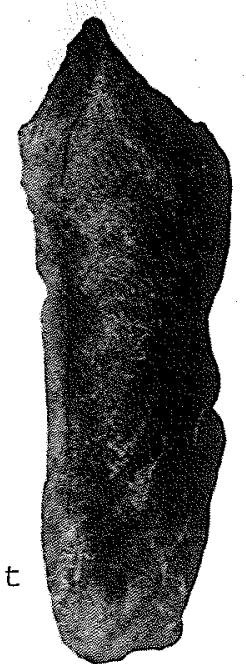

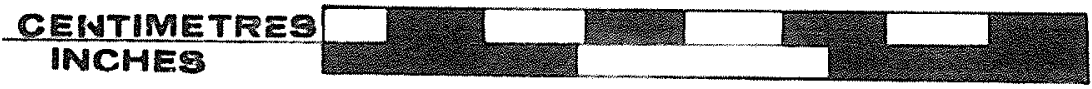

Fig. 22. Seahorse Gu11y site tools. House 8: a-e, burins, f-g, harpoon blades; $h$, side blade, $i$, scraper; $j$, fragmentary chisel. House 9: $\mathrm{k}-\mathrm{m}$, burins; $\mathrm{n}-\mathrm{p}$, en blades; $\mathrm{q}-\mathrm{r}$, flake tools; $\mathrm{s}$, microblade; $t$, graver or perforator. 
absence of lithic flakes, all suggest a brief occupation. Three bird bones found on the interior surface of this house indicate that the season of occupation may have been summer.

HOUSE 9

The stone alignment of House 9 was located 1400 feet north of the datum point. Stones composing the feature began approximately three feet east of the base 1ine. House 9, like al1 the houses on the site ridge, was burned over, removing most of the tundra mat. Artifacts were collected from the surface and two three inch levels were excavated within the presumed living area. A balk was left between the eastern and western halves of the excavation.

DWELLING REMAINS

No certain patterning of the stones of this feature could be recognized. The rocks appear to have been much disturbed. However, there are eleven stones, the bases of which remain buried to a depth of three inches or more and these obviously have not been disturbed recent1y. Seven of these undisturbed stones lay in the southeastern corner of the feature, but only three of these seem to outline the dwelling. Three buried stones lie along the northern edge and another on the southwestern corner (Map 17).

The largest concentration of medium sized (twenty - thirty pound) stones is on the eastern and southeastern portion of the alignment. Another group of stones was present on the western side of the house. The stones of this alignment are so scattered that no confident interpretation of the shape of the dwelling base can be made. Since circular 


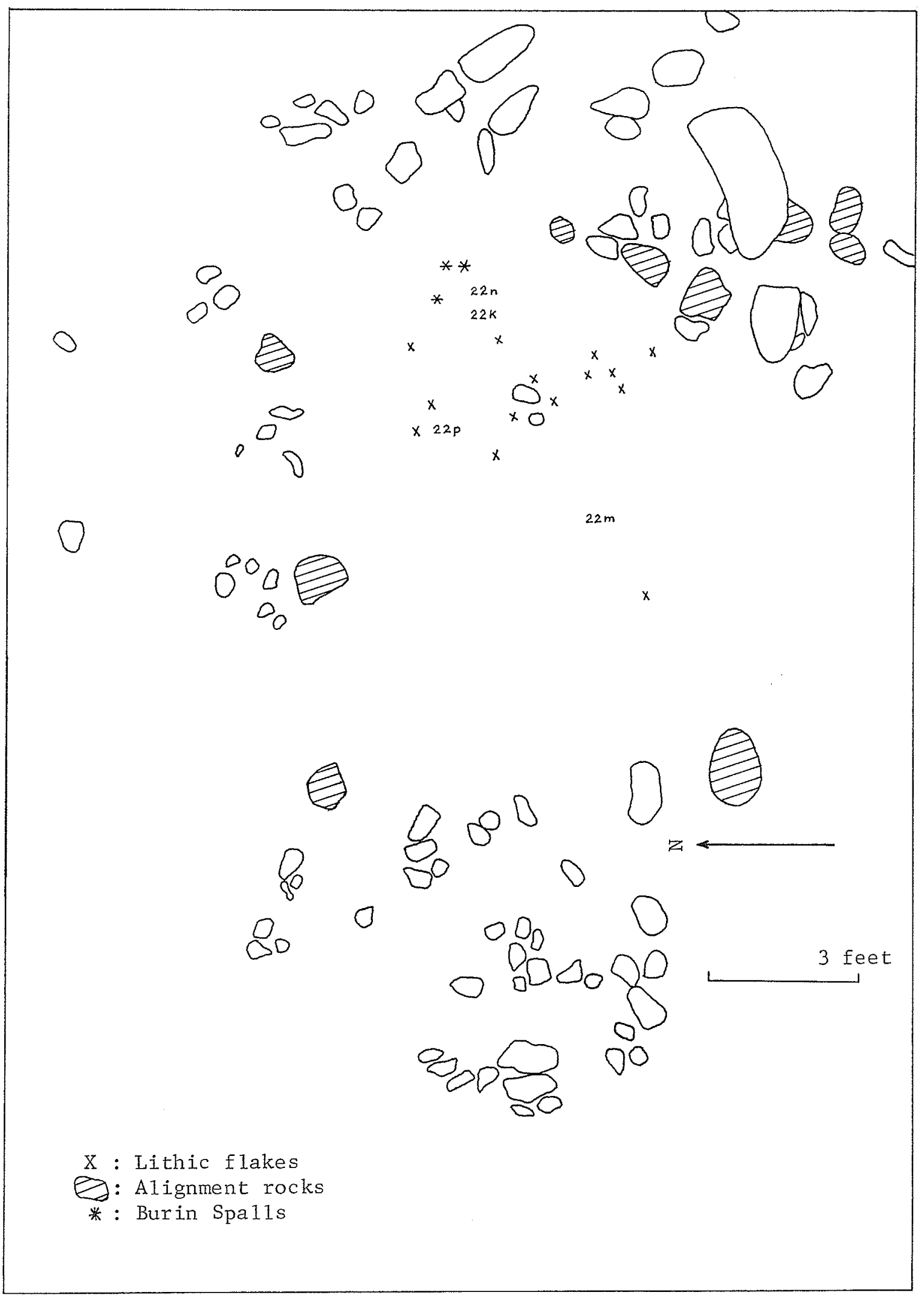

Map 17. Floor plan of House 9. 
alignments are most characteristic of this northern settlement and as the rocks do form a vaguely circular pattern, the stone alignment of House 9 is considered to be round.

\section{ARTIFACTS}

Artifacts were found both on the surface of House 9 and also in the excavations. Side blades, knives, and scrapers were not recovered from this dwelling, nor were any large or other tools present.

$\underline{\text { Smal1 Tools }}$

Burins

One sma11 burin (Fig. 22,k) was discovered in leve1 1 excavations of the east central area of the dwelling. The left margin is dorsally bevelled, ground and deeply concave. The right margin differs in being straight. The bifacially flaked base is straight and lightly ground. The hinge fracture area is dorsally flaked, but the scars of three spall removals are still discernable. The right side of the distal tip is transversely spalled, producing a projecting, graver-like tip. Made of whitish chert, the dimensions of this delicate tool are 17, 12 and $4 \mathrm{~mm}$.

The exact location of a broken burin (Fig. 22,1) found within the feature is not known. The left lateral edge is concave, dorsally beve11ed, ventrally flaked and ground. The right margin is similar, but straight. The convex base is bifacially flaked. The distal end is missing, but two hinge fractures are still discernable on the left edge. The material is a whitish chert; the width is $12 \mathrm{~mm}$. and the thickness 4 $\mathrm{mm}$. 
Another sma11 burin (Fig. 22,m) was found in the excavation of level 2 of the eastern half of the dwelling. The upper right margin flares slightly, making this edge slightly concave. It is dorsally bevelled and ground. The left margin is straight, thick, and completely unworked. The convex base is very slightly dorsally retouched. The distal platform is ground and although the burin facet and hinge fractures are dorsally flaked, the scars of eight spall removals are still visible. Made on a cortex flake of light grey chert, the dimensions of this burin are $17,12.5$, and $3 \mathrm{~mm}$.

Burin Spa11s

Eleven burin spalls were recovered from the excavations of level 1. Three more were found on the surface of the central dwelling area. Twelve of the spalls are secondary, eight of which have been struck from ground platforms (the others are indeterminable). Six spalls have been used as tools with oblique dorsal unifaces worked on their distal ends. The two primary spalls were both removed from ground striking platforms, but neither have been used as spall tools.

\section{End Blades}

The occupants of this dwelling appear to have emphasized the production of very small tools. This emphasis is continued with the end blades. One small lanceolate point (Fig. $22, \mathrm{p}$ ) was found in leve1 1 of the central portion of the dwelling. Both lateral edges are straight, with slight notches about midway along the point. These nicks may simply be fortuitous and may not be notches at all. All edges are regularly bifacially flaked, producing long narrow flake scars. The straight base 
and the lower lateral edges are unground. This grey chert specimen is $29 \mathrm{~mm}$. long, $12 \mathrm{~mm}$. wide, and $3 \mathrm{~mm}$. thick.

\section{Harpoon B1ades}

Two triangular end blades may be harpoon blades, although they are unusually small. One (Fig. $22, n$ ) is complete and made on a thin flake of 1ight grey chert. It is marginally retouched only, and the two corners of the base of the triangle have been removed. Found in level 1, its dimensions are $18,11.5$, and $2 \mathrm{~mm}$.

The lower half of a similar end blade (Fig. 22,0) was also recovered. It was not recognized in the field and was discovered in the laboratory in the flakes collected from level 1. Made on a marginally retouched thin flake of whitish chert, it is $13 \mathrm{~mm}$. wide and $2 \mathrm{~mm}$. thick,

\section{$\underline{\text { Side Blades }}$}

These tools were absent from House 9.

Knives

Knives were not found in House 9.

\section{Scrapers}

Scrapers were not recovered from this house.

\section{Unifacial B1ades and Microblades}

A broken microblade (Fig. 22,s) was recovered from House 9. It has been struck from a core of light grey chert. One of the lateral margins is ventrally flaked. Triangular in cross-section, the width of this specimen is $8 \mathrm{~mm}$. and the thickness is $2 \mathrm{~mm}$. 
Two problematic tools were recovered. These consist of bulbar light grey chert flakes, rectanguloid in shape. Both have sma11 unifacially flaked concavities on one or more edges. One flake is $20 \mathrm{~mm}$. 1ong and the other $18 \mathrm{~mm}$. (See Fig. 22, q-r)

With the flakes found on the surface was a blade-like flake of grey pyroclastic (Fig. 22,t). It is $65.5 \mathrm{~mm}$. long and $21 \mathrm{~mm}$. wide. One end is dorsally flaked on both margins to form a graver tip.

Large Tools

Large tools were not recovered from House 9.

Other Tools

Tools of organic or unusual lithic materials were not recovered from this house.

\section{DEBITAGE}

Lithic flakes found scattered on the surface of the interior of the stone alignment included three flakes of brown pyroclastic, one of grey pyroclastic and five of green cherty sedimentary material. One of the latter has a ground striking platform. Whitish cherts were represented by three smal1 core-like pieces and nine flakes.

Many more flakes were found in leve1 1. Dark red pyroclastic material predominated with thirty-five flakes, sixteen of which have ground platforms. Green cherty material was represented by twenty-one flakes, only two of which have ground platforms. Seven brown pyroclastic flakes, two with ground platforms, and eight flakes of banded grey sedimentary material, both groups with two ground platforms, were also found. 
One of the latter has a completely ground dorsal surface, evidence that these flakes were struck from a large tool in the process of reshaping it. A banded black material similar to rhyolite was represented by seven flakes, one with a ground platform. In addition, fifteen small retouch flakes of fine-grained white chert were recovered.

Flakes of six different kinds of large tool material were recovered from this house. Each group of flakes of the same lithic material is composed of relatively small numbers of flakes and includes some flakes that have been struck from the dulled edges of large tools. The sma11 numbers of flakes indicate that complete large tools were not being manufactured here while the presence of ground platforms make it clear that large tools were only being reshaped in this house.

FAUNAL REMAINS

No identifiable bones were found. A few unidentified bones which appear to be bird bones were recovered from the surface. No other bones were present.

\section{SUMMARY}

Although the stone alignment of House 9 is disturbed, a circular interpretation is accepted. Tools and lithic flakes were concentrated in a small area within this alignment (Map 17). The tools are relatively small but are not as carefully knapped as is usual for very small Pre-Dorset tools.

The economic base of the House 9 occupants is not evidenced by sea mammal remains, however, the two triangular end blades were probably once set into harpoon toggle heads of ivory or antler. Such toggle heads 
are used in sealing. The side notched end blade suggests the hunting of land animals, perhaps the birds whose skeletal remains were found on the surface of the dwelling interior.

Significantly, knives and scrapers which may be women's tools were not recovered. Perhaps the notched flake tools (Fig. 22,q,r) were used in activities carried out by females. The flake perforator (Fig. $22, t)$ may also be a woman's tool.

The debitage from House 9 represents the remains of a minimum of six large tools. A11 of these were used, dulled tools that were reshaped in the dwelling in order to give them new sharp edges. Very few finegrained white chert flakes were found, indicating that sma11 tool manufacture was not an important activity of the inhabitants during the time this house was occupied.

HOUSE 10

House 10 was located approximately sixty-five feet east of the eastern edge of the cobble mantle. Measurements were made to the edge of the limestone slabs along the western wall of the feature. This wall is eighty-five feet east of the 1400 foot north stake on the base line, which runs up the centre of the cobble mantle. House 10 is at the southern end of a boulder field which flanks the eastern side of the cobble mantle. The house ruin is situated on a large patch of gravel and cobbles, now bare of vegetation.

\section{DWELLING REMAINS}

The stone alignment marking House 10 is very diffuse (Fig. 26,a). No recognizable patterning of the rocks composing the feature is discern- 


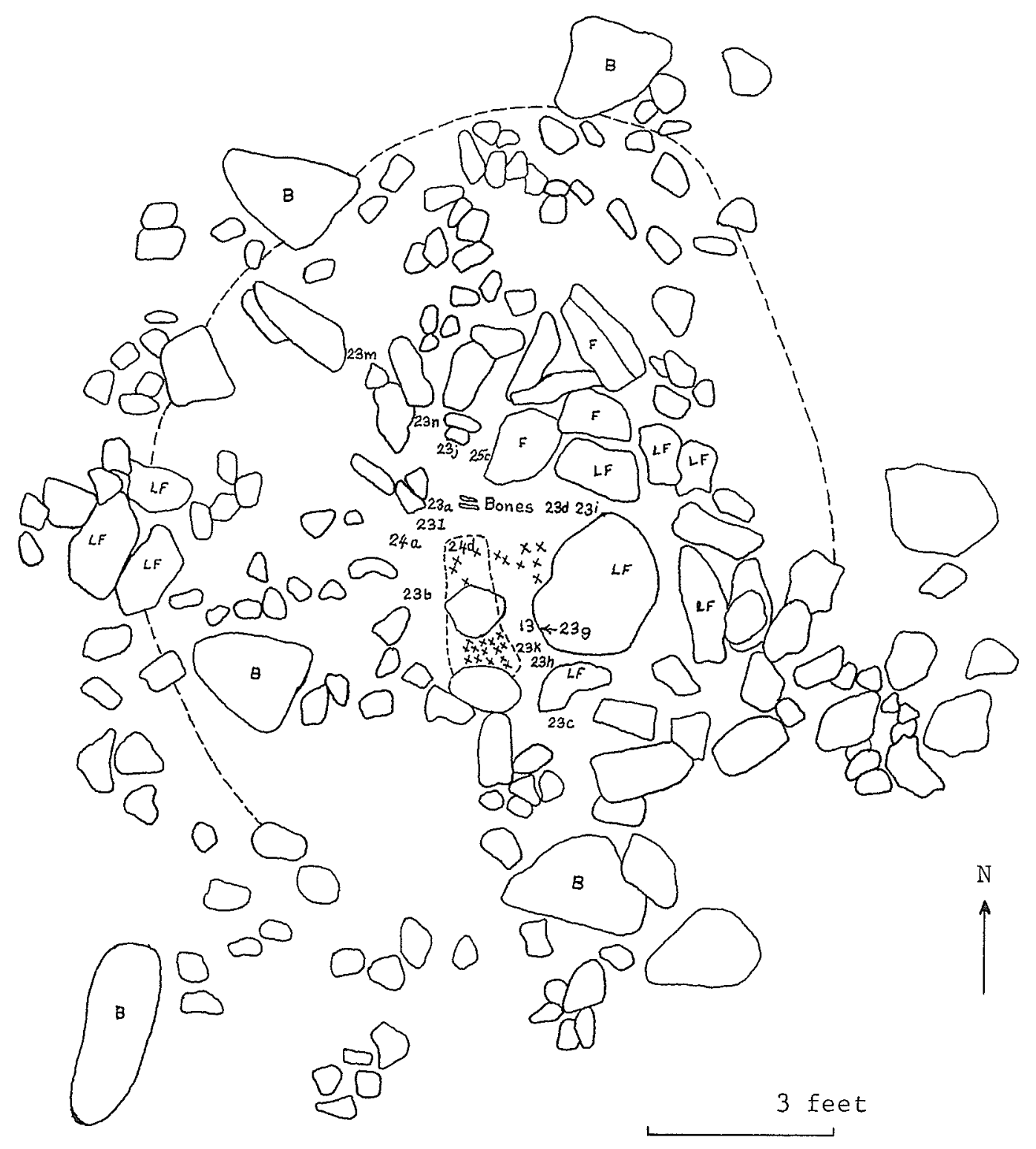

$\square 24 b$

$X$ : Lithic flake

B : Boulder or bedrock

F : Flagstone

LF : Limestone flag

... : Edge of dwelling depression

Map 18. Floor plan of House 10. 
ab1e. The floor of this feature, like those of Houses 11, 12, and 13, is depressed to a depth of a few inches. As with House 13, the semisubterranean nature of this floor is exaggerated because of the placement of the house in a slight natural depression. When discovered and recorded, the "interior" of this dwelling was depressed to a depth of four or five inches. That this depression is still present after more than two millenia, indicates that this floor was, in fact, dug through the tundra mat into the gravel subsoil. This suggestion is corroborated by the discovery of artifacts to a depth of five inches in the interior of the house, where they have become covered as the depression has slowly been filled by natural agencies.

Within the dwelling, six flat slabs of limestone were recorded, positioned near one another, in proximity to the western edge of the dwelling (Map 18). With these six stones were another three flagstones of grey quartzite, apparently derived from the local bedrock. These flagstones appear to have been laid down as a floor covering.

The depressed area occupied by this dwelling was about twelve feet in diameter, being roughly circular. This may be the area occupied by the dwelling, believed to have been a skin tent. However, the majority of the artifacts were massed within a tiny subrectangular area, eight and a half feet long and six and a half feet wide. This small area includes enough quartzite rocks to have held down a tent and has the above described flagstone "pavement" at one end.

\section{ARTIFACTS}

As noted above, the artifacts were concentrated within a small 
area. Burins were not as frequent in this dwelling as in others, but four were recorded.

Sma11 Tools

\section{$\underline{\text { Burins }}$}

An unusual burin (Fig. 23,a) was discovered at a depth of two inches in the centre of the house depression. Made of light grey chert, the base has been snapped off. This burin is very wide and both the short left margin and the right are concave. The left margin is dorsally bevelled, and the right bifacially flaked, however both are ground. The striking platform is heavily ground and although most of the hinge fractures have been removed by dorsal bevelling, the scars of six spall removals are still discernable. The width is $21.5 \mathrm{~mm}$. and the thickness 5 $\mathrm{mm}$.

Another "odd" burin (Fig. 23,b) was also found at a depth of two inches near the centre of the house. Relatively long and narrow, it is stemmed by dorsal bevelling and grinding. The oblique, slightly convex base is ventrally thinned. The distal platform has been prepared by the removal of a transverse spall, however, only two spalls were struck off. Made of whitish chert, the dimensions are 45, 14, and $5.5 \mathrm{~mm}$.

A smaller, more delicate burin (Fig. 23,c) was discovered three inches below the surface near the southern edge of the dwelling. It has been completely utilized and the burin facet is dorsally bevelled. The striking platform is absent, but seven spalls were removed during the last stages of use of the burin. Both lateral edges have been prepared through dorsal bevelling and grinding. The left margin is concave and 
the right slightly concave. The base is ventrally thinned, slightly convex, and unground. Made of grey-white chert, the dimensions of this speciment are 19,15 , and $4 \mathrm{~mm}$.

A small burin (Fig. 23,d) made on a thin flake of whitish chert was discovered at a depth of three and a half inches in the centre of the eastern cluster of flagstones. Only partially utilized, the striking platform has been prepared by heavy grinding and four spalls have been struck off. Both lateral margins have been dorsally flaked and ground. The left margin is slightly concave, the right straight. The base is irregular and either broken or unmodified. Dimensions are 22, 10, and 3 $\mathrm{mm}$.

Also found within this dwelling was a burin-1ike tool (Fig. 23,f). Of whitish chert, it is dorsally flaked, except for the bifacial thinning of the straight distal edge. The lower lateral edges are notched. No portion of this tool has been ground. Dimensions are 17, 10, and $1.5 \mathrm{~mm}$. A burin (Fig. 23,e) which is more like the above tool than the burins was recovered in the excavation of leve1 2. It is made on a smal1 thin flake of greyish chert which has been stemmed by dorsal bevelling of the left margin and ventral thinning of the right. Only the left margin and the distal striking platform are ground. The platform is dorsally bevelled and two spalls have been removed from the upper left corner. The base is slightly convex and unworked. Dimensions are 14.5, 10, and $2.5 \mathrm{~mm}$.

Burin Spal1s

Four burin spalls were discovered in level 2 excavations. These are all of grey chert and have been struck from a burin with a ground 


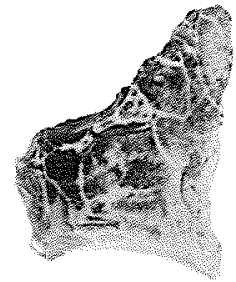

2
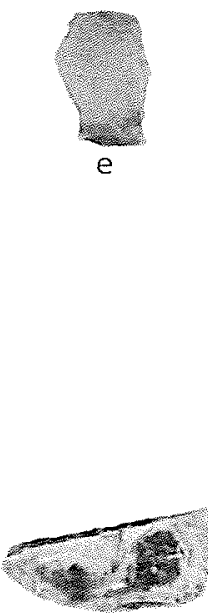

i

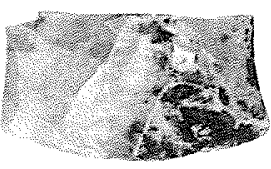

1
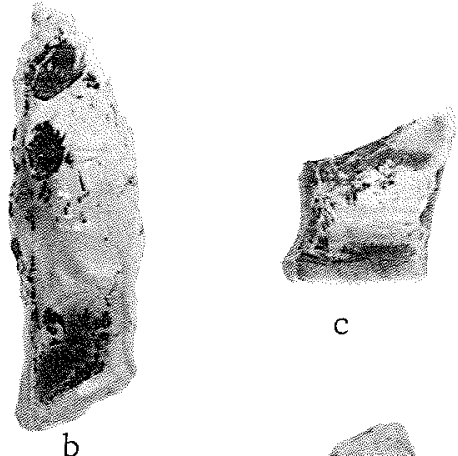

C

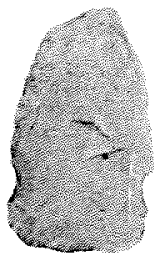

g

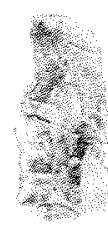

d

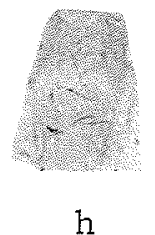

h
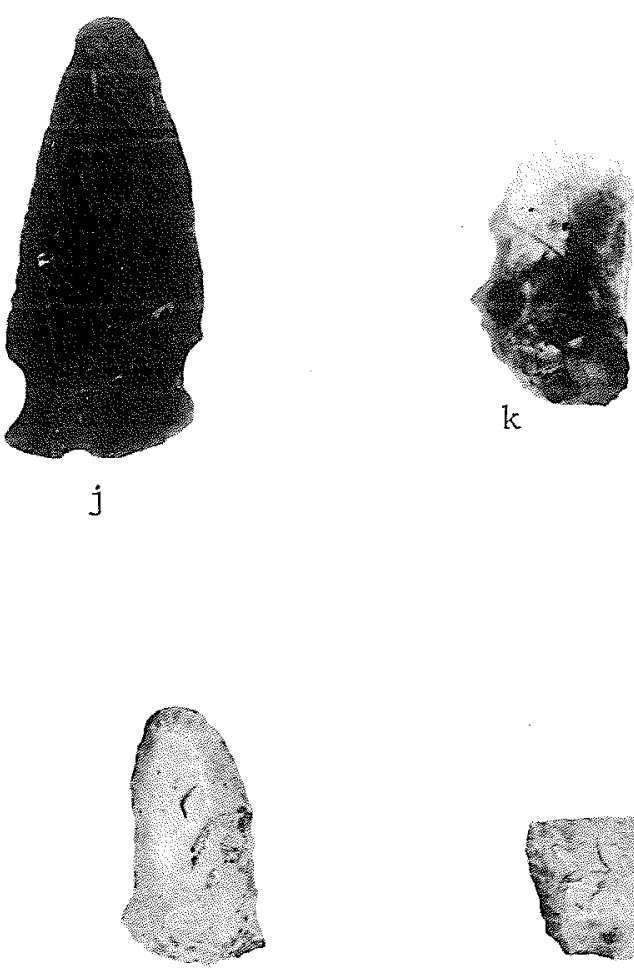

m

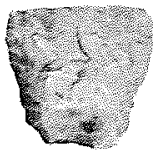

n

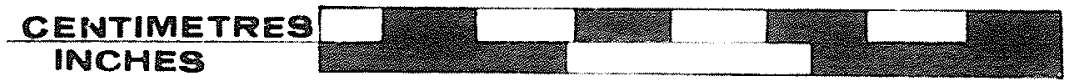

Fig. 23. Seahorse Gully site tools. House 10: a-e, burins; f, burin-1ike tool; $g-i$, end blades; $j$, hafted knife; $k-m$, scrapers. 
striking platform. One of the two primary spalls has been distally flaked on the dorsal surface to form an oblique scraping edge.

End Blades

Two end blades were found in the excavation of level 1. One (Fig. $23, \mathrm{~g}$ ) was discovered at a depth of three inches near the centre of the dwelling. It is completely bifacially flaked with shallow notches set low on the lateral margins. These are ground. The base is slightly convex and unground. The tip is broken but has been reflaked to form an unpointed but sharp distal end. Made of grey-brown chert, this specimen is $26 \mathrm{~mm}$. Iong, $15 \mathrm{~mm}$. wide, and $4 \mathrm{~mm}$. thick.

A base (Fig. 23,i) of an end blade was found at a depth of three and one half inches below the surface among the flagstones on the eastern side of the depression. Like other end blade bases it is convex, bifacially flaked and unground. It is most similar to the bases of sidenotched end blades, but is unusually wide. The width is $22 \mathrm{~mm}$. and the thickness $3.5 \mathrm{~mm}$.

Harpoon Blades

A triangular end blade of greyish-brown chert was found near the centre of the house at a depth of an inch. An harpoon blade, it is very small compared to harpoon blades from other settlements. This triangular blade is bifacially flaked on all margins. The lateral edges are straight and the base slightly convex. Neither are ground. The tip is broken, but the width is $14 \mathrm{~mm}$. and the thickness $2.5 \mathrm{~mm}$. (see Fig. 23,h).

Side B1ades

Side blades were not recovered from House 10. 
A small notched knife (Fig. 23,j) of grey-green cherty material was discovered at a depth of three inches near the centre of the depression. The ventral surface is only marginally retouched while the dorsal surface has been more completely flaked. The convex base is dorsally flaked and ground. The body of the knife is asymmetrical, as the convex edge (35 mm. long) is shorter than the opposite straight edge (37 mm. long). The lower lateral notches are bifacially flaked and ground. The margins are all dulled, and the wear patterns of the convex edge indicate a side to side scraping motion rather than a sawing action. Both surfaces of this knife are lightly polished.

\section{Scrapers}

Two notched or stemmed asymmetrical scrapers were recovered. One (Fig. 23,k) was found on the surface among the limestone flags on the eastern edge of the central flake concentration. The single notch set half way along the right lateral edge is unusual. The left margin is straight and like the notch is ground. Only the convex base, which is dorsally thinned, and ground, has not been dorsally bevelled. The scraping edge is convex and dulled and crushed. Made on a curved flake of grey-white chert, the dimensions of this scraper are 28, 16, and $5 \mathrm{~mm}$.

Another offset scraper (Fig. $23, \mathrm{~m}$ ) was discovered at a depth of five inches beneath the surface in the northwestern portion of the depression. The convex base is dorsally thinned and slightly ventrally thinned. The lateral edges and the scraping edge are dorsally bevelled. The lower lateral margins are stemmed and the only grinding present on this specimen is on the right margin. Made of fine greyish chert, the dimensions of this scraper are 27,13 , and $5.5 \mathrm{~mm}$. 
All the attributes of another tool fragment (Fig. 23,1) suggest that it is the base of an offset scraper. The lower right margin is concave, dorsally bevelled and ground. The convex base is bifacially flaked and ground. The left margin is bifacially flaked, straight and also ground. The specimen differs only in its large size; it is $28 \mathrm{~mm}$. wide, and $6 \mathrm{~mm}$. thick. The material is a greyish chert that is very carefully knapped.

A sma11 scraper, trapezoidal in out1ine (Fig. 23,n) was uncovered at a depth of four inches near the centre of the depression. The non parallel lateral edges are dorsally bevelled while the parallel ends are dorsally thinned. The length from one parallel margin to the other is $15 \mathrm{~mm}$. The widest end is $15.5 \mathrm{~mm}$. across and the shortest is $9 \mathrm{~mm}$. The thickness is $4 \mathrm{~mm}$.

\begin{abstract}
Unifacial Blades and Microblades
These tools were not recovered from House 10 .
\end{abstract}

\title{
Flake Tools
}

The presence of flake tools was not recognized.

\section{Large Tools}

Three large pieces of red pyroclastic were found on the surface of the south central area of the depression. Two pieces are roughly plano-convex in cross-section while a third is bifacially flaked with a more lenticular cross-section. This last piece seems to be the unfinished working end of a wide gouge. In addition, four, more complete, large tools were recovered and are described below. 
A small gouge of brown pyroclastic (Fig. 24,a) was found in the central area of the depression. It is triangular in cross-section and appears to have been reworked from a larger tool. The proximal end is keeled, pointed, and much battered. The distal end is convex in outline and hollowed on the ventral surface. The dorsal surface is chipped and polished to form a sharp working edge while the lateral margins are heavily ground. This specimen is $92 \mathrm{~mm}$. Iong, $33.5 \mathrm{~mm}$. wide, and $25 \mathrm{~mm}$. thick.

A battered gouge of red pyroclastic (Fig. 24,b) was discovered on the surface, approximately five feet south of the depression edge. It appears to once have been of the gouge variety which is narrow with on $1 y$ slight marginal constrictions. Most of the working end is broken off, but was once ground and polished. The dorsal surface of the proximal end is also polished. The lateral edges are heavily ground. Presently, this gouge is $104 \mathrm{~mm}$. Iong, $50 \mathrm{~mm}$. wide and $25 \mathrm{~mm}$. thick.

\section{Chise1s}

A flaked piece of banded grey cherty sedimentary material (Fig. $24, c)$ was found seven feet south of the dwelling depression. One end is pointed with a chisel-like tip. This tip is $7 \mathrm{~mm}$. wide and dorsally polished. The lateral margins are dorsally bevelled and unground. The cross-section is roughly plano-convex. The proximal end of this tool is much battered, suggesting that the tool was used as a chisel and struck on this end. Dimensions are 92, 47, and $24 \mathrm{~mm}$.

\section{Scraper Planes}

These tools were not recovered from House 10 . 

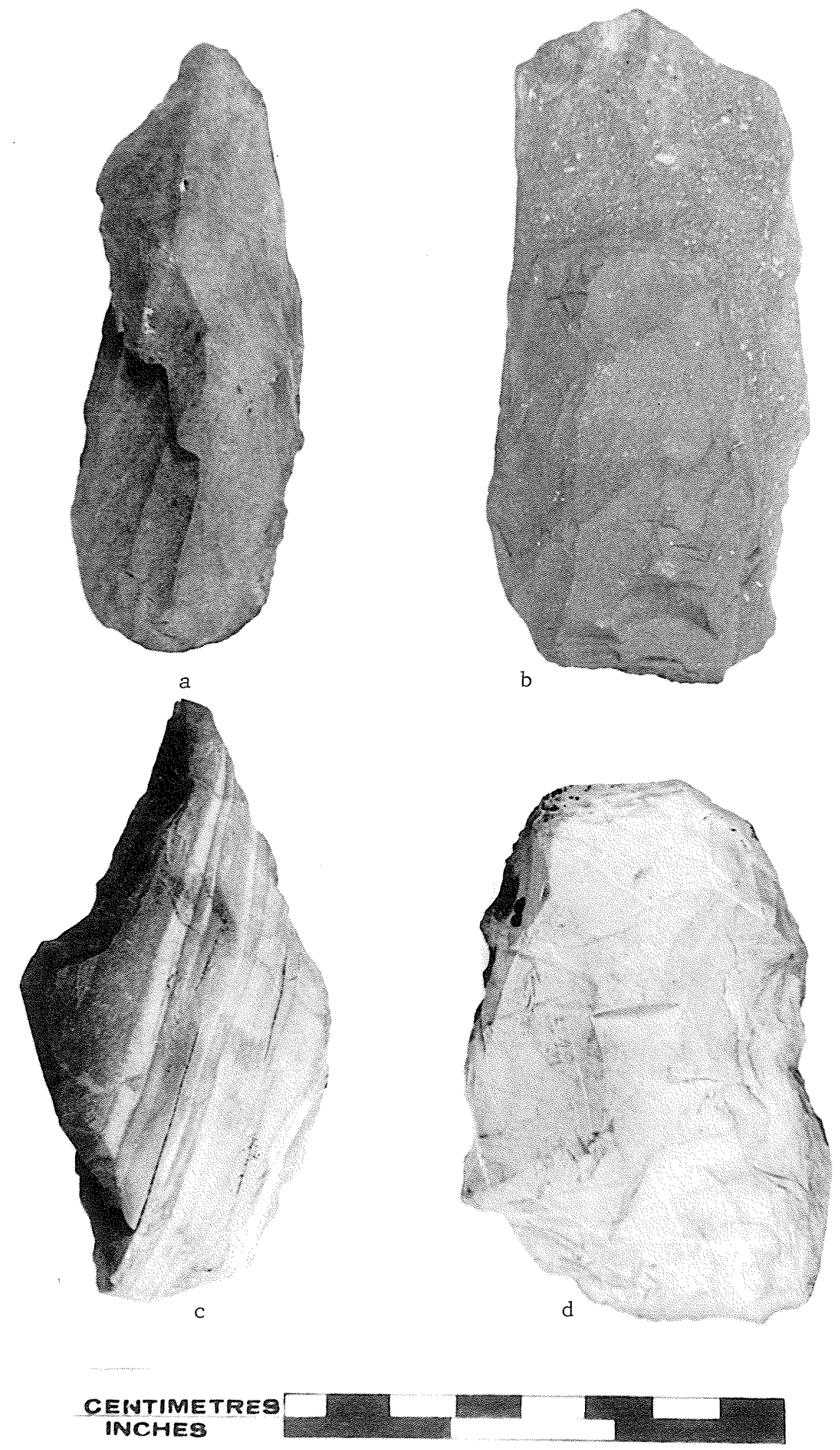

Fig. 24. Seahorse Gully site tools. House 10: a, gouge; b, battered gouge (?); c, chise1; d, adze blade. 
On the surface near the centre of the depressed area, a large tool of grey-green cherty material was discovered. This tool (Fig. 24,d) appears to be a battered adze blade. Roughly lenticular in cross-section, the edges are bifacially knapped and ground where not broken. The working edge is slightly convex and has had one corner broken off. Dimensions of this tool are $72.5,45$, and $20 \mathrm{~mm}$.

Other Tools

Organic Materials

During the excavation of level 1, an antler tip was discovered (Fig. 25,c). It was located in the central area of the depression. This curved tine tip has been hacked or chopped off in a manner similar to a piece from House 5. One surface is disintegrated while the other retains much of the original surface. No cuts or abrasions are present on the tip or the undamaged surfaces. The length of this specimen is $86 \mathrm{~mm}$. and the thickness $24 \mathrm{~mm}$.

\section{Other Lithic Tools}

An unusual artifact was found near the centre of House 10 , on the surface. It is a relatively large chunk of granite which is cylindrical in shape, $5.8 \mathrm{~cm}$. thick and $10.2 \mathrm{~cm}$. in diameter. The two main surfaces are roughly flat and all of the circumference except one flattened area (5.5 $\mathrm{cm}$ long) has been shaped with a groove averaging $2.3 \mathrm{~cm}$. wide and $4 \mathrm{~mm}$. deep. This artifact weighs 1011 grams and has probably been fashioned for the attachment of a cord around the groove. It is possible that this object was a net weight. 
Four large tools were represented in the debitage by working edges struck off in the process of working the tools. Two are from the working edges of chise1s, both of banded grey cherty sedimentary stone. One is dulled, clearly much used, another is in mint conditon and not yet polished. The latter may have been accidently snapped off during the manufacturing process. Of similar stone is a fragment of gouge edge, dorsally and ventrally polished, but marginally dulled, as if through use. Another chisel tip, of brown pyroclastic, is very similar to the first described above. It is dorsally and ventrally polished and marginally dulled. Several concentrations of flakes within the dwelling were noted and collected. One consisted of grey banded flakes from the reworking of a chise1, as evidenced by the above described chise1 tip found within the concentration. This flake cluster was found in the same area as the knife $(23 j)$. Another concentration of the same material (Map 18,13) was found three feet away. It also contained a pick end which is described above.

Scattered throughout leve1 1 was a random assortment of flakes, dominated by banded grey cherty sedimentary rock. Many of the flakes have been struck from the ground edges of large tools. Lower frequencies of brown and red pyroclastic as well as greenish cherts were present. The major concentration of red pyroclastic flakes occurred in the central portion of the feature. Here, red flakes were found on the surface and to a depth of four inches. Some 275 flakes were concentrated here. Five of these flakes have ground platforms.

The presence of nine large tools in House 10 is directly evidenced by the four fragments described aboveand the single fragmentary and four 
complete large tools discussed previously. However, only four lithic materials are represented by these eight tools. These materials are; (1) brown pyroclastic, (2) red pyroclastic, (3) grey banded cherty sedimentary, and (4) grey-green cherty sedimentary. Another three lithic materials; (1) grey pyroclastic, (2) dark grey cherty sedimentary, and (3) black cherty sedimentary, are represented in the 1ithic flakes (Table 17), indicating that at least three more tools were present in House 10. The near absence of chert flakes in this dwelling is of interest. The twenty flakes of grey and white chert are mainly retouch flakes. Clearly, the emphasis was on the working and reworking of large tools.

\section{FAUNAL REMAINS}

Several bones were found beneath the flagstones of the "floor" of House 10. These included the proximal fragment of a right seal femur and a distal fragment of a left seal femur. With these were six phalanges, seven rib fragments, and nineteen other unidentified fragments.

Mixed with the concentration of red pyroclastic flakes were the distal end of a right seal humerus and eleven unidentifiable bone fragments. Random finds of bone throughout level 1 included the left and right mastoid regions of a fragmentary seal skull plus two other skull fragments probably from the same animal. Also identifiable was the proximal fragment of a left seal scapula. Unidentifiable specimens include thirty phalanges, twenty-six rib fragments, a vertebral fragment, and a smashed and chopped bone. A large chip of ivory or bone was also recovered.

While many of the above bones appear to be of the small ringed seal, two very interesting bones are those of a bearded seal (Erignathus 
LITHIC DEBRIS FROM HOUSE 10

\begin{tabular}{|c|c|c|c|c|}
\hline & Area & Material & Tota1 & $\begin{array}{l}\text { Ground } \\
\text { Platform }\end{array}$ \\
\hline 1 & $\begin{array}{l}\text { Surface and level } 1 \text {, } \\
\text { south central area } \\
\text { of the depression }\end{array}$ & $\begin{array}{l}\text { Red pyroclastic } \\
\text { Brown pyroclastic } \\
\text { Grey pyroclastic } \\
\text { Green cherty sedimentary } \\
\text { Grey banded cherty } \\
\text { sedimentary } \\
\text { Dark green cherty } \\
\text { sedimentary } \\
\text { Whitish chert }\end{array}$ & $\begin{array}{r}275 \\
1 \\
1 \\
12 \\
\\
3\end{array}$ & $\begin{array}{l}5 \\
- \\
- \\
4 \\
-\end{array}$ \\
\hline 2 & Level I flakes & $\begin{array}{l}\text { Red pyroclastic } \\
\text { Brown pyroclastic } \\
\text { Grey banded cherty } \\
\text { sedimentary } \\
\text { Black cherty sedimentary } \\
\text { Green cherty sedimentary } \\
\text { Whitish chert }\end{array}$ & $\begin{array}{r}164 \\
22 \\
35 \\
8 \\
7 \\
12\end{array}$ & $\begin{array}{r}12 \\
9 \\
20 \\
2 \\
1 \\
-\end{array}$ \\
\hline 3 & $\begin{array}{l}\text { Flake concentration } \\
\text { three inches deep } \\
\text { (Fig. } 19, j)\end{array}$ & $\begin{array}{l}\text { Red pyroclastic } \\
\text { Grey banded cherty } \\
\text { sedimentary } \\
\text { Whitish chert }\end{array}$ & $\begin{array}{r}1 \\
36 \\
3\end{array}$ & $\begin{array}{r}- \\
18 \\
-\end{array}$ \\
\hline 4 & $\begin{array}{l}\text { Flake concentration } \\
\text { three inches deep } \\
\text { (Map } 18,13 \text { ) }\end{array}$ & $\begin{array}{l}\text { Grey banded cherty } \\
\text { sedimentary } \\
\text { Whitish chert }\end{array}$ & $\begin{array}{r}56 \\
2\end{array}$ & $\begin{array}{r}16 \\
-\end{array}$ \\
\hline 5 & Leve1 2 & $\begin{array}{l}\text { Red pyroclastic } \\
\text { Brown pyroclastic } \\
\text { Grey banded cherty } \\
\text { sedimentary }\end{array}$ & $\begin{array}{r}14 \\
20 \\
70 \\
751\end{array}$ & $\begin{array}{r}2 \\
6 \\
22\end{array}$ \\
\hline
\end{tabular}


barbatus). One fragmentary right femur of an adult bearded seal and the proximal shaft portion of a right fibula, also of a bearded seal, were found in level 1 (H. Savage, personal communication, 1970). Dr. Howard Savage (personal communication, 1970) also identified two teeth from level 1:

The large tooth portion, No. 3 , is from a lower canine tooth of a large Bear, while the smaller one, No. 4, is the left lower 3 rd incisor with a similar origin (perhaps from the same individual). I am not able to distinguish between Polar Bear or Grizzly Bear as their source.

Dr. Savage also commented that the polar bear would be more likely to be found coastally than the grizzly bear.

From level 2 excavations came two skull fragments, nine phalanges, four rib fragments and a vertebral fragment, all of ringed seal size. Also found in leve1 2 was the broken premolar of a wolf (G. Lammers, personal communication, 1970). Fifteen unidentifiable bone fragments were found as well.

\section{SUMMARY}

House 10 was an intensively occupied Pre-Dorset dwelling. Lithic flakes and tools were concentrated in a very small area, only eight and a half feet long and six and a half feet wide. This house had fewer artifacts scattered outside of it than any other equally productive habitation area. It may be a fair speculation to suggest that such a concentration of activities indoors may have been a result of cold weather. No bird bones were present in the faunal remains from House 10 , suggesting that it was occupied during a cooler season. The presence of remains of the bearded seal, however, seems to indicate the presence of open water. It is possible, though, that these seals may have been present throughout the winter in the open leads at the floe edge. 
As is characteristic of three other houses in the northern settlement, the floor of House 10 is depressed a few inches and a portion of it has been paved with limestone and grey quartzite slabs. There is no discernable stone alignment around the house depression and it is not clear what dwelling shape was present.

The burins from this dwelling exhibit unusual variety in size, in the length-width ratios, and in general style. One burin is stemmed (both lateral margins are concave) while another is unusually long (Fig. $23, \mathrm{~b})$. The other two burins conform more closely to the attributes characteristic of Seahorse Gully burins.

The recovery of a burin-like tool from this dwelling is of particular significance. It is flaked and not bifacially ground, as is usual for Dorset burin-like tools, however, it is very similar to a flaked burin-1ike tool from one of the Dorset houses at the sixty foot level of the Seahorse Gully site (Nash 1970:5). This specimen demonstrates that an element characteristic of the Dorset culture was known in the earlier Pre-Dorset period.

The presence of both ringed seal and bearded seal remains reflects the maritime emphasis of the economy of the inhabitants of this dwelling. The single small harpoon blade provides evidence of the use of the toggle harpoon. Polar bear and wolf bones are of particular interest since they suggest that these Pre-Dorset Eskimos hunted large and fierce animals as well as birds and seals. The side notched end blade is probably an arrow point used in hunting land animals.

The presence of the grooved weight, possibly a netsinker, provides the only evidence from the whole site of fishing. Stone weights have 

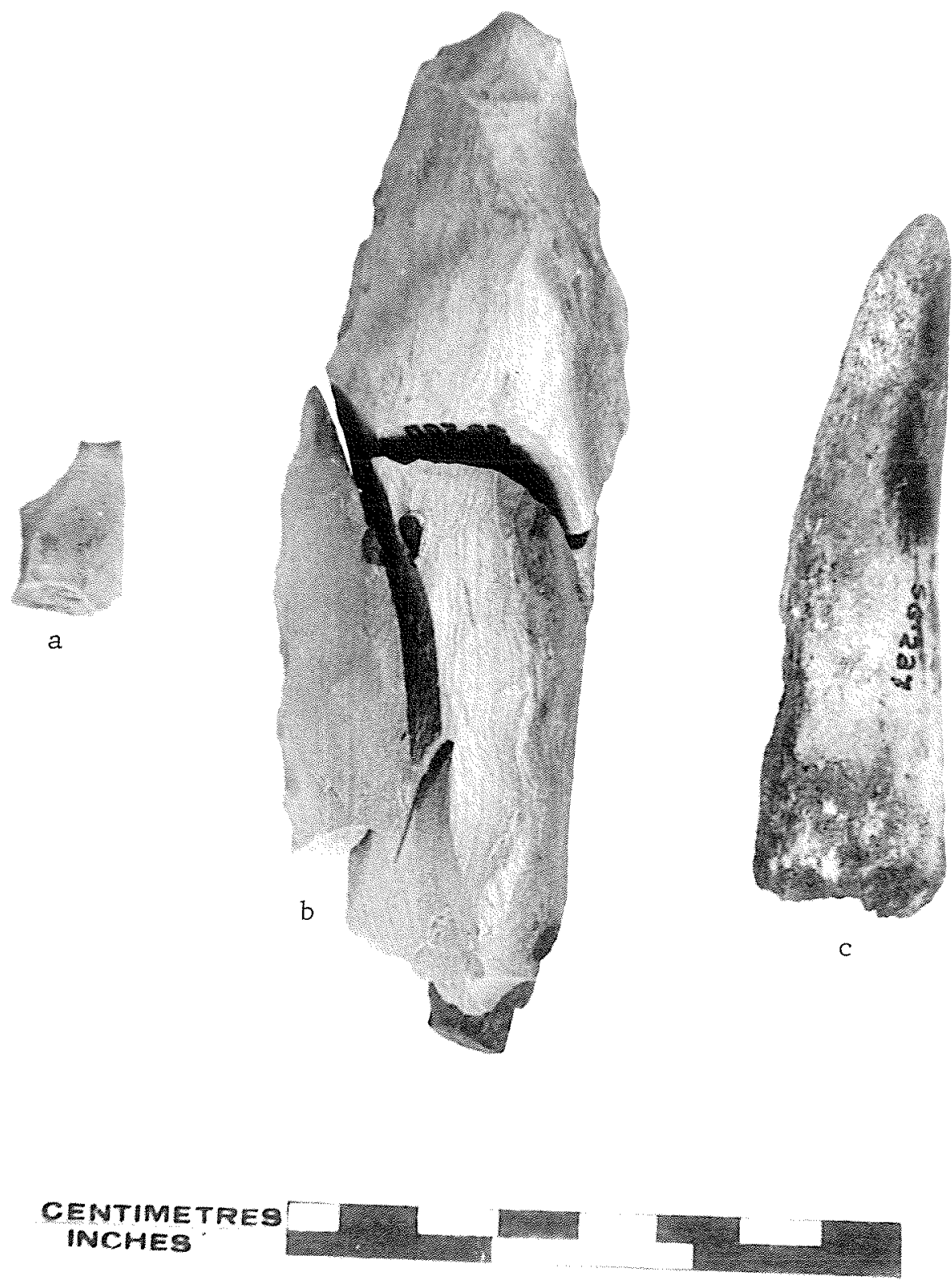

Fig. 25. Seahorse Gully site artifacts. House 1l: a, burin. House 12: b, large tool (chisel ?). House 10: c, antler tine. 
been recovered from other early Eskimo sites in the Arctic, but they are very rare (Taylor 1968:92).

HOUSE 11

The centre of House 11 was situated 1520 feet north of datum. The distance from the base line east, to a point in the centre of this former dwelling, was twelve feet four inches. This habitation area was located on the eastern edge of the cobble mantle, adjacent to a field of huge boulders which flanks this edge of the mantle.

\section{DWELLING REMAINS}

The feature marking House 11 was a depressed area surrounded by many stones. The interior of the dwelling was depressed to a depth of from four to five inches. In the process of digging out this area, prehistorically, the floor appears to have been cleared of the large and small grey cobbles scattered throughout the mantle. These were massed around the perimeter of the depression and probably were used to hold down tent coverings (Map 19). It is likely that the natural depression between the boulder field on the east and the cobble mantle on the immediate west side of the feature was taken advantage of and simply enlarged to form the basin occupied by the dwelling. This basin was more circular than oblong in shape, with inside dimensions of approximately eleven by thirteen feet.

Seven grey quartzite flagstones were found arranged in a line, inside the southern half of the dwelling. These may have formed a kitchen area or an entrance way. House 11 was not excavated, partly because of the lack of time, but also because very few artifacts were 


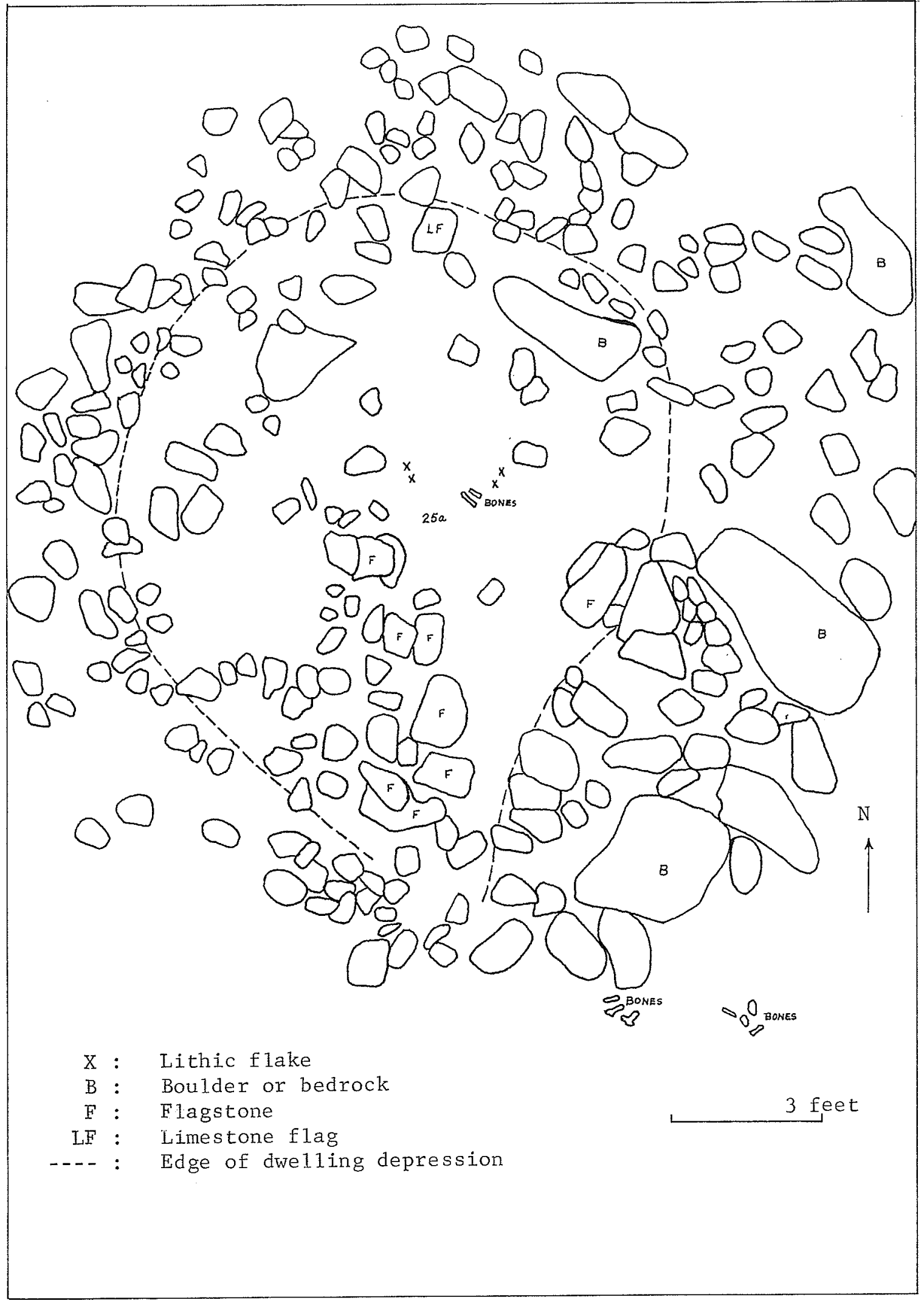

Map 19. Floor plan of House 11. 
recovered from the surface. Thus, below, those objects collected from the surface of the house are described.

\section{ARTIFACTS}

Only four lithic specimens were found; a burin, and three other flakes.

Sma11 Tools

Only one small tool, a burin, was found. It is possible that excavation of this dwelling would have revealed more smal1 tools.

\section{Burins}

The single burin (Fig. 25,a) recovered is of grey chert. The short left margin is concave and is carefully dorsally bevelled and ventrally thinned. The right margin is straight and dorsally bevelled only. Both margins are completely ground. The base is dorsally thinned, with very slight ventral flaking. The bulb of percussion of the ventral side remains largely intact, and it is evident that unsuccessful attempts have been made to remove it. The base is slightly convex.

Al1 the hinge fractures have been removed through the dorsal bevelling of this edge. Only the last two spalls struck off have left scars. The distal platform is broken so that the present dimensions are 23, 13, and $4.5 \mathrm{~mm}$. This burin was discovered on the surface, in the approximate centre of the depression.

Large Tools

Large tools were not recovered from House 11. 
No other tools were found on this dwelling's surface.

\section{DEBITAGE}

Three chert flakes were found on the surface of the feature. Two are grey and one is pink in colour. No flakes of pyroclastic material were recovered.

\section{FAUNAL REMAINS}

Two fragments of bone were collected from the surface of the feature. One is a fragment of a left seal scapula. The other bone may be a fragment of this same scapula.

\section{SUMMARY}

House 11 was an oval or circular Pre-Dorset dwelling set in a basin between the mantle and a boulder field. The dwelling depression may have originally been excavated to a greater depth, as with the passage of time it must have been filled in by several inches of sand and gravel. Although presently depressed to a depth of four or five inches in the centre, an illusion of greater depth results from the fact that the house is located in an already depressed area.

The general lack of artifacts suggests a short occupancy. However, the excavation of this floor would undoubtedly have uncovered more artifacts. There is a tendency for artifacts in houses with subterranean floors to be buried more deeply than artifacts from houses set flat on the ground. The faunal remains indicate the hunting of sea mammals, principally the ringed seal. 
The remains of this dwelling were discovered approximately twenty feet south of House 11, on the gravel surface of the eastern edge of the cobble mantle. The southern edge of the houses depression was 1500 feet north of the centra1 datum point.

\section{DWELLING REMAINS}

The presence of a stone alignment played little part in the recognition of this dwelling. A large depression up to five inches in depth was present and it was noted that small stones tended to be scattered around the edges of this depression. This shallow basin was oval or oblong in shape, approximately nine feet wide and thirteen and a half feet 1ong. Four grey quartzite stones found in the centre of the depression were associated with a central concentration of flakes (Map 20). Since these stones appear to have been the centre of dwelling activities it is likely they formed part of a hearth.

Only lithic flakes were recovered from House 12. Excavations might have produced more artifacts, however, the pressure of time did not permit the excavation of this relatively indefinite feature, with its paucity of surface artifacts.

Sma11 Tools

Small tools were not recovered from the surface of House 12 .

Large Tools

Only one large tool, a chisel, was recovered from this habitation area. 


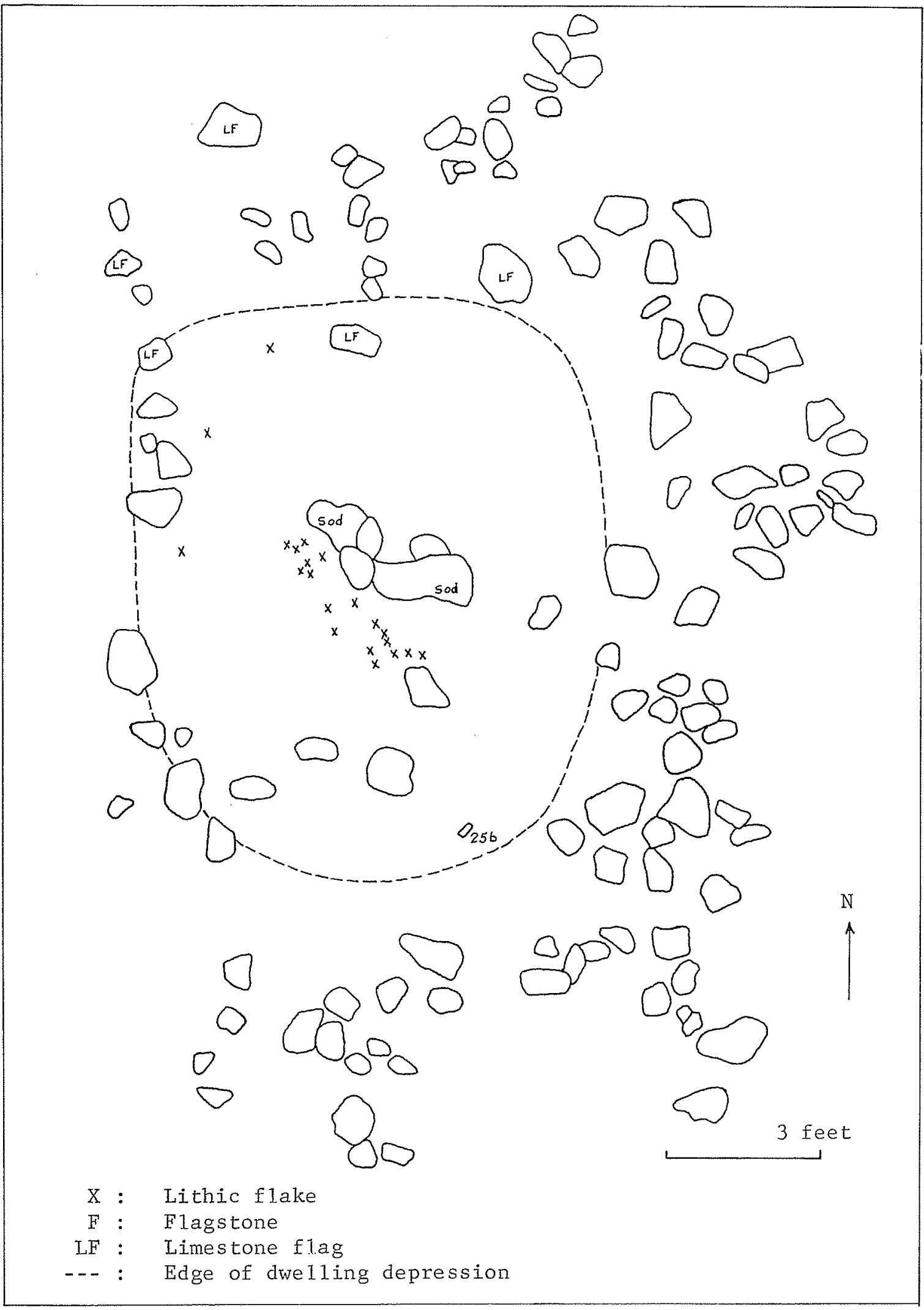

Map 20. F1oor plan of House 12. 
Only a few objects were found and these were predominantly flakes from the resharpening of a chisel. This chisel was found broken into several pieces, only the four largest of which could be fitted together. Two of these, the working tip of the chisel and a large central portion were found along the southern and southwestern margin of the depression. The other two pieces were found in the middle of the dwelling with numerous other flakes. These four large flakes form most of the chise 1 (Fig. 25,b). Made of brown pyroclastic, the working tip is ventrally hollowed and both surfaces have been rubbed or polished. At present, this narrow working tip is crushed and battered and this may be the reason that attempts were made to resharpen the tool.

The end opposite from the chisel tip appears to have been chipped into a gouge edge. Although not ground on either surface, this edge is marginally dulled, either through use or intentional grinding. This fragmentary large tool provides evidence that large tools were not simply reworked into the same tool, but might be reshaped into something quite different.

Other Tools

Unusual lithic tools or tools of organic materials were not recovered from House 12 .

\section{DEBITAGE}

Other refuse from the reworking of this large tool is eighteen brown pyroclastic flakes. Eleven of these have been struck from the dulled margins of the tool. One of these is polished over the dorsal surface. Also recovered from the central area of the depression were 
five flakes of grey cherty sedimentary material. Three of these have ground platforms. As this material is that used for large tool manufacture and since three flakes have been struck from the ground and dulled edges of a large tool, it is clear that this large tool was reshaped in this dwelling.

\section{SUMMARY}

House 12 had a depressed floor with a central hearth. The depression is oval or oblong in shape with stones scattered around it. It is possible that gravel was heaped around the lower edges of a tent cover.

At least two large tools were reworked in this dwelling. The fact that no other tools were discovered suggests a short occupancy, and it is unlikely that excavation would result in a changed interpretation of the length of occupation.

HOUSE 13

House 13 was the most northerly Pre-Dorset dwelling at the Seahorse Gully site. It marked the farthest extent of occupational debris along the cobble mantle. The southern end of this dwelling was approximately 1829 feet north of datum and ten feet west of the base line.

\section{DWELLING REMAINS}

House 13 was characterized by an oval alignment of stones around a central depression. This feature is interpreted as an oval tent ring surrounding a semisubterranean dwelling floor (Map 21). This floor was depressed from five to six inches, and originally may have been deeper. Several rocks and boulders have fallen or rolled into the shallow basin. 


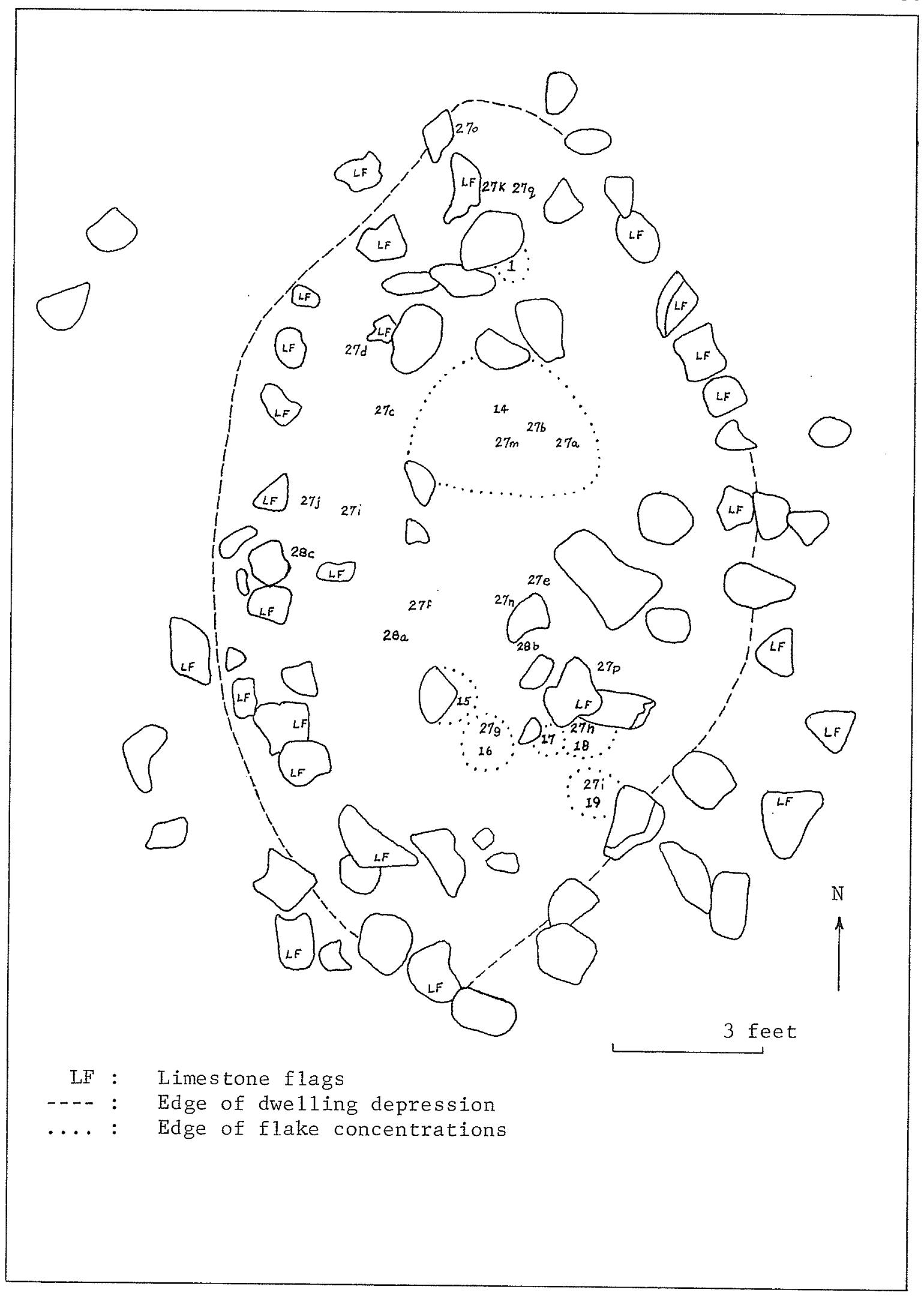

Map 21. Floor plan of House 13. 
Seven of these are clustered at the northern end and six inside the southern portion of the house (Fig. 26,b).

The use of limestone slabs characterizes House 13. Eight of these line the eastern edge of the depression and another fifteen limestone slabs are present along the western edge. All of these flags appear to be in. situ, essentially undisturbed. A few limestone flags are present on the depressed floor, but a "pavement" of these was not present. This house was about sixteen feet long and ten feet wide. It was excavated in two three inch levels.

\section{$\underline{\text { ARTIFACTS }}$}

Sma11 Tools

Burins, burin spal1s, an end blade, scrapers, and flake tools were the only small tools recovered from House 13. Harpoon blades, side blades, knives, and unifacial blades or microblades were not found.

\section{Burins}

Ten whole and fragmentary burins were recovered from House 13. A11 but one of these were found in level 1 excavations at depths ranging from one inch to three inches below the surface. One burin (Fig. 27,j) was found in level 2 at a depth of five inches on the west central edge of the (Map 21). The burins are quite standardized in their attributes, with transversely spalled or ground distal striking platforms, convex, bifacially flaked bases (unground), dorsally thinned and bevelled lateral margins with rare ventral flaking, and oblique burin facets. An attribute which occurs only among these burins is the ventral flaking of the burin facet. This feature is idiosyncratic and probably reflects the unusual 


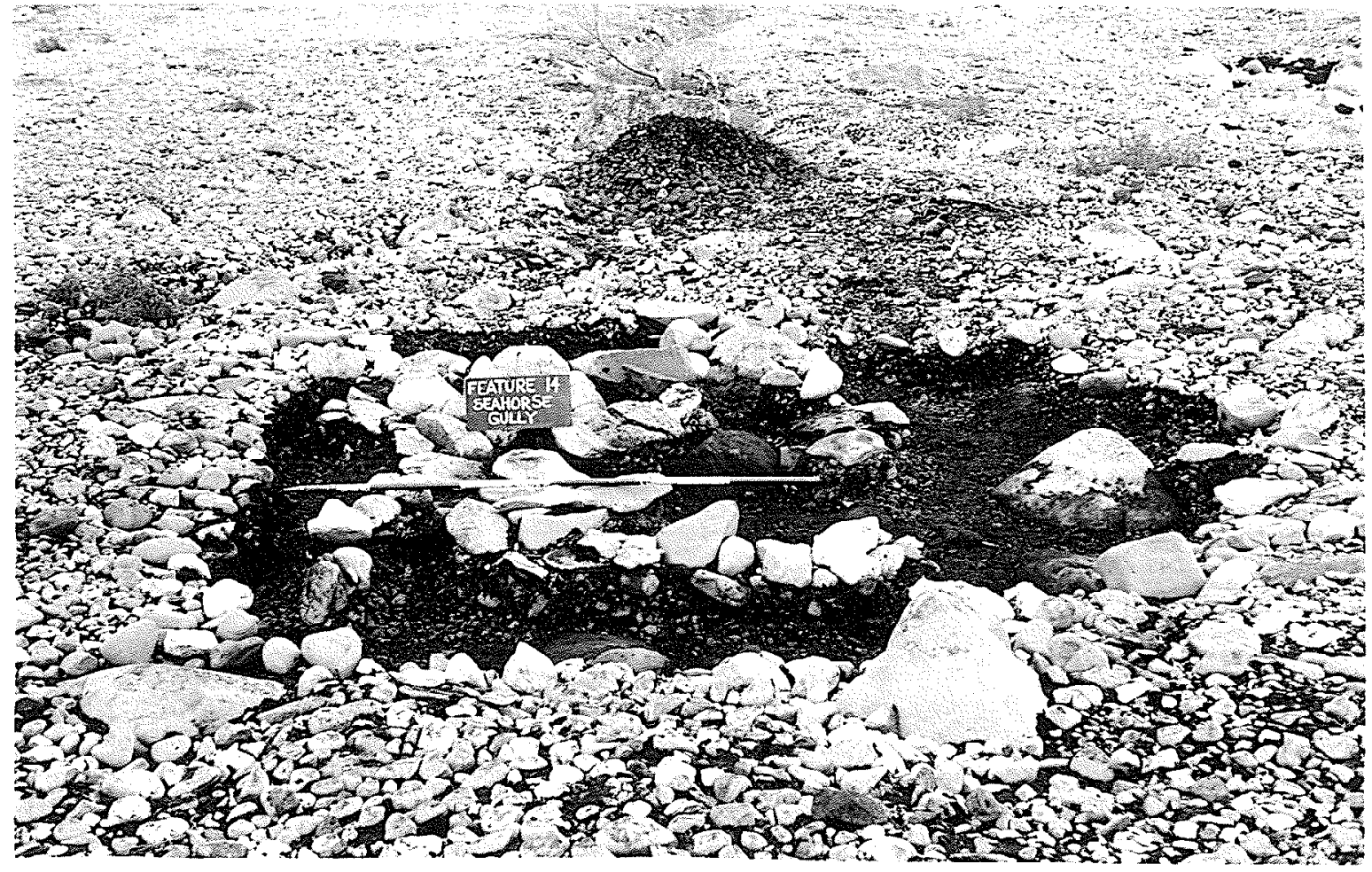

Fig. 26,a. The excavation of House 10, 1ooking east.

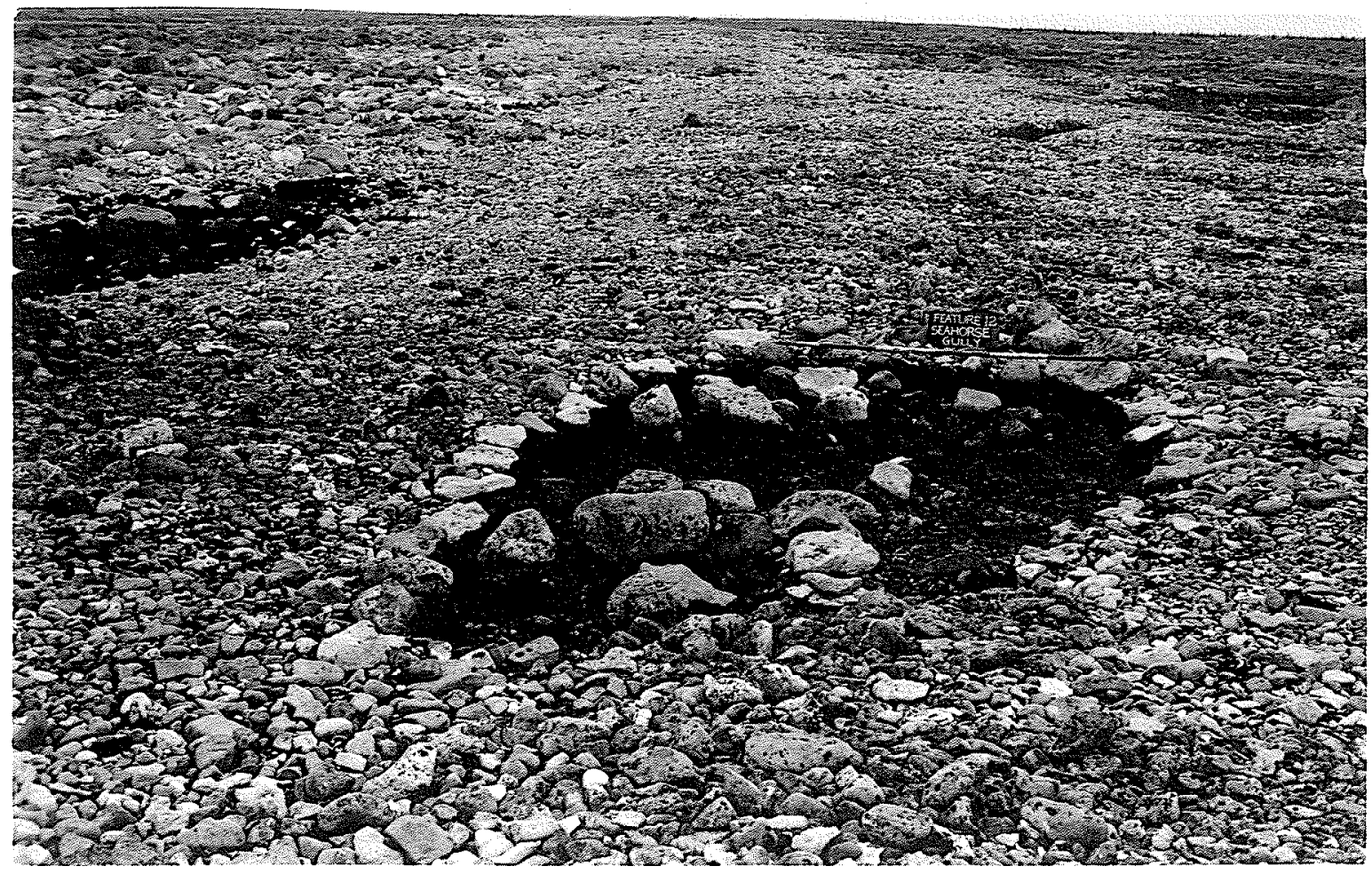

Fig. 26,b. The excavation of House 13. The view is towards the south, looking along the cobble mantle. 
manufacturing habits of one of the persons who lived in this dwelling. Grinding of the burin faces is tentatively recognized in three cases. One of these (Fig. 27,a) is very slightly smoothed on the dorsal surface. Another two burins (Fig. 27,d,j) appear to have been ground on their distal ventral surfaces.

\section{Burin Spal1s}

Two burin spal1s were found on the surface of the central area of the depression. One is a primary spall of pink chert. It is proximally ground and the opposite end is flaked to form a uniface tool. The other spall is secondary, also struck from a ground platform, but does not appear to have been utilized as a tool. Another burin spall was found in leve1 1 excavations in the southern half of the basin, near the surface finds of spalls. This spall is primary, has a ground platform and is of pink chert.

\section{End Blades}

The base of a lanceolate end blade (Fig. 27,k) was recovered in the northern part of the dwelling in level 1 , at a depth of two inches below the surface. The base is convex with rounded corners and is unground. The lower lateral edges are straight, also unground, and contract slightly to the base. Made of whitish chert, this fragment is completely bifacially knapped. Flake scars are irregular in size and spacing. The greatest width is now $18 \mathrm{~mm}$. and the thickness is $6.5 \mathrm{~mm}$.

Harpoon Blades

These tools were not recovered from House 13. 
ATTRIBUTES OF BURINS FROM HOUSE 13

1 DISTAL PLATFORM
a. Ground
b. Dorsally Flaked
c. Transversely Spalled
d. Ventrally Flaked

2 BASE
a. Concave
b. Straight
c. Convex
d. Dorsa11y F1aked
e. Ventrally Flaked
f. Ground

3 RIGHT LATERAL EDGE
a. Concave
b. Lateral Flare
c. Straight
d. Convex
e. Ground
f. Ventrally Flaked
g. Dorsally Bevelled

4 LEFT LATERAL EDGE
a. Concave
b. Notched
c. Straight
d. Convex
e. Ground
f. Ventrally Flaked
g. Dorsally Bevelled

5 BURIN FACET
a. Oblique
b. Vertica1
c. Acute
d. Dorsally Flaked
e. Ventrally Flaked

6 BURIN SURFACES
a. Ventral
b. Dorsal

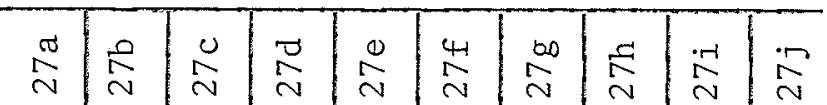

\begin{tabular}{l|l|l|l|l|l|l|l|l} 
& & & & & & & & \\
\end{tabular}




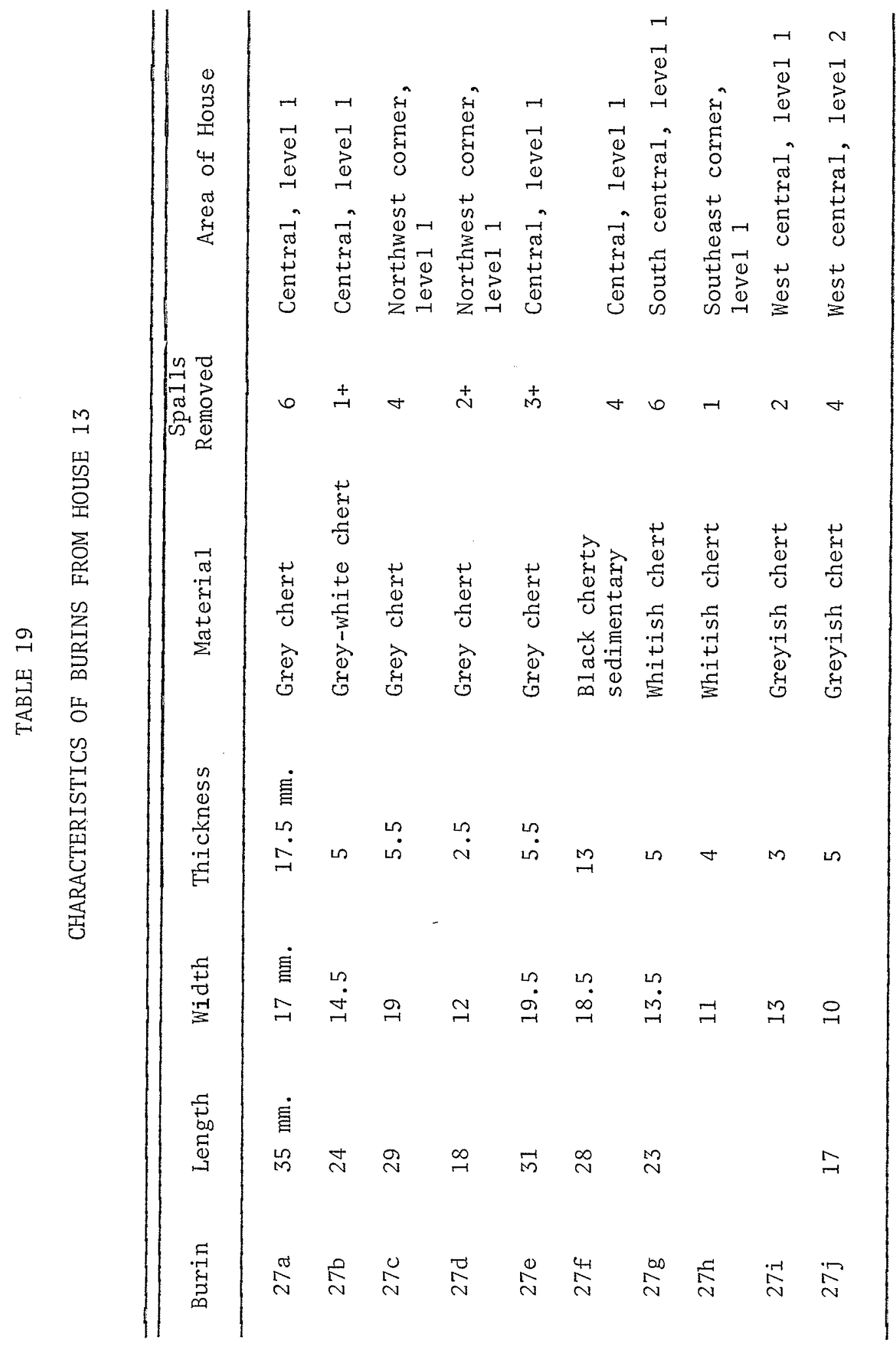




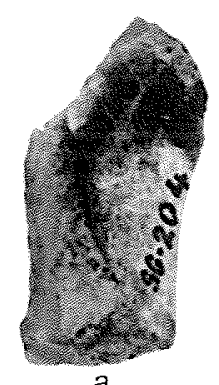

a
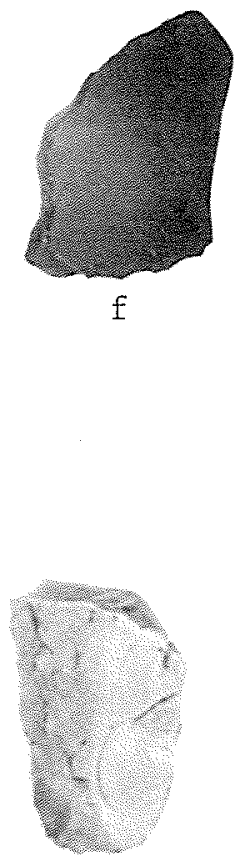

k

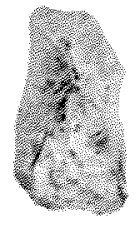

p

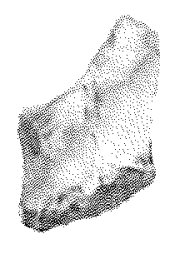

b

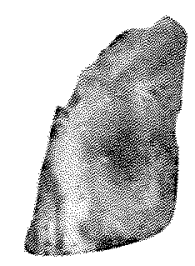

g

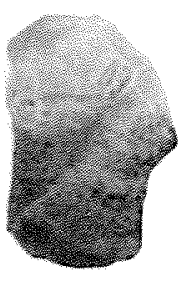

1

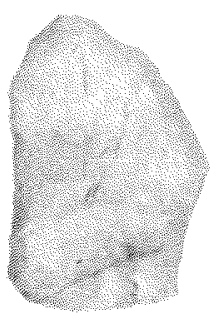

q

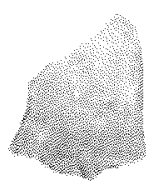

d
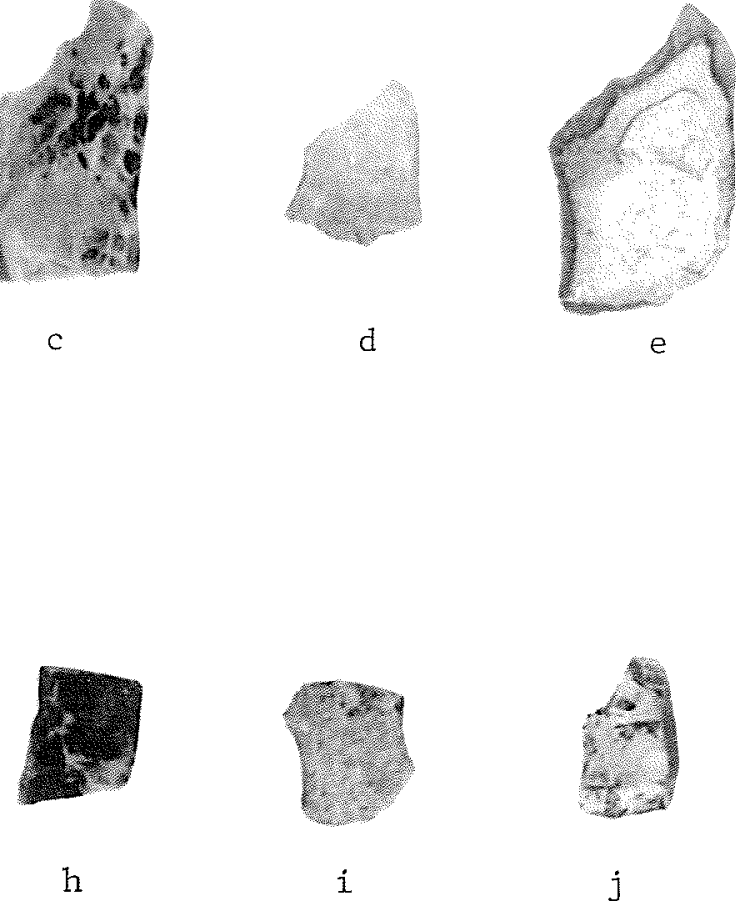

h

i

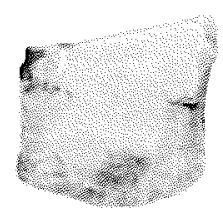

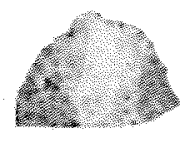

$\mathrm{m}$

n

O
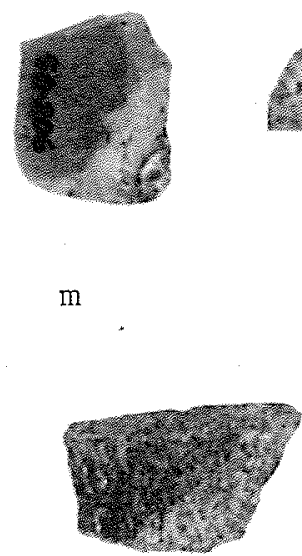

I

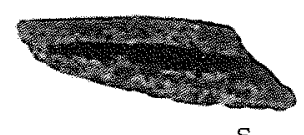

$\mathrm{s}$

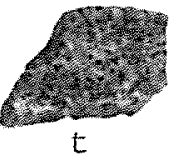

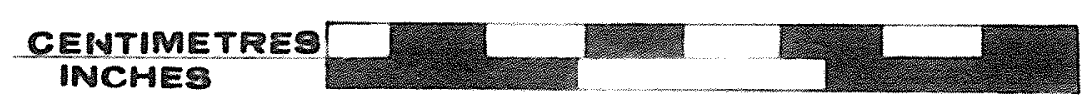

Fig. 27. Seahorse Gully site tools. House 13: a-j, burins; $k$, end blade base; $1-q$, scrapers; $r-t$, steatite fragments. 
Side Blades

Side blades were not found in this dwelling.

$\underline{\text { Knives }}$

Knives were not found in House 13.

\section{Scrapers}

"Notched" asymmetrical scrapers are very common in this dwelling. Only one (Fig. 27,1) was found on the surface, near the west central "wa11". This tool is made on a curved flake of grey chert, of which only the dorsal surface has been flaked. The right margin is concave and the left only slightly so. Both are heavily ground. The convex base is unground. Unlike all the other edges which are dorsally flaked, the convex scraping edge is dorsally bevelled. This scraping edge is crushed and dulled. Dimensions are 26, 18, and $5.5 \mathrm{~mm}$.

Another five scrapers, or fragments thereof, were found in the excavation of level 1. The base of an asymmetrical scraper (Fig. 27,m) was found in the northern portion of the basin, at a depth of one and a half inches below the surface. The distal tip has broken off, but part of an oblique concave scraping edge is still present. This scraping edge and both lateral margins are dorsally bevelled. The right margin is slightly concave and like the straight left edge, is ground. The base is convex, bifacially thinned and ground. Made of grey chert, this tool is $16 \mathrm{~mm}$. wide and $4.5 \mathrm{~mm}$. thick.

A fragment of a scraper (Fig. 27,n) was found in the centre of the dwelling basin at a depth of one inch. Dorsally flaked, this piece is probably the distal end of an unfinished scraper. It is roughly flaked from grey chert, presently $17 \mathrm{~mm}$. wide and $5 \mathrm{~mm}$. thick. 
Also recovered was the basal portion of an asymmetrical scraper (Fig. 27,o) made of greyish chert. The left margin is straight, bifacially flaked and heavily ground. The base differs only in its convexity. The right edge is concave, dorsally bevelled, and ground. Found at the extreme northern end of the stone alignment, at a depth of two inches, this specimen is $21 \mathrm{~mm}$. wide and $3.5 \mathrm{~mm}$. thick.

A complete scraper (Fig. 27,q) whose base is similar to "o" was found about a foot away, also at the extreme northern tip of the dwelling, at a depth of 3 inches. This scraper (Fig. 27,q) was found at the top of the level 2 excavations. Made of grey chert, the convex base of this specimen is bifacially flaked and lightly ground. The lateral edges are both subconcave, dorsally bevelled and ground. The oblique, convex scraping edge is also dorsally bevelled and is not crushed or dulled. The greatest width of this scraper is $20.5 \mathrm{~mm}$, the length is $30.5 \mathrm{~mm}$., and the thickness $4 \mathrm{~mm}$.

A small offset scraper (Fig. 27,p) was recovered between two and three inches below the surface in the southeastern portion of the basin. Made on a thick flake of grey chert, all the edges are dorsally bevelled except the convex base which is bifacially flaked. Both lateral edges have distal concavities, but only a portion of the left is ground. The slanting scraping edge is dorsally bevelled and straight to slightly concave. The distal tip is broken off. Dimensions are 21, 10.5, and 6 $\mathrm{mm}$.

Unifacial Blades and Microblades These tools were not recovered from House 13. 
Two fragmentary flake tools or tools broken in the process of manufacture were recovered from House 13. One of these chert flakes was found at a depth of half an inch near the centre of the depression. This fragmentary piece is bevelled and thinned on one edge and thinned only on the other. It probably represents the initial stages in the manufacture of a tool.

Another broken flake of greyish chert is very thin and is marginally retouched on the ventral side, but only partially retouched on the dorsal surface. This delicate retouch may indicate use of this flake as a sharp cutting instrument. This flake was recovered from level 2 excavations.

Large Tools

\section{Gouges}

One large tool fragment of cherty grey-green quartzite (Fig. 28,a) was discovered near the centre of the dwelling at a depth of one inch. It does not easily fit into any of the large tool categories previously established, but may be the unfinished working edge of a gouge. The lateral edges are slightly convex as is the working edge. Plano-convex in cross-section, all edges are bifacially worked. This artifact is 55.5 $\mathrm{mm}$. wide and $20.5 \mathrm{~mm}$. thick.

\section{Chise1s}

The working tip of a carefully ground and polished chise1 (Fig. 28, b) came from a cluster of stones in the northeastern quadrant of the dwelling. It was found about five inches below the surface. The lateral margins contract to the distal (working) tip which is convex and about 


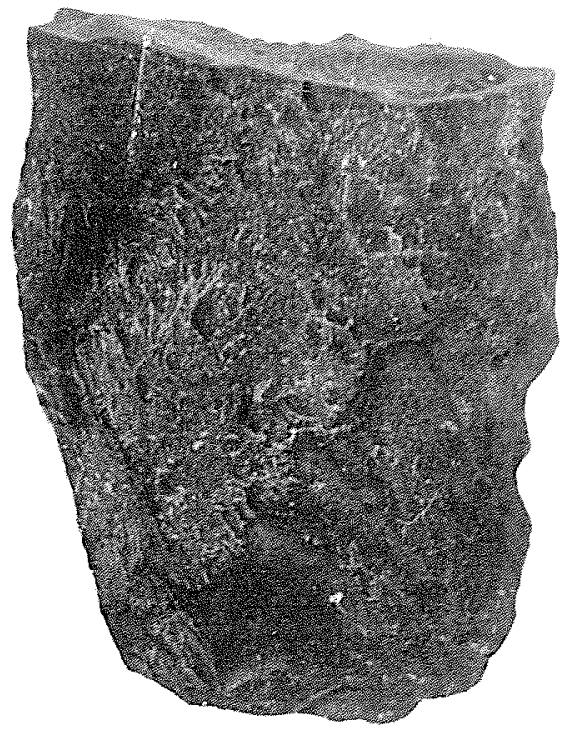

a
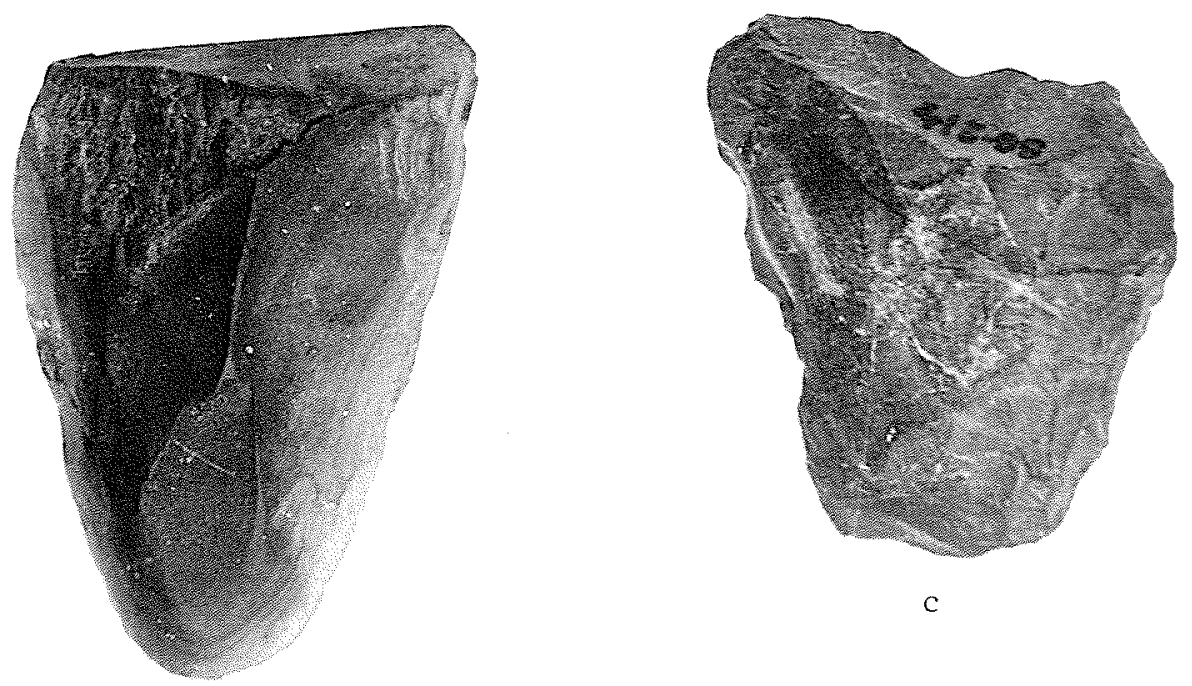

$\mathrm{b}$

\section{CEINTIMETRES INCHES}
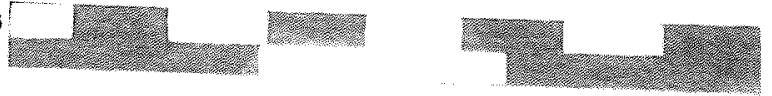

Fig. 28 . Seahorse Gully site tools. House 13: a, gouge fragment; b, chisel tip; c, chisel tip (?). 
$20 \mathrm{~mm}$. wide. This end is dorsally polished, and ventrally flaked, but through use the edge has become dulled and crushed. Flat on the ventral surface and rounded on the dorsal, this tool is plano-convex in crosssection. The lateral edges are ground or dulled. Made of a black, sedimentary, shale-like material, this chisel is $46 \mathrm{~mm}$. wide and $25 \mathrm{~mm}$. thick. From the centre of the western edge of the dwelling came another fragmentary large tool (Fig. 28,c). Made of a banded black chert-1ike material, it also seems to be unfinished. It appears to be the working edge of a chisel. It is roughly bifacially flaked and is plano-convex in cross-section. This specimen is $46.5 \mathrm{~mm}$. thick and $56 \mathrm{~mm}$. wide.

\section{Scraper Planes}

These tools were not found in House 13 .

Adze Blades

Adze blades were not recovered from this dwelling.

Other Tools

\section{Worked Organic}

Three of the four bones recovered appear to be parts of tools, whose polished surfaces have aided in their preservation. Two are splinters of ivory, the rounded tip of one suggesting use as a pressure flaker. Another is a polished piece of antler or ivory with one squared edge preserved. The fourth fragment is deeply pitted, but could be a fragment of a seal fibula.

Other Lithic Tools

Three fragments of a steatite vesse1 (Fig. 27,r,s,t) were dis- 
covered in the excavation of level 1 of the southern half of the dwelling area. All are rim fragments, and all are slightly curved. The style of this vessel differs from that of the oval dishes from the southern half of the site. The rims are thinner and more delicate with thicknesses of 4, 4.5, and $4.5 \mathrm{~mm}$. The margins are not rounded but are flattened and angular in cross-section. It is possible that a deep, thin walled, probably oval vessel is represented. However, the rims are more like those of vessels from the Dorset settlement at Seahorse Gully than those believed to be from the earlier Pre-Dorset settlement. Nash (1970:7) has described one of the smaller Dorset vessels in this manner:

The squarish vessel has slightly curved sides, flaring outward from the small base at an angle of about $48^{\circ}$. The walls are $0.62 \mathrm{~cm}$. thick and the height of the vessel is 3.2 $\mathrm{cm}$.

\section{DEBITAGE}

Debris from the knapping of large tools predominated in the lithics recovered from House 13. Only thirty-five flakes out of a total of 361 are of fine white cherts. Dark cherty or rhyolite-like (volcanic derivatives) materials dominated the flakes collected. The occurrence of at least seven distinctive materia1s; (1) red, (2) brown, and (3) grey pyroclastics, (4) green, (5) grey, and (6) black cherty sedimentarys, and (7) black rhyolite or dacite, indicate that at least this number of tools were worked.

The evidence for the reworking (resharpening) of large tools is extensive. Aside from the fact that flakes of every lithic material are struck from the ground or dulled edges of large tools, ground and polished but marginally dulled fragments of gouge and chisel edges were also recovered. 
LITHIC DEBRIS FROM HOUSE 13

\begin{tabular}{|c|c|c|c|c|}
\hline & Area & Material & Total & $\begin{array}{l}\text { Ground } \\
\text { Plat form }\end{array}$ \\
\hline 1 & Surface & $\begin{array}{l}\text { Whitish chert } \\
\text { Red pyroclastic } \\
\text { Brown pyroclastic } \\
\text { Grey pyroclastic } \\
\text { Green cherty sedimentary } \\
\text { Dark green cherty } \\
\text { sedimentary } \\
\text { Grey cherty sedimentary }\end{array}$ & $\begin{array}{l}5 \\
5 \\
7 \\
8 \\
9\end{array}$ & $\begin{array}{l}- \\
2 \\
6 \\
- \\
4 \\
5 \\
2\end{array}$ \\
\hline 2 & $\begin{array}{l}\text { Flake concentra- } \\
\text { tion, leve1 } 1 \\
\text { (Map } 21,1)\end{array}$ & $\begin{array}{l}\text { Grey banded cherty } \\
\text { sedimentary }\end{array}$ & 50 & 23 \\
\hline 3 & $\begin{array}{l}\text { Flake concentra- } \\
\text { tion, leve1 } 1 \\
\text { (Map } 21,14)\end{array}$ & $\begin{array}{l}\text { Brown pyroclastic } \\
\text { Grey pyroclastic } \\
\text { Grey cherty sedimentary } \\
\text { Green cherty sedimentary } \\
\text { Black rhyolite-like } \\
\text { Whitish chert }\end{array}$ & $\begin{array}{r}17 \\
11 \\
2 \\
8 \\
50 \\
12\end{array}$ & $\begin{array}{r}8 \\
3 \\
- \\
8 \\
20 \\
-\end{array}$ \\
\hline 4 & $\begin{array}{l}\text { Flake concentra- } \\
\text { tion, leve } 1 \\
\text { (Map } 21,15)\end{array}$ & $\begin{array}{l}\text { Brown pyroclastic } \\
\text { Green cherty sedimentary } \\
\text { Grey banded cherty } \\
\text { sedimentary } \\
\text { Whitish chert }\end{array}$ & $\begin{array}{r}4 \\
7 \\
23 \\
9\end{array}$ & $\begin{array}{l}- \\
2 \\
8 \\
-\end{array}$ \\
\hline 5 & $\begin{array}{l}\text { Flake concentra- } \\
\text { tion, leve } 1 \\
(\text { Map } 21,16)\end{array}$ & $\begin{array}{l}\text { Brown pyroclastic } \\
\text { Green cherty sedimentary } \\
\text { Banded black and grey } \\
\text { cherty sedimentary }\end{array}$ & $\begin{array}{r}1 \\
4 \\
20\end{array}$ & $\begin{array}{l}- \\
2 \\
8\end{array}$ \\
\hline 6 & $\begin{array}{l}\text { F1ake concentra- } \\
\text { tion, leveI } 1 \\
\text { (Map } 21,17)\end{array}$ & $\begin{array}{l}\text { Red pyroclastic } \\
\text { Brown pyroclastic } \\
\text { Green pyroclastic }\end{array}$ & $\begin{array}{r}11 \\
3 \\
1\end{array}$ & $\begin{array}{l}8 \\
3 \\
1\end{array}$ \\
\hline 7 & $\begin{array}{l}\text { Flake concentra- } \\
\text { tion, leve } 11 \\
(\text { Map } 21,18)\end{array}$ & $\begin{array}{l}\text { Dark green cherty } \\
\text { sedimentary } \\
\text { Brown pyroclastic }\end{array}$ & $\begin{array}{r}10 \\
1\end{array}$ & $\begin{array}{l}6 \\
-\end{array}$ \\
\hline 8 & $\begin{array}{l}\text { Flake concentra- } \\
\text { tion, 1eve } 11 \\
\text { (Map } 21,19)\end{array}$ & $\begin{array}{l}\text { Brown pyroclastic } \\
\text { Green pyroclastic } \\
\text { Red pyroclastic } \\
\text { Dark green cherty } \\
\text { sedimentary }\end{array}$ & $\begin{array}{l}2 \\
1 \\
1 \\
4\end{array}$ & $\begin{array}{l}2 \\
1 \\
1\end{array}$ \\
\hline
\end{tabular}


TABLE 20 - Continued

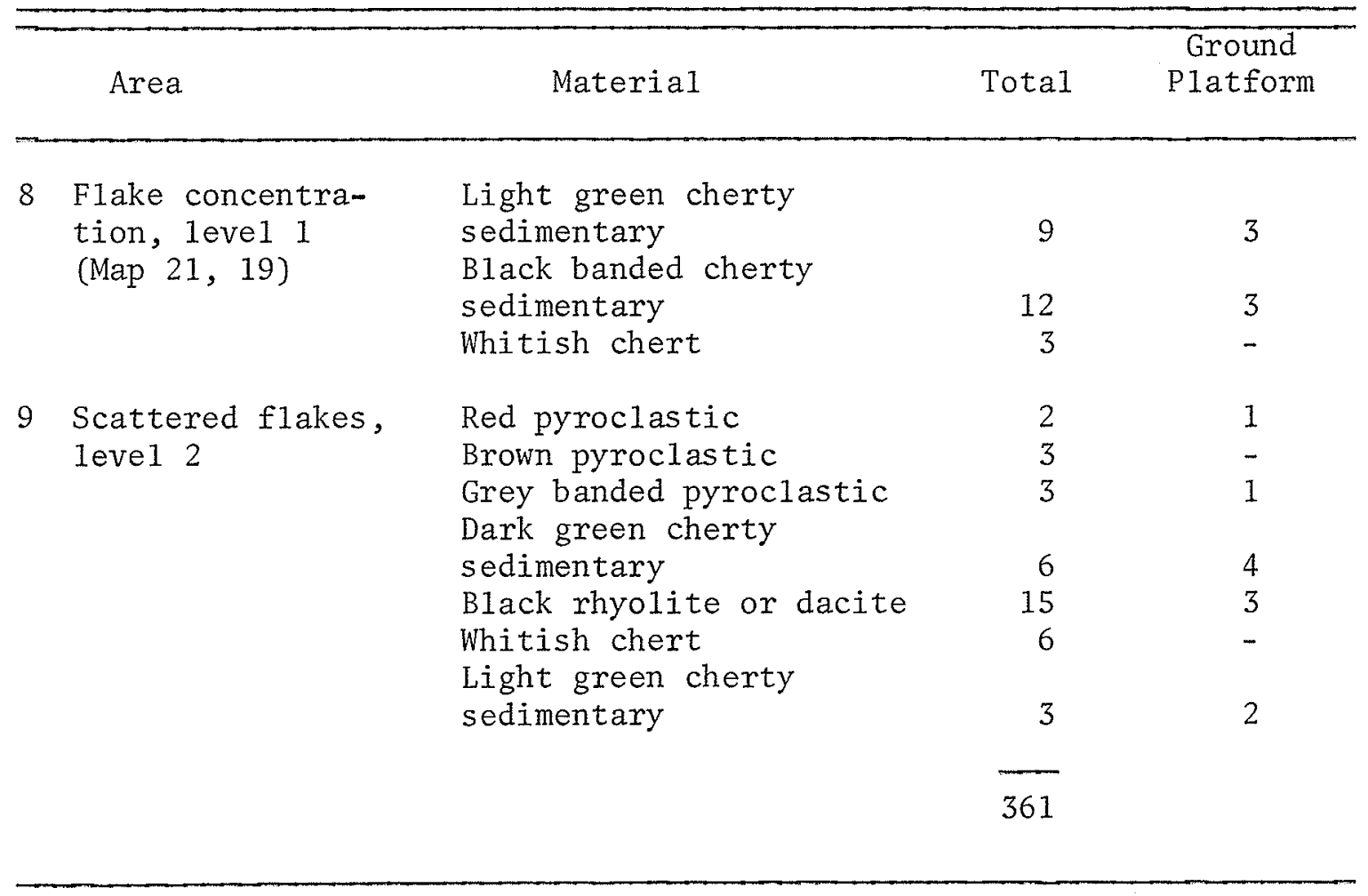


One of the grey pyroclastic flakes from the surface is completely polished over its dorsal surface. Two green chert flakes are from a ventrally and dorsally ground working edge, as are two flakes of brown pyroclastic from the surface. One of the grey pyroclastic flakes from leve1 1 (Map 21,16) is polished over one surface as is a flake of black rhyolite.

One flake of cherty grey material from a different flake concentration (Map 21,15) has been struck from the bifacially polished working edge of a gouge. Concentrated in the same area of the depression was another pocket of flakes (Map 21, 16), clearly debris from the knapping of the same tools. One of these, a green cherty flake, has been struck from the ventrally and dorsally polished edge of a large tool. A nearby cluster of flakes (Map 21, 17) contained a brown pyroclastic flake polished over its dorsal surface.

A fifth flake concentration (Map 21,18) contained no portions of large tool edges, but a sixth (Map 21,19) did. This was a black cherty flake from the bifacially polished working edges of a gouge.

The concentration of knapping activities in the southern half of the dwelling is clear, with at least 226 of 361 flakes, occurring in the southern portion. Many of the level 2 flakes were found here also. The one significant concentration from the northern end of the feature consisted entirely of fifty flakes of a grey banded cherty material.

\section{FAUNAL REMAINS}

Bones are generally absent from this dwelling. This may be due to the high exposed location of this house atop the cobble mantle. Only 
a thin layer of protective tundra developed here and preservation may have been poor. However, four bone fragments were recovered, and although these are in a poor condition, and three are humanly modified, it seems probable that bones of a larger size should have survived. The absence, therefore, of animal bones is inexplicable, unless few were caught by the dwelling inhabitants.

\section{SUMMARY}

The dwelling remains of House 13 differed in several respects from those of the central and southern settlements; (1) the interior was slightly depressed, (2) flagstones were used extensively, and (3) the shape was oval. This house contained a variety of large tool materials representing the reworking of at least seven large tools. The twentytwo small tools recovered and the large amount of debitage indicate that House 13 was inhabited for a lengthy period.

The absence of large harpoon blades, side blades, and knives is puzzling, but is characteristic of the northern settlement as a whole (Table 21). Also puzzling is the paucity of faunal remains. If even one seal was eaten in the house, a few bones should be present. Four bones were recovered, but three of these are tool fragments, and the other is unidentifiable.

One soapstone vessel was damaged in House 13. Since only a smal1 portion of the rim was shattered, the still usable vessel was apparently taken away when the occupants abandoned the house. This rim was a unique find in the northern settlement and is stylistically different from the rims of steatite vessels from the southern settlement. Another 
unusual characteristic of this dwellings tool remains is the presence of six scrapers, more than were found in any other individual house at the site. These scrapers provide evidence of much skin and hide working. A minor feature, unique to House 13 , is the presence of ventral flaking on the burin facets.

SUMMARY OF SETTLEMENT EVIDENCE

The northern settlement, as recorded, consisted of six round and oval dwelling remains. Although a few other habitation areas were noted, only those six dwellings described in this chapter were recorded. These houses were scattered along the cobble mantle, with only House 10 located off the mantle, to the east.

Four of these houses are characterized by an attribute not characteristic of the rest of the Seahorse Gully dwellings. This is the presence of a depressed floor, sunken four or five inches. The fact that the depressions are still discernable after 3000 years suggests they were originally deeper. All of these dwellings are circular or oval, very different from those of the central settlement. The stones used to hold down the tent bases are sma11 and numerous. In some cases (Houses 11 and 13) it seems that gravel has simply been heaped on the lower edges of the tent covering. Also characteristic of these dwellings is the use of flagstones in their construction. House 13 was outlined with limestone flags and several of the dwellings had large numbers of flags laid on their floors.

The details of the tool kits used by the inhabitants of this northern settlement differ in several respects from those of the central 


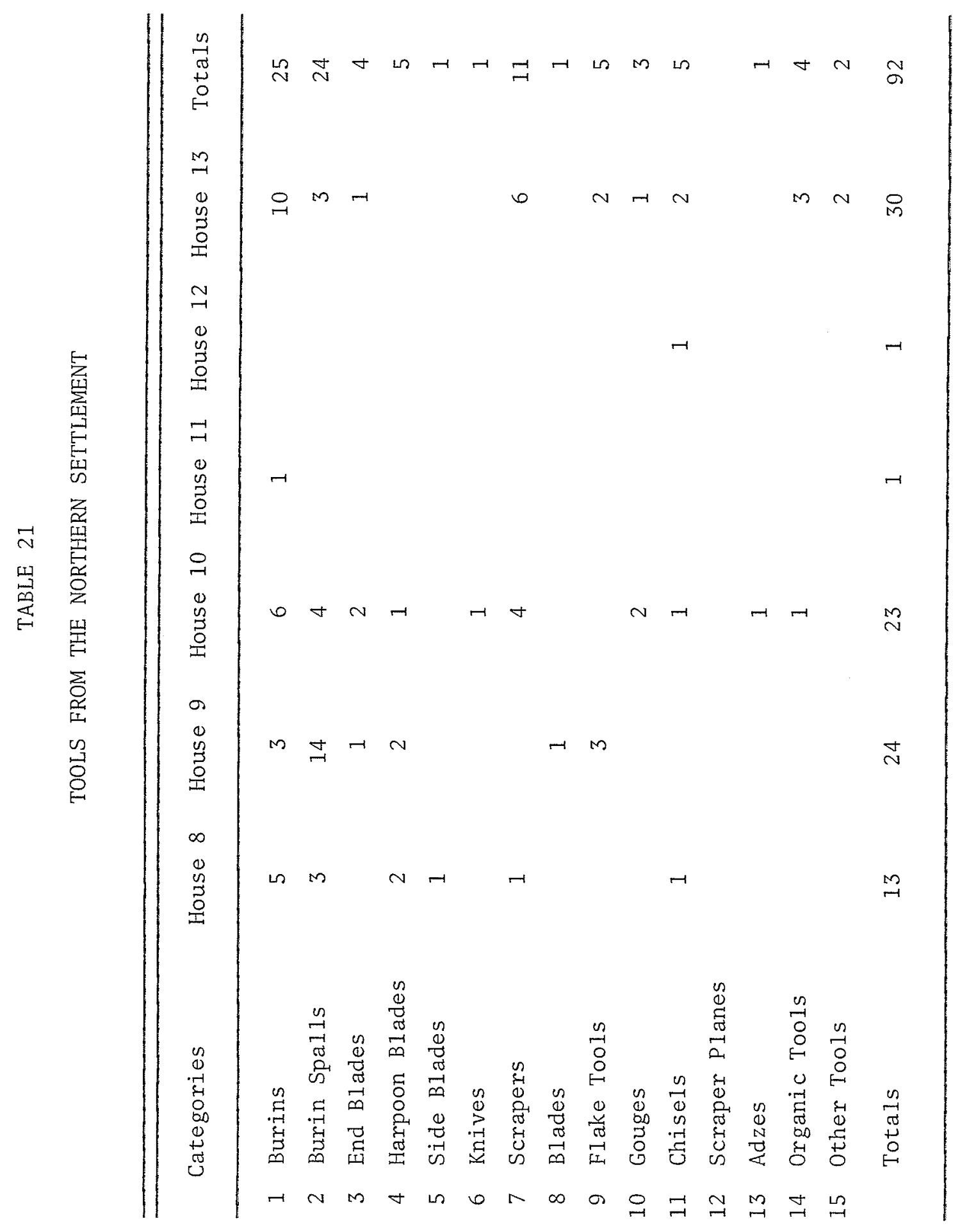


and southern occupants. Tiny triangular harpoon blades are found only in this northern portion of the site. Only two larger harpoon blades (from House 8) were recovered. Notched end blades were present in the houses of this settlement; none were found in the central area, and none in the southern dwellings. Narrow, stemmed asymmetrical knives were not common in the northern settlement, in fact only one offset knife (House 10) was recovered. Large side scrapers and oval biface knives did not occur in this settlement.

The presence of three unusual steatite fragments (House 13) also differentiates the tool kit possessed by the inhabitants of this settlement. The recovery of a burin-like tool from House 10 demonstrates the distinctive nature of this group of tools and emphasizes the Dorset traits evident throughout the whole of the Seahorse Gully Pre-Dorset site.

The season of occupation of this settlement may have been the summer as bird bones were associated with Houses 8 and 9 and bearded seal remains were present in House 10. However, several of the dwellings have been carefully prepared by interior excavations and this may have been a response to cold temperatures. As there is evidence for both cool and warmer seasons, it is possible that the settlement was occupied during part of winter and a portion of the summer. 
CHAPTER VIII

SETTLEMENT AND SETTLEMENT PATTERNS

INTRODUCTION

In the three preceding chapters, the characteristics of three Pre-Dorset settlements at the Seahorse Gully site have been presented. These settlements occupied geographically separate areas and each was distinguished by (1) differing house styles, (2) the presence or absence of certain tool categories and varieties, and (3) by the nature of the use of the occupied area - whether intensively or extensively.

\section{SETTLEMENT ARCHAEOLOGY}

The three Pre-Dorset settlements can probably be most effectively interpreted through the use of a settlement pattern model and the definition of settlement archaeology as outlined by K.C. Chang (1967b). Of course, the classic work utilizing the settlement archaeology approach was composed by Gordon Willey on the Viru Valley in Peru. Willey defined the settlement pattern,

... as the way in which man disposed himself over the landscape on which he lived. (Willey 1953:1)

Settlement pattern studies were the first sort of archaeology to clearly utilize a conjunctive approach. The conjunctivity of these studies is reflected in a concern with social organization as it affects territorial spacing of humans and the general internal workings of archaeological cultures. This concern is reflected in Willey's statement:

Because settlement patterns are, to a large extent, directly shaped by widely held cultural needs, they offer a strategic starting point for the functional interpretation of archaeological cultures. (Willey 1953:1) 
A concern with conjunctive archaeology, with sociocultural "constructions" is characteristic of an archaeological trend initiated by Walter W. Taylor. Previously, archaeologists were concerned mainly with typologies, the formal qualities of archaeological information, and, ...the ordering of cultural materials in temporal sequence together with an attempt to demonstrate their derivations and cross-cultura1 relationships. (Taylor 1948:92)

The work of V. Gordon Childe in Europe and W. W. Taylor (and others) in North America eventually resulted in a realization of "use and function" (Chang 1967b:11). From this developed an interest in the socioeconomic system in which artifacts were manufactured and used. Conjunctive and settlement archaeology have developed and matured during the last two decades. The sophisticated approaches and techniques of the contemporary school of anthropological archaeology (as championed by Sally R. and Lewis R. Binford) are a fairly direct development from Taylor's concept of conjunctive archaeology.

K.C. Chang combines the anthropological and settlement pattern approach, retaining an emphasis on the crucial place of ecology in the shaping of human societies. Ecological archaeology is closely related to the settlement pattern approach. Since settlement patterning is determined by socio-economic organization in relationship to environment, it is clearly ecologically based. Human ecology is directly related to at least two foci of interest which are traditionally archaeological, namely: (1) technology (artifacts) and, (2) environment (as evidenced by floral and faunal remains, soil characteristics, etc.).

Since human ecology may be defined as the mutual relationship between a cultural system and its environment, and the adaptive change of the system with time and space (Clarke 1968:84) and since the settle- 
ment pattern and technology are major cultural buffers between humans and their environment, the importance and the possibilities of archaeological evidence in constructing extinct systems is clear.

To summarize, the technology (and ideology) of any cultural group provides restraints in dealing with the environment. In turn, the environment and its resources (as exploited with a given technology) influences the settlement pattern of a human group. This settlement pattern is then reflected upon the social organization. The internal structure of the society becomes patterned for relatively efficient functioning within the settlement pattern, which may involve (in the case of bands) dispersion or aggregation of persons, depending on the season.

The technology, environment, and settlement pattern, therefore, are all keys to the social organization of an extinct group. The technology of the Churchill Pre-Dorset Eskimos has been presented in Chapters IV, V, VI, and VII, and the modern and ancient environments in Chapters I and II. At present, the settlement pattern is not yet clearly defined and the major emphasis of this chapter, therefore, is to outline that pattern. With knowledge of the settlement pattern it may be possible to postulate the major characteristics of the social organization of the three Pre-Dorset settlements (communities) at the Seahorse Gully site.

THE SETTLEMENT AND THE COMMUNITY

Chang's major emphasis is the definition of a settlement, a necessary first step in the determination of its patterning. His concept 
of the settlement is based directly on the original human community, whether a camp, a village, or a town. Chang's "community" is clearly similar to that defined by Beardsley et al. (1956:133).

Most important in the category of terminology is our use of "community," defined as the largest grouping of persons in any particular culture whose normal activities bind them together into a self-conscious, corporate unit, which is economically self-sufficient and politically independent. At its simplest, this is a band or horde; at its most complex, a nation or empire. In between, it may be a village or town and its environs. A tribe or culture would normally be composed of several communities in our sense, sharing common language and culture but independent in the conduct of normal daily life.

As defined in this quote, a community can be almost any social group, the members of which conceive of themselves as a distinct separable social entity. Such a definition of community is much too broad and all inclusive to reflect any particular type of social organization or structure. Chang can be interpreted as using the term community to indicate one basic fact; the presence of a living group of humans in proximity to one another.

Since the concept of community concerns people in the flesh-and-blood sense, which cannot be archaeologically retrieved, I have suggested the concept of settlement to substitute for it. (Chang 1967b:15)

Therefore, in using the word "community" it is apparent that Chang conceives of the dichotomy between the community and settlement not as indicative of two states of any particular social grouping, but simply as that between, (1) an area occupied by humans and, (2) an area no longer occupied. As a result, archaeological concern with the community becomes a matter of interpreting the data as it reflects the extinct social entity that once inhabited the area under investigation. The archaeologist must attempt to recreate the internal social structure of the living human group that once occupied his site. 
Although time is not ignored in settlement archaeology, for the purposes of archaeological study, the settlement is considered in a static state. This is similar to the manner in which the social anthropologist considers his society to be in a stationary state. This coincidence of static interests illustrates the concern of the settlement archaeologist with societal studies, with finding, "social dimensions for the archaeological reality" (Chang 1967b:41).

Chang's most rigid criteria for the identification of a settlement are contained in the following quote (Chang 1967b:41):

The basic data for recognition and delineation consists solely and always of archaeological data in their widest and most empirical sense and include (1) artifacts, (2) other evidence of human occupation, and (3) their depositional context. An archaeological settlement is defined as a unit having such data as its content with a spatial and a temporal dimension delineating a stationary state.

According to Chang $(1962: 28)$, the settlement, once delineated, lends itself to further analysis. A basic assumption is, "that the dwelling houses in a village can be regarded as the basic spatial constituents of the village" (Chang 1962:28). The Seahorse Gully site certainly contains the remains of dwelling units, however vague their identification and recognizable attributes may be at times. Assuming that these are the basic units locating people in space:

...we may consider that the problems as to where these houses are located topographically, what considerations in terms of natural resources underlie the selection of the locales, during what season of the year and/or for how many years these locales are occupied, and what subsistence activities are engaged in by their occupants, can be referred to as problems pertaining to the settlement patterns. (Chang 1962:28)

CIRCUMPOLAR SETTLEMENTS

Chang has also developed a typology of circumpolar settlement 
patterns. These are grouped under two major classes: (1) year-round settlements, and (2) seasonal settlements. Since there is no evidence (e.g. thick refuse deposits) that the Seahorse Gully habitations were year-round, they must fall into the realm of seasonal settlements. Chang has grouped the seasonal settlement-complex under another two headings, (A) sedentary seasonal settlements, and (B) temporary seasonal settlements. The former is defined as follows:

...the annual subsistence region of a group of occupants remaining permanently unchanged. (Chang 1962:30)

The latter is defined as a situation in which:

... a group of people has to change its habitation from one annual subsistence region to another after one or several years' occupancy because of exhaustion of the ecological potentiality of the whole region and the occupants'inability to effect artificial recuperation, among other factors. (Chang 1962:30)

Chang has fitted the whole circumpolar area into the seasonal settlement-complex. He demonstrates that all northem American Indian settlements can be classified under the category of sedentary seasonal settlements. However, of the central Eskimo, he writes:

On the strength of the available data, one would tend to characterize the settlement patterns of the Central Eskimos as of the temporary seasonal settlement type, even though this may only reflect our ignorance in this respect. (Chang 1962:32)

Recent publications by Damas (1968:111-117, 1969a:116-141, 1969b: 40-64) and Balikci (1968:78-82) suggest very strongly that the Copper, Netsilik, and Iglulik Eskimos did not have temporary, but had sedentary seasonal settlements. Chang has divided this latter settlement subcategory into two; (1) with permanent bases:

...the locales of the main seasonal settlements remain permanently unchanged,

and (2) with transient bases: 


\begin{abstract}
...the locales of the various seasonal settlements (particularly the main sites of occupation) keep changing after one or several years occupancy because of exhaustion of the ecological potentiality of particular locales and the occupants inability to effect artificial recuperation among other factors, though the whole annual subsistence region of the group remains unchanged. (Chang 1962:30)
\end{abstract}

Clearly, the transient based sedentary seasonal settlement is most characteristic of the central Eskimos (especially the Iglulingmiut). There does not appear to have been "exhaustion of the ecological potentiality of the whole region" (Chang 1962:30), leading to its abandonment. Since the Eskimos of the Central Arctic are able to locate their seasonal settlements in the same general area year after year, it is likely that the Pre-Dorset Eskimos, inhabiting the less severe subartic Churchill area should also have been able to locate their settlements within a relatively restricted area, for an indefinite period of time.

THE EXPLOITIVE PATTERN

June Helm, while accepting Chang's distinction between the settlement and the community pattern, adds the exploitive pattern, ...being the total set of activities in the acquisition of life's goods through the application of technology upon environment. (Helm 1969a:213)

The exploitive pattern forms the basic organization of factors influencing the settlement pattern, and according to Helm (1969a:213):

We may further predicate that directives underlying community patterns stem most immediately from significant social relationships, as culturally defined.

Utilizing information regarding ethnographically known central Eskimo groups, it is possible to construct testable hypotheses concerning the annual economic cycle of groups living almost three millenia To do this with any hope of accuracy, some knowledge of the palaeo- 
environment must be available. As constructed in Chapter II, it appears that the climate was not greatly different from that presently experienced, although the coast line of the Churchill area was somewhat different in shape.

The fauna does not appear to have differed from that presently known. All three settlements at the Seahorse Gully site display great reliance on sea mammals, particularly the ringed seal, and to a lesser extent the bearded seal. The bearded seal does not remain beneath the winter ice and it is unlikely that it would be found in the Churchill area during that season. Polar bears were present, as were wolves, and caribou. No fish remains were found in excavations and it must be assumed that the same species as are now found were also present in the past, in the same places at the same seasons. Although many tiny bones of migratory birds were found, only two, a gull (species unknown) and the black guillemot, were identifiable.

Ethnographic examples of recent Eskimo exploitive patterns can provide ideas upon which to base hypotheses. Therefore, an outline of the economic cycle of the Iglulik Eskimos is presented below. The Iglulingmiut are chosen since they inhabited a coastal environment to the north of the Churchill region. The major difference is that the Iglulingmiut live in a more severe Arctic area as compared with the Churchill subarctic climate. However, like the Iglulingmiut, the Seahorse Gully Pre-Dorset hunters appear to have practised the marine hunting of sea mammals from watercraft.

The annual economic cycle of the various bands of the Iglulingmiut varied slightly from area to area, however, in the Chesterfield Inlet 
area it was as follows (Balikci 1969:118):

1. Midwinter (Jan-Apr):

2. Spring (May-June):

3. Summer (Jul-Oct): a. Breathing hole sealing.

b. Walrus and Muskox hunting.

a. Hunting basking seals.

a. Sealing from kayaks - also hunting walruses, narwhal, and beluga.

b. Young men inland to hunt caribou, a little fishing also.

4. Early winter (Nov-Dec): a. Idleness, fishing and clothes sewing.

During each season a number of alternative means of subsistence were practicable if other failed, although in summer there was always a division of hunters, with young men going inland with light kayaks to hunt caribou and older men with heavier sea going kayaks remaining on the coast to hunt sea mammals (Damas 1969a:129).

On the basis of ethnographic analogy, known faunal resources, climate, and technology, an hypothetical exploitive pattern may be constructed for the Pre-Dorset settlements at Seahorse Gully. It appears that the Seahorse Gully settlements were occupied, at least partially, during periods of open water. The presence of the bones of migratory birds indicates some habitation during the summer. Probably summer sealing from substantial watercraft was practised. During the summer beluga whales should have been plentiful, however, they do not seem to have been taken. In late summer the movement of fish back up the rivers may have been taken advantage of, although the caribou migration would be the most prominent factor in the attraction of people inland.

By the end of August the caribou migration would have begun, to continue until late october. At this time caribou could have been ambushed at lake or river crossings. During the fall, sealing from 
watercraft would have become difficult or impossible because of deteriorating weather conditions. Survival should have been surest if the hunting groups moved inland during the period of fall storms to hunt caribou and possibly to fish. The products of these economic activities may have supported the population throughout the autumn, after which time a move back to coast would be made.

The only practicable means of winter survival can be expected to have been breathing hole sealing, especially since walruses and muskoxen are and probably always were rare in the Churchill region. Therefore, the Pre-Dorset hunters must have spent most of the winter out on the sea ice or on offshore islands such as the Seahorse Gully site. The lean months of late winter, therefore, could be ekked out with breathing hole sealing, changing to the hunting of basking seals in the spring.

THE SETTLEMENT PATTERN

At present, only the coastal portion of the annual Pre-Dorset economic cycle is known and the season of occupation of this area is difficult to interpret. The above exploitive pattern, therefore, must remain hypothetical and unsubstantiated until more is know of the inland economic activities. It is possible that an important inland economy was absent and for this reason the construction of the settlement pattern must remain completely tentative.

The dangers and limitations inherent in the use of ethnographic analogy are realized and the admonitions of Binford (1968:269) and Freeman(1968:262-267) have been carefully studied. It is clear that the Pre-Dorset technology was radically different from that of the historic Thule-descended Eskimos. The utilization of the ice and snow technology 
(igloo's, etc.) by the Pre-Dorset Eskimos has not been satisfactorily demonstrated. Certainly, the absence of snow knives suggests that snow houses were not made. The dog seems to have been rare and the dog sled unknown. These two factors alone should have resulted in a Pre-Dorset economic pattern very different from that of modern Eskimo groups. Non use of the igloo would make winter camps on the sea ice very difficult to set up, if not impossible, and could limit movement as tent covers would have to be carried everywhere. The absence of the dog sled would also have far reaching consequences. In comparing T1, early or PreDorset, faunal remains of Southampton Island with the historic Sadlermiut remains, Collins (1956:65) found a significant difference:

Caribou, which were the second most important source of food for the Sadlermiut, were hunted very little by the earlier people. This was undoubtedly a matter of necessity rather than choice. The T1 people had no dogs and therefore no effective means of winter transportation. Lacking the mobility of the later Sadlermiut, who possessed the dog sled, they would have been unable to make long hunting trips to the highlands in the eastern part of the island where the caribou mostly lived. With their hunting activities thus restricted, they would be forced to depend almost entirely on local food resources, mainly sea mammals and birds.

Collins does not consider the possibility that the TI people may have spent part of their annual cycle in the caribou hunting area and thus had about the same access to the caribou as the Sadlermiut who had a more stable home base. We may, though, consider the Pre-Dorset Eskimos to have possessed less potential mobility than recent Eskimos. This does not necessarily mean that they moved less often, but that they would be forced to move less quickly with fewer material goods (in winter, at any rate).

If an economic cycle consisting of inland fishing and hunting 
during the fall and early winter, with coastal sealing practised from late winter through summer, is postulated, the use of watercraft would appear to be a necessity. M.S. Maxwell (1960:187) stresses the fact that the climate at the time of the initial spread of Arctic Small Tool Cultures was warmer than at present. Since, "large, open leads in the sea ice" prevent extensive dog sled travel between land masses, PreDorset peoples with small hand-drawn sleds would find winter crossings difficult or impossible. Therefore, the use of boats for summer crossings may be accepted as a matter of fact.

The hunting of caribou may also be accepted as a matter of fact, for human survival in the Arctic depends equally on both sufficient food and adequate clothing. The caribou must be relied upon for skins with the insulating quality necessary to keep men alive during winter hunting expeditions. Such skins must be of fawns killed in the fall during the annual migration.

Until the sites of inland caribou hunting settlements are known it will not be possible to suggest with any confidence that these PreDorset Eskimos used boats to attack swimming caribou. The use of boats on the western coast of the Hudson Bay during the summer indicates the presence of very sophisticated watercraft and great skill in their use. The prevailing northwesterly winds make boating very dangerous as the possibility of being blown out to sea always exists. In fact, the extensive utilization of the eastern side of the Seahorse Gully site indicates that the boatmen kept in the lee of the islands whenever possible. Use of small boats in the fall would seem detrimental to survival as storms would be certain to take the lives of hunters and many days could 
pass when no boat could venture out. During this period it is likely that survival was ensured by journeying inland to fish and hunt caribou.

On the basis of the constructed exploitive pattern and the evidence for the repeated use of the Seahorse Gully site (by at least three different Pre-Dorset groupt) at approximately the same seasons, it appears that these Pre-Dorset peoples utilized seasonal settlements in a subsistence region that remained more or less permanent. At any rate, sites occupied by these Pre-Dorset Eskimos have not yet been found over Iarge areas of the western coast of the Hudson Bay. The lack of habitation build up (middens) indicates that these seasonal settlements were characterized by transient bases. However, these seasonal settlements were scattered along a relatively restricted portion of the coast and the evidence to date suggests that islands were favoured habitation areas, as Seahorse Gully, Twin Lakes, Second Burton Rock and probably many other sites once islands (such as the present location of Fort Churchill) were occupied by these Pre-Dorset Eskimos.

In summary, available evidence indicates that the Seahorse Gully Pre-Dorset settlements are those inhabited by groups of people with sedentary seasonal settlements (their annual subsistence region, including a few miles of coastline and perhaps a larger inland area, remained permanently unchanged). However, the locales of the various seasonal settlements, the main sites of occupation, appear to have been in different areas, changing from place to place within the annual subsistence region (Chang 1962:30). The locales of the main seasonal settlements did not "remain permanently unchanged" as is the case with permanent based sedentary seasonal settlements. 
The settlement pattern of these Pre-Dorset hunters, therefore, is viewed as basically divided into two portions, (1) a coastal, late winter through summer, relatively sedentary series of settlements, and (2) an inland, fall to early winter series of settlements. Probably, the greater part of the year was spent on the sea coast, perhaps out on the ice during the winter. 
CHAPTER IX

COMMUNITY AND COMMUNITY PATTERN

INTRODUCTION

The construction of the community and its patterning of social relationships is potentially more difficult and more susceptible to error than the construction of exploitive and settlement patterns for which, perhaps, more concrete evidence is available. Conceivably, very detailed data of a different order from that customarily stressed by archaeologists is needed for the successful construction of the community and its patterning. It is quite possible that data believed to be indicative of certain social relationships relates to other phenomena completely, or that the archaeologist may not even know what information is pertinent to his problems. With these disturbing thoughts in mind, the following constructions are attempted with caution and may be perused with some scepticism for the archaeologist now finds himself in the unusual position of dealing not with technology and its application to an environment, but with the social units behind the technology and their organization into a coherent, patterned entity.

THE COMMUNITY AND ITS PATTERNING

Chang (1962:28) defines the community as the "local social group", and:

Such matters as the placement of houses in a community, the social ties among their inhabitants, their relationship in terms of political control, social behaviour, and mental attitude, can be made the subject of the study of community patterns. (Chang 1962:28)

Chang demonstrates his concept of the community and its patterning 
through an analysis of groups belonging to his two major circumpolar community types: (1) the Siberian, and (2) the Eskimo. While the Siberian community is a complex sociopolitical unit "composed of individuals unilineally determined by descent and/or unilocally recruited by marriage" (Chang 1962:33), the Eskimo community type is a "weak social unit" consisting of

...loosely organized households, with the "looseness" indicated in the irregularity of the community layout, which has resulted from the flexibility of membership (a newcomer can settle whereever he likes) (Boas 1888:581; Honigmann 1946:

51) and, presumably, by the lack of an explicit tendency for a symbolically oriented layout. (Chang 1962:33)

Unilineality is not an organizing principle among Eskimo communities.

If the Seahorse Gully settlements are to be discussed as communities, a basic assumption must be that they can be considered as in a stationary state; as a contemporaneous grouping of social units. The variations in amounts of occupational debris in the various dwellings of each settlement make it quite clear that individual dwellings were used for differing lengths of time. This does not mean that some or all of the houses were not inhabited simultaneously for at least a short period of time. Also, it must be noted that the grouping of similar dwellings with similar technologies into separate settlements within the site, argues for the contemporaneity of those dwellings. In other words, people who shared a similar Pre-Dorset culture probably were relatives and friends who camped together in a small area of the site.

Chang (1967b:41) defines the stationary state of the settlement" ...on the basis of the features of contrast and complementarity exhibited by its content. The variations incorporated into such a unit must be of such a nature, taken together, that they represent either a single cultural tradition or a strong coherence of different cultural strains; that they complete an 
actual or presumable self-sufficient sphere of day-in-dayout activities; that they exhibit contrast with other such spheres in other areas, nearby or distant; and that they contrast with other such spheres in another micro-time, immediately or remotely preceding or following.

By this definition, the Seahorse Gully settlements can be considered in a stationary state and this may also be applied to the community occupying the settlement. Basic to Chang's work is the assumption that there is a correlation between the settlement and the community patterns. Corollary to this is the belief that the settlement pattern is governed by exploitive or ecological factors only while the community pattern is influenced mainly by the settlement pattern (ultimately based on the exploitive pattern). Damas, however, would not restrict influences on the settlement pattern to ecological factors only. He (Damas 1969b:52) believes that "sociological and social psychological factors" are also important in the determination of settlement patterns. His work among the central Eskimos suggests that this is, in fact, true. The clearest example of the lack of economic factors in the establishment of a settlement occurred in the fall when several families grouped together for the sewing of the winter clothes. Almost no economic activities occurred at this time. Also, Damas $(1968: 117)$ does not believe there is a very close relationship between the settlement and the community patterns:

Although strong arguments can be advanced for a close harmony existing between the pattern of exploitation and certain features of the settlement pattern in the Eskimo area and probably in the world of hunters as a whole, the relationships that exist between these settlement patterns and variable community patterns appear to be less rigid and perhaps will allow alternatives in every conceivable case.

In this statement Damas is expressing conclusions based on his studies of the social organization (community pattern) of the Copper, 
Netsilik and Iglulik Eskimos. Although sharing similar settlement patterns their social organizations differ quite markedly. The internal composition of the communities varied, being based on partnerships among the Copper, kinship among the Iglulik, and a combination of the two among the Netsilik Eskimos. However, variations of this detail and minutiae are almost impossible to obtain from archaeological material and certainly will not be of concern with the Seahorse Gully Pre-Dorset communities.

Damas did, however, find characteristics common to all three groups and these may be of an order that is archaeologically detectable:

The largest winter concentrations of people were of about the same size, ninety to 100 people. (2) This number (100) was also the average band size and the winter aggregations generally represented the local band group.

Although there was much fluidity of personnel among the bands within the major regions, it appears that 60 to 70 per cent of the members of one winter's sealing aggregation - band assemblage would return the following year so that a core of members remained from year to year. (Damas 1969a:126)

(4) Male kinship ties tend to dominate the composition of the band aggregates (Damas 1969a:125). (5) From five to eight of these bands form a dialectical tribe of about 500 persons (Damas 1969a:122). (6) This dialectical tribe is ninety to ninety-five per cent a closed breeding unit with a unique subculture (Damas 1969a:126).

Obviously the band is of particular interest to the archaeologist as aggregations of the 100 or so band members probably produced many of the settlements he is interested in. The Eskimo band varies in size from fifty to 300 people, averaging about 100 (Damas 1969a:125). It is identified by name with its territory and during the summer and fall is 
composed of smaller local groups subsisting within the band area. Also; "Periodic meeting of these segments generally take place, at which time there are usually associated ceremonial activities" (Damas 1969a:123). It is shown by Damas that the Eskimo band, while fluid, is characterized by seventy to 100 per cent kin links, most of which (half) are male oriented.

The Iglulingmiut (a dialectical tribe) with a population of about 500 were divided into five or six camps during the winter, with each camp identifiable as a band and named. These winter camps, with populations up to 100 people, were associated with breathing-hole sealing and often were maintained from January until May. In the spring (May-June) they split into smaller groups of about twenty persons, each group hunting basking seals on the sea ice. These small local groups continued throughout the summer hunting seals, narwhal and walruses from kayaks. Later in the summer, into the fall, the young men travelled inland to hunt caribou, while the "older men stayed at the coast and hunted in pairs or groups of three" (Damas 1969b:47). By November the young and old reunited to share the resources of sea and 1 and and to form the winter camps. According to Damas (1969b:47):

Elsewhere, especially in much of the Iglulik area, the sewing group was often coterminous with the winter aggregation so that the actual duration of the group could have been as long as six months, even though the site of the settlement would be moved several times during that period, and a certain amount of fluctuation in membership took place.

This summary of the social organization of the Iglulingmiut, as it relates to the exploitive pattern is presented in order to provide an indication of the possibilities of the environment in its effects on human 
settlement. However, as has been noted previously, the historic Thuledescended Eskimos were the heirs of more than 2500 years of Eskimo 1ife and adaptation in the Arctic following the Pre-Dorset Eskimo period. During this time their use of the environment appears to have become more efficient, perhaps because of innovations in technology. Clearly, these differences in technology and the resulting human ecological relationships, must have affected the social organization.

THE PRE-DORSET COMMUNITIES AND COMMUNITY PATTERNS

In this context, the construction of the community and its patterning rests on the prior construction of the settlement and the settlement pattern. It is postulated, therefore, that the three settlements at Seahorse Gully are the remains of three communities. Each of these communities appears to have included a relatively large conglomeration of people present, at least partially, during the summer. It is likely, judging by the paucity of remains in many dwellings, that these Pre-Dorset population aggregations existed for a much shorter time than those of ethnographically known Eskimos. There is no evidence for the lengthy occupation of many houses. Also, it is unlikely that these population clusters were as large as those of historic Eskimos. For instance, the northern settlement contains only seven or eight discernable dwelling remains. Unless the average dwelling numbers were high, this suggests the presence of only forty or fifty people. If, in fact, population aggregates were smaller than those of historic Eskimos, this may be a reflection of a different and perhaps less productive exploitive pattern resulting from the lack of certain technological complexes (dog sled, use of igloos, etc.). 
It is suggested, therefore, that a group of about fifty persons composing the local band, or a large portion of it, formed the communities at each of the three Pre-Dorset settlements at the Seahorse Gully site. The population of each community left its house remains, artifacts, refuse, etc. to be identified as settlements. The fact that each of the three settlements at Seahorse Gully is differentiable may reflect the fact that the closely related peoples in each community shared more cultural (technological) traits than did the persons of the three separate communities.

On the other hand, it must be noted that the technologies of each of the settlements are very similar and in some cases dwelling contents could be shuffled from one settlement to the other without causing any archaeological confusion. However, the total configuration of the dwellings and the associated artifacts of each settlement is sufficiently distinctive to indicate occupation by slightly differing groups (bands).

It is not possible to suggest whether social integration through kinship ties was paramount in these communities or if some other form of societal binding was present. According to Chang (1962:34):

Most of the Eskimo communities are characterized by the looseness of their organization, the fluctuation of their membership, and the bilateral system of their inhabitants.

This societal organization, while perhaps slightly exaggerated, is believed to be reflected in the irregular patterning of Eskimo settlements. There is no regularity in the placement of the Seahorse Gully dwellings and the only patterning apparent is the consistent appearance in each settlement of one or two houses that are very rich in artifacts. This irregularity of patterning of settlement composition, 
coupled with the considerable variation in artifacts in the dwellings of one settlement suggest that the Seahorse Gully settlements represent the sites of communities with a loose, fluctuating membership.

As yet there is no evidence on which to base any postulates concerning the settlements and community makeup of Pre-Dorset Eskimos who may have hunted caribou inland during the fall. It is, therefore, most prudent to reserve any speculative comments, except that there appears to be no reason why they should differ from those of recent Eskimos. It does seem though, that the economy of these Pre-Dorset Eskimos was characterized by a relatively extreme maritime adaptation based winter and summer on sealing.

If the Seahorse Gully communities were, in fact, band-like groupings, it is likely that they were simply a portion of a larger dialectical tribe perhaps composed of a few hundred people. Such a "tribe" would have inhabited a large area of the Churchill coast. As is characteristic of the Pre-Dorset populations this tribe had, probably through social and genetic isolation, developed a unique culture differing markedly from all other Pre-Dorset cultures known at present. If this tribe was, in fact, culturally distinctive and stable in its region of occupation, its cultural remains should occupy an easily identifiable portion of the western coast of the Hudson Bay. If it was a breeding and social isolate to a marked degree, the archaeological culture should have easily identifiable borders.

While the distinctiveness of this Pre-Dorset culture may be stressed it must also be realized that relationships with other early Eskimo cultures to the north are everywhere evident. The prolific use of 
steatite by one of the communities indicates constant communication, including movement and trade, with the northern populations, for steatite is believed to be available only in the central Arctic. Also, the Dorset elements that prevade the Seahorse Gully Pre-Dorset material indicate the steady movement of ideas from the north (assuming that a complex of traits identifiable as Dorset originated in the central Eskimo area and not in the peripheries).

\section{SUMMARY}

The Churchill sites indicate the presence about 3000 years ago of well established and organized band groups with an economy based, for much of the year, on the marine resources of the Hudson Bay, particularly the ringed seal. These groups carried a late Pre-Dorset culture with many Dorset elements included. While the social organization may have been relatively loose, the technology, environmental knowledge and exploitive pattern were evidently correspondingly complex. Many discrete and specialized tools were made, each obviously designed for a limited variety of jobs. The application of this technology, although complex, to the hunting and precessing of Arctic fauna clearly has resulted in a relatively limited source of energy. As a result, survival is believed to have been dependent on periodic movements between coastal and inland locations. Such adjustments to the environment clearly influenced the social organization which probably was based on groupings of nuclear and extended family units.

At certain seasons, population aggregates appear to have formed in various settlements along the coast. On the evidence of faunal remains, these Pre-Dorset aggregations seem to have occurred at least 
partially during an open water season. They may have endured from late winter through early summer. It is possible that a major winter aggregation on the sea ice did occur, although this can never be known for certain.

The Seahorse Gully communities, each composed of seven or eight dwellings, probably each had a population of about fifty persons. These people formed the local band group or a large portion of it. Such a band was a loosely organized social unit, fluctuating in membership, but united by a preponderance of kinship ties.

The lack of substantial refuse indicates that these aggregates lasted, at Seahorse Gully, for a relatively short time, perhaps only a few days or weeks. However, this period had to be of sufficient length to satisfy the social needs of people dispersed for lengthy periods of the year. Concerning the Central Eskimos, Damas has written:

The winter assemblages provided opportunity for reaffirming social ties that had not been realized during much of the preceding phases of the year's cycle. It was at these winter gatherings that chief occasions for shamanistic performances, games and dances took place. (Damas 1969b:52)

It is safe to assume that these activities were equally important to the Pre-Dorset Eskimos of 3000 years ago. 


\section{BIBLIOGRAPHY}

This bibliography inc1udes not on $1 y$ those references cited in the text of the thesis, but also other works which were consulted concerning the Arctic Sma11. Tool Tradition. These extra publications have provided needed background information to this writer and may be useful to any reader studying the Arctic Small Tool Tradition

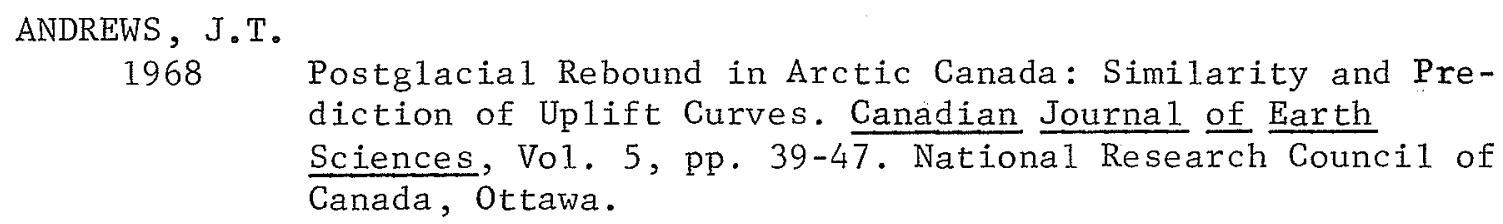

1968 The Netsilik Eskimos: Adaptive Processes. In Man the Hunter, edited by R.B. Lee and I. Devore, pp. 78-82. A1 dine Publishing Company, Chicago.

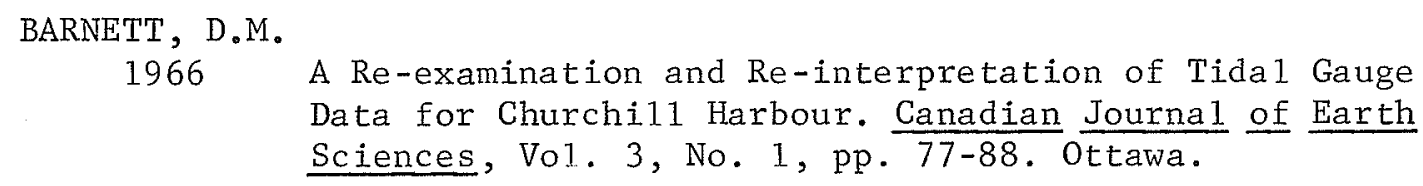


BINFORD, L.R.

1968 Methodologica1 Considerations of the Archaeologica1

Use of Ethnographic Data. In Man the Hunter, edited by

$R_{0} B$ 。 Lee and $I_{0}$ Devore, pp. $268-273$. Aldine Publishing

Company, Chicago.

BIRKETT-SMITH, K

1929 The Caribou Eskimos, II. Report of the Fifth Thule Expedition 1921-24, Vo1. V. Gyldendalske Boghande1, Nordisk

Forlag, Copenhagen.

BOAS, FRANZ

1888

The Centra1 Eskimos. The 6th Annua1 Report of the Bureau of Ethnology, 1884-85, pp. 409-660, Washington.

BRYSON, R.A., $W_{\circ} N$. Irving, and J॰A. Larson

1965 Radiocarbon and Soil Evidence of Former Forest in the

Southern Canadian Tundra. Science, Vo1. 147, No. 3653, pp. 46-48. Washington.

BRYSON, R。A。 and $W_{\circ} M_{0}$. Wendland

1967 Tentative Climatic Patterns for some Late Glacia1 and PostGlacial Episodes in Centra1 North America. In Life, Land and Water, edited by W.J. Mayer-Oakes, pp. 271-298. University of Manitoba Press, Winnipeg.

BURKITT, M。C。

1920 Classification of Burins or Gravers. Proceedings of the Prehistoric Society of East Anglia for 1919-20, Vo1. 3, Pt. 2, pp.306-310. London.

CHANG, $\mathrm{K}_{0} \mathrm{C}$ 。

1962 A Typology of Settlement and Community Patterns in some Circumpolar Societies. Arctic Anthropology, Vo1. 1, pp. 28-41. Madison.

1967a Major Aspects of the Interrelationships of Archaeology and Ethnology. Current Anthropology, Vo1. 8, No. 3, pp. 227-234. Utrecht.

1967b Rethinking Archaeology. Randon House, New York.

CHENEY, T。A。 and D。K. BeckeI

1955 An Environmenta1 Analysis of Fort Churchi11, Manitoba, Region. Cornel1 University, Ithaca.

CLARKE, D.L。

1968 Analytical Archaeology. Methuen and Company Limited, 11

New Fetter Lane, London EC4. 
COLLINS, H.B。

1956 The T-1 Site at Native Point, Southampton Island, NoW.T。 Anthropologica 1 Papers of the University of Alaska, Vo1. 4, No. 2, pp. 63-89.

1958 Present Status of the Dorset Problem. Proceedings of the Thirty-Second International Congress of Americanists, Copenhagen, 1956, pp. 557-560. Munksgaard.

1962 Bering Strait to Greenland. In "Prehistoric Cultural Relations between the Arctic and Temperate Zones of North America", edited by John M. Campbe11, pp. 126-139. Arctic Institute of North America Technica1 Paper No. 11. Montrea1.

DAMAS, D.

1968 The Diversity of Eskimo Societies. In Man the Hunter, editors R.B. Lee and I. Devore, pp. 111-117. Aldine Publishing Company, Chicago.

1969a Characteristics of Central Eskimo Band Structure. In "Contributions to Anthropology: Band Societies", edited by D。 Damas, pp. 116-141. Nationa1 Museum of Canada Bu11etin No. 228, Ottawa.

1969b Environment, History, and Centra1 Eskimo Society. In "Contributions to Anthropology: Ecologica1 Essays", edited by D. Damas. National Museum of Canada Bulletin No. 230, pp. 40-64. Ottawa.

DEKIN, $A_{0} A_{0}$ Jr.

1969 Paleo-Climate and Pre-historic Cultural Interaction in the Eastern Arctic, A Paper Prepared for Oral Presentation at the 34 th Annual Meeting of the Society for American Archeology, Milwaukee, May 1969. Unpublished, in author's files.

1970 Paleo-C1imate and Paleo-Ecology of the Eastern North American Arctic During its Occupancy by Man (2500 BC to date), A Paper Prepared for Ora1 Presentation at the Third Annual Meeting of the Canadian Archaeological Association, Ottawa, March 1970. Unpublished, in author!'s files.

DOAN, $K_{0} A_{0}$ and $C_{0} W_{0}$ Douglas

1953 Beluga of the Churchill Region of Hudson Bay. Canada Fisheries Research Board Bulletin No. 98. Ottawa.

ELSON, J.A.

1967 Geology of Glacial Lake Agassiz. In Life, Land and Water, edited by W.J. Mayer-Oakes, pp. 37-97. University of Manitoba Press, Winnipeg. 


\begin{abstract}
FREEMAN, L。G。Jr.
1968 A Theoretica 1 Framework for Interpreting Archaeologica1

Materia1s. In Man the Hunter, editors $R_{0} B$. Lee and Irven

Devore, pp. 262-267. Aldine Publishing Company, Chicago.

GIDDINGS, J.L。

1951 The Denbigh Flint Complex. American Antiquity, Vol. 16, No. 3, pp. 193-203. Salt Lake City.

1956a A Flint Site in Northernmost Manitoba. American Antiquity, Vo1. 21, No. 3, pp. 255-268. Sa1t Lake City.

1956b The Burin Spall Artifact. Arctic, Vo1. 9, No. 4, pp. 229237. Montrea1.

1962 Onion Portage and Other F1int Sites of the Kobuk River. Arctic Anthropology, Vo1. 1, No. 1, pp. 6-27. Madison.

1967 Ancient Men of the Arctic. A.A。 Knopf, New York.

HARP, E。 Jr .

1962

The Culture History of the Centra1 Barren Grounds. In "Prehistoric Cultural Relations between the Arctic and Temperate Zones of North America", edited by J. Campbe11, pp. 69-75. Arctic Institute of North America Technical Paper No. 11. Montrea1.

1964 The Cultural Affinities of the Newfoundland Dorset Eskimo. Nationa1 Museum of Canada Bulletin No. 200. Ottawa.
\end{abstract}

HELM, J。

1969a Remarks on the Methodology of Band Composition Ana1ysis. In "Contributions to Anthropology: Band Societies", edited by D. Damas, pp. 212-217. National Museum of Canada Bulletin No. 228. Ottawa.

1969b Relationship between Settlement Pattern and Community Pattern. In "Contributions to Anthropology: Ecological Essays", edited by D. Damas, pp. 151-152. Nationa1 Museum of Canada Bu1letin No. 230. Ottawa.

HONIGMANN, J。J。

1946 Ethnography and Acculturation of the Fort Ne1son Slave. Yale University Publications in Anthropology, No. 33. New Haven.

HUNTER, J。G。

1968 Fishes and Fisheries. In Science, History and Hudson Bay, Vo1. 1, editor C.S. Bea1s, pp. 361-378. Queen's Printer, Ottawa.

HUSTICH, I。 1954

On Forests and Tree Growth in the Knob Lake Area, QuebecLabrodour Peninsula. Acta Geographica, Vo1. 13, pp. 1-60. HeIsinki. 
JEHL, J。R。 and B。A。 Smith

1970 Birds of the Churchill Region, Manitoba. Special Publi-

cation No. 1, Manitoba Museum of Man and Nature, Winnipeg.

KELSALL, J。P.

1968 The Migratory Barren-Ground Caribou in Canada. Canadian

Wildlife Service. Queen's Printer, Ottawa.

KNUTH, E。

1954 The Paleo-Eskimo Culture of Northeast Greenland Elucidated

by three New Sites. American Antiquity, Vo1. 19, No. 4, pp. 367-81. Salt Lake City.

1958 Archaeology of the Farthest North. Proceedings of the 32nd Internationa 1 Congress of Americanists, Copenhagen, 1956, pp. 562-573. Copenhagen.

LAMONT, H.A.

1949 Ice Conditions over Hudson Bay and Related Weather Phenomena. American Meteorological Society Bulletin, Vo1. 30, No. 8, pp. 288-289. Worcester.

LAUGHLIN, W.S. and W.E. Taylor Jr.

1960 A Cape Dorset Culture site on the West Coast of Ungava Bay. In "Contributions to Anthropology, 1958", Nationa1 Museum of Canada Bu1letin No. 167, pp. 1-28. Ottawa.

LEE, $H_{\circ} A_{0}$

1960 Late Glacial and Postglacial Hudson Bay Sea Episode. Science, Vo1. 131, No. 3412, pp. 1609-1611. Washington.

1968 Quaternary Geology. In Science, History and Hudson Bay, -Vo1. II, editor C.S. Beals, pp. 503-543. Queen's Printer, Ottawa.

LOWTHER, G。R。

1962 An Account of an Archaeologica1 Site on Cape Sparbo, Devon Island. In "Contributions to Anthropology, 1960, Pt. 1", Nationa1 Museum of Canada Bulletin No 180, pp. 1-19. Queen's Printer, Ottawa.

MANSFIELD, A.W。

1967 Seals of Arctic and Eastern Canada. Fisheries Research Board of Canada Bulletin No. 137. Ottawa.

MAXWELL, M.S。

1960 The Movement of Culture in the Canadian High Arctic. Anthropologica, n.s., Vo1. 2, No. 2, pp. 177-189. Ottawa.

1962 Pre-Dorset and Dorset sites in the Vicinity of Lake Harbour, Baffin Island, $N_{0} W_{0} T$ 。 In "Contributions to Anthropology 1960, Pt. 1." Nationa1 Museum of Canada Bulletin No. 180, pp. 2055. Ottawa. 


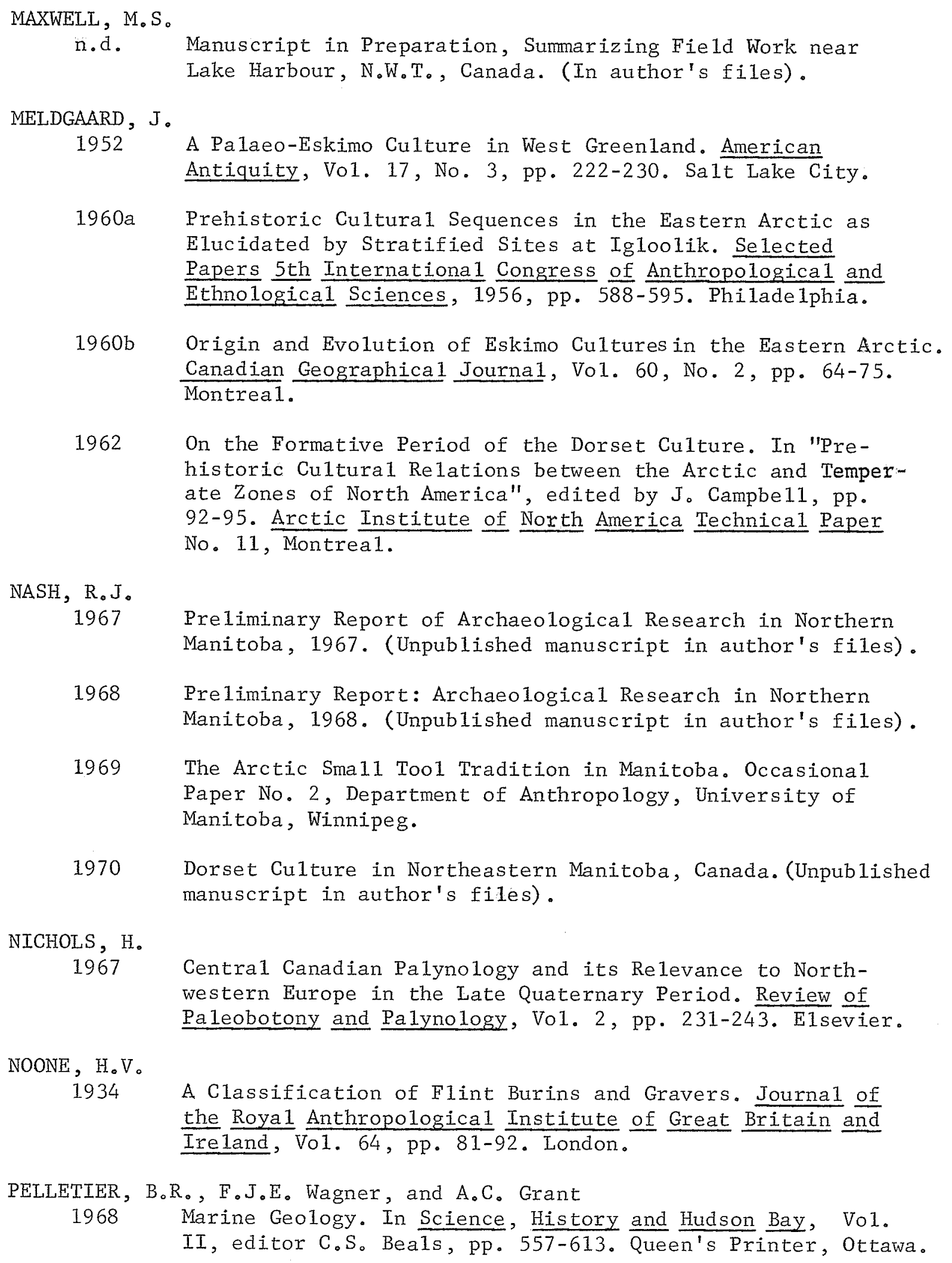

$1960 \mathrm{~b}$ Origin and Evolution of Eskimo Cultures in the Eastern Arctic. Canadian Geographica I Journa1, Vo1. 60, No. 2, pp. 64-75. Montrea1.

1962 On the Formative Period of the Dorset Culture. In "Prehistoric Cultural Relations between the Arctic and Temperate Zones of North America", edited by J。Campbe11, pp. 92-95. Arctic Institute of North America Technical Paper No. 11 , Montrea1.

NASH, R.J.

1967 Preliminary Report of Archaeological Research in Northern Manitoba, 1967. (Unpublished manuscript in author's files).

1968 Preliminary Report: Archaeological Research in Northern Manitoba, 1968. (Unpublished manuscript in author's files).

1969 The Arctic Sma11 Too1 Tradition in Manitoba. Occasiona1 Paper No. 2, Department of Anthropology, University of Manitoba, Winnipeg.

1970 Dorset Culture in Northeastern Manitoba, Canada. (Unpublished manuscript in author's files).

NICHOLS, H.

1967 Central Canadian Palynology and its Relevance to Northwestern Europe in the Late Quaternary Period. Review of Paleobotony and Palynology, Vo1. 2, pp. 231-243. E1sevier.

NOONE, $\mathrm{H} . \mathrm{V}$ 。 1934 A Classification of Flint Burins and Gravers. Journal of the Roya1 Anthropologica1 Institute of Great Britain and Ireland, Vo1. 64, pp. 81-92. London.

PELLETIER, B。R。, F。J.E. Wagner, and A.C. Grant 1968 Marine Geology. In Science, History and Hudson Bay, Vol. II, editor C.S。Beals, pp. 557-613. Queen's Printer, Ottawa. 
PREBLE, E $E_{0} A_{0}$

1902 A Biological Investigation of the Hudson Bay Region.

North American Fauna, No. 22, pp. 1-40. Washington.

PRUITT, $\mathrm{W}_{\circ} \mathrm{O}$, $\mathrm{Jr}$.

1959 Snow as a Factor in the Winter Ecology of the Barren-

Ground Caribou (Rangifer Arcticus). Arctic, Vol. 12, No. 3, Montrea1.

RAINEY, $F$ 。 and $E$ 。 Ra1ph

1959 Radiocarbon Dating in the Arctic. American Antiquity, Vo1. 24, No. 4, pp. 365-374. Sa1t Lake City.

RITCHIE, J。C。

1956 The Native Plants of Churchi11, Manitoba. Canadian Journa1 of Botany, Vo1. 34, pp. 269-320. Ottawa.

1957 The Vegetation of Northern Manitoba. II. A Prisere on the Hudson Bay Lowlands. Ecology, Vo1. 38, pp. 429-435. Brook1yn.

ROUSSELIERE, G。M。

1963 Palaeo-Eskimo Remains in the Pe11y Bay Region, N.W.T. In

"Contributions to Anthropology 1961-62, Pt. 1". National

Museum of Canada Bul1etin No. 193, pp. 162-183. Ottawa.

SCOGGAN, $\mathrm{H}_{0} \mathrm{~J}$ 。

1957 Flora of Manitoba. Nationa1 Museum of Canada Bulletin No. 140. Ottawa.

1959 The Native Flora of Churchi11, Guide Book. Nationa1 Museum of Canada. Ottawa.

SHELFORD, $V_{0} E$ 。 and $A_{0} C$. Twomey

1941 Tundra Animal Communities in the Vicinity of Churchil1. Ecology, Vo1. 22, pp. 47-69. Brook1yn.

SMITH, D。A. and J.B。 Foster

1957 Notes on the Sma11 Mamma1s of Churchi11, Manitoba. Journa1 of Mammology, Vo1. 38, No. 1, pp. 98-115. Washington.

STEWARD, V。E。

1955 Theory of Culture Change. Urbana: University of I1linois

Press.

STRUEVER, S。

1968

Woodland Subsistence-Settlement Systems in the Lower

I11inois Valley. In New Perspectives in Archaeology, editors

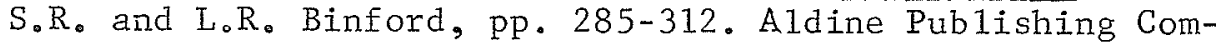
pany, Chicago.

TAVERNER, P.A。 and G.M. Sutton

1934 The Birds of Churchill, Manitoba. Anna1s of the Carnegie Museum, Vo1. 23, pp. 1-83. Washington. 
TAYLOR, W。E. 1959

Review and Assessment of the Dorset Problem. Anthropologica, n.s., Vol. 1, Nos. 1 and 2, pp. 24-46. Ottawa.

1962 Pre-Dorset Occupations at Ivugivik in Northwestern Ungava. In "Prehistoric Cultural Relations between the Arctic and Temperate Zone of North America", edited by J. Campbe11, pp. 80-91. Arctic Institute of North America Technical Paper No. 11. Montrea1.

1967 Summary of Archaeological Field Work on Banks and Victoria Islands, Arctic Canada, 1965. Arctic Anthropology, Vo1. IV, No. 1, pp. 221-243. Madison.

1968 The Arnapik and Tyara Sites, An Archaeological Study of Dorset Culture Origins. Memoirs of the Society for American Archaeology, No. 22. Salt Lake City.

TAYLOR, W.W.
1948

A Study of Archaeology. Memoir No. 69. American Anthropologist, Vo1。50, No. 3, Pt. 2. Carbondale.

THOMPSON, J。B。

1968 The Climate of the Hudson Bay. In Science, History and Hudson Bay, edited by C.S。Bea1s, pp. 263-286. Queen's Printer, Ottawa.

TYRRELL, J。B。

1898 Report on the Doobaunt, Kazan and Ferguson Rivers and the North-west Coast of the Hudson Bay and on Two Overland Routes from Hudson Bay to Lake Winnipeg. Geological Survey of Canada, Annual Report, Vo1. 9, Pt. 5, pp. 5-218. Ottawa.

WILLEY, G。R。

1953 Prehistoric Settlement Patterns in the Viru Valley, Peru. Bureau of American Ethnology Bulletin No. 155. Smithsonian Institution, Washington, $\mathrm{D}_{0} \mathrm{C}$.

WILLIAMS, M。Y。

1947 The Geological History of Churchi11, Manitoba. Western Miner, Vo1. 21, pp. 39-42. Vancouver. 